\title{
Operating Manual
}

multi EA 4000

Elementary analyzer

$\mathrm{C}, \mathrm{S}$ and $\mathrm{Cl}$ solids analysis

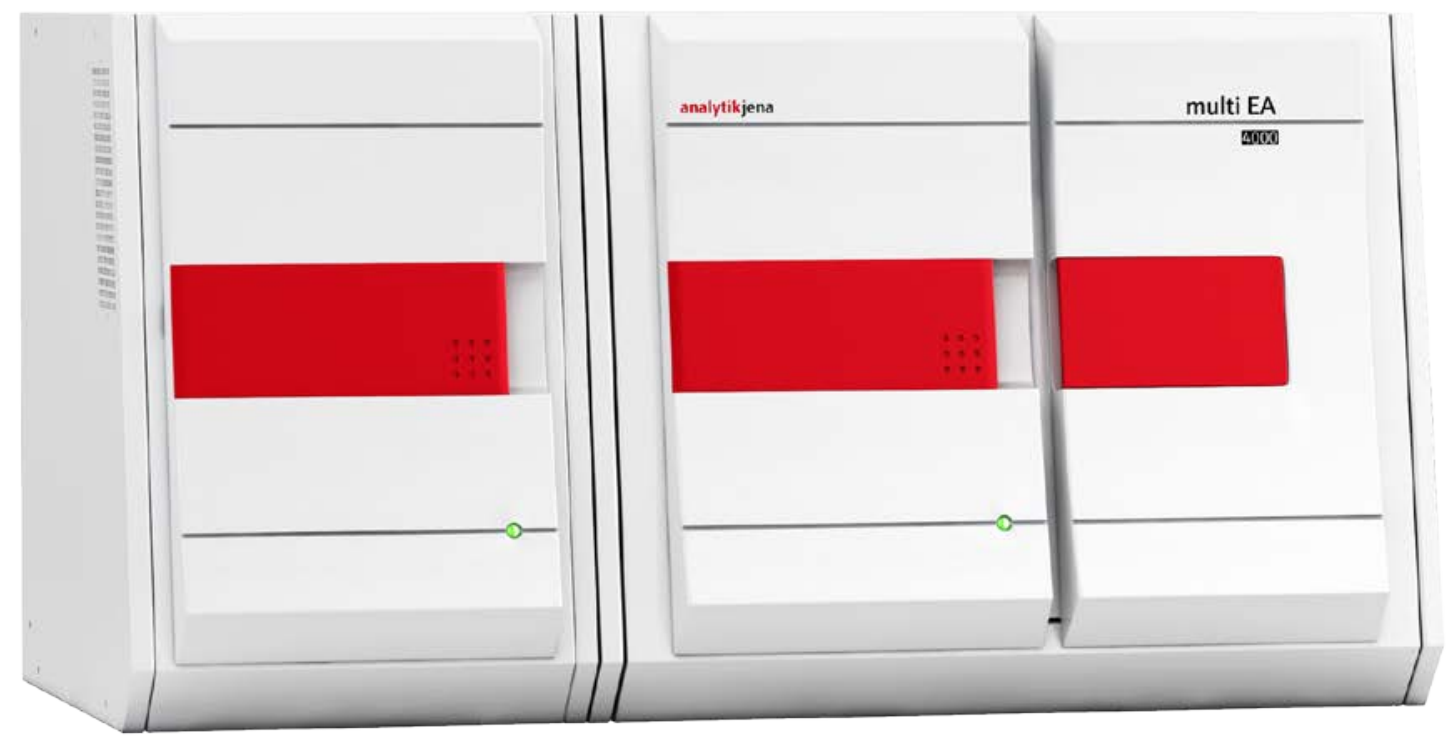


Manufacturer

Service

General information

Copyrights and

Trademarks

Documentation number

Edition

Implementation of the

Technical Documentation
Analytik Jena AG

Konrad-Zuse-Str.1

07745 Jena $\cdot$ Germany

Phone + $493641 / 7770$

Fax $\quad+493641 / 779279$

Email info@analytik-jena.de

Analytik Jena AG

Konrad-Zuse-Str. 1

07745 Jena $\cdot$ Germany

Phone + $493641 / 77-7407$ (Hotline)

Email service@analytik-jena.de

http://www.analytik-jena.com

multi EA and multiWin are registered trademarks of Analytik Jena AG in Germany. Microsoft and Windows are registered trademarks of Microsoft Corp.

The identification with ${ }^{\circledR}$ or TM is omitted in this manual.

$11-0302-001-23$

02.18

Analytik Jena AG

(C) Copyright 2018, Analytik Jena AG 


\section{Contents}

Basic information

User manual notes

Intended use

Warranty and liability

Safety instructions

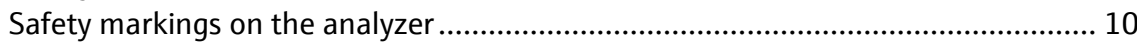

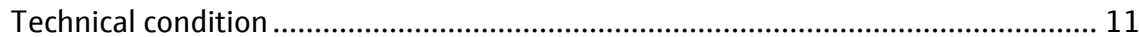

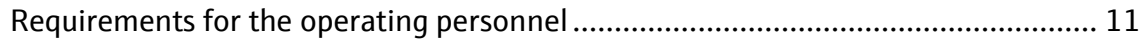

Safety instructions, transport and commissioning ................................................... 12

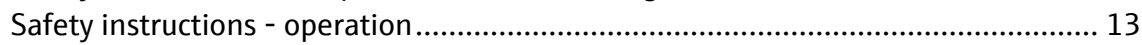

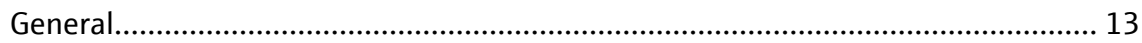

Safety instructions - Protection against explosion and fire ................................... 13

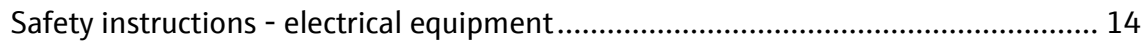

2.5.4 Safety instructions for compressed gas cylinders and systems............................... 14

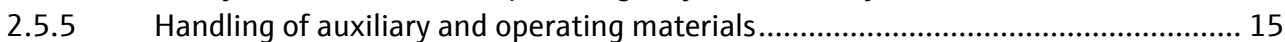

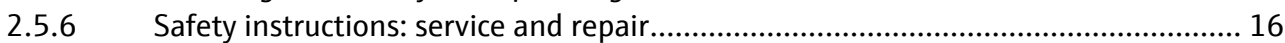

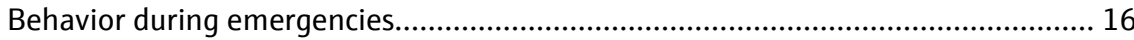

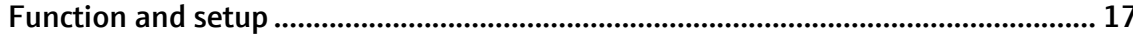

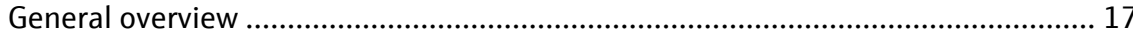

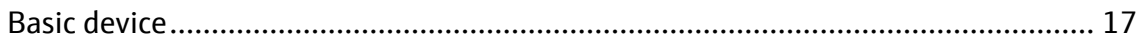

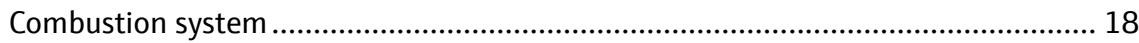

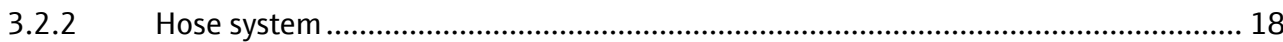

3.2.3 Components for measuring gas drying and cleaning ............................................. 19

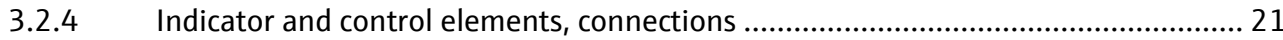

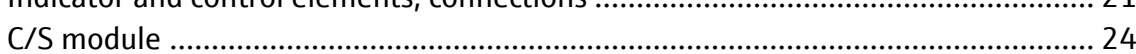

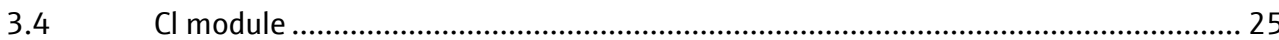

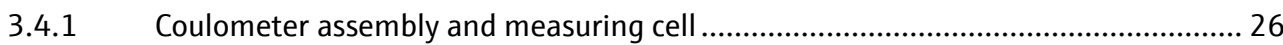

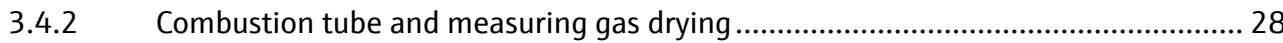

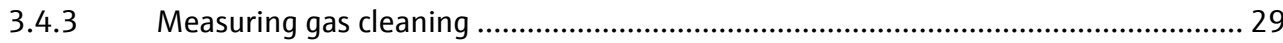

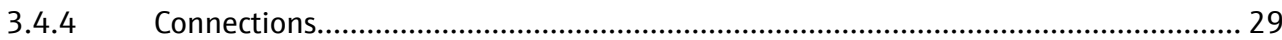

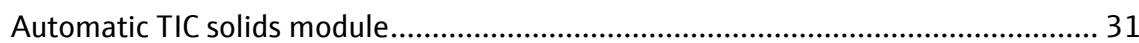

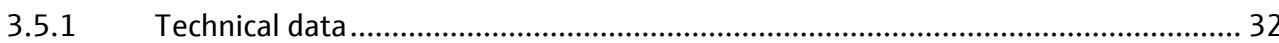

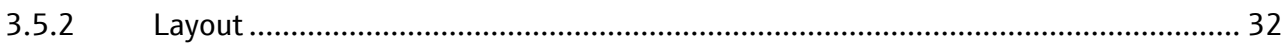

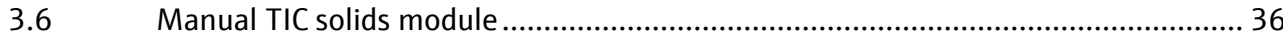

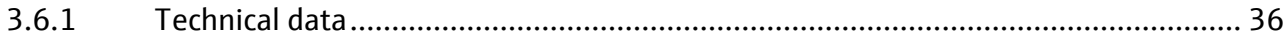

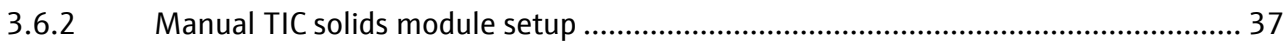

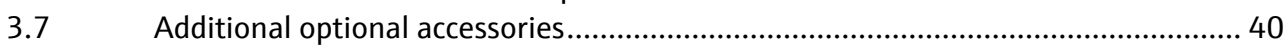

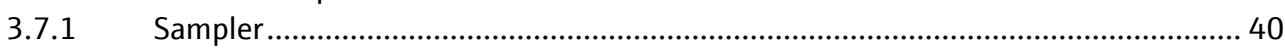

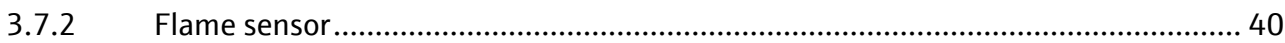

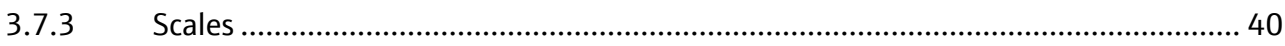

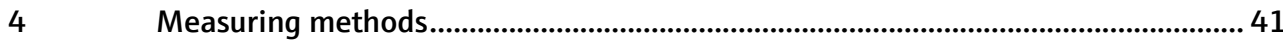

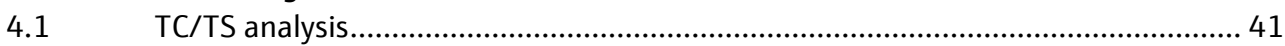

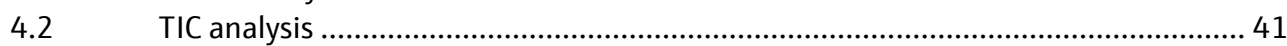

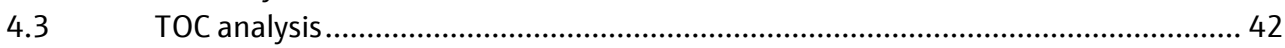

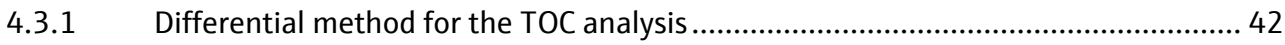

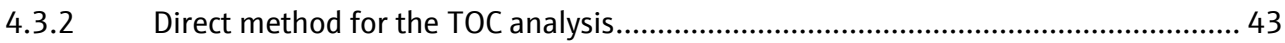

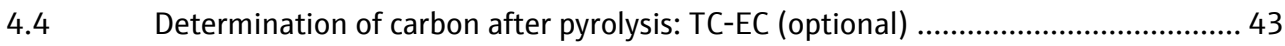

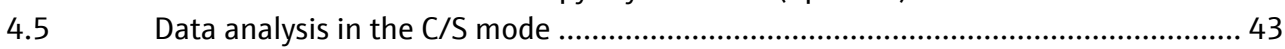

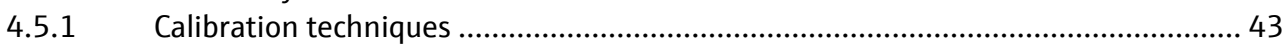

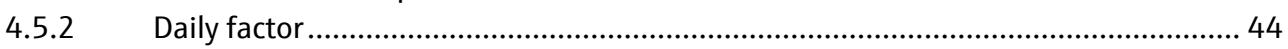

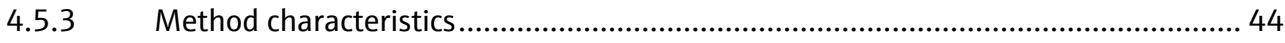

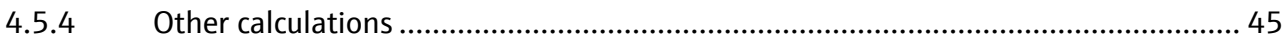

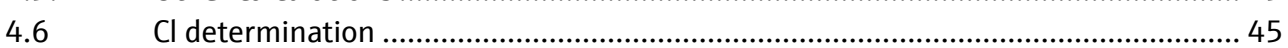

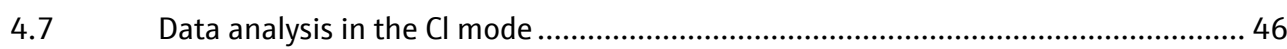


Measurement with

Site requirements.

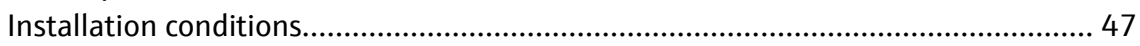

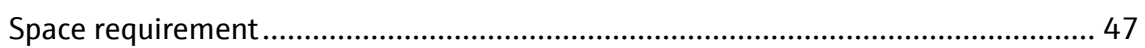

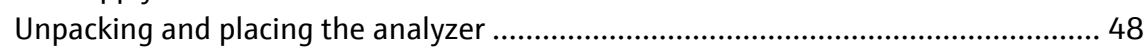

Positioning the analyzer with various detector modules ....................................... 49

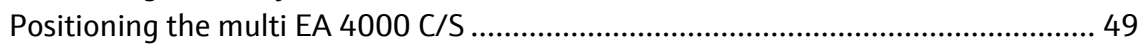

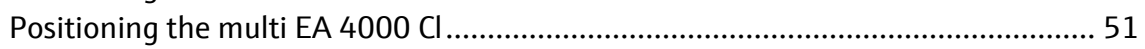

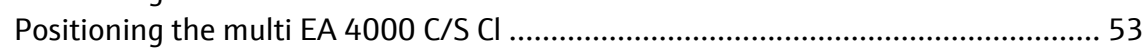

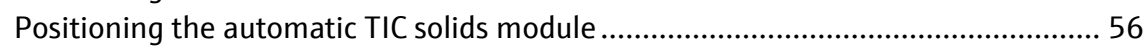

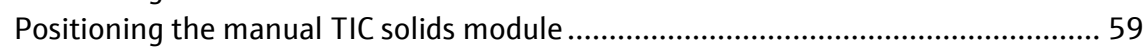

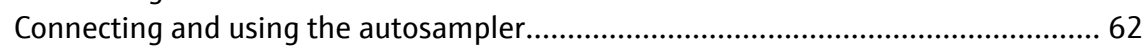

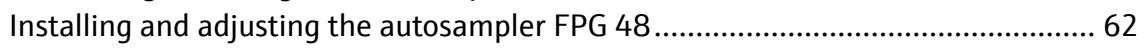

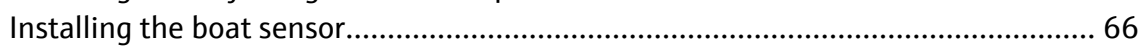

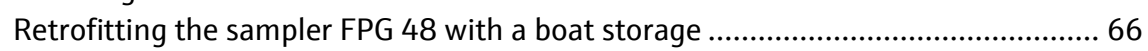

Measurement cancellation when using the sampler FPG 48 ....................................68

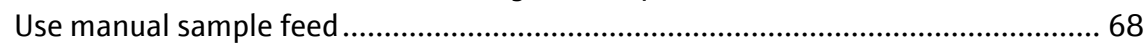

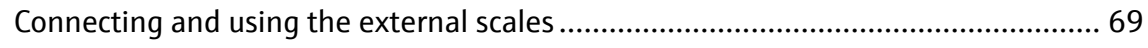

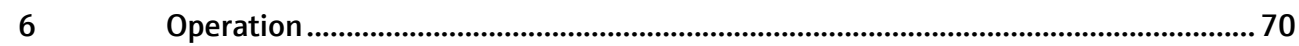

6.1 Activation / warm-up phase / setup ..................................................................... 70

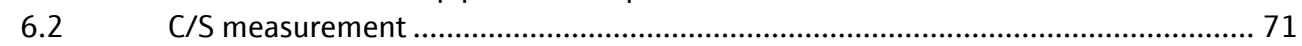

6.2.1 Preparing the multi EA 4000 and $\mathrm{C} / \mathrm{S}$ module..................................................... 71

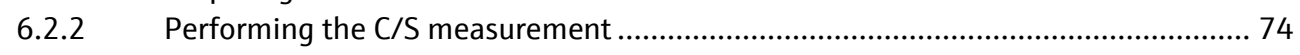

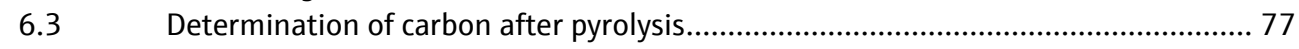

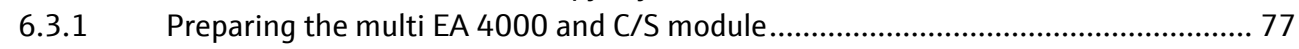

6.3.2 Performing the determination of carbon after pyrolysis........................................ 77

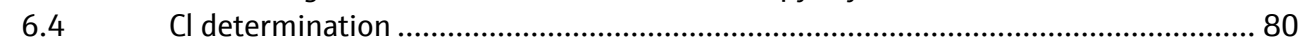

6.4.1 Preparing the multi EA 4000 for $\mathrm{Cl}$ measurements ............................................ 80

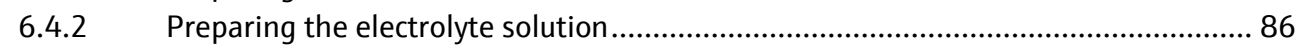

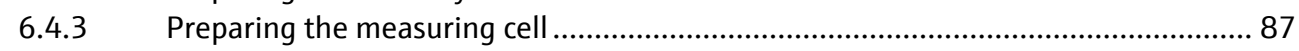

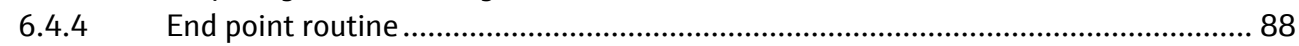

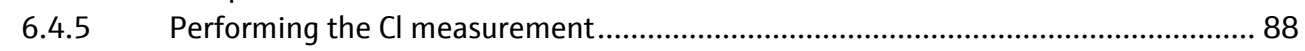

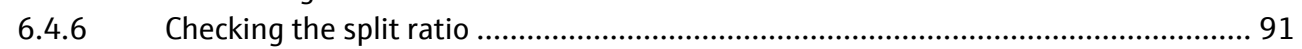

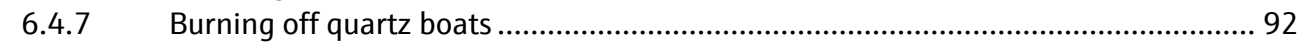

6.5 TIC/TOC determination with the automatic TIC solids module.............................. 92

6.5.1 Preparing the automatic TIC solids module for the analysis ................................... 92

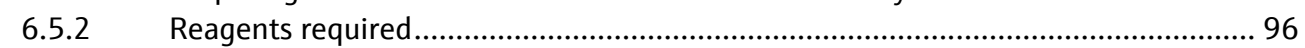

6.5.3 TIC determination with the automatic TIC solids module ......................................... 96

6.5.4 TOC determination based on differentiation method .............................................. 98

6.5.5 TOC measurement using direct determination .................................................... 101

6.6 TIC determination with the manual TIC solids module ........................................... 103

6.6.1 Preparing the manual TIC solids module and analyzer ............................................ 103

6.6.2 Performing a TIC measurement ......................................................................... 103

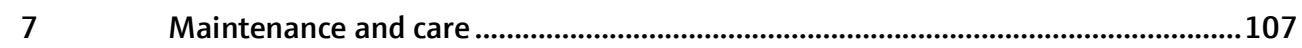

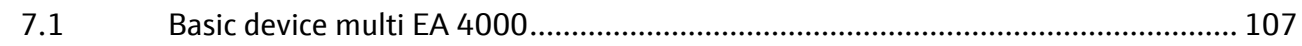

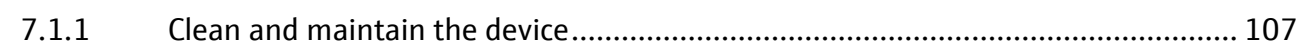

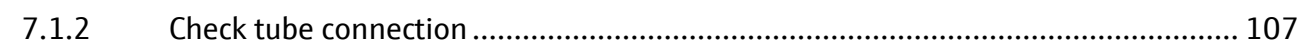

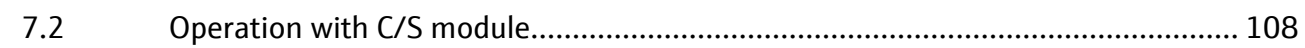

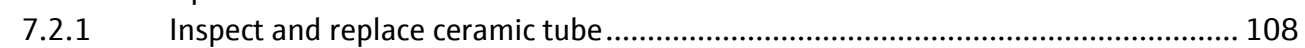

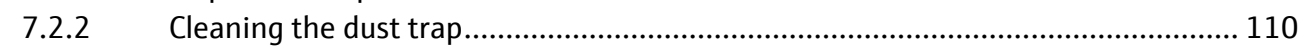

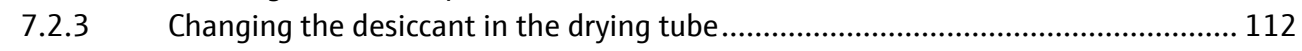

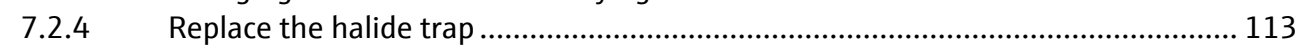




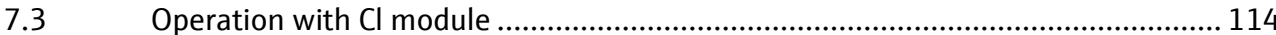

7.3.1 Replacing the sulfuric acid/cleaning the sulfuric acid container .............................. 114

7.3.2 Servicing/replacing the quartz glass combustion tube............................................ 115

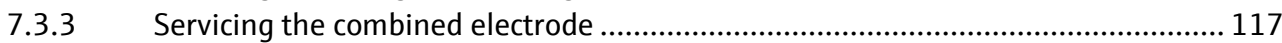

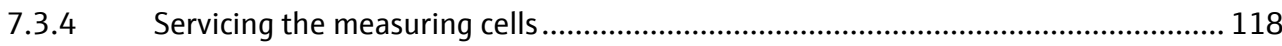

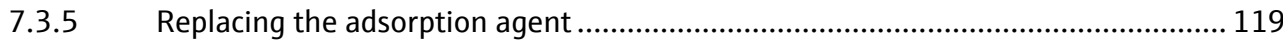

7.4 Operation with the automatic TIC solids module ................................................. 119

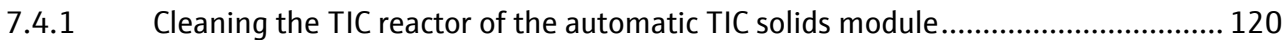

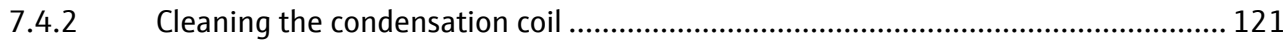

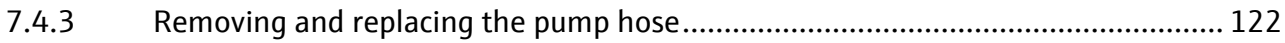

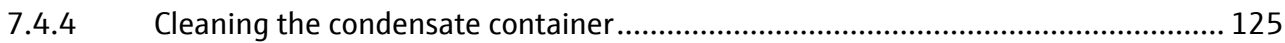

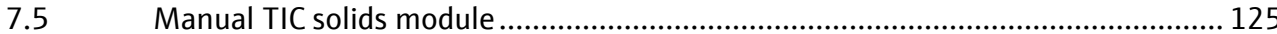

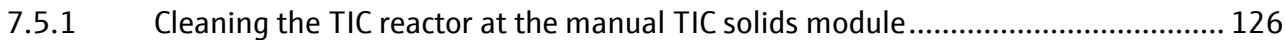

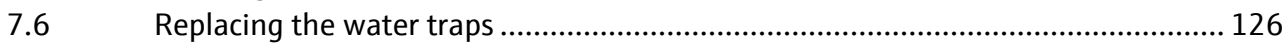

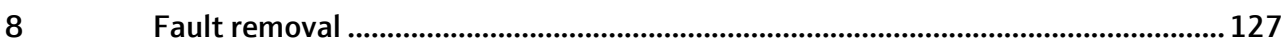

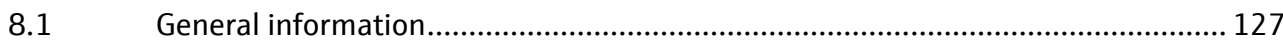

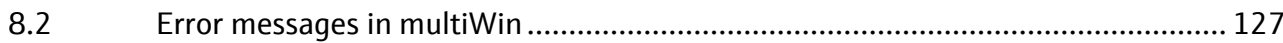

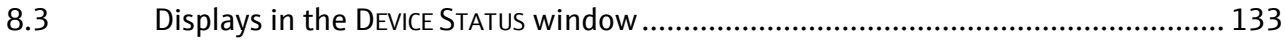

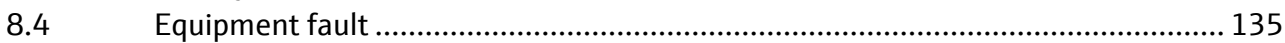

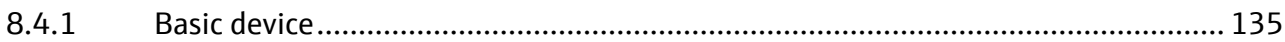

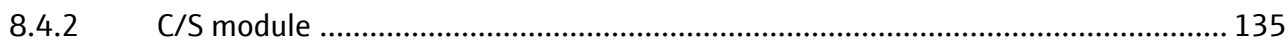

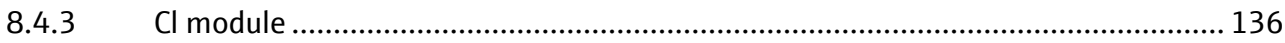

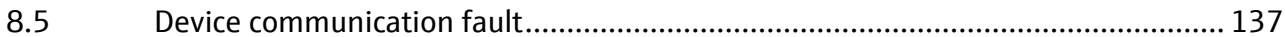

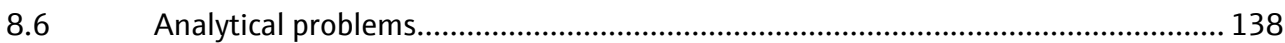

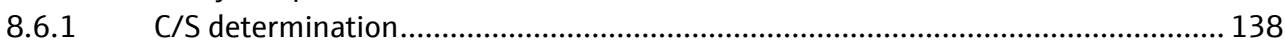

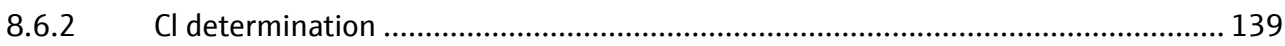

8.6.3 TIC determination (automatic TIC solids module) ................................................. 140

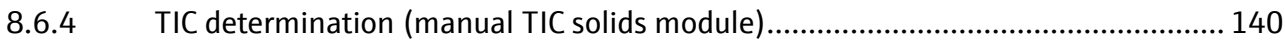

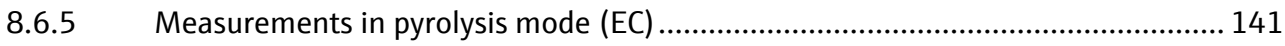

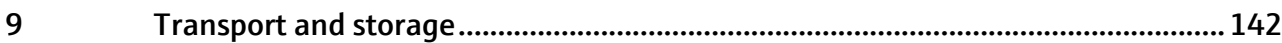

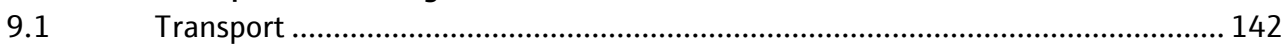

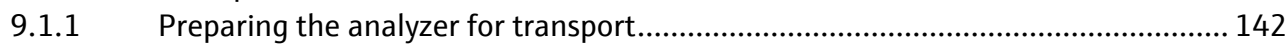

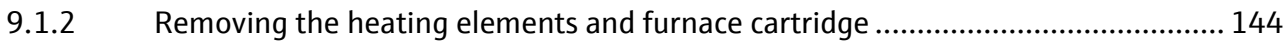

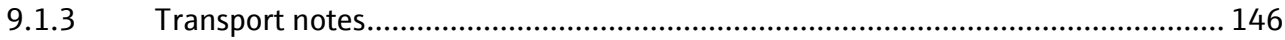

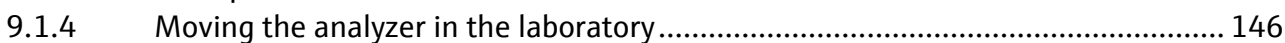

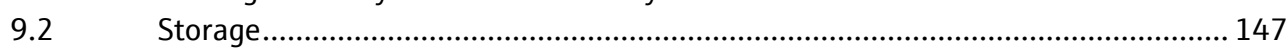

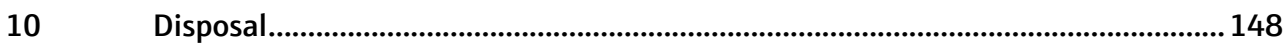

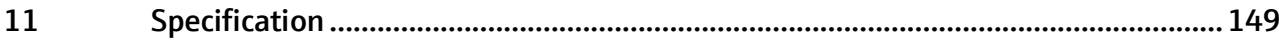

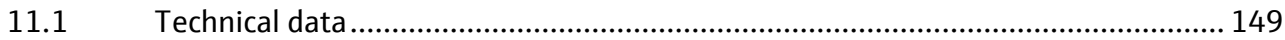

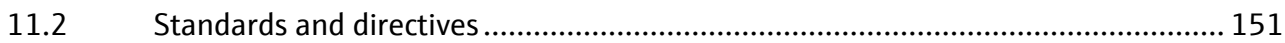




\section{Figures}

Figure 1 Gas sluice and horizontal furnace of the basic device multi EA 4000 ....... 18

Figure 2 Flow regulators at the basic device multi EA 4000_.................................. 19

Figure 3 Dust trap at the combustion furnace........................................................... 20

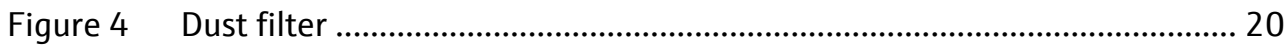

Figure 5 Drying tube and halide trap ..................................................................... 21

Figure 6 Status light at the basic device multi EA 4000.......................................... 21

Figure 7 Control elements behind the front door of the multi EA 4000 ….............. 22

Figure 8 Connections on the right-hand side of the multi EA 4000......................... 22

Figure 9 Connections on the left-hand side of the multi EA 4000 ............................ 23

Figure 10 Connections at the rear of the multi EA 4000........................................ 23

Figure 11 Indications and connections at the C/S module..................................... 25

Figure $12 \quad$ Cl module ................................................................................................ 26

Figure 13 Measuring cell design........................................................................... 27

Figure 14 Combined electrode for the measuring cell .............................................. 27

Figure 15 Quartz combustion tube with gas sluice ................................................... 28

Figure 16 Sulfuric acid containers for measuring gas drying .................................. 28

Figure $17 \quad$ Halide trap and adsorption tube in the $\mathrm{Cl}$ module .................................. 29

Figure $18 \mathrm{Cl}$ module connections in combination with a C/S module ..................... 30

Figure 19 Connections for the coulometric measuring cell in the $\mathrm{Cl}$ module.......... 30

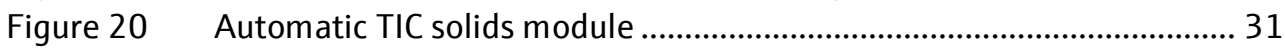

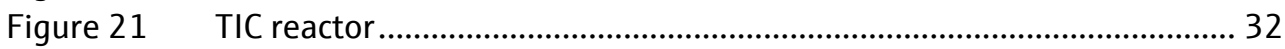

Figure 22 Hose pumps at the automatic TIC solids module .................................. 33

Figure 23 Measuring gas drying and cleaning at the aut. TIC solids module.......... 34

Figure 24 Dust filter before the changeover valve................................................. 34

Figure 25 Connections at the automatic TIC solids module ................................... 35

Figure 26 Manual TIC solids module........................................................................ 36

Figure 27 TIC reactor of the manual TIC solids module.......................................... 37

Figure $28 \quad$ Flow regulator for the oxygen flow..................................................... 37

Figure 29 Metering pump for acid on the manual TIC solids module .................... 38

Figure 30 Measuring gas drying and cleaning at the man. TIC solids module....... 39

Figure 31 Connections at the manual TIC solids module........................................ 39

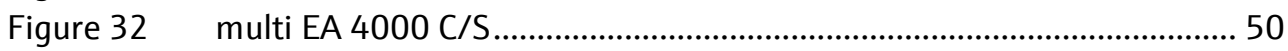

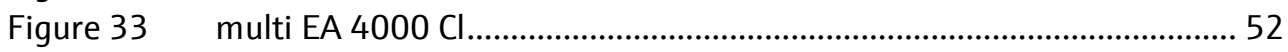

Figure 34 multi EA C/S Cl for C/S measurements ................................................ 54

Figure 35 multi EA $4000 \mathrm{C} / \mathrm{S} \mathrm{Cl}$ for $\mathrm{Cl}$ measurements ........................................... 55

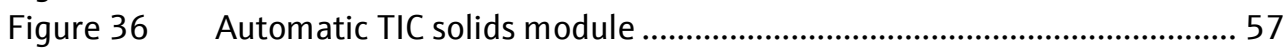

Figure 37 multi EA 4000 C/S with automatic TIC solids module........................... 58

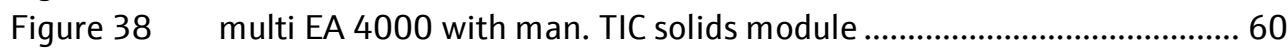

Figure 39 multi EA $4000 \mathrm{C} / \mathrm{S} \mathrm{Cl}$ with man. TIC solids module ................................. 61

Figure 40 Retrofit kit for FPG 48 to use the boat storage ........................................ 67

Figure 41 Gas sluice for $C / S$ measurements ...................................................... 71

Figure 42 Ceramic tube with dust trap and gas sluice ........................................... 72

Figure 43 Inspecting the halide trap and drying tube............................................... 74

Figure 44 Quartz combustion tube with gas sluice ................................................... 80

Figure 45 Coupling element for $\mathrm{Cl}$ measurements................................................... 81

Figure 46 Components for connecting the TIC reactor and ceramic tube .............. 93

Figure 47 Screw connection at the halide trap..................................................... 107

Figure 48 Dust filter........................................................................................... 111

Figure 49 Clamping the pump hoses................................................................. 123

Figure 50 Window STATUS ANALYZER................................................................... 133 


\section{Basic information}

\section{$1.1 \quad$ User manual notes}

Conventions

Symbols and signal words used
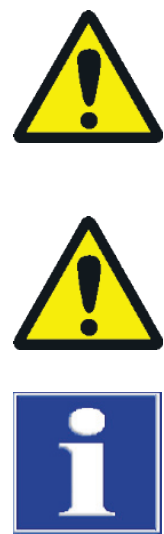

The analyzer multi EA 4000 is intended for operation by qualified specialist personnel observing this user manual.

The user manual informs about the design and operation of the analyzer and provides personnel familiar with elementary analysis the necessary expertise for the safe handling of the equipment and its components. The user manual further includes notes on the maintenance and service of the equipment and potential causes and remedies of any faults.

Instructions for actions that occur in chronological order are numbered and combined in action units.

Warnings are indicated by warning triangles and a signal word. The type, source and consequences of the danger are stated together with notes on preventing the danger.

The elements of the control and analysis program are indicated as follows:

- Program terms are indicated by small caps (e.g., FILE menu).

- Buttons are shown by square brackets (e.g., [OK]).

- Menu items are separated by arrows (e.g., FILE $\gg$ OPEN).

The user manual uses the following symbols and signal words to indicate hazards or instructions. The warnings are always placed before an action.

\section{WARNING}

Indicates a potentially hazardous situation that might cause death or very serious injuries (deformities).

\section{CAUTION}

Indicates a potentially hazardous situation which might cause light or minor injuries.

\section{NOTICE}

Provides information on potential material or environmental damage. 


\subsection{Intended use}

Waste management

Environmental monitoring

Power station

Material testing

Research and teaching
The elementary analyzer multi EA 4000 is a device for the determination of total carbon content and/or total sulfur content or for the determination of total chlorine content in solid or paste-like samples. After appropriate sample preparation, it can also be sued for AOX determination.

The system is configured and extended in accordance with the specific analytical requirements.

The analyzer multi EA 4000 is versatile in its application due to its robust modular design, ease of operation and expandability.

The multi EA 4000 is particularly suited for TIC/TOC determination in waste as well as total chlorine determination in substitute fuels.

The multi EA 4000 permits simultaneous carbon and sulfur determination in sediment and soil analysis.

An important area of use for the multi EA 4000 is the sulfur determination in coal or ash residue as well as the detection of residual carbon in ash from combustion systems. Here too, chlorine determination in substitute fuels is of importance.

The multi EA 4000 enables the rapid sulfur and/or carbon determination in construction materials, such as cement or plaster, in ceramic materials or glass samples.

Due to the many configuration options the multi EA 4000 suitable for use in teaching and research.

The analyzer multi EA 4000 must only be used for the methods for the detection of the total carbon and/or the total sulfur content in and/or the determination of the total chlorine content in solid, paste-like or liquid samples. Any other use is not as intended! Only the operator is liable for any damages that result from this.

In particular, it is prohibited to use the analyzer to analyze flammable liquids or substances that could farm explosive mixtures. No concentrated acids may be analyzed with the analyzer.

The device must only be operated with oxygen 2.5 and argon 4.6 or better.

The operational safety of the analyzer multi EA 4000 is only ensured during proper use according to the information in this user manual. The intended use also includes the adherence to the installation conditions prescribed by Analytik Jena AG that are available from the customer service address stated on the title page. 


\subsection{Warranty and liability}

The warranty duration and liability comply with the legal requirements and the provisions in the general terms and conditions of Analytik Jena AG.

Deviations from the intended use described in this user manual result in limitations of warranty and liability in the event of a damage. Damage to wearing parts is not included in the warranty.

Warranty and liability claims are excluded for personal injury and property damage due to one or several of the following causes:

- use of the multi EA 4000 analyzer other than intended

- improper commissioning, operation and service of the analyzer

- modifications of the equipment without prior consultation with Analytik Jena AG

- operation of the device with faulty safety equipment or improperly fitted safety and protection equipment

- inadequate monitoring of the equipment components subject to wear

- use of other than original spare parts, wearing parts or consumables

- improper repairs

- faults due to the non-observance of this user manual 


\section{Safety instructions}

For your own safety and to ensure error-free and safe operation of the analyzer multi EA 4000, please read this chapter carefully before using the appliance.

Observe all safety notes listed in this user manual and all messages and displayed by the multiWin control and analysis software on the monitor.

\subsection{Safety markings on the analyzer}

Warnings and information symbols have been attached to the analyzer and accessories whose content must always be observed.

Damaged or missing safety symbols can cause incorrect actions leading to personal injury or material damage! The safety symbols must not be removed! Damaged safety symbols must be replaced immediately!

The following safety symbols have been attached to the analyzer and accessories:

Weaning
Warning against hot surface
Warning against hand injury from crushing $\begin{aligned} & \text { Warning against substances hazardous to health } \\ & \text { Warning against corrosive } \\ & \text { substances } \\ & \text { The device contains controlled substances. Analytik Jena AG guarantees } \\ & \text { will not cause any environmental danger or health risk within this period } \\ & \text { if the device is used as intended. }\end{aligned}$




\subsection{Technical condition}

The analyzer corresponds in its design and construction to the current state of the art technology. Unauthorized modifications or changes, especially such that affect the safety of the staff and the environment, are generally not allowed.

- Any manipulation of the safety equipment is prohibited! In case of an accident, manipulations of the safety equipment will be interpreted as deliberate!

- The operator must only operate the analyzer in a sound and operationally safe condition. The technical condition must always comply with the legal requirements and regulations.

- Prior to every use, the analyzer must be checked for damage and sound condition.

- Any changes in the analyzer affecting its safety must be reported by the operating personnel to the operator immediately.

- The equipment components must only be connected to supply cables intended and designed for this purpose.

- All safety equipment and interlocks must be well accessible and regularly checked for proper operation.

\subsection{Requirements for the operating personnel}

The analyzer multi EA 4000 must only be operated by qualified specialist personnel instructed in the use of the analyzer. The instruction must also include conveying the content of this user manual and the user manuals of other system components or addon equipment.

The analyzer may pose dangers if it is not used by trained personnel, improperly or other than intended.

Therefore, every person tasked with the operation of the analyzer must have read and understood this user manual and the user manuals of any additional equipment before carrying out the respective tasks. This also applies if the respective person has already worked with or been trained on this kind of analyzer.

It is recommended that the operator have the operating personnel confirm the knowledge of the content of the user manual in writing. The ultimate responsibility for the accident-free operation of the analyzer rests with the operator or the specialist personnel authorized by him.

In addition to the safety at work instructions in this user manual the generally applicable safety and accident prevention regulations of the respective country of operation must be observed and adhered to. The operator must ascertain the latest version of these regulations.

The user manual must be accessible to the operating and service personnel at any time!

The following has to be observed:

- The analyzer must only be commissioned, operated and serviced by trained personnel instructed in technical safety. 
- The operation or servicing of the analyzer by minors or individuals under the influence of alcohol, drugs or medication is not permitted.

- It must be ensured that only authorized personnel works at the analyzer.

- The operating personnel must be familiar with the dangers arising from measuring liquids. The appropriate protective equipment must be used.

- Prior to pauses or at the end of the work appropriate skin cleaning and protection measures must be carried out.

- Eating, drinking, smoking or handling open flames in the operating room of the analyzer is prohibited!

\subsection{Safety instructions, transport and commissioning}

The analyzer is always installed by the customer service department of Analytik Jena AG or its authorized and trained specialist personnel. Independent assembly and installation are not permitted. Incorrect installation can create serious hazards.

The following has to be observed:

- Insufficiently secured components pose a risk of injury! During transport, the components of the equipment must be secured in accordance with the instructions in the user manual.

- Only transport the analyzer in its original packaging! Ensure that the transport protections have been fitted and the analyzer is completely empty.

- To prevent health damage the following must be observed when moving the analyzer in the laboratory (lifting and carrying):

- For reasons of safety, 2 persons are required to transport the analyzer and must position themselves on both sides of the equipment.

- Because the analyzer does not feature any handles, firmly grip the device from the bottom and make sure prior to simultaneous lifting the device that the sensitive components at the front are protected by the closed doors.

- The guide values and statutory limits for lifting and carrying loads without auxiliary equipment must be observed and adhered to.

- For a transport beyond moving within the building the heating elements and furnace cartridge must be removed from the basic device. The re-installation of these device components and subsequent commissioning must be performed by the customer service department of Analytik Jena AG or authorized and trained specialist personnel.

- Risk of damage to health due to improper decontamination! Perform a professional and documented decontamination of the device before returning it to Analytik Jena. The decontamination report is available from Service when registering the return.

Analytik Jena must refuse acceptance of contaminated devices. The sender may be liable for damage caused by inadequate decontamination of the device. 


\subsection{Safety instructions - operation}

\subsubsection{General}

The operator of the analyzer must make sure before each commissioning that the condition of the analyzers including the safety equipment is sound. This applies in particular after each modification or extension of the analyzer or its repair.

The following has to be observed:

- The analyzer must only be operated if all protective equipment (e.g. covers, drip pans for chemicals and doors) are present, properly installed and operational.

- The sound condition of the protection and safety equipment must be checked regularly. Any defects must be corrected as soon as they occur.

- Protective and safety equipment must never be removed, modified or switched off during operation.

- Free access to the power switch on the back of the enclosure has to be ensured during operation.

- The ventilation equipment on the multi 4000 and the extension modules must be in good working condition. Covered ventilation grilles or slits etc. may cause the device to break down or may cause damage to it.

- The analyzer must not be switched on without a heated combustion tube.

- The furnace operates with temperatures of up to $1500{ }^{\circ} \mathrm{C}$. The hot components (furnace, gas sluice, dust trap, boat) must not be touched during or directly after the operation of the analyzer.

In manual operation, the hot boats must be deposited on the surface of the manual feed or on some other heat-resistant surface.

- During automatic cooling, do not interrupt the power supply. In case of prolonged power failure during operation disconnect the mains plug and open the ride side panel of the basic device to prevent damage from overheating. When removing the side panel there is a risk of injury from sharp-edged components. To not touch the heating elements or the hot furnace!

- Keep all combustible materials away from the analyzer.

- At the autosampler there is a risk of crushing! The autosampler arm, the gripper and the boat carousel move during activation, initialization, adjustment and measurement operation. Keep an adequate distance to avoid having your hands crushed.

\subsubsection{Safety instructions - Protection against explosion and fire}

The analyzer must not be operated in an explosive environment. Smoking or handling open flames in the operating room of the analyzer is prohibited!

The operating personnel must be familiar with the location of the fire-fighting equipment in the operating room of the analyzer. 


\subsubsection{Safety instructions - electrical equipment}

Work on electrical components of the analyzer may only be carried out by a qualified electrician in accordance with the applicable electrical engineering rules. Life-threatening electrical voltages and high currents may occur in the interior of the analyzer!

The following has to be observed:

- Extension modules or system components must always be connected to or disconnected from the analyzer in a deactivated condition.

- Before opening the analyzer, it must be switched off from the equipment switch and the mains connector must be disconnected from the mains outlet!

- Any work on the interior of the analyzer may only be carried out by the customer service of Analytik Jena AG and specially authorized technicians. This excludes the removal of the heating element and the furnace cartridge for transport. The re-installation and subsequent commissioning must, however, only be carried out by customer service and authorized specialist personnel.

- The electrical components must be checked regularly by a qualified electrician. Any defects, such as loose connections, faulty or damaged cables, must be repaired without delay.

- The analyzer and additional modules must be switched off immediately at the power switches and the power supplies disconnected from the mains if there is any interference with the electric components.

\subsubsection{Safety instructions for compressed gas cylinders and systems}

The carrier gases (argon and/or oxygen) are taken from compressed gas containers or local compressed gas systems. The required purity of the gas must be ensured $(\rightarrow$ see section "Technical data" p.149)!

Work on compressed gas cylinders and systems must only be carried out by individuals with specialist knowledge and experience in compressed gas systems.

The following has to be observed:

- The safety instructions and guidelines for operating compressed gas cylinders or compressed gas systems that apply at the operating location must be strictly complied with.

- Compressed gas containers must only be operated and stored upright and must be secured to a permanent structure or suitable frame for compressed gas containers. Only move the compressed gas container after securing it to a suitable trolley.

- Compressed air hoses and pressure reducers may only be used for the assigned gases.

- Pipes, hoses, screw connections and pressure reducers for oxygen must be kept free from grease.

- Oxygen is a strong oxidizer that significantly accelerates combustion. Take care when handling oxygen containers since highly pressurized oxygen may cause serious explosions when coming into contact with ignitable materials.

- All pipes, hoses and screw connections must be checked regularly for leaks and externally visible damage. Leaks and damaged must be repaired without delay. 
- Any leak from which gases escape (except oxygen/air) may result in an oxygenstarved atmosphere causing suffocation. The area in which compressed gas containers are stored and the area around the device must be ventilated adequately to prevent the development of an oxygen-starved atmosphere.

- Prior to inspections, service and repairs the valves must be closed and the analyzer vented!

- After successful repair and service of the components of the compressed air containers or system, the analyzer must be checked for sound operation prior to recommissioning!

- Unauthorized assembly and installation are not permitted!

\subsubsection{Handling of auxiliary and operating materials}

The operator is responsible for the selection of substances used in the process as well as for their safe handling. This is particularly important for radioactive, infectious, poisonous, corrosive, combustible, explosive and otherwise dangerous substances.

When handling dangerous substances local safety codes and guidelines must be observed.

The following general notes do not replace the specific local regulations or the regulations in the safety data sheets of the manufacturers for the auxiliary and operating materials.

The following has to be observed:

- The relevant regulations and the notes in the safety data sheets of the manufacturers have to be observed and complied with regards to storage, handing, use and disposal for all auxiliary and operation materials used during operation or maintenance of the analyzer.

- Special care must be taken when handling concentrated acids, such as sulfuric acid and acetic acid used during analysis and the desiccant magnesium perchlorate.

Acetic acid vapor may also develop during chlorine analysis and strongly irritate the respiratory tracts.

When preparing the electrolyte solution organic substances hazardous to health, such as methanol or thymol, are used.

- Auxiliary and operation materials may never be placed in containers or vessels for food. The approved containers for the relevant material are to be used. These must be labeled accordingly. The notes on the labels have to be observed!

- When working with quartz wool avoid the creation of dust! Inhaled dust might cause irritation to respiratory tracts.

- Protective goggles and rubber gloves have to be worn when handing reagents. The notes on the labels have to be observed.

- Biological samples must be handled according to local guidelines regarding the handling of infectious material.

- Caution when handing quartz glass and glass parts. Risk of broken glass and therefore risk of injury! 
- Auxiliary and operating materials as well as their containers may not be disposed in domestic waste or enter the sewage system or the soil. The applicable regulations for disposal of these materials must be meticulously observed.

- Ensure good room ventilation in working rooms.

\subsubsection{Safety instructions: service and repair}

The analyzer is usually serviced by the customer service department of Analytik Jena AG or its authorized and trained specialist personnel.

Independent servicing can maladjust or damaged the analyzer. Therefore, the operator may generally only carry out the tasks listed in chapter "Maintenance and care", p. 107.

- Any service and repair work at the analyzer may usually only be carried out in the switched-off condition (unless stated otherwise).

- Prior to servicing or repair, the energy and gas supplies must be disconnected and the analyzer must be $v$ vented!

- Only use original accessories and original replacement parts from Analytik Jena AG. The notes in section "Service and care" must be observed.

- All protective equipment must be reinstalled correctly immediately after completion of the service and repair work and be checked for operation!

- The exterior of the analyzer may only be cleaned with a damp, not dripping, cloth after the analyzer has been switched off.

- Service tasks and the replacement of system components (removal of the combustion tube, service of the dust trap) must only be carried out after a sufficiently long cooling down phase.

\subsection{Behavior during emergencies}

The analyzer must be switched off from the main switch (in the multi EA and its modules on the equipment back plate) and the power supplies must be disconnected from the mains in case of dangerous situations or accidents.

Because a rapid response can save lives during an emergency, the following has to be ensured:

- The operating staff must be familiar with the location of safety equipment, accident and danger alarms as well as first aid and rescue equipment as well as their handling.

- The operator is responsible for the respective training of the operating staff.

- All equipment for first aid (first-aid kit, eyewash bottles, stretcher, etc.) as well as equipment for firefighting (fire extinguishers) must be within reach and easy to access. All equipment has to be in a sound condition and should be checked regularly. 


\section{$3 \quad$ Function and setup}

\subsection{General overview}

The analyzer multi EA 4000 is of modular design. The basic device (combustion unit with furnace module HTS1500) is combined with one or several detector modules dependent on the task:

- Basic device

- Carbon and/or sulfur module (C/S module)

- Chlorine module (Cl module)

- TIC solids module (automatic or manual)

It is possible to change from $\mathrm{C} / \mathrm{S}$ to $\mathrm{Cl}$ determination without modifying the electrical connections. The ceramic tube is then replaced with a quartz glass combustion tube.

Sample introduction to the combustion furnace takes place:

- automatic using the autosampler FPG 48

- manual using manual feed

The device system can be combined with scales with an interface to the control computer, which automatically transfer the sample volume for the calculation of the analysis results.

The control electronics is located in a detector module in accordance with the basic configuration:

- in the $\mathrm{C} / \mathrm{S}$ module if a $\mathrm{C} / \mathrm{S}$ module is connected

- in the $\mathrm{Cl}$ module if the analyzer is not combined with a $\mathrm{C} / \mathrm{S}$ module

The control of the analyzer and the analysis of the measurements takes place via the control and analysis software multiWin ${ }^{\circledR}$ installed on an external PC.

\subsection{Basic device}

The basic device of the multi EA 4000 consists of the following main components:

- Combustion system

- Hose system

- Components for measuring gas drying and cleaning

- Indicator and control elements, connections 


\subsubsection{Combustion system}

The combustion furnace is a resistor-heated horizontal furnace for combustion temperatures up to $1500^{\circ} \mathrm{C}$. A combustion tube serves as reactor. The carrier and combustion gas is supplied via an open gas sluice to the inside of the combustion tube. Because the gas flow of the carrier and combustion gas is greater than the intake flow of the measuring gas, the resulting overpressure at the combustion tube inlet prevents measuring gas from escaping or ambient entering the combustion tube.

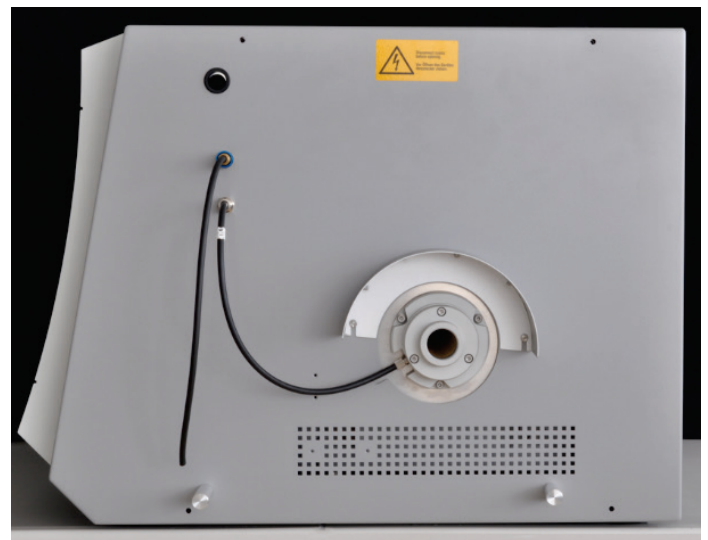

Open gas sluice

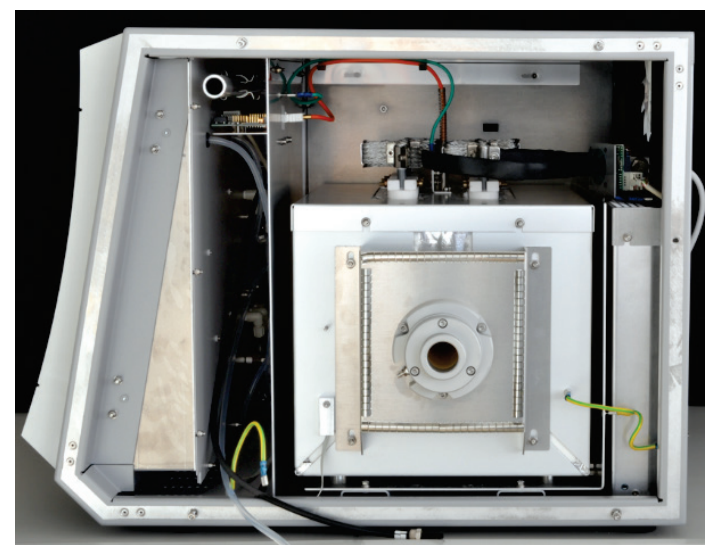

Horizontal furnace (ride side panel opened)

Figure 1 Gas sluice and horizontal furnace of the basic device multi EA 4000

The combustion tube for $\mathrm{C} / \mathrm{S}$ determination is made of a special high temperature ceramic material (HTC-High Temperature Ceramic). This is particularly robust, corrosionresistant and low in wear. Thanks to the HTC technology, samples can be digested without catalysts at temperatures of up to $1500{ }^{\circ} \mathrm{C}$. For especially difficult matrices, the combustion temperature can be increased to $1800^{\circ} \mathrm{C}$ with special aggregates (use of the exothermic effect).

A quartz tube is used as combustion tube for $\mathrm{Cl}$ determination. This is a high chemical inertia against $\mathrm{HCl}$ and prevents low results and memory effects during the analysis. The maximum furnace temperature is $1000^{\circ} \mathrm{C}$ when using the quartz tube.

The combustion system is equipped with a temperature controller that monitors the heating of the furnace, maintains the temperature at the target value and prevents overheating.

\subsubsection{Hose system}

The connection between the individual components of the basic device and to the analysis modules is by way of a hose system. The layout of the hose system in the respective module configurations can be found in the hose diagrams in section "Positioning the analyzer with various detector modules" p. $49 \mathrm{ff}$. 
The gas flows for carrier gas and combustion gas are controlled through manually adjustable flow regulators at the front of the basic device.

An integrated suction pump ensures a stable flow of the measuring gas through the detector. The required intake flow is set using the "pump" valve at the flow regulator.

The pump and the gas flows are automatically activated once the multiWin program has been started and the temperature of the combustion furnace differs by less than $50 \mathrm{~K}$ from the target temperature. If the temperature differs by more than $50 \mathrm{~K}$ from the target temperature, the pump and gas flows are automatically deactivated.

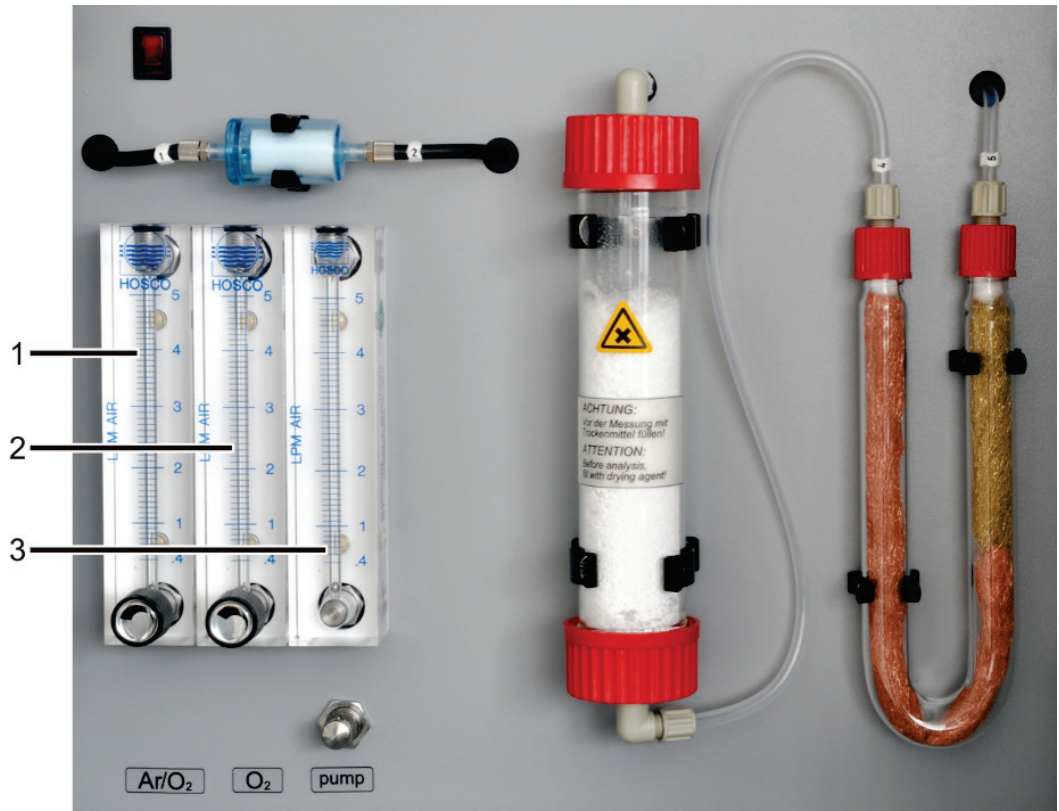

Figure 2 Flow regulators at the basic device multi EA 4000

1 Flow regulator for argon/oxygen " $\mathrm{Ar} / \mathrm{O}_{2}$ "

3 Flow regulator for "pump" intake flow

2 Flow regulator for oxygen " $\mathrm{O}_{2}$ "

\subsubsection{Components for measuring gas drying and cleaning}

Dust trap for $\mathrm{C} / \mathrm{S}$ determination
The dust trap is attached directly to the ceramic combustion tube. Combustion dust sediments there. Larger particles in the gas flow hit against a plate set vertically to the gas flow and drop down. 
Dust filter

Drying tube and halide trap for $\mathrm{C} / \mathrm{S}$ determination

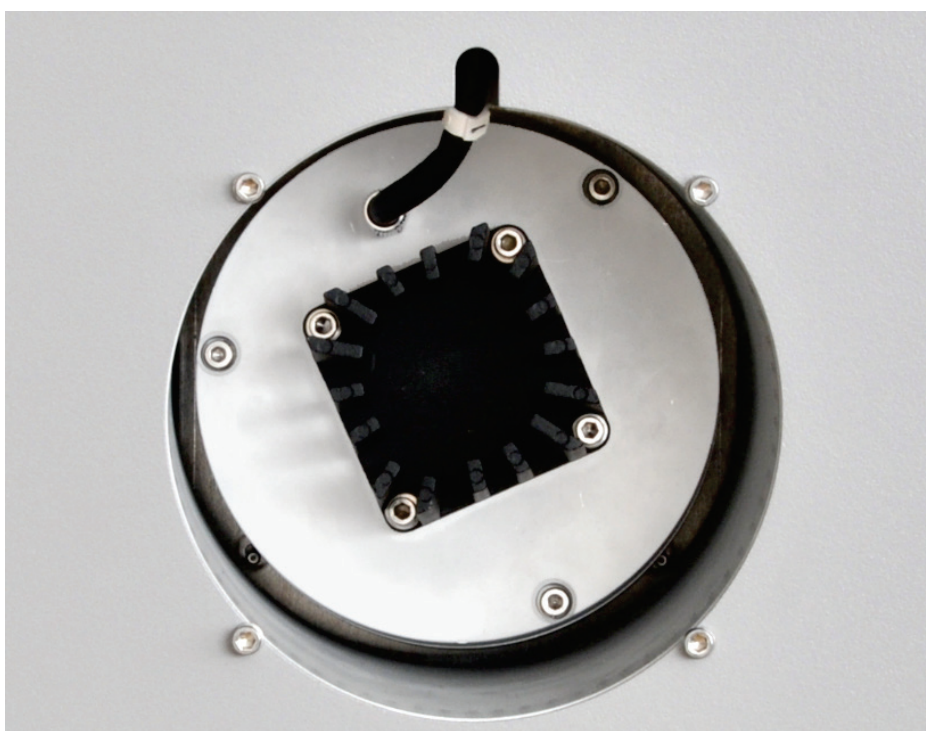

Figure 3 Dust trap at the combustion furnace

The dust trap is arranged easily accessible on the left side of the device behind the contact guard.

Directly after the dust trap a dust filter has been installed in the gas path. It holds back particles which the dust trap could not manage to remove from the measuring gas.

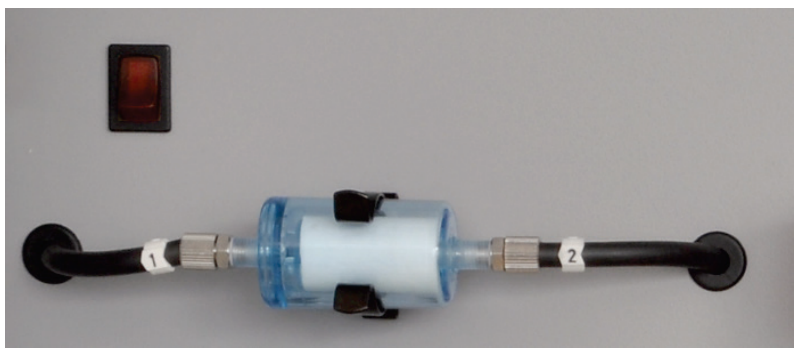

Figure 4 Dust filter

The drying tube, filled with magnesium perchlorate as a desiccant, has been installed in the gas path for drying the measuring gas during $\mathrm{C} / \mathrm{S}$ determination.

A halide trap ( $U$ tube) is has been installed in the basic device to remove interfering substances from the measuring gas and to protect the detectors and the flow regulator. The $U$ tube is filled with special copper wool and brass wool. The filling of the halide trap has to be renewed at the latest once half of the copper wool or the brass wool is discolored. 


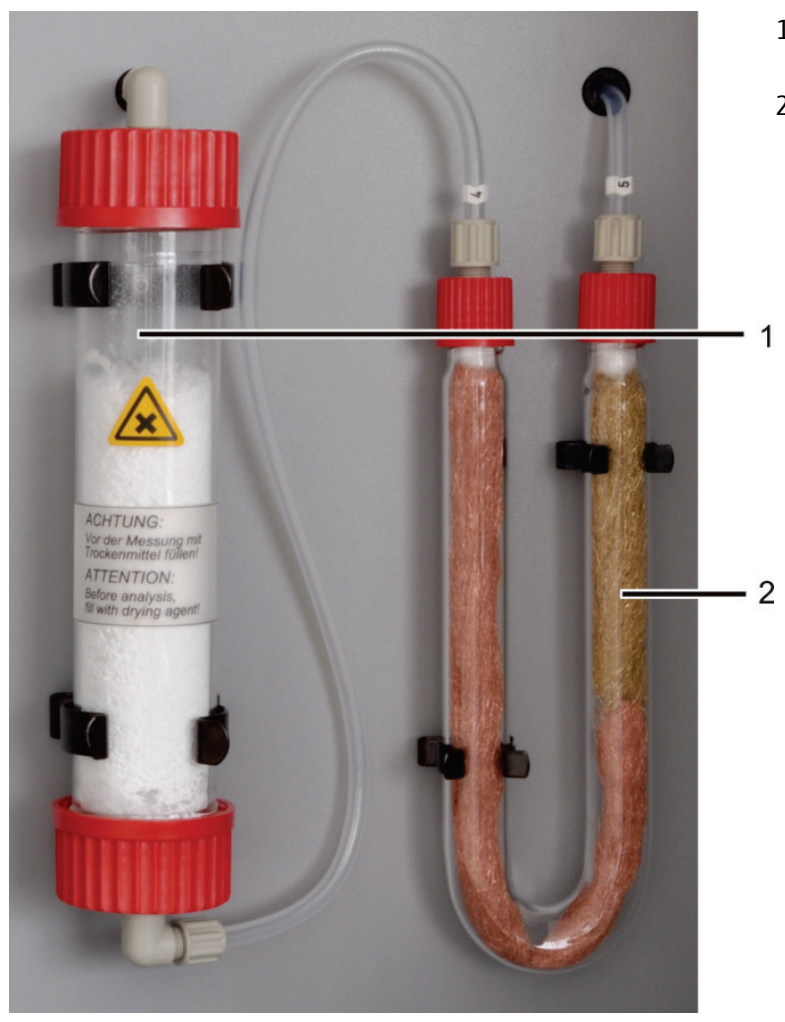

1 Drying tube with magnesium perchlorate

2 Halide trap

Figure 5 Drying tube and halide trap

\subsubsection{Indicator and control elements, connections}

The green LED at the left door of the analyzer illuminates after the analyzer has been switched on.

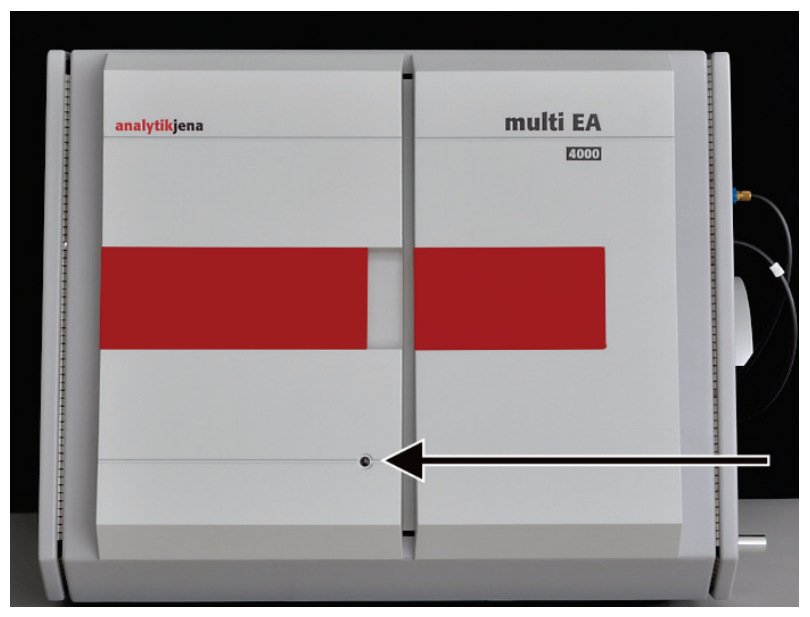

Figure 6 Status light at the basic device multi EA 4000

Behind the front doors are the On/Off switch and the flow regulators for manual gas flow control. 


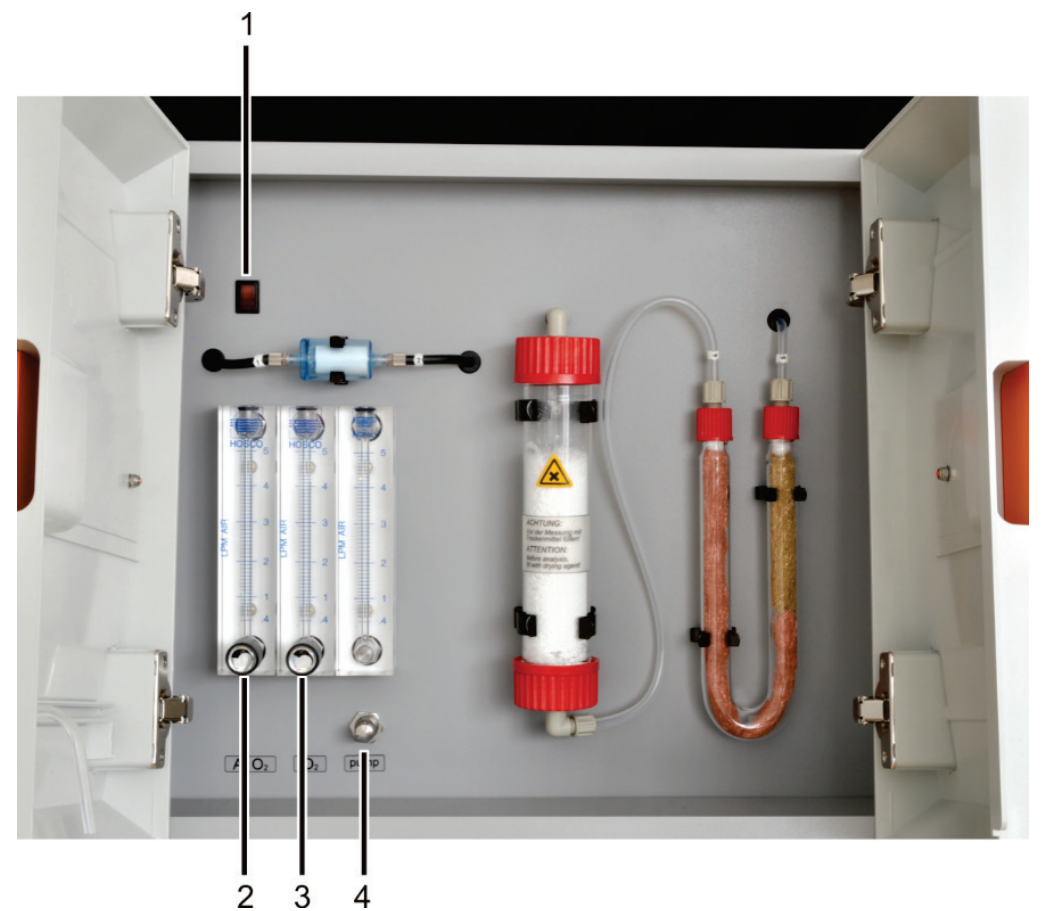

Figure 7 Control elements behind the front door of the multi EA 4000

1 On/Off switch

2 Flow regulator to control the oxygen or argon flow "Ar/ $\mathrm{O}_{2}$ "
3 Flow regulator to control the oxygen flow " $\mathrm{O}_{2}$ "

4 Flow regulator to control the "pump" intake flow
Connections on the righthand side
Located on the right-hand side of the multi EA 4000 are the openings of the combustion furnace with gas sluice and gas hoses for oxygen and argon. Through the channel ( 4 in Figure 8 ) the measuring gas and bypass hoses can be routed to the $\mathrm{Cl}$ module.

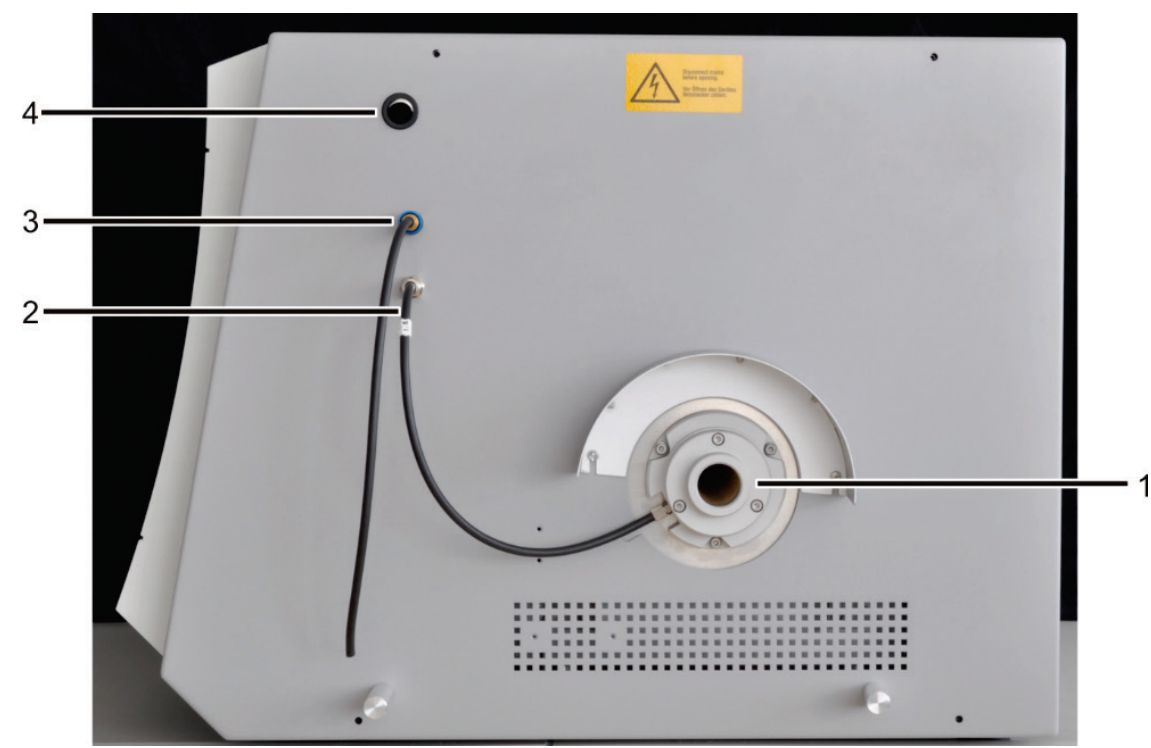

Figure 8 Connections on the right-hand side of the multi EA 4000

1 Opening of the combustion furnace with gas sluice and heat guard

2 " $\mathrm{O}_{2}$ " connection for connection to the combustion tube/gas sluice/TIC reactor
3 "Ar" connection for connection to the combustion tube/gas sluice

4 Channel for measuring gas and bypass hoses during $\mathrm{Cl}$ measurements 
Connections on the left-hand side

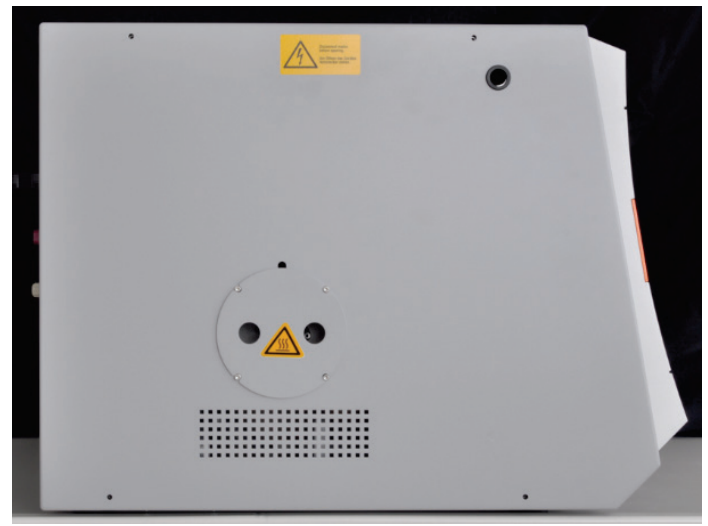

Left-hand side with dust trap contact guard the connection for the measuring gas.
On the left-hand side behind the contact guard is the opening for the dust trap with

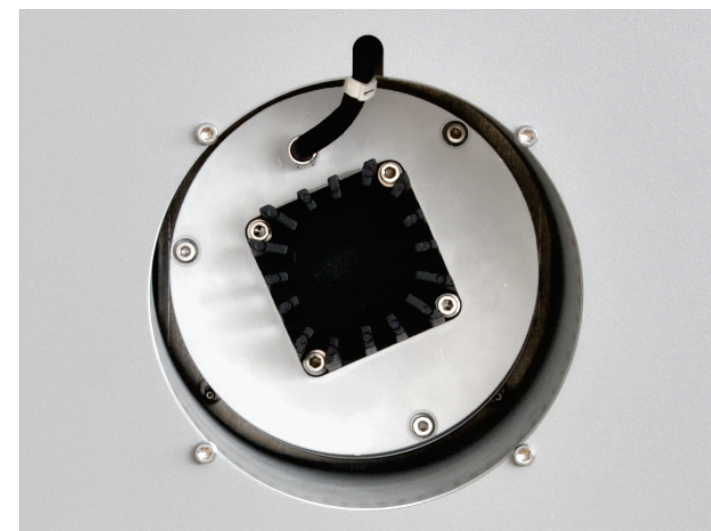

Dust trap with measuring gas connection

Figure 9 Connections on the left-hand side of the multi EA 4000

Connections at the rear
At the rear of the multi EA 4000 are the mains switch, the gas inlets for the oxygen and argon supply, the connections for the connection to the $\mathrm{C} / \mathrm{S}$ or $\mathrm{Cl}$ module and the mains connection cable.

Using the mains switch the multi EA 4000 can be completely disconnected from the mains, which is important for maintenance and repair.

If the mains switch is switched on, the analyzer is in standby mode. For daily operation the multi EA 4000 is switched on and off from the On/Off switch at the front (1 in Figure 7 ). The analyzer is then still e.g. ventilated when switched off. During extended interruptions of measurements lasting several days, the multi EA 4000 must be disconnected from the mains using the mains switch.

NOTICE! During operation both switches must be on.

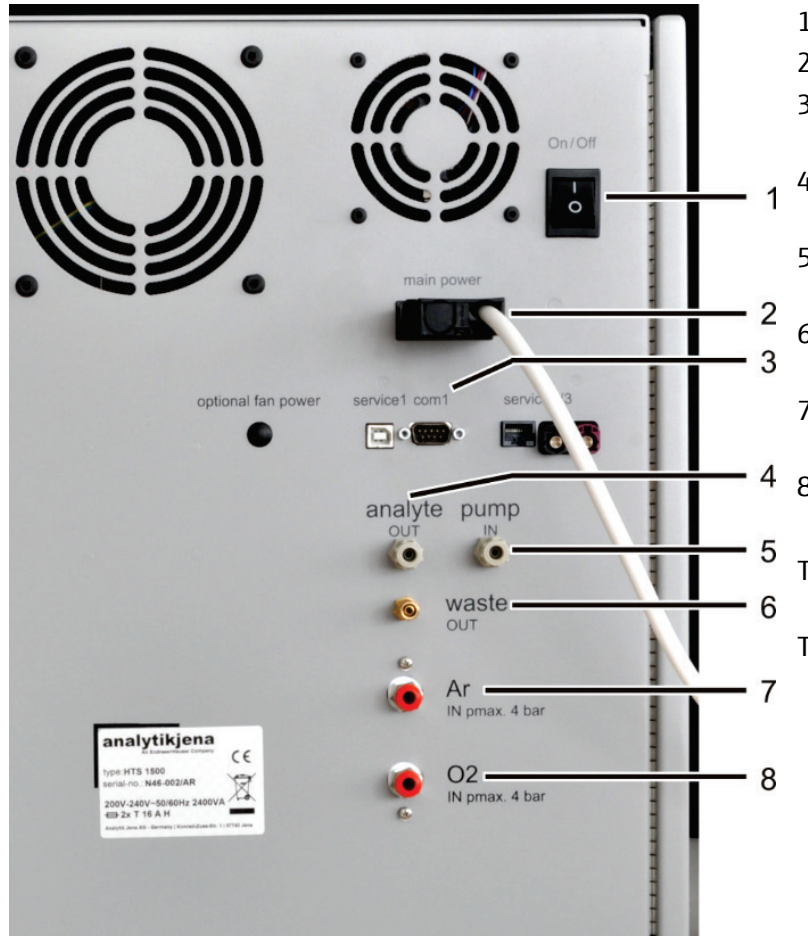

1 Mains switch

Mains cable

3 "com 1 " connection to the C/S module or $\mathrm{Cl}$ module

4 "analyte out" connection to the C/S module

5 "pump in" connection to the $\mathrm{C} / \mathrm{S}$ module or $\mathrm{Cl}$ module

6 "waste out" connection measuring gas outlet

Gas connection "Ar" for argon during $\mathrm{Cl}$ measurements and pyrolysis

Gas connection " $\mathrm{O}_{2}$ " for oxygen

The "service 1,2,3" connections are reserved for customer service.

The "optional fan power" connection is not occupied.

Figure 10 Connections at the rear of the multi EA 4000 


\section{$3.3 \quad \mathrm{C} / \mathrm{S}$ module}

Versions of the

$\mathrm{C} / \mathrm{S}$ module

Detectors

Measurements using the VITA method

Gas flow control

Connections
The C/S detector module is available in three versions:

- the C/S module with

$\mathrm{CO}_{2}$ and $\mathrm{SO}_{2}$ detectors for the simultaneous determination of carbon and sulfur

- the C module with

$\mathrm{CO}_{2}$ detector for the determination of carbon

- the S module with

$\mathrm{SO}_{2}$ detector for the determination of sulfur

The control electronics is always located in the C/S module.

The NDIR detectors (Non-Dispersive Infrared Absorption Detector) are located behind the rear right side panel of the analyzer.

Gases with molecules from different atoms have specific absorption bands in the infrared range. When a light beam is sent through an arrangement of cells, which contains active IR gases, these gases absorb the characteristic wavelengths of the total radiation. The share is proportional to their concentration in the gas mixture.

The detectors used in the $\mathrm{C} / \mathrm{S}$ module are selective for $\mathrm{CO}_{2}$ and $\mathrm{SO}_{2}$.

The $\mathrm{CO}_{2} / \mathrm{SO}_{2}$ molecules are detected by measuring technology as long as they remain in the cell of the NDIR detector. Due to fluctuations of the measuring gas flow during the $\mathrm{CO}_{2} / \mathrm{SO}_{2}$ measurement the $\mathrm{CO}_{2} / \mathrm{SO}_{2}$ molecules are sometimes detected by spectrometry for a longer (low gas flow) or shorter (higher gas flow) time.

Using the VITA method (dwell time coupled integration for TOC analyses), the measuring gas flow is detected parallel to the NDIR signal. Occurring flow variations are compensated to a constant gas flow by computer-controlled normalization of the signal and only integrated afterwards.

To this end, a flow regulator has been arranged very close to the NDIR detector flow.

A flow regulator monitors the required intake flow; the values are recorded in the software. Deviations from the permissible target value are displayed and the oxygen flow can be corrected at the "pump" valve of the flow regulator of the basic device multi EA 4000 ( 3 in Figure 7). During a measurement, the values are used for the integral correction using the VITA method.

The green LED at front of the analyzer illuminates after the module has been switched on. On the rear are the mains switch with mains input and fuse holder, the connections for connecting to the basic device and the other add-on modules and the inlets and outlets for the measuring gas flows. 


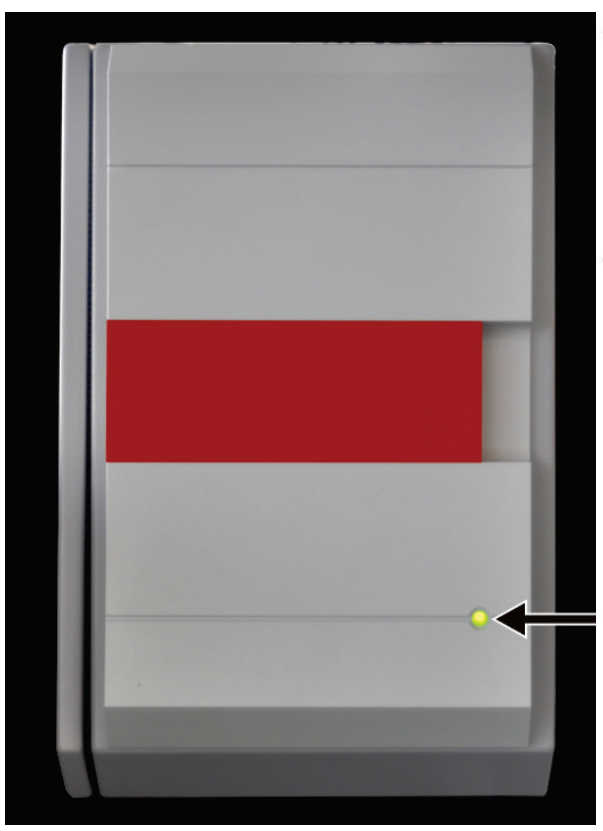

Figure 11 Indications and connections at the $\mathrm{C} / \mathrm{S}$ module

1 "PC" USB port for connection to the PC

2 "valve" connection - connection to the flame sensor or automatic TIC solids module (optional)

3 "COM" connection - connection to the combustion module HTS1500 of the multi EA 4000 or automatic TIC solids module (optional)

4 "scale" connection - connection of the scales

5 "sampler" connection - connection of the autosampler FPG 48

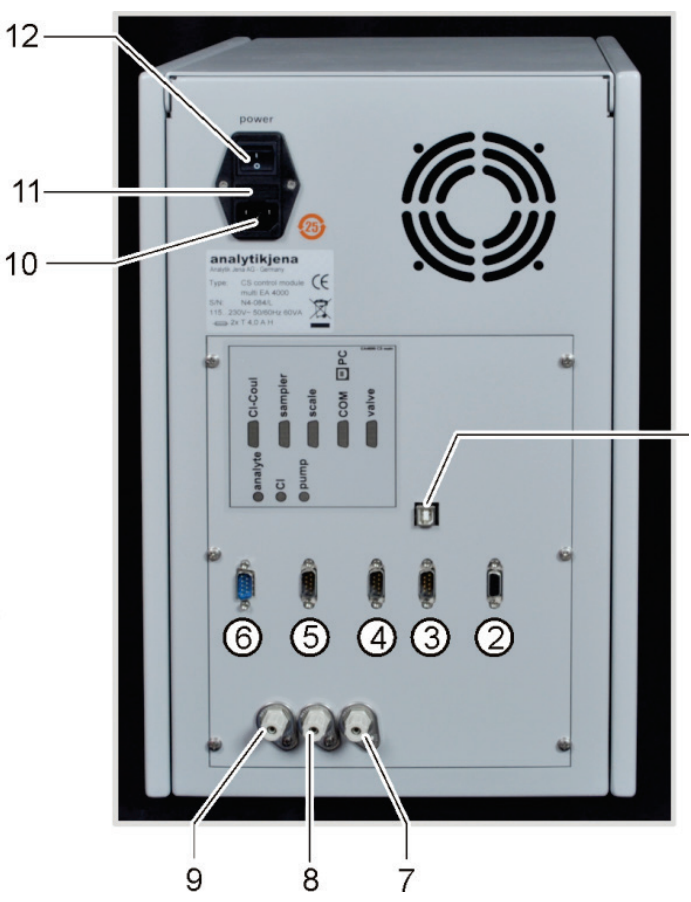

$6 \mathrm{Cl}$-Coul - connection to the $\mathrm{Cl}$ module

7 Gas outlet "pump" - connection to the multi EA 4000

8 Gas connection "Cl" - connection to the $\mathrm{Cl}$ module

9 Gas inlet "analyte" - measuring gas inlet

10 mains plug connection

11 Fuse holder

12 Mains switch

\subsection{Cl module}

The $\mathrm{Cl}$ module consists of the following main components:

- Wide-range coulometer for amperometry

- Stirrer/cooling block for the measuring cells

- Measuring cells with electrodes

- Sulfuric acid container, with split outlet and safety container where applicable

- Split valve

- Buffer container as pressure compensation to compensate for the switching pulses of the split valve

- Adsorption tube

- Halide trap

For the multi EA $4000 \mathrm{Cl}$ the control electronics is also housed in the $\mathrm{Cl}$ module. 


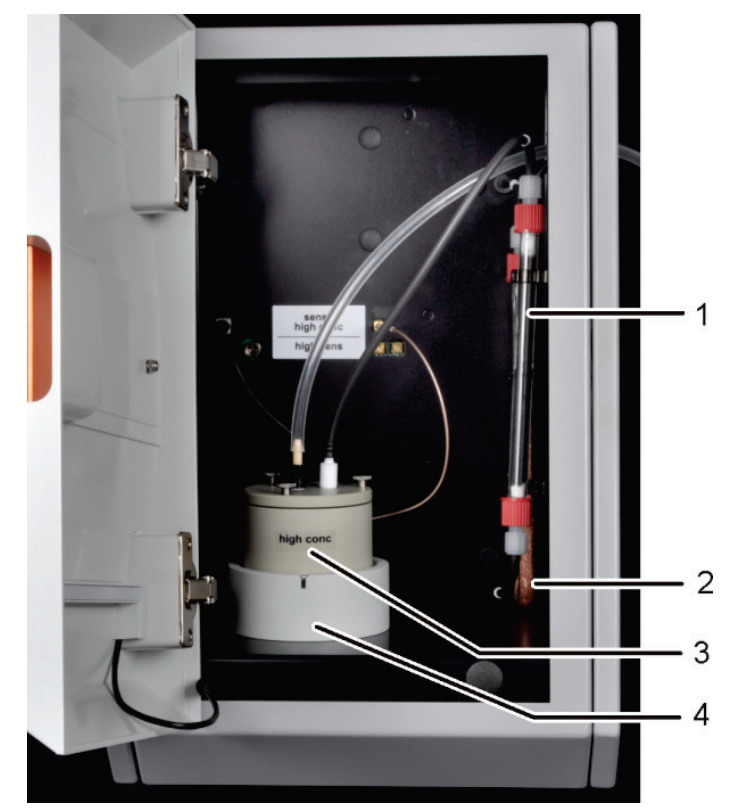

1 Adsorption tube

2 Halide trap

3 Measuring cell with electrodes

4 Stirrer/cooling block

Figure $12 \mathrm{Cl}$ module

\subsubsection{Coulometer assembly and measuring cell}

The measuring cell is available in 2 versions:

\begin{tabular}{lll}
\hline & $\begin{array}{l}\text { "sensitive" measuring cell } \\
\mathbf{4 0 ~ m l}\end{array}$ & $\begin{array}{l}\text { "high concentration" } \\
\text { measuring cell } 150 \mathrm{ml}\end{array}$ \\
\hline Electrolyte volume & approx. $20 \mathrm{ml}$ & approx. $120 \mathrm{ml}$ \\
\hline $\begin{array}{l}\text { Measuring range - absolute } \\
\mathrm{Cl} \text { (without measuring gas } \\
\text { splitting) }\end{array}$ & $1-100 \mu \mathrm{g}$ & $10-1000 \mu \mathrm{g}$ \\
\hline $\begin{array}{l}\text { Measuring range } \\
\text { (with measuring gas split- } \\
\text { ting) }\end{array}$ & $1-2 \mathrm{mg}$ abs. Total chlorine & $\begin{array}{l}10 \mu \mathrm{g}-20 \mathrm{mg} \text { abs. } \\
\text { Total chlorine }\end{array}$ \\
\hline $\begin{array}{l}\text { Stirring principle } \\
\text { Indication principle }\end{array}$ & $\begin{array}{l}\text { Alternating current bi-am- } \\
\text { perometry }\end{array}$ & $\begin{array}{l}\text { Alternating current bi-am- } \\
\text { perometry }\end{array}$ \\
\hline $\begin{array}{l}\text { Generation principle } \\
\text { Generator current }\end{array}$ & anodic silver dissolution & anodic silver dissolution \\
\hline $\begin{array}{l}\text { Temperature control to } \\
\text { operating temperature }\end{array}$ & dynamic up to $1 \mathrm{~mA}$ & dynamic up to $10 \mathrm{~mA}$ \\
\hline
\end{tabular}

The measuring cell consists of the electrode space, which takes the electrolyte solution, and the stirrer block arranged in the module. At the floor of the electrode space is the generator anode in the form of a stable silver plate. The magnetic stirrer runs above the anode.

The cell is sealed airtight with a cover and three knurled head screws. The two cover penetrations (holes) are used to mount the combined electrode and a suction olive. 
The marked opening is intended for the amperometric combined electrode. The unmarked opening is used for direct injection into the measuring cell or to connect the suction olive.

When the chlorine module is switched on, the magnetic stirring rod in the measuring cell cup starts moving. The preset cell temperature is $20^{\circ} \mathrm{C}$ and can be modified as method parameter in the multiWin program.

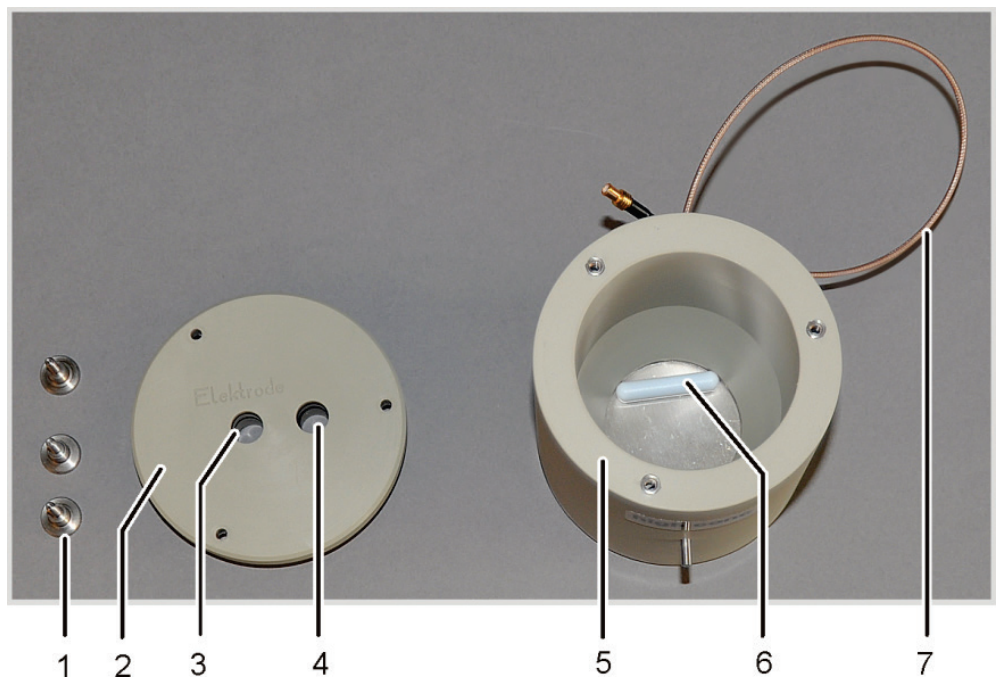

Figure 13 Measuring cell design

1 Knurled head screws

2 Cover

3 Opening for electrode (labeled)

5 Electrode space with silver anode

6 Magnetic stirring rod

7 Electrical connection of the measuring cell

4 Opening for olive to connect extraction hose or direct injection

The combined electrode combines indicator electrodes $(\mathrm{Ag})$, generator cathode $(\mathrm{Pt})$ and gas inlet. The generator anode is as a silver circle in the two base elements of the measuring cells (see above).

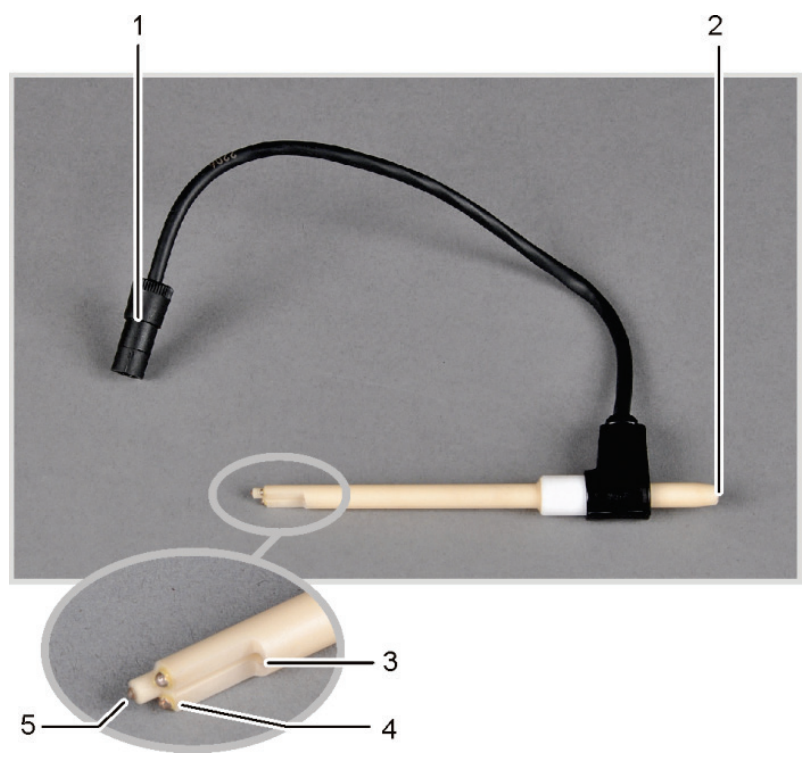

Connector

2 Measuring gas hose connection

3 Gas inlet to the measuring cell

4 Indicator electrodes $(\mathrm{Ag})$

5 Generator cathode (Pt)

Figure 14 Combined electrode for the measuring cell 


\subsubsection{Combustion tube and measuring gas drying}

A quartz tube is used as combustion tube for $\mathrm{Cl}$ determination. The oxygen supply for combustion is via a bypass in the quartz tube. The measuring gas is inducted at the side connection of the quartz tube and routed via the drying to the $\mathrm{Cl}$ module. The gas sluice filled with argon prevents the measuring gas from escaping at the entrance of the combustion tube. The end of the combustion tube is sealed with quartz wool to prevent dust from entering the hose system of the multi EA 4000.

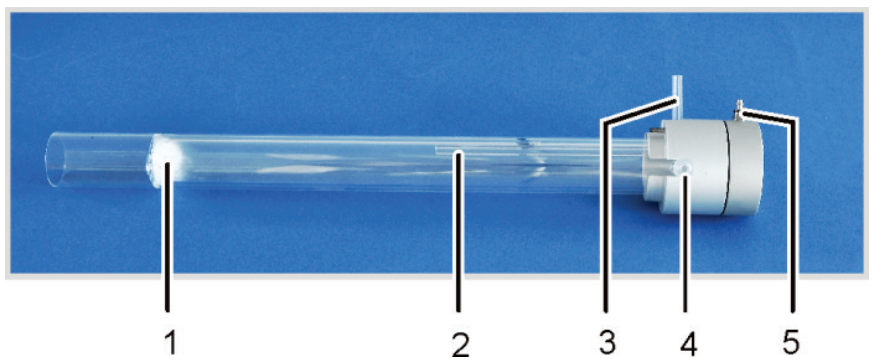

Figure 15 Quartz combustion tube with gas sluice

1 Quartz wool plug

2 Bypass for oxygen supply

3 Oxygen connection adapter
4 Measuring gas outlet with boat connection

5 Argon supply at the gas sluice

Hydrogen chloride $(\mathrm{HCl})$ has a high affinity with water and therefore dissolves in condensed water. During analysis, this behavior causes low results or memory effects. To prevent condensation, the measuring gas must be dried as soon as it exits the combustion tube. Concentrated sulfuric acid is used as desiccant. Two special sulfuric acid containers are used dependent on the method with or without measuring gas splitting.

If the sulfuric acid container with split outlet is used, an additional safety container is installed in the gas path. This catches sulfuric acid that might be sucked out of the sulfuric acid container.

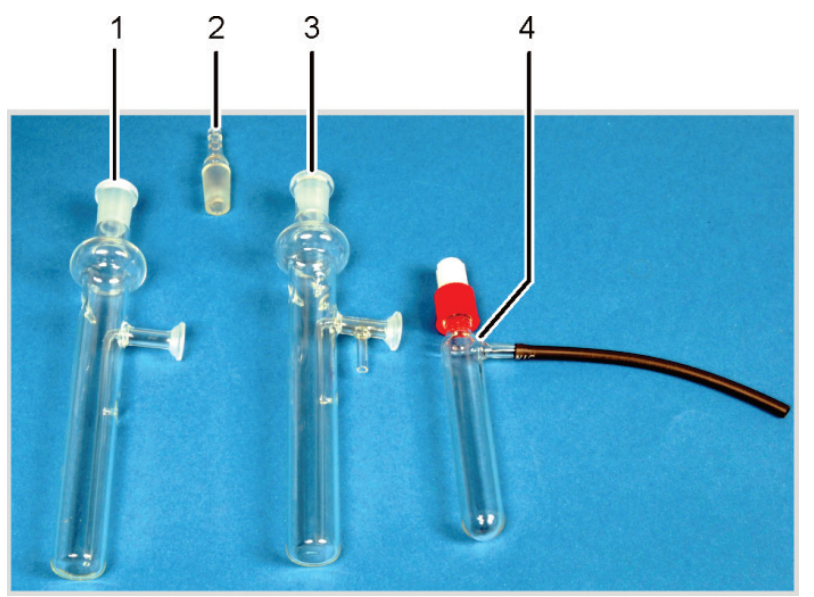

1 Sulfuric acid container without split outlet

2 Gas olive

Sulfuric acid container with split outlet

4 Safety container

Figure 16 Sulfuric acid containers for measuring gas drying 


\subsubsection{Measuring gas cleaning}

Halide trap

Adsorption tube

\subsubsection{Connections}

The green LED at front of the $\mathrm{Cl}$ module illuminates after the module has been switched on.

Dependent on the equipment of the multi EA 4000 with or without $C / S$ module, the connections for connecting to the $\mathrm{C} / \mathrm{S}$ module or the basic device and the autosampler are located at the rear.

The hoses for the supply of measuring gas and the bypass are routed via the channel in the basic device through the opening in the right-hand device wall into the chlorine module. 

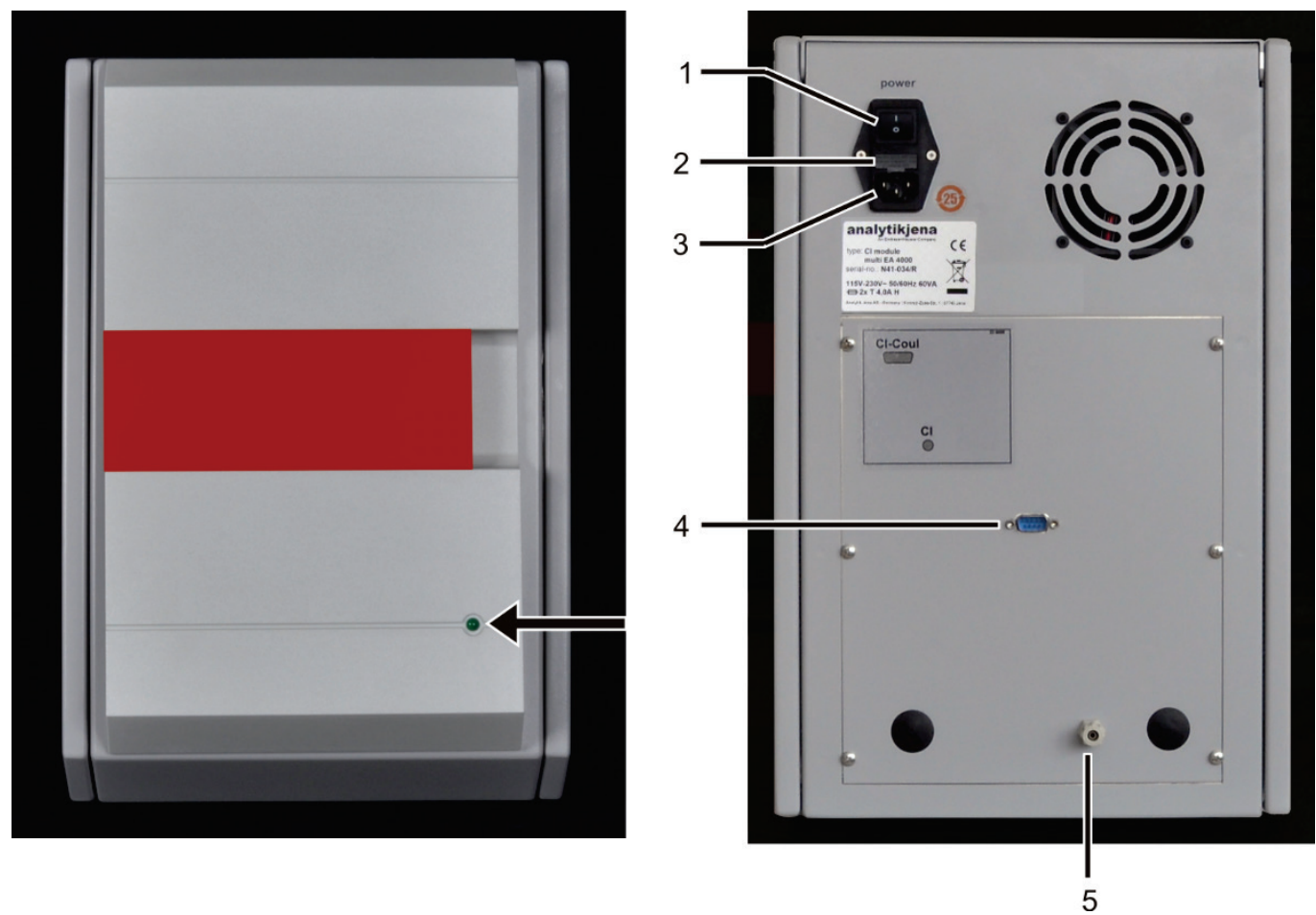

Figure $18 \mathrm{Cl}$ module connections in combination with a $\mathrm{C} / \mathrm{S}$ module

1 Mains switch

2 Fuse holder

3 mains plug connection
4 "Cl-Coul" connection - connection to the $\mathrm{C} / \mathrm{S}$ module

5 Gas connection "Cl" - connection to the $\mathrm{C} / \mathrm{S}$ module

If no $\mathrm{C} / \mathrm{S}$ module has been installed, the $\mathrm{Cl}$ module has additional interfaces on the rear for the communication with the multi EA 4000 and the autosampler. The interface assignment has been described in section "Positioning the multi EA $4000 \mathrm{Cl}$ " p. 51.

The electrical connections for the measuring cell and the combined electrode are located on the inside rear wall of the device.

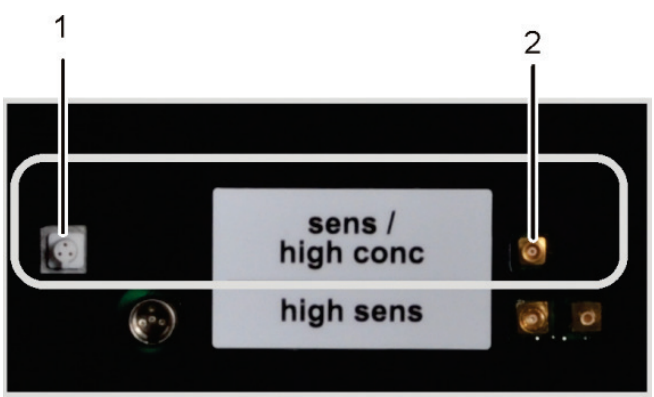

1 Connection for the combined electrode

2 Connection for the measuring cell with silver anode

Figure 19 Connections for the coulometric measuring cell in the $\mathrm{Cl}$ module 


\subsection{Automatic TIC solids module}

The automatic TIC solids module complements the multi EA 4000 for the determination of the TIC (TC, TOC) in solids. Carbon dioxide generated through acidification and purging is transferred to the NDIR detector of the multi EA 4000. The following analysis modes are possible:

- TIC determination

- TOC determination based on differentiation method

- TOC determination based on direct method

The automatic TIC solids module is only suitable for automatic operation in combination with the multi EA $4000 \mathrm{C}$ or multi EA 4000 C/S and the autosampler FPG 48.

The automatic TIC solids module consists of the following components:

- TIC reactor

- Phosphorous acid pump

- Components for measuring gas cleaning and drying

- Connections

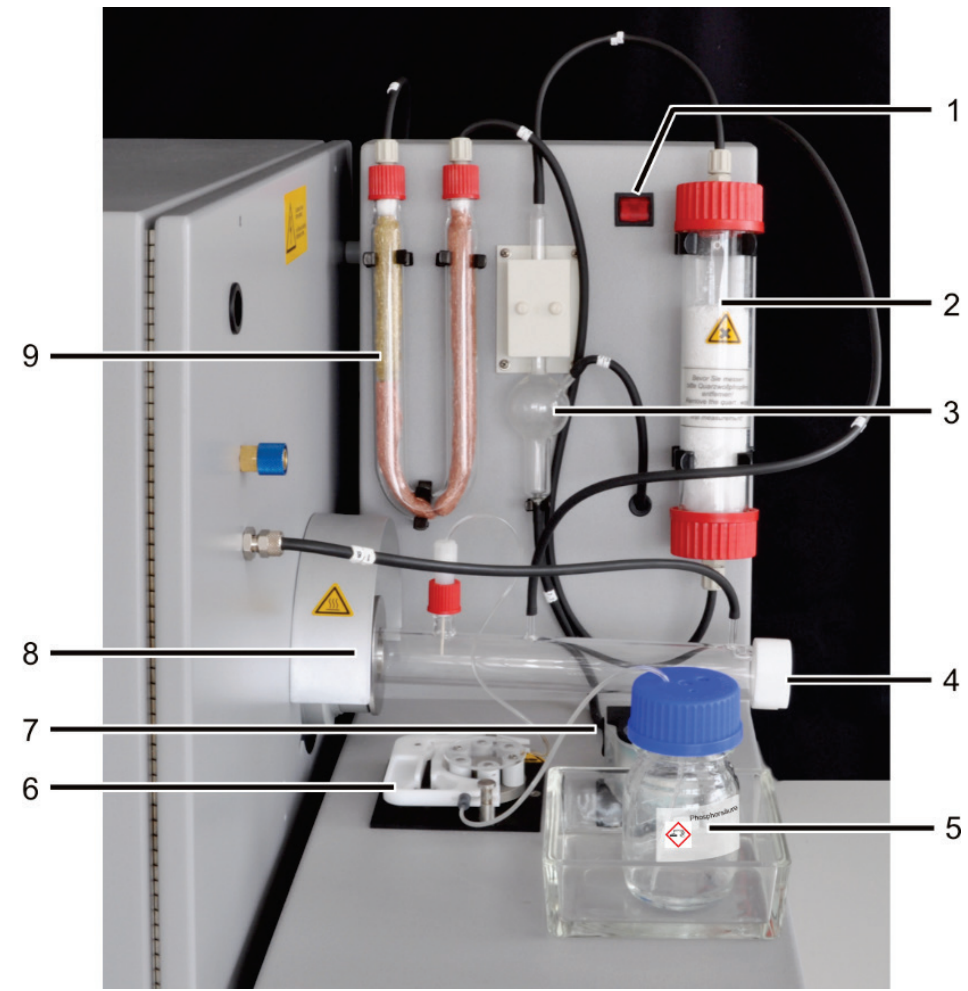

Figure 20 Automatic TIC solids module
1 Mains switch
Drying tube
3 Condensate container
4 TIC reactor
5 Bottle for phosphoric acid

6 Acid pump for phosphoric acid or hydrochloric acid

7 Condensate pump

8 Connection of the TIC reactor to the multi EA 4000

9 Halide trap 


\subsubsection{Technical data}

\begin{tabular}{|c|c|}
\hline General characteristics & \\
\hline Designation/type & Automatic TIC solids module \\
\hline \multirow[t]{2}{*}{ Dimensions } & $300 \times 470 \times 550 \mathrm{~mm}$ \\
\hline & Autosampler: $520 \times 500 \times 700 \mathrm{~mm}$ \\
\hline Mass & approx. $5 \mathrm{~kg}$ \\
\hline \multicolumn{2}{|l|}{ Procedural data } \\
\hline Measuring methods & TIC \\
\hline Detection & NDIR (coupled with VITA method) \\
\hline Sample volume & up to $3000 \mathrm{mg}$ (TC) or $50 \mathrm{mg}$ (TIC) \\
\hline \multicolumn{2}{|l|}{ Electrical variables } \\
\hline connection & $100-240 \mathrm{VAC}( \pm 10 \%), 50-60 \mathrm{~Hz}$ \\
\hline Fuses & $\begin{array}{l}\text { T } 2 \text { AH (Only use original fuses by Analytik Jena } \\
\text { AG!) }\end{array}$ \\
\hline Maximum power consumption & $20 \mathrm{VA}$ \\
\hline Interface to the $\mathrm{C} / \mathrm{S}$ module & RS 232 \\
\hline
\end{tabular}

\subsubsection{Layout}

The quartz tube is attached to the ceramic combustion tube with a coupling. A knurled ring with screw thread claps the TIC reactor and seals the connection through pressure on the inner sealing rings. The reactor includes the connections for acid supply, measuring gas outlet and oxygen supply. The oxygen supply at the reactor inlet implements a gas sluice that prevents measuring gas from escaping through the open inlet. The ceramic boats loaded with samples are transferred to the reactor with the specially adapted autosampler FPG 48.

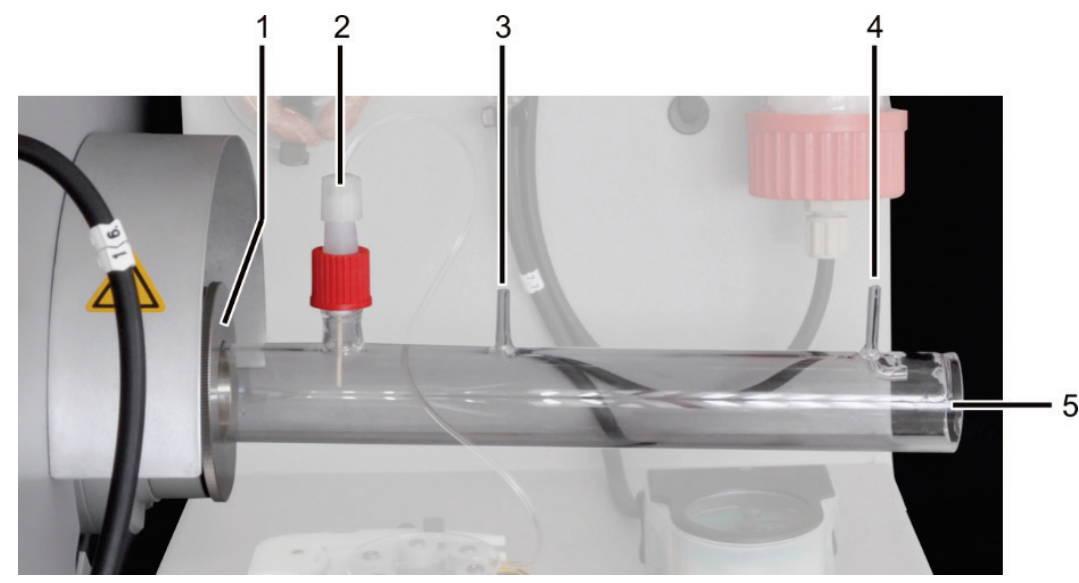

Figure $21 \mathrm{TIC}$ reactor

1 Bracket at the multi EA 4000

4 Oxygen supply inlet

2 Acid supply via ceramic cannula

5 Insert for ceramic boats

3 Measuring gas outlet 
Hose system

Components for measuring gas drying and cleaning
The connection between the individual components is made with labeled hoses. The hose diagram is available in section "Positioning the automatic TIC solids module" $p$. 57.

For the supply of the phosphoric acid and removal of the condensate, hose pumps are used. The phosphoric acid pump transports $40 \%$ phosphoric acid to the TIC reactor. The condensate pump automatically pumps the condensate from the measuring gas drying after each measurement.

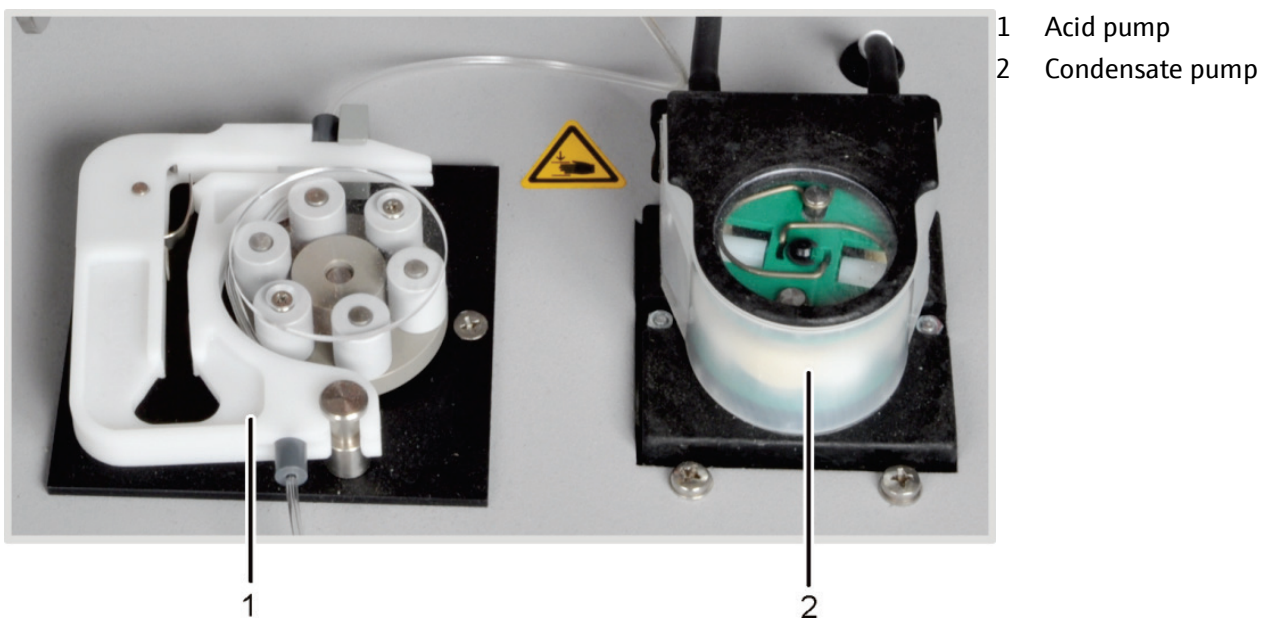

Figure 22 Hose pumps at the automatic TIC solids module

Whilst the sample boat is continuously moved towards the multi EA 4000 by the autosampler FPG 48, phosphoric acid is evenly added to the sample.

The measuring gas released is passed from the reactor to the condensation coil attached to the rear of the automatic TIC solids module. The analyte gas is cooled down quickly in the condensation coil and the water vapor condenses. The measuring gas/water mixture is passed via a hose to the gas/fluid separator, consisting of a condensate container and a Peltier cooling block.

The measuring gas is passed via the side inlet to the condensate container. The measuring gas is dried by freezing in the cooling block. The dry measuring gas is routed via the top connection out of the condensate container. The condensate pump pumps the condensate draining through the bottom outlet automatically to the waste container after each measurement.

The measuring gas is then routed through the drying tube filled with magnesium perchlorate. This completes the drying.

A halide trap ( $U$ tube) is has been installed after the measuring gas drying in the gas path to remove interfering substances from the measuring gas and to protect the detectors and the flow regulator in the C/S module. The U-tube is filled with special copper wool and brass wool. The filling of the halide trap must be renewed at the latest once half of the copper wool is discolored or the brass wool is discolored. 


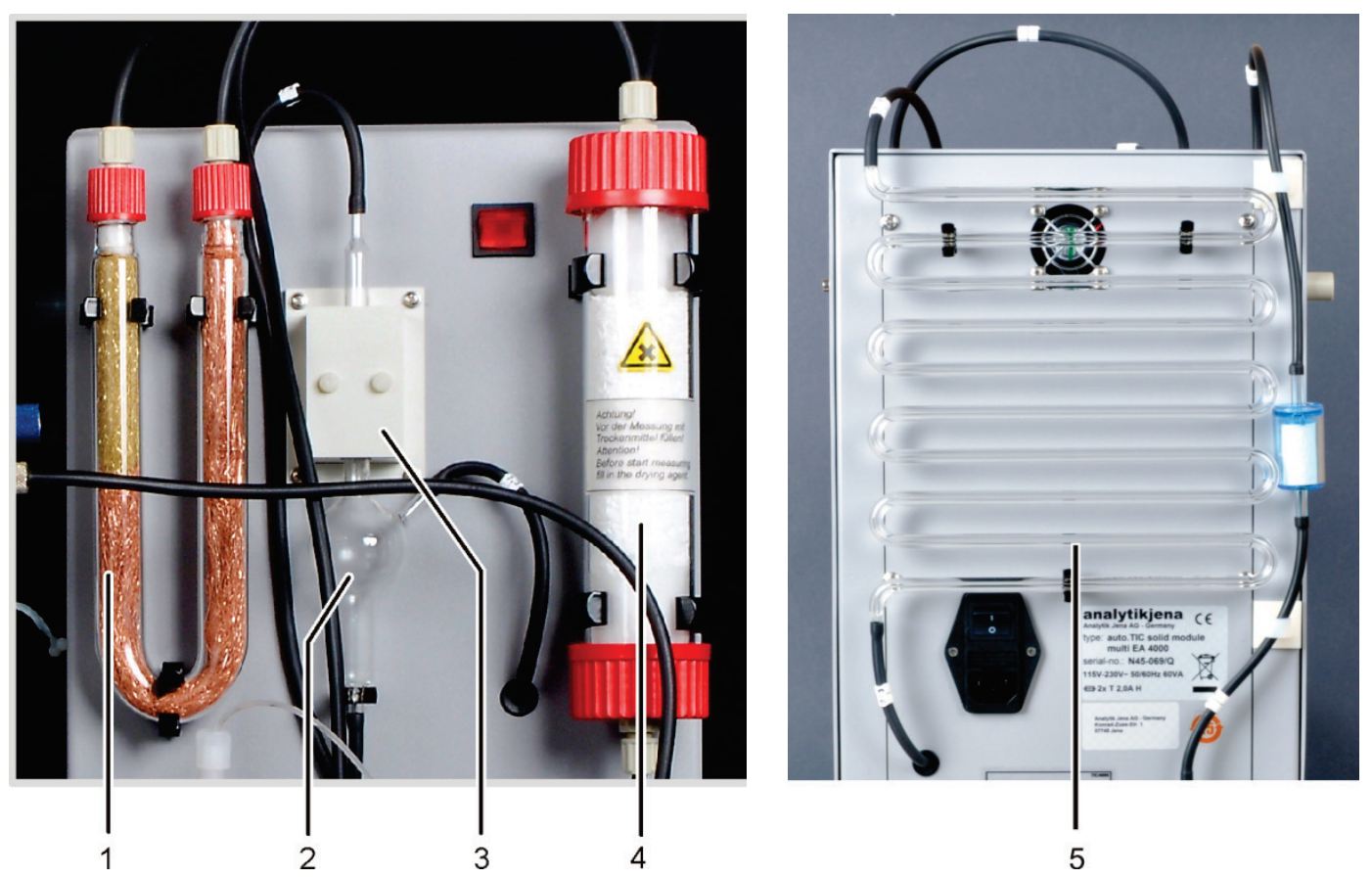

Figure 23 Measuring gas drying and cleaning at the aut. TIC solids module

1 Halide trap

4 Drying tube

2 Condensate container

5 Condensation coil

3 Peltier cooling block

A dust filter has been placed between the halide trap ( 1 in Figure 23) and the changeover valve at the rear of the automatic TIC solids module.

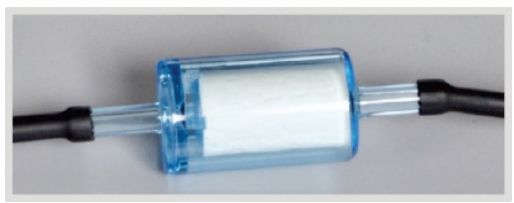

Figure 24 Dust filter before the changeover valve 

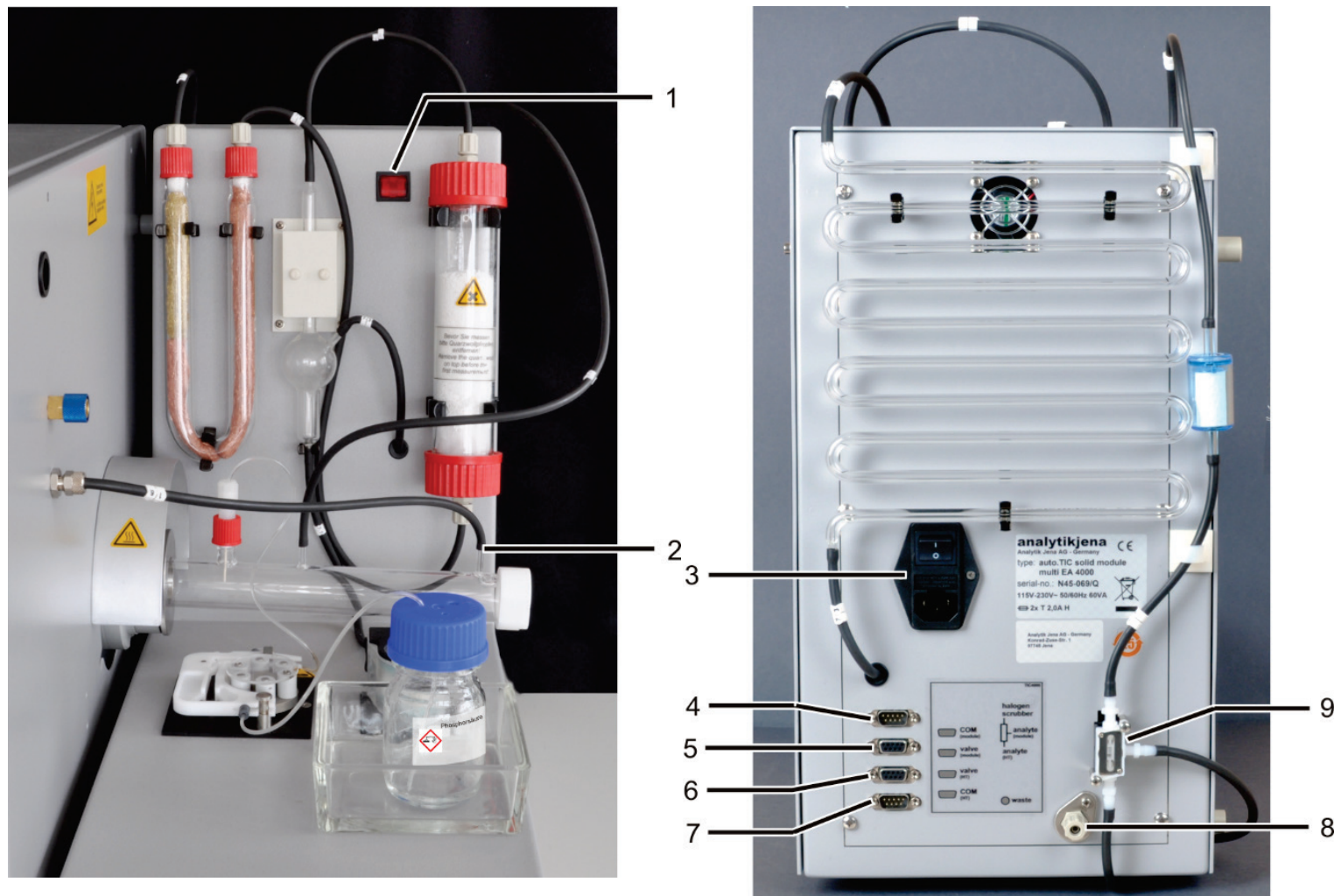

Figure 25 Connections at the automatic TIC solids module

1 Mains switch

2 Gas connection for oxygen at the TIC reactor

3 Power input module with mains switch and fuse holder

4 Gas connection "COM module for connection to the $\mathrm{C} / \mathrm{S}$ module

5 "valve module" connection for connection to the C/S module

The automatic TIC solids module is equipped with two mains switches. Because the switch at the mains input module under the condensation coil is poorly accessible, there is a second one at the front. Both mains switches must be on during operation. To deactivate the device, it is sufficient to use the switch at the front. 


\subsection{Manual TIC solids module}

The manual TIC solids module allows the determination of TIC in solids in conjunction with the multi EA $4000 \mathrm{C}$ or the multi EA $4000 \mathrm{C} / \mathrm{S}$. Acidification of the samples and purging of TIC is performed at elevated temperatures. The measuring gas is transported with the carrier gas to the detector of the C/S module. The manual TIC solids module is designed exclusively for the manual supply of samples only. Automated sample supply with an autosampler is not possible.

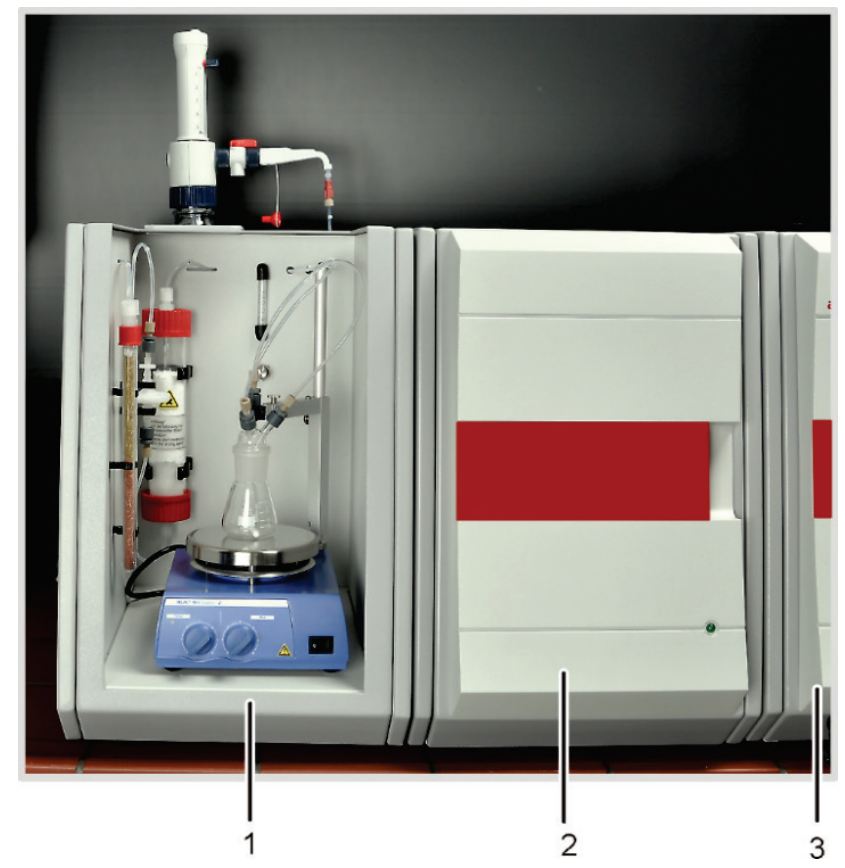

1 Manual TIC solids module

2 C/S module

3 Basic device multi EA 4000

Figure 26 Manual TIC solids module

\subsubsection{Technical data}

\begin{tabular}{|c|c|}
\hline \multicolumn{2}{|l|}{ General characteristics } \\
\hline Designation/type & Manual TIC solids module \\
\hline Dimensions & $300 \times 750 \times 550 \mathrm{~mm}$ \\
\hline Mass & approx. $10 \mathrm{~kg}$ \\
\hline \multicolumn{2}{|l|}{ Procedural data } \\
\hline Measuring methods & TIC \\
\hline Detection & NDIR (coupled with VITA method) \\
\hline Sample volume & up to $3000 \mathrm{mg}$ \\
\hline \multirow[t]{2}{*}{ Gas supply } & Oxygen min. 2.5 \\
\hline & $200-400 \mathrm{kPa}(29-58 \mathrm{psi})$ \\
\hline \multicolumn{2}{|l|}{ Electrical variables } \\
\hline \multirow[t]{2}{*}{ connection } & $220-240$ V AC $( \pm 10 \%), 50 / 60 \mathrm{~Hz}$ \\
\hline & (100 V AC / 115 V AC upon request) \\
\hline Fuses & $\begin{array}{l}\text { T } 10 \text { A H (Only use original fuses by Analytik } \\
\text { Jena AG!) }\end{array}$ \\
\hline Maximum power consumption & $415 \mathrm{VA}$ \\
\hline
\end{tabular}




\subsubsection{Manual TIC solids module setup}

TIC reaction chamber

A $50 \mathrm{ml}$ Erlenmeyer flask is used as the reactor to which a TIC head with three connections for the supply of phosphoric acid, oxygen as the carrier gas and the measuring gas outlet is attached.

A magnetic stirrer with a heating work plate ensures the sample is mixed well with the added acid and heats the mixture slightly to speed up the reaction.

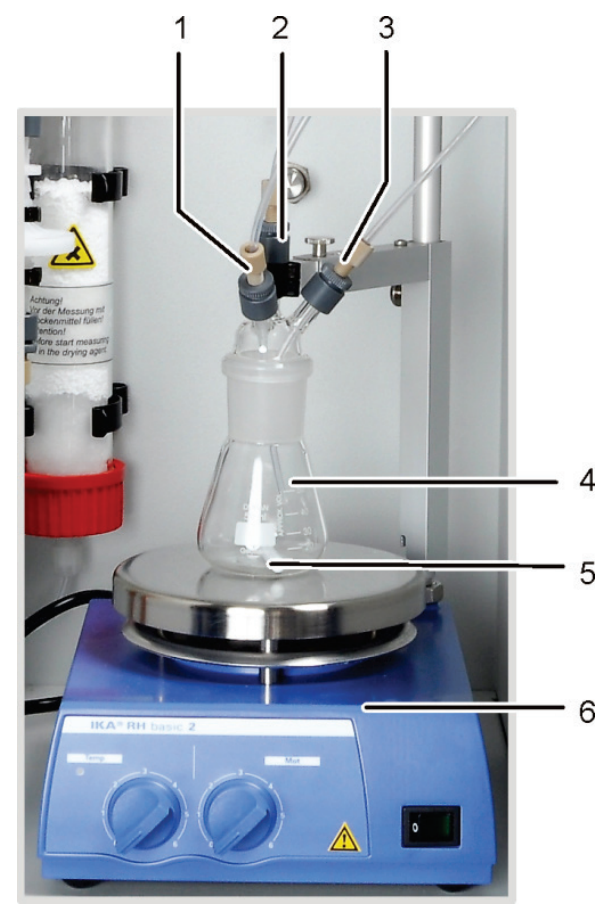

1 Supply of phosphoric acid (hose no. 6)

2 Measuring gas outlet

3 Supply of carrier gas (oxygen)

4 Erlenmeyer flask

5 Magnetic stirring rod

6 Magnetic stirrer with heated working plate

Figure 27 TIC reactor of the manual TIC solids module

Flow setting of the carrier gas flow
The carrier gas flow is set via the $\mathrm{O}_{2}$ " needle valve with measuring glass on the separating wall in of the manual TIC solids module.

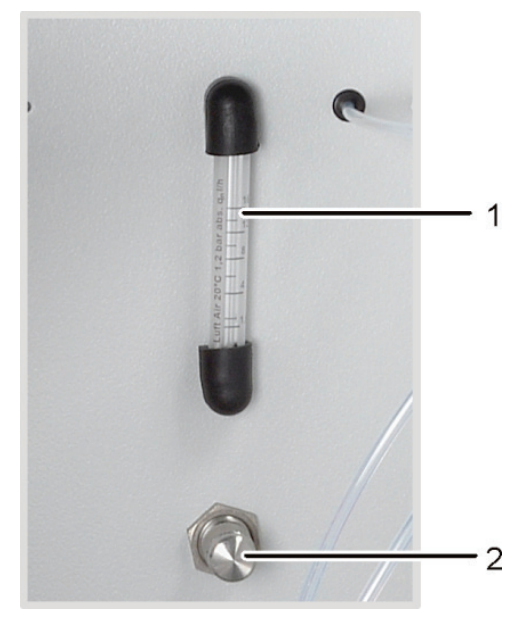

1 Measuring glass

2 Needle valve

Figure 28 Flow regulator for the oxygen flow 
Supply of acid

Measuring gas drying and cleaning
The acid is metered with the metering pump by hand. The hose for supplying acid to the reactor is connected to the metering pump with a valve. The valve in the faucet of the metering pump must be closed after acid has been supplied to the reactor. This prevents acid from being inadvertently drawn into the analyzer.

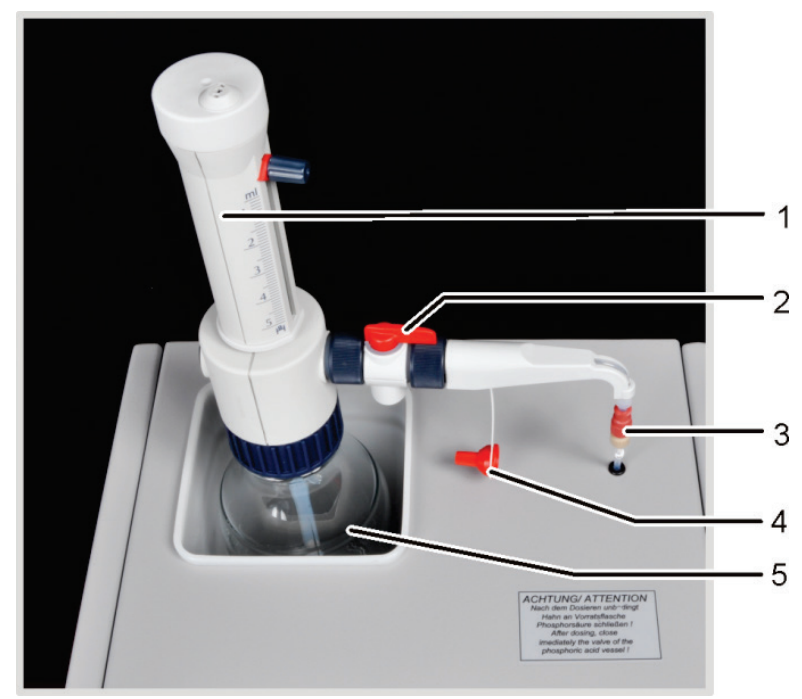

1 Metering pump with scale

2 Recirculation valve

3 Valve for connecting the metering hose

4 Sealing cap

5 Phosphoric acid bottle

Figure 29 Metering pump for acid on the manual TIC solids module

A drying tube, filled with magnesium perchlorate as a desiccant, is installed in the gas path immediately downstream of the reactor.

The desiccant cartridge is followed by two water traps. The larger water trap (TC prefilter) retains aerosol during operation, the smaller water trap (disposable retention filter) retains rising water.

A halide trap is used to remove interfering substances from the measuring gas and to protect the detectors and the flow regulator in the C/S module. The U-tube of the halide trap is filled with a special copper wool and brass wool. The filling of the halide trap has to be renewed at the latest once half of the copper wool or the brass wool is discolored. 


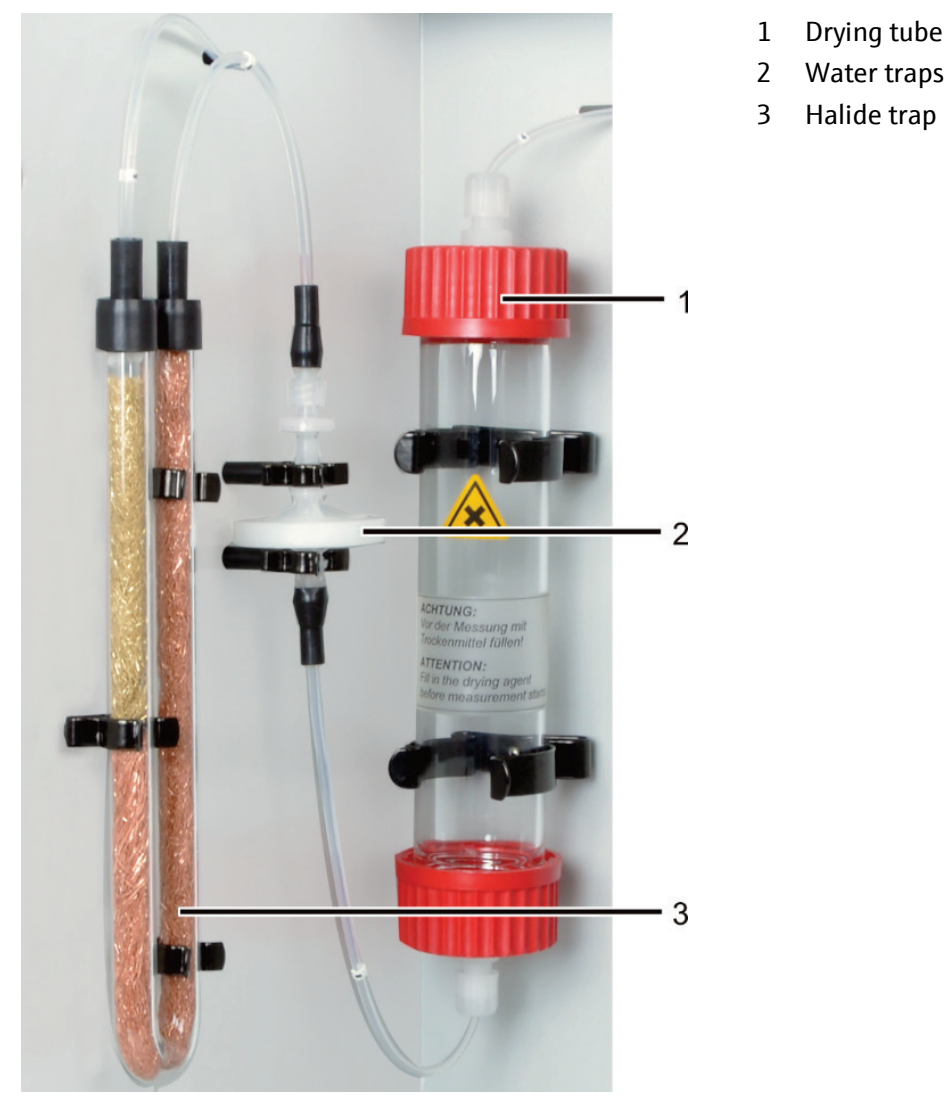

Figure 30 Measuring gas drying and cleaning at the man. TIC solids module

\section{Connections}

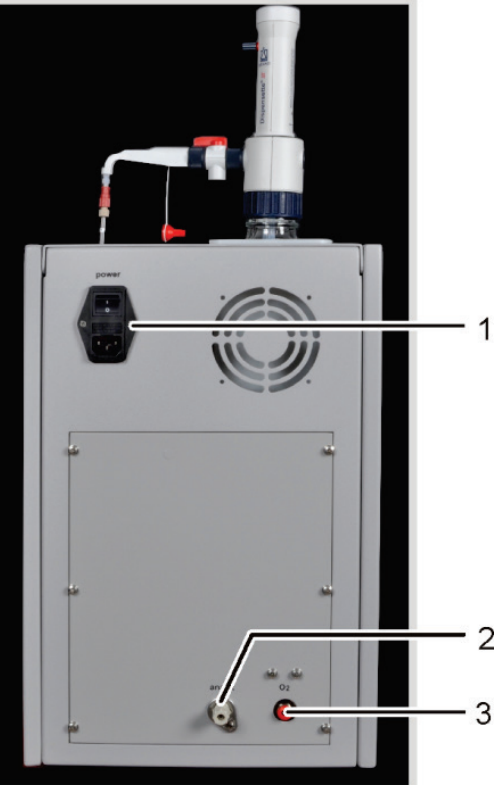

Figure 31 Connections at the manual TIC solids module
1 Power input module with mains switch and fuse holder

2 Measuring gas outlet "analyte"

3 Carrier gas connection " $\mathrm{O}_{2}$ " 


\subsection{Additional optional accessories}

\subsubsection{Sampler}

Autosampler FPG 48

Two versions of sampler are available for the sample feed of the multi EA 4000:

- the solid autosampler FPG 48

- the manual feed

Manual feed

The autosampler FPG 48 offers space for 48 sample boats. The boats are automatically picked from the trays and transferred to the combustion furnace. The feed for the transfer is computer-controlled. Dependent on the equipment the boats are placed back on the autosampler after the measurement or discarded in a waste container after cooling.

For analyses in the quartz combustion tube ( $\mathrm{Cl}$ measurements) the FPG 48 can be combined with a flame sensor.

The manual feed is a robust device facilitating the movement of the ceramic hook with the straight aligned sample boats into the combustion furnace. In the manual sample feed it is important that with highly reactive samples the transfer into the combustion tube must be slow and controlled.

\subsubsection{Flame sensor}

A flame sensor can optionally be combined with the autosampler FPG 48 for $\mathrm{Cl}$ determination. The flame sensor captures the combustion of highly reactive samples in the quartz tube visually and controls the boat advance in accordance with the brightness of the flame. The ensuing optimized combustion characteristics lead to precise measuring results.

\subsubsection{Scales}

Scales can be connected for the automatic volume transfer for the calculation of the analysis results. The samples must be weighted in accordance with the instructions in the program. The determined weights are automatically transferred to the sample table. 


\section{$4 \quad$ Measuring methods}

The analyzer multi EA 4000 is used to determine the following parameters as sum parameters.

- TS - Total Sulfur

- TC - Total Carbon

- $\mathrm{TCl}$ - Total Chlorine

- TOC - Total Organic Carbon

- TIC - Total Inorganic Carbon

- EC - Elemental Carbon

- TC-EC - Determination of carbon after pyrolysis

- $\mathrm{AOC}$ - Degradable organic carbon

In the control and analysis software multiWin the detection of several parameters can be combined.

\subsection{TC/TS analysis}

The multi EA 4000 with C/S module is a special system for the simultaneous or individual determination of the total carbon and total sulfur in solid and paste-like samples using high temperature oxidation in an oxygen flow.

A sample aliquot is weight precisely in a combustion boat and transferred completely into the hot zone of the furnace. There the sample is digested and oxidized in the oxygen flow at high temperature.

$$
\begin{array}{lll}
R+\mathrm{O}_{2} & \rightarrow & \mathrm{CO}_{2}+\mathrm{H}_{2} \mathrm{O} \\
\mathrm{R}-\mathrm{S}+\mathrm{O}_{2} & \rightarrow & \mathrm{SO}_{2}+\mathrm{CO}_{2}+\mathrm{H}_{2} \mathrm{O}
\end{array}
$$

R carbonic substance

The resulting measuring gas is dried and the halide it contains removed. The $\mathrm{CO}_{2} / \mathrm{SO}_{2}$ content in the carrier gas is analyzed with the NDIR detectors which are selective for $\mathrm{CO}_{2}$ and $\mathrm{SO}_{2}$.

\subsection{TIC analysis}

During TIC analysis, the total inorganic carbon from carbonates and hydrogen carbonates in solid and powder samples is detected. Cyanides, cyanates, isocyanates and carbon particles are not detected. 
To determine the inorganic carbon (TIC), acid is added to an aliquot of the sample. This leads to the decomposition of the carbonates/hydrogen carbonates contained therein. The $\mathrm{CO}_{2}$ is purged and detected. No thermal oxidation takes place.

$3\left(\mathrm{CO}_{3}\right)^{2-}+2 \mathrm{H}_{3} \mathrm{PO}_{4} \rightarrow 3 \mathrm{H}_{2} \mathrm{O}+3 \mathrm{CO}_{2}+2\left(\mathrm{PO}_{4}\right)^{3-}$

The sample digestion takes place in a TIC solids module. The measuring gas is detected in the $\mathrm{C} / \mathrm{S}$ module.

\subsection{TOC analysis}

During the TOC analysis the total organic carbon content of a sample is detected. In the multi EA 4000 the TOC content can be determined in two ways:

- Differential method

- Direct method

The differential method should be used when the sample contains easily purgeable organic substances as benzene, cyclohexane, chloroform, etc. The differential method should not be used when the TIC content of the sample is significantly higher than the TOC content.

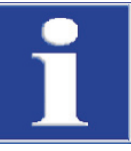

\section{NOTICE}

For the TOC analysis with the automatic TIC solids module the differential method is preferred. The combustion tube and detectors are not exposed to acid in this case.

\subsubsection{Differential method for the TOC analysis}

The differential method can take place using the automatic TIC solids module. The sample is weight in on two boats. Two consecutive measurements are used to determine TIC and TC. The calculated difference is given as TOC. The differential method detects volatile as well as non-volatile organic carbon compounds.

$T O C=T C-T I C$

$\begin{array}{ll}\text { TOC } & \text { total organic carbon } \\ \text { TC } & \text { total carbon } \\ \text { TIC } & \text { total inorganic carbon }\end{array}$




\subsubsection{Direct method for the TOC analysis}

With the automatic TIC solids module the TIC and TOC can also be determined directly. After purging the TIC in the reactor with hydrochloric acid and the determination of the TIC content the sample boat is transferred into the combustion tube. As with the TC/TS analysis, the sample is digested and oxidized in the oxygen flow at high temperature.

For the determination of the TOC with the automatic TIC solids module hydrochloric acid must be added to the sample. For the TOC analysis the differential method is therefore preferred.

For the determination of the TOC without using the automatic TIC solids module hydrochloric acid is added to the solids sample in the combustion boat to remove the inorganically bound carbon. The $\mathrm{CO}_{2}$ developing from the carbonates in the reaction evaporates. The wet sample with added acid is dried in the drying cabinet at $<40{ }^{\circ} \mathrm{C}$ for min. 3 hours where the excess hydrochloric acid evaporates. The sample prepared in this way can then be examined in the multi EA 4000 for organically bound carbon as for the TC/TS analysis.

Because the acid only releases $\mathrm{CO}_{2}$ from carbonates and hydrocarbonates, elementary carbon or the carbon from carbides, cyanides, isocyanates and thiocyanates is also detected as TOC.

\subsection{Determination of carbon after pyrolysis: TC-EC (optional)}

The determination of the carbon content of a sample takes four steps in the optional pyrolysis mode.

The original sample is weighed in in two boats- boat 1 and boat 2 .

1. The sample in boat 1 is first pyrolized in the argon flow. In the process the volatile parts of the carbon compounds contained escape at the selected temperature. Ideally and / or after appropriate pretreatment the elementary carbon (EC) remains on the boat.

2. The share of the remaining carbon (EC) in the already pyrolized sample is determined through combustion in the oxygen flow.

3. The sample in boat $\mathbf{2}$ is moved into the oxygen flow for the determination of the total carbon content (TC).

4. From the difference of the two measurements obtained (TC and EC) the volume of degradable or active carbon can be derived.

\subsection{Data analysis in the C/S mode}

\subsubsection{Calibration techniques}

Every parameter (procedure) of a method can be calibrated. The parameters of a method to be calibrated can be individually defined. Not all parameters need necessarily be calibrated. 
For every parameter up to three calibration functions can be stored in a method. The allocation is automatic.

The calibration function is calculated mass-related. Linear and quadratic calibration functions are calculated in accordance with the equations (5) and (6) through regression calculation.

$$
\begin{aligned}
& c=\left(k_{1} \times I_{\text {Netto }}+k_{0}\right) / m \\
& c=\left(k_{2} \times I_{\text {Netto }}^{2}+k_{1} \times I_{\text {Netto }}+k_{0}\right) / m \\
& \text { c target concentration of the standard } \\
& \text { m sample mass } \\
& I_{\text {net }} \text { net integer } \\
& \mathrm{k}_{0}, \mathrm{k}_{1}, \mathrm{k}_{2} \text { calibration coefficients }
\end{aligned}
$$

The regression type (linear or quadratic) can be defined by the user. It is possible to select individual measuring points or measured values for the calculation of the current calibration (manual outlier selection). Individual standards can, where required, also be redetected or additional measuring points added to the calibration.

The multiWin software offers the option to pursue different calibration strategies adapted to the analytical task dependent on the measuring range and sample matrix. With the multi EA 4000 multipoint calibrations are performed with variable sample volumes and constant concentrations.

\subsubsection{Daily factor}

Via the day factor it is possible to check and correct the calibration with a standard. All subsequent measurement results are multiplied by this factor. The day factor is calculated in accordance with the equation (7).

$F=\frac{C_{\text {soll }}}{C_{\text {ist }}}$

\subsubsection{Method characteristics}

Remaining standard deviation

Method standard deviation

Method variation coefficient
The remaining standard deviation (remaining variance) expresses the dispersion of the integers around the regression function (regression precision).

The standard deviation of the method describes in a unique and general way the quality of the calibration. For the unique evaluation of the quality the standard deviation of the method must be used.

The variation coefficient of the method (relative standard deviation of the method) should be used for the comparison of different calibrations with different calibration ranges. 
Correlation coefficient

Coefficient of

determination
The correlation coefficient compares the dispersion of the calibration measuring points of the regression function with the total dispersion of the calibration. If all calibration measuring points are on the calculated regression function, the correlation coefficient is +1 or -1 . With a positive correlation coefficient the regression function is increasing, with a negative coefficient it is decreasing.

The square of the correlation coefficient is called the coefficient of determination.

\subsubsection{Other calculations}

Average value

Boat blank
For all measurements where multiple determinations are carried out the average value (AV), standard deviation (SD) and variation coefficient (VC) are calculated and displayed. For each sample a triple determination can be carried out as a maximum.

For measurements of TOC with the automatic TIC solids module in the differential method or determination of carbon after pyrolysis (TC-EC) only a single determination takes place.

The average value of the final result is calculated from the concentrations determined for the individual detections.

The boat blank is determined by introducing an empty boat or a boat with additives for the sample into the combustion furnace and analyzing it.

The boat blank value can be determined separately and entered in the control and analysis software multiWin. This value can change over time and must be redetermined before the start of each measuring series. Otherwise the value last entered will be used.

\subsection{Cl determination}

The samples to be examined are fed to the combustion chamber in a quartz glass boat via an open gas sluice. The sample is first pyrolized in the inert gas flow (argon). The resulting pyrolysis products are completely incinerated in the oxygen flow with some delay.

The reaction is based on the following equation:

$\mathrm{R}-\mathrm{Cl} \quad \rightarrow \quad \mathrm{HCl}+\mathrm{CO}_{2}+\mathrm{H}_{2} \mathrm{O}+$ Oxide

The $\mathrm{HCl}$ share is determined by way of coulometry after measuring gas drying. In this the chloride ions react fully with electrolytically generated silver ions to form silver chloride.

$$
\begin{aligned}
& \mathrm{Ag} \quad \rightarrow \quad \mathrm{Ag}^{+}+\mathrm{e}^{-} \\
& \mathrm{Ag}^{+}+\mathrm{Cl}^{-} \quad \rightarrow \quad \mathrm{AgCl}
\end{aligned}
$$

From the charge used up to generate the silver ions it is possible to calculate the chloride volume based on Faraday's law. 


\subsection{Data analysis in the $\mathrm{Cl}$ mode}

\subsubsection{End point routine}

After filling the measuring cell or after each change of the electrolyte solution an end point routine must be performed to define the operating point of the system. The indication value determined represents both the starting point and the end point of titration. The end point routine is started via the multiWin software.

\subsubsection{Measurement with split / split factor}

In the operating mode with split the measuring gas from the combustion chamber is divided into a defined ratio. Only some of the reaction gas reaches the measuring cell for analysis, allowing also for high concentrations to be determined. For $\mathrm{Cl}$ content in the lower concentration range no gas splitting is used. All of the measuring gas passes the drying unit and the measuring cell.

For working with gas splitting shares of $10 \%$ and $20 \%$ of the measuring gas can be selected. The current split factor of a method can be entered/viewed in the method window on the tab CALIBRATION as DAILY FACTOR (menu item METHOD METHOD - EDIT).

When creating a new split method the split factor must first be transferred by manual input from an existing method with the same split ratio.

The current split factor is checked and, where necessary, corrected using standards.

\subsubsection{Analysis}

The coulometric $\mathrm{Cl}$ determination is an absolute analysis method. Bi calibration takes place. The result is stated in the analysis report in the absolute mass [ $\mu \mathrm{g}]$ and as concentration $[\mu \mathrm{g} / \mathrm{g}]$ or $[\mathrm{mg} / \mathrm{g}]$. 


\section{$5 \quad$ Commissioning}

\subsection{Site requirements}

\subsubsection{Installation conditions}

The following requirements are placed on the climatic conditions in the operating room of the analyzer:

- Temperature range: $+10^{\circ} \mathrm{C}$ to $+35^{\circ} \mathrm{C}$

- Max. humidity: $90 \%$ at $30^{\circ} \mathrm{C}$

- Air pressure: $70 \mathrm{kPa}$ to $106 \mathrm{kPa}$

As far as possible, the atmosphere in the laboratory should be free of TOC and dust and free from draft, corrosive and organic vapors and vibration. Smoking is prohibited in the operating room of the analyzer!

The following requirements are placed on the location of the analyzer:

- Do not locate the analyzer directly near a door or window.

- Place the analyzer on a heat-resistant and acid-resistant surface.

- Do not locate the analyzer near sources of electromagnetic interference.

- Avoid direct sunlight and radiation from heaters onto the analyzer. If necessary provide air conditioning.

- Never obstruct the front doors, the side panels and the ventilation slots of the analyzer with other equipment or furnishings!

- Keep a safety distance of at least $5 \mathrm{~cm}$ from the back and the right side of the equipment to other equipment or walls!

\subsubsection{Space requirement}

The required space depends on the number of components needed for measurement. Leave adequate space for the $\mathrm{PC}$, monitor, printer and any add-on equipment.

\subsubsection{Energy supply}

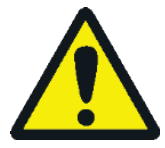

\section{WARNING}

The analyzer multi EA 4000 must only be connected to a properly grounded mains outlet in accordance with the voltage specifications on the type plate!

The multi EA 4000 is operated from the single phase alternating current mains. 
For the use of the basic device with the furnace module (HTS1500) in areas with mains voltages of $100 \mathrm{~V} / 115 \mathrm{~V} / 120 \mathrm{~V} / 127 \mathrm{~V}$ a 2 phase connection is possible using optional accessories. Contact Analytik Jena AG if required. This installation may only be performed by the customer service department of Analytik Jena AG or by specialist personnel authorized and trained by Analytik Jena AG!

The installation of the electrical equipment of the laboratory must comply with the standard DIN VDE 0100. After the connection point an electrical current in accordance with the standard IEC 38 must be available.

\subsubsection{Gas supply}

The operator is responsible for the gas supply and the corresponding connections and pressure reducers.

Connection hoses with outer diameter $6 \mathrm{~mm}$ and inner diameter $4 \mathrm{~mm}$ are included with the delivery.

Before initial operation, close the flow regulators for argon/oxygen $\left(\mathrm{Ar} / \mathrm{O}_{2}\right)$ and oxygen $\left(\mathrm{O}_{2}\right)$ by turning them clockwise $(1,2$ in Figure 2 p. 19). Adjust the gas flows later according to the method used.

\subsection{Unpacking and placing the analyzer}

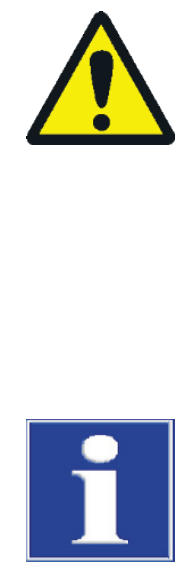

\section{WARNING}

The analyzer multi EA 4000 must only be set up, assembled and installed by the customer service department of Analytik Jena AG or trained specialist personnel authorized by Analytik Jena AG!

Any unauthorized intervention in the analyzer can endanger the user and the operational safety of the equipment and limits or completely invalidates any warranty claims.

\section{NOTICE}

Retain the transport packaging! Return transport for service must be in the original packaging. This alone prevents transport damage.

The analyzer multi EA 4000 is unpacked and assembled by the customer service department of Analytik or authorized and trained specialist personnel.

Please check when unpacking the device for completeness and soundness of the delivery in accordance with the packing list included.

After assembly the customer service tests the analyzer and documents the test. 


\subsection{Positioning the analyzer with various detector modules}

\section{NOTICE}

Always switch off the multi EA 4000 before positioning!

Connecting or disconnecting electrical contacts may damage the sensitive electronic components of the multi EA 4000 and detector modules.

\subsubsection{Positioning the multi EA $4000 \mathrm{C} / \mathrm{S}$}

Connections

For the combination multi EA 4000 - C/S module the following connections must be in place:

\begin{tabular}{lll}
\hline multi EA 4000 connections & $\Rightarrow$ & Target \\
\hline "analyte out" & $\Rightarrow$ & C/S module "analyte" \\
\hline "O ${ }_{2}$ Oxygen gas connection \\
\hline Mains cable & $\Rightarrow$ & Mains connection \\
\hline "com1" & $\Rightarrow$ & C/S module "COM" \\
\hline "pump in" & $\Rightarrow$ & C/S module "pump" \\
\hline "Ar" & $\Rightarrow$ & $\begin{array}{l}\text { Gas connection for argon (only required for } \mathrm{Cl} \\
\text { measurement and determination of carbon after } \\
\text { pyrolysis) }\end{array}$ \\
\hline "waste out" & & Open outlet for the exhaust air of the analyzer \\
\hline Additional C/S module con- & $\Rightarrow$ & Target \\
nections & $\Rightarrow$ & USB port for connection to the computer \\
\hline "PC" & $\Rightarrow$ & External scales (optional) \\
\hline "scale" & $\Rightarrow$ & Connection of the autosampler FPG 48 \\
\hline "sampler" & $\Rightarrow$ & Mains connection \\
\hline Socket for mains plug & &
\end{tabular}

The following hose diagram (Figure 32) also applies for the optional determination of carbon after pyrolysis. For the pyrolysis measurement attach an additional extraction pipe close to the furnace inlet. 
Hose diagram

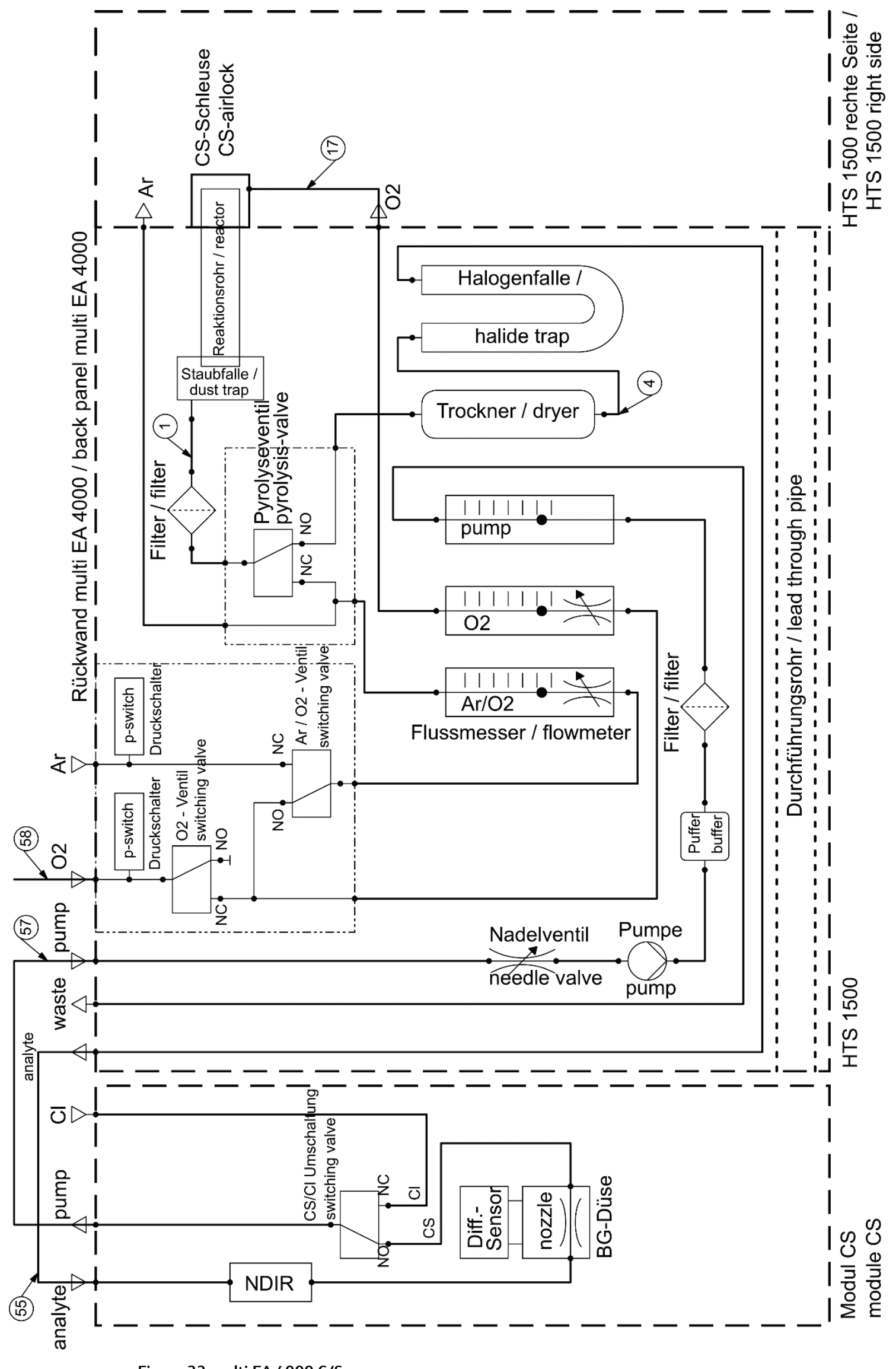

Figure 32 multi EA 4000 C/S 


\subsubsection{Positioning the multi EA $4000 \mathrm{Cl}$}

Connections

\begin{tabular}{lll}
\hline multi EA 4000 connections & & Target \\
\hline "analyte out" & $\Rightarrow$ & Open outlet \\
\hline "O " & $\Rightarrow$ & Oxygen gas connection \\
\hline "Ar" & $\Rightarrow$ & Argon gas connection \\
\hline Mains cable & $\Rightarrow$ & Mains connection \\
\hline "com1" & $\Rightarrow$ & Cl module "COM" \\
\hline "pump in" & $\Rightarrow$ & Cl module "pump" \\
\hline "waste out" & $\Rightarrow$ & Open outlet for the exhaust air of the analyzer \\
\hline Additional Cl module connec- & & Target \\
tions & & \\
\hline Socket for mains plug & $\Rightarrow$ & Mains connection \\
\hline "sampler" & $\Rightarrow$ & Connection of the autosampler FPG 48 \\
\hline "PC" & $\Rightarrow$ & USB port for connection to the computer \\
\hline "scale" & $\Rightarrow$ & External scales (optional) \\
\hline
\end{tabular}


Hose diagram

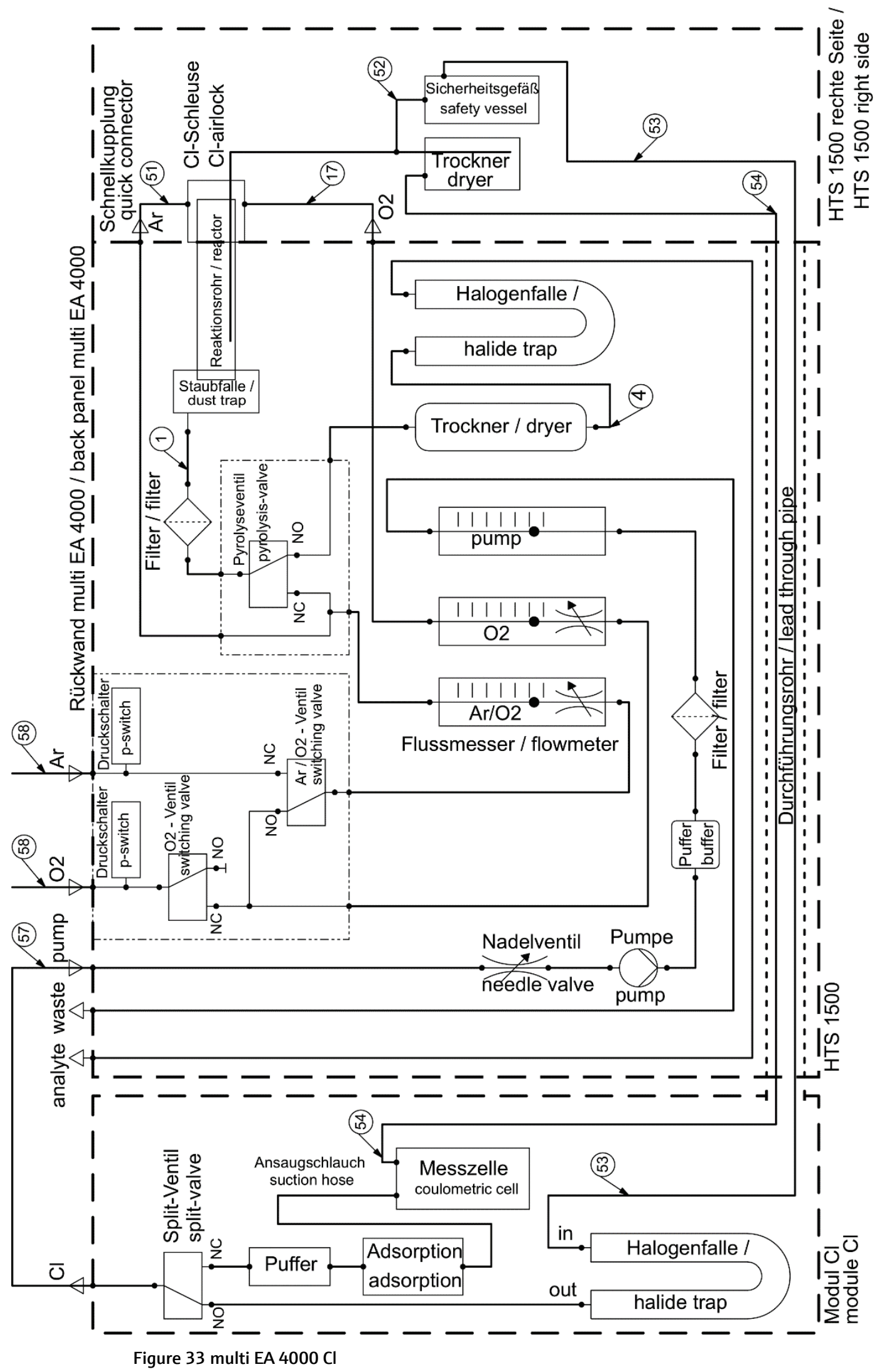




\subsubsection{Positioning the multi EA $4000 \mathrm{C} / \mathrm{S} \mathrm{Cl}$}

Connections

For the combination multi EA 4000 - C/S module - Cl module, the following connections must be in place:

\begin{tabular}{|c|c|c|}
\hline multi EA 4000 connections & & Target \\
\hline "analyte out" & $\Rightarrow$ & C/S module "analyte" \\
\hline "O $\mathrm{O}_{2}$ & $\Rightarrow$ & Oxygen gas connection \\
\hline Mains cable & $\Rightarrow$ & Mains connection \\
\hline "com1" & $\Rightarrow$ & C/S module "COM" \\
\hline "pump in" & $\Rightarrow$ & C/S module "pump" \\
\hline "Ar" & $\Rightarrow$ & $\begin{array}{l}\text { Gas connection for argon (only required for } \mathrm{Cl} \\
\text { measurement and pyrolysis) }\end{array}$ \\
\hline "waste out" & $\Rightarrow$ & Open outlet for the exhaust air of the analyzer \\
\hline $\begin{array}{l}\text { Additional C/S module con- } \\
\text { nections }\end{array}$ & & Target \\
\hline "PC" & $\Rightarrow$ & USB port for connection to the computer \\
\hline "Cl-Coul" & $\Rightarrow$ & $\mathrm{Cl}$ module "Cl-Coul" \\
\hline "scale" & $\Rightarrow$ & External scales (optional) \\
\hline "sampler" & $\Rightarrow$ & Connection of the autosampler FPG 48 \\
\hline Socket for mains plug & $\Rightarrow$ & Mains connection \\
\hline $\begin{array}{l}\text { Additional Cl module connec- } \\
\text { tions }\end{array}$ & & Target \\
\hline "Cl" & $\Rightarrow$ & $\mathrm{C} / \mathrm{S}$ module "Cl" \\
\hline Socket for mains plug & $\Rightarrow$ & Mains connection \\
\hline
\end{tabular}

The following hose diagram (Figure 34) also applies for the optional determination of carbon after pyrolysis. For the pyrolysis measurement, attach an additional extraction pipe close to the furnace inlet. 
Hose diagrams

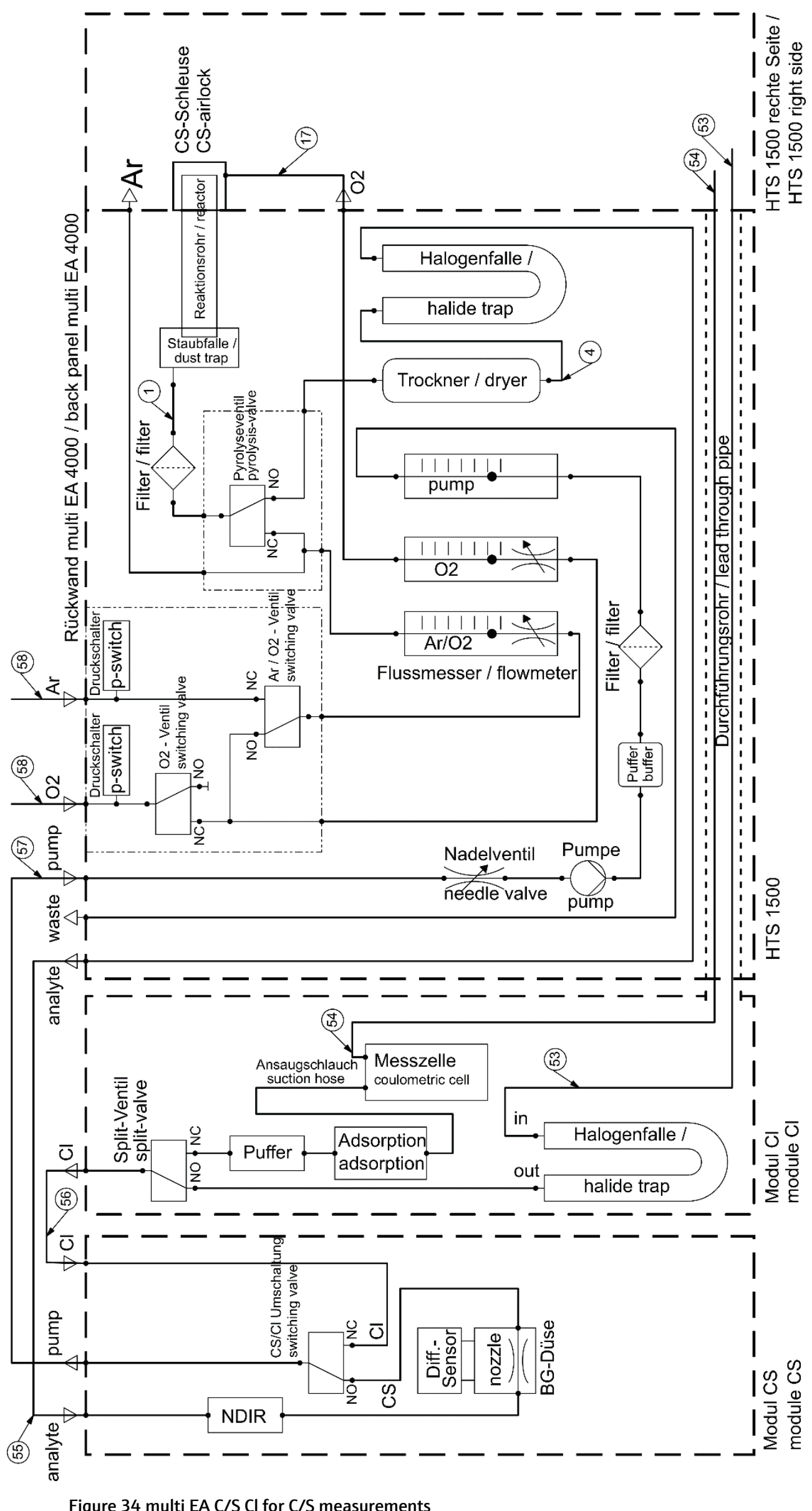

Figure 34 multi EA C/S Cl for C/S measurements 


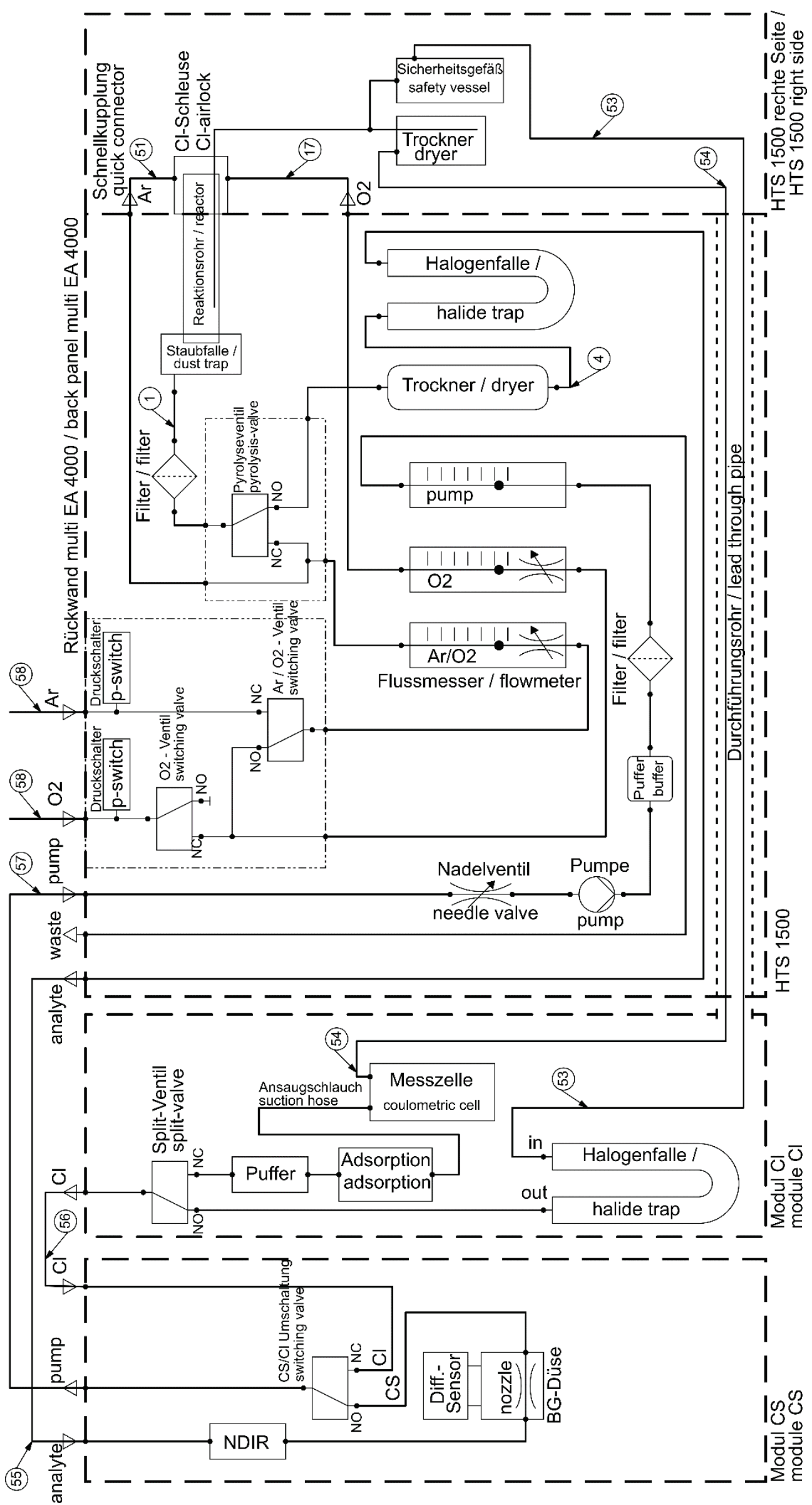

Figure 35 multi EA $4000 \mathrm{C} / \mathrm{S} \mathrm{Cl}$ for $\mathrm{Cl}$ measurements 


\subsubsection{Positioning the automatic TIC solids module}

Connections

For the combination multi EA 4000 - C/S module - Cl module, the following connections must be in place:

\begin{tabular}{|c|c|c|}
\hline multi EA 4000 connections & & Target \\
\hline "analyte out" & $\Rightarrow$ & TIC module "analyte (HT)" \\
\hline "O & $\Rightarrow$ & Oxygen gas connection \\
\hline Mains cable & $\Rightarrow$ & Mains connection \\
\hline "com1" & $\Rightarrow$ & TIC module "COM (HT)" \\
\hline "pump in" & $\Rightarrow$ & C/S module "pump" \\
\hline "Ar" & $\Rightarrow$ & $\begin{array}{l}\text { Gas connection for argon (only required for } \mathrm{Cl} \\
\text { measurement and pyrolysis) }\end{array}$ \\
\hline "waste out" & $\Rightarrow$ & Open outlet for the exhaust air of the analyzer \\
\hline $\begin{array}{l}\text { Additional C/S module con- } \\
\text { nections }\end{array}$ & & Target \\
\hline "PC" & $\Rightarrow$ & USB port for connection to the computer \\
\hline "valve" & $\Rightarrow$ & TIC module "valve (module)" \\
\hline "scale" & $\Rightarrow$ & External scales (optional) \\
\hline "COM" & $\Rightarrow$ & TIC module "COM (module)" \\
\hline "sampler" & $\Rightarrow$ & Connection of the autosampler FPG 48 \\
\hline "analyte" & $\Rightarrow$ & TIC module "analyte (module)" \\
\hline Socket for mains plug & $\Rightarrow$ & Mains connection \\
\hline $\begin{array}{l}\text { Additional TIC module con- } \\
\text { nections }\end{array}$ & & Target \\
\hline "waste" & $\Rightarrow$ & $\begin{array}{l}\text { Connection for the waste hose to drain the conden- } \\
\text { sate }\end{array}$ \\
\hline Socket for mains plug & $\Rightarrow$ & Mains connection \\
\hline
\end{tabular}


Hose diagrams

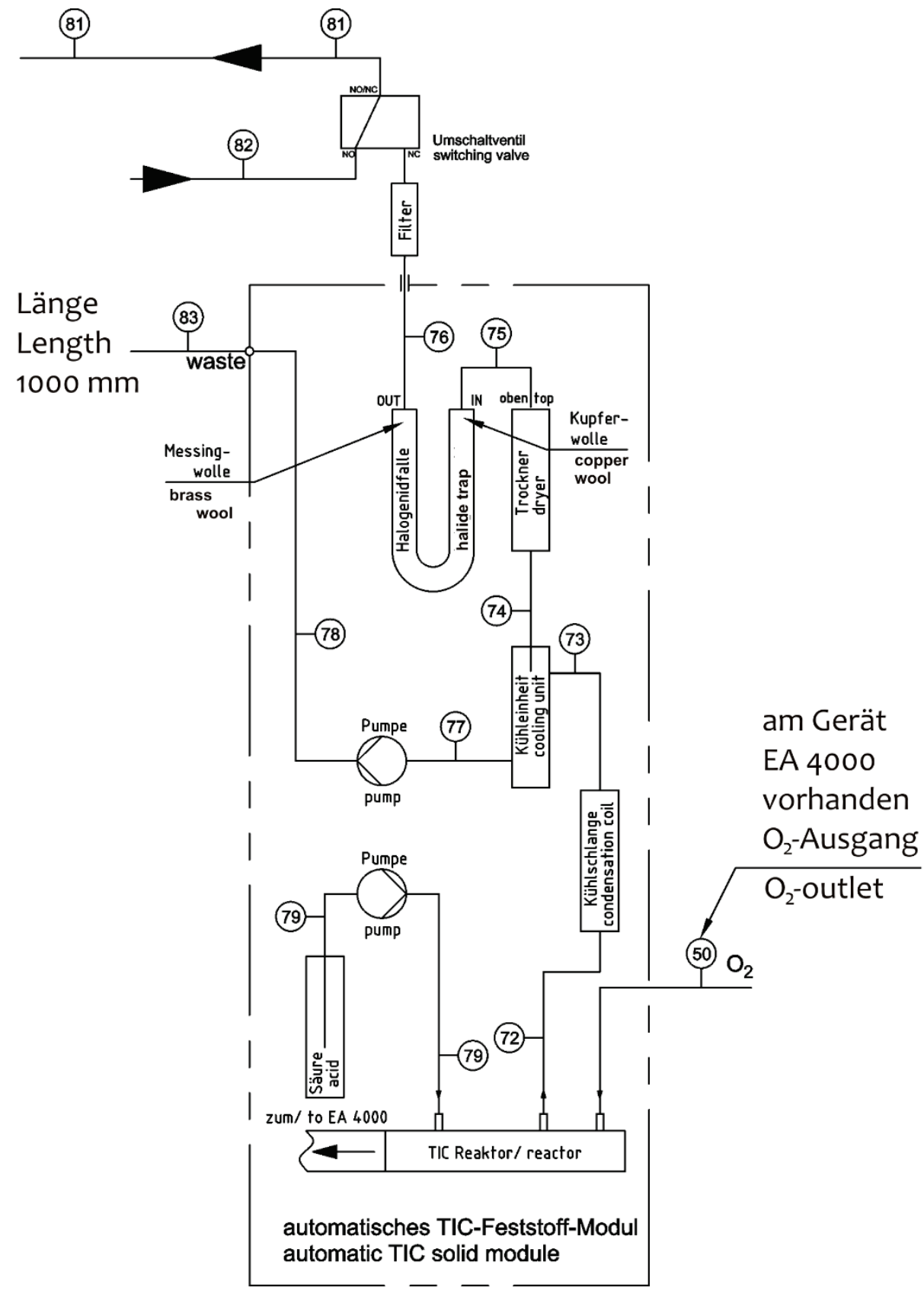

Figure 36 Automatic TIC solids module 


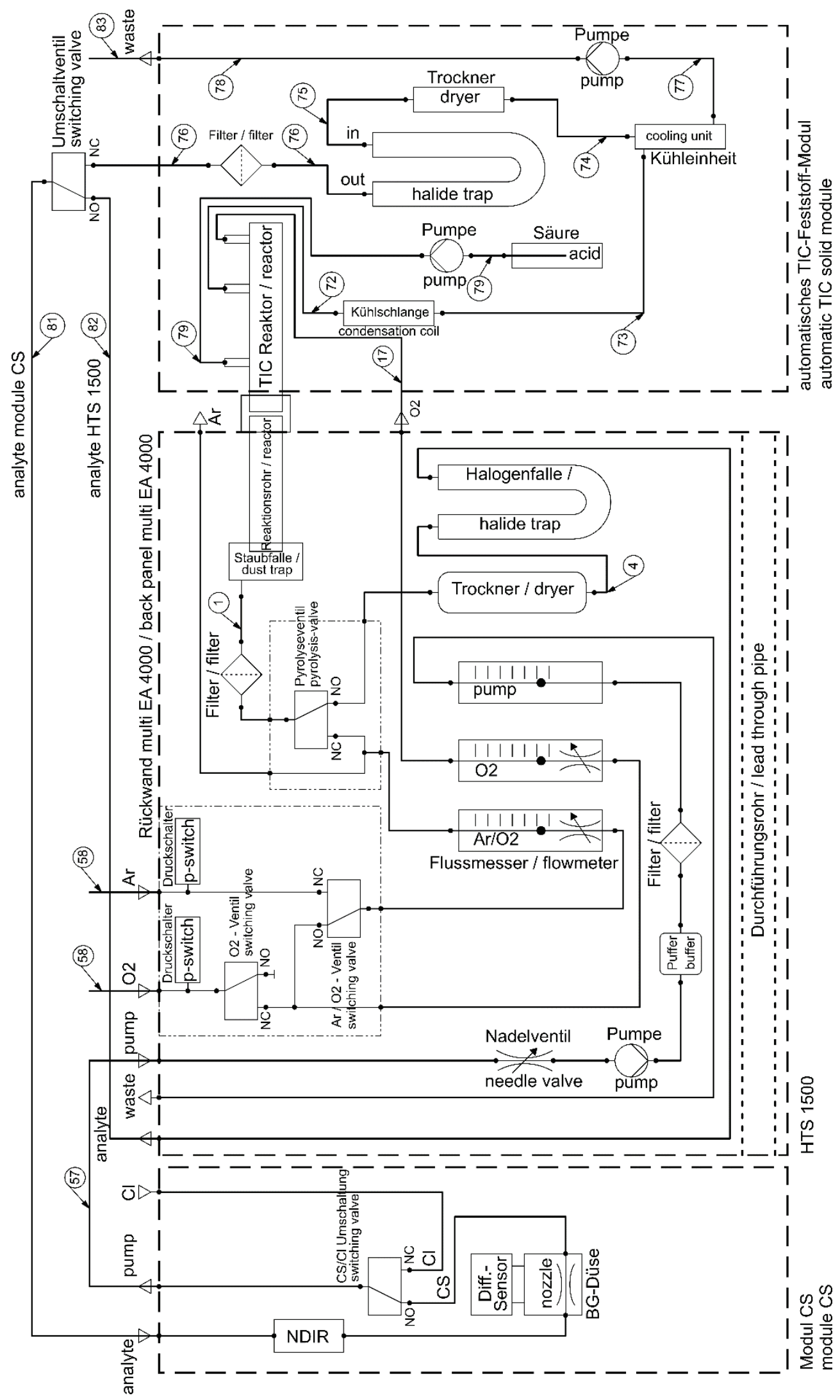

Figure 37 multi EA 4000 C/S with automatic TIC solids module 


\subsubsection{Positioning the manual TIC solids module}

Connections

For the combination multi EA 4000 - C/S module - TIC solids module, the following connections must be in place:

\begin{tabular}{lll}
\hline multi EA 4000 connections & & Target \\
\hline "analyte out" & $\Rightarrow$ & Open \\
\hline "O2" & $\Rightarrow$ & Oxygen gas connection \\
\hline Mains cable & $\Rightarrow$ & Mains connection \\
\hline "com1" & $\Rightarrow$ & C/S module "COM" \\
\hline "pump in" & $\Rightarrow$ & Open \\
\hline "Ar" & $\Rightarrow$ & Argon gas connection \\
\hline "waste out" & $\Rightarrow$ & Open outlet for the exhaust air of the analyzer \\
\hline C/S module connections & & Target \\
\hline "PC" & $\Rightarrow$ & USB port for connection to the computer \\
\hline "scale" & $\Rightarrow$ & External scales (optional) \\
\hline "pump" & $\Rightarrow$ & Open \\
\hline Socket for mains plug & $\Rightarrow$ & Mains connection \\
\hline "analyte" connection & $\Rightarrow$ & TIC module "analyte" \\
\hline $\begin{array}{l}\text { Additional TIC module con- } \\
\text { nections }\end{array}$ & $\Rightarrow$ & Mains connection \\
\hline "O2" & $\Rightarrow$ & Oxygen gas connection with quick-release coupling \\
\hline Socket for mains plug & & Set oxygen inlet pressure to 200 to $400 \mathrm{kPa}$ \\
\hline & & (29 - 58 psi) \\
\hline
\end{tabular}


Hose diagrams

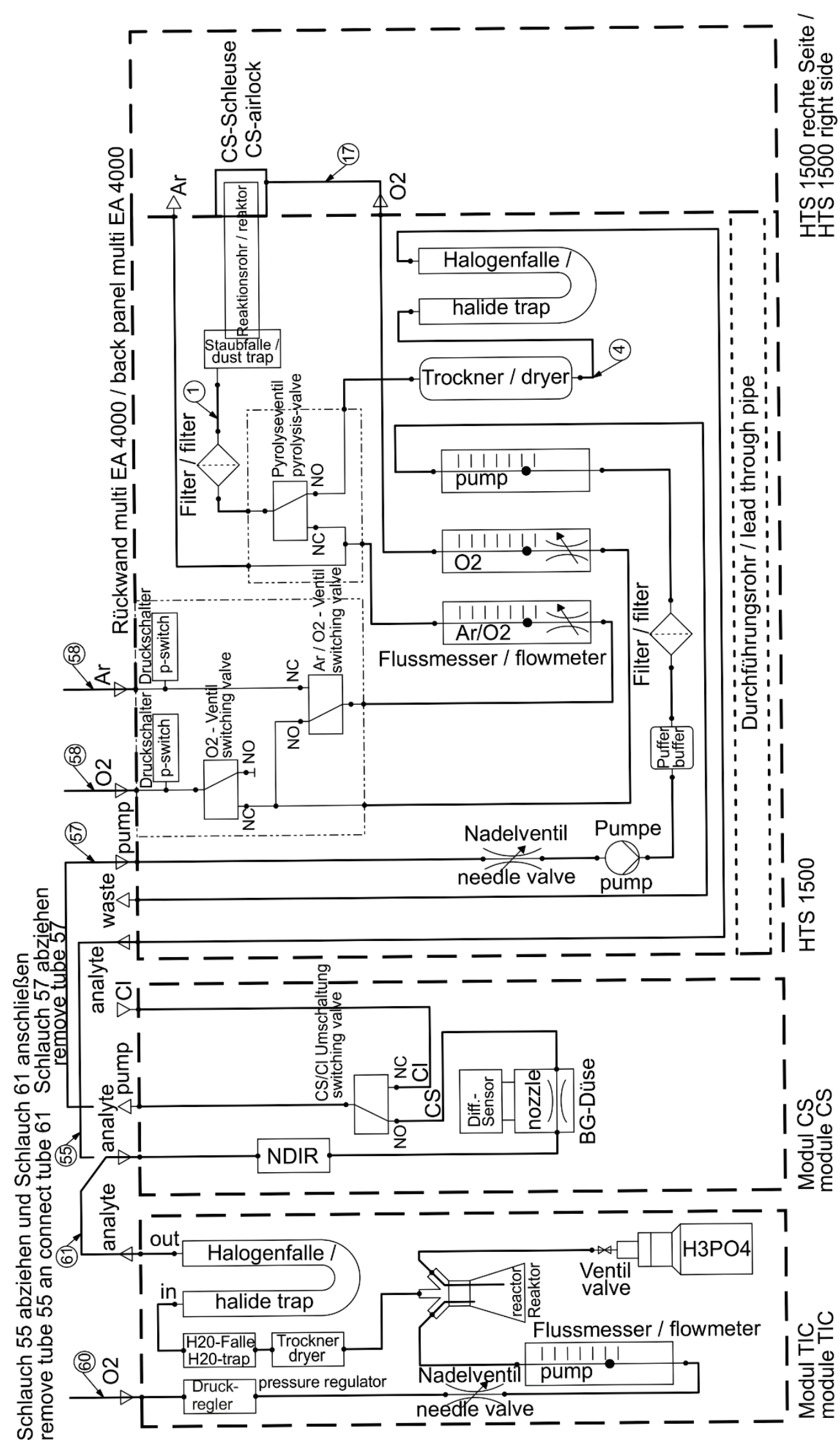

Figure 38 multi EA 4000 with man. TIC solids module 


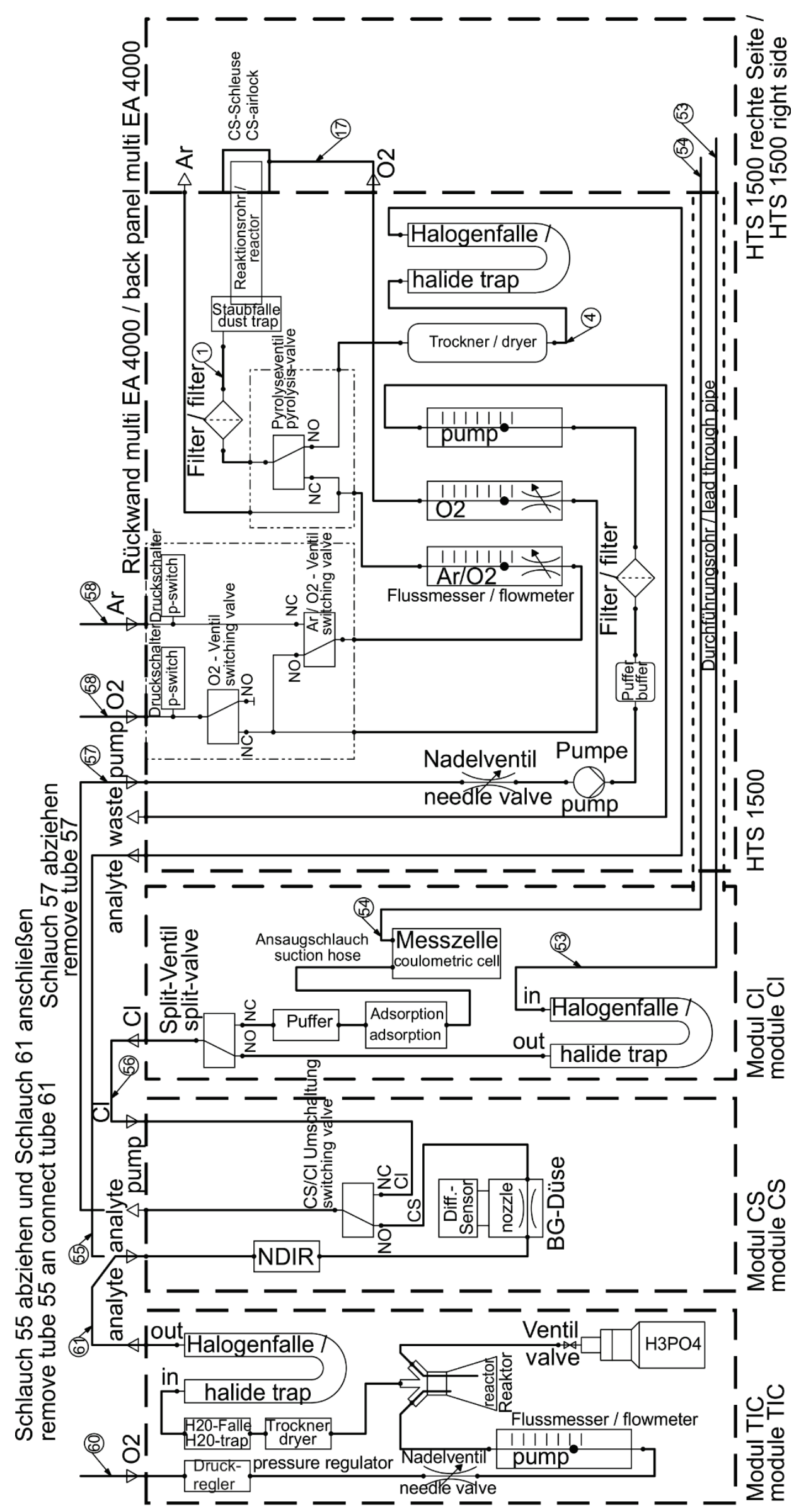

Figure 39 multi EA $4000 \mathrm{C} / \mathrm{S} \mathrm{Cl}$ with man. TIC solids module 


\subsection{Connecting and using the autosampler}
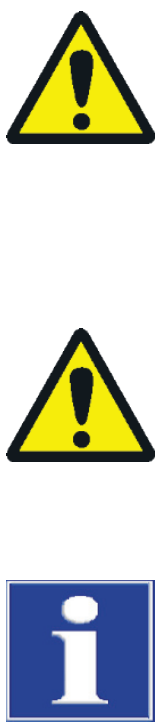

\section{CAUTION}

There is a risk of burns at the hot the combustion furnace! Allow the basic device to cool down sufficiently before positioning and aligning the autosampler!

During autosampler operation, there is a risk of burns at the hot boat and ceramic hook! After pulling out of the furnace, the boat and hook remain hot for a long time.

\section{CAUTION}

Risk of crushing! The autosampler arm, the gripper and the boat carousel move during activation, initialization, adjustment and measurement operation. Keep an adequate distance to avoid having your hands crushed.

\section{NOTICE}

Only adjust the device in the switched-off state. Otherwise, the sensitive electronics may be damaged.

Make sure that the autosampler is parallel to the basic device and level with the working tube! If the sample boat is inserted into the furnace at an angle or not at the right height relative to the working tube, the ceramic hook might break or the work tube be damaged.

\subsubsection{Installing and adjusting the autosampler FPG 48}

Connect the sampler to the analyzer as follows:

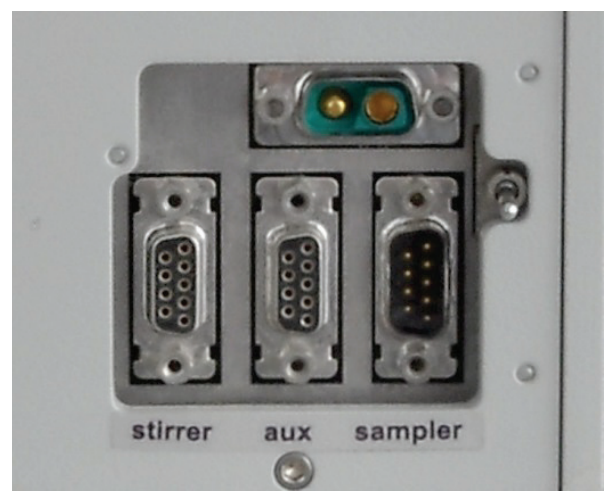

1. Place the autosampler to the right of the analyzer.

2. Plug the cable on the low voltage side of the table power supply into the connection at the rear of the autosampler. Connect the power supply to the mains.

3. Connect the data cable supplied to the "sampler" interface at the rear of the sampler. Connect the other end of the cable to the "sampler" interface at the rear of the module with the control unit ( $\mathrm{C} / \mathrm{S}$ module or $\mathrm{Cl}$ module).

4. Connect the boat sensor to the "aux" connection at the rear of the sampler.

5. Plug the grounding conductor into the connection at the rear of the basic device. 

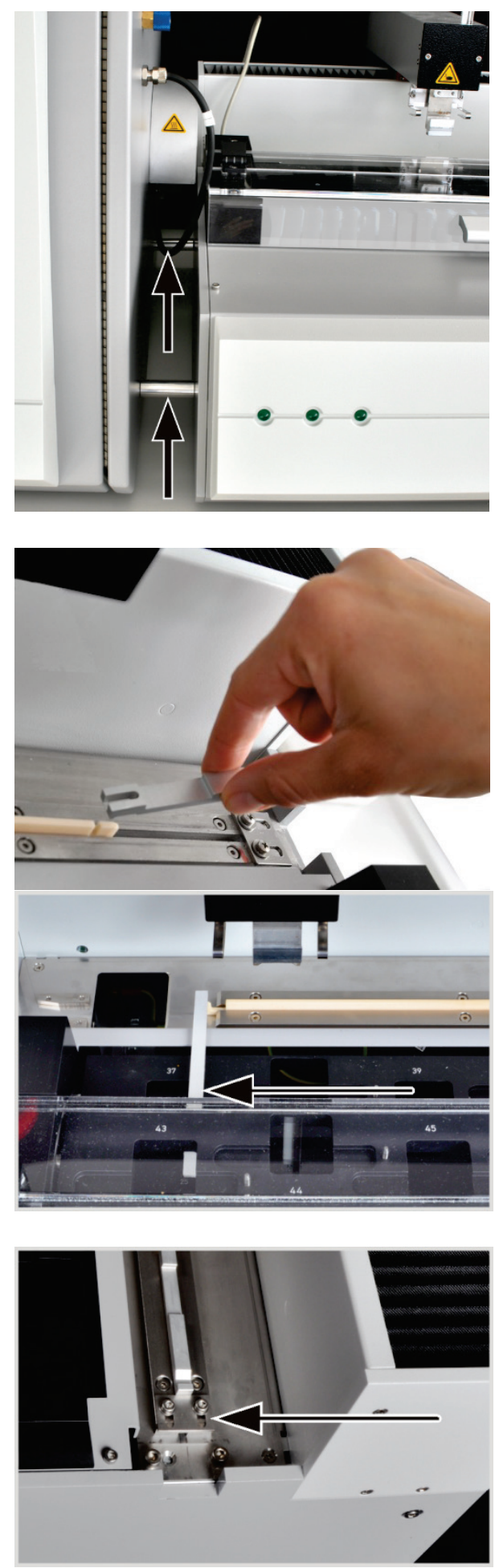

6. Position the autosampler parallel to the basic device. The hook extension must be centered with the gas sluice.

Move the autosampler to the basic device until the FPG 48 touches the spacers at the basic device. A gap of $2 \mathrm{~mm}$ then remains between the FPG 48 and the gas sluice to allow for the compensation of thermal expansion of the combustion tube.

7. Using the adjustable feet correct the height of the autosampler, if necessary. The bottom edge of the opening of the gas sluice must be level with the upper edge of the storage surface of the autosampler.

8. Place the ceramic hook into the guide rail of the autosampler.

9. Place the sliding rod onto the hook until the pin engages in the slot.

10. Place a boat into the feeder (hook the eye of the boat into the hook) and carefully move the boat manually into the furnace. Make sure that the hook is not wedged or angled. If not, change the position of the autosampler.

11. Check the start position of the ceramic hook. The hook must be flush with the right-hand edge of the left-hand boat position (here position 37).

To do so, place a straight paper or plastic strip (e.g. a ruler) against the edge and align the tip of the ceramic hook with it.

12. If the factory setting is not correct, loosen the screws at the stop plate of the guide rail. Move the plate until it touches the end of the sliding rod. Secure the stop plate with the screws.

NOTICE! Do not move the sampler arm manually if the sampler is switched on. The drives of the FPG 48 could be damaged.

Align the gripper using the multiWin software for the following positions:

- Position 1

- Sliding position

- Ejection rail (e.g. after installation of the automatic TIC solids module) 


\section{Position 1}

1. Switch on the basic device, the detector with control unit, the automatic TIC solids module, where applicable, and the FPG 48. Start the multiWin software and initialize the analyzer.

2. Select the menu command SYSTEM $\downarrow$ SAMPLER AlignMENT. A window with the same name opens.
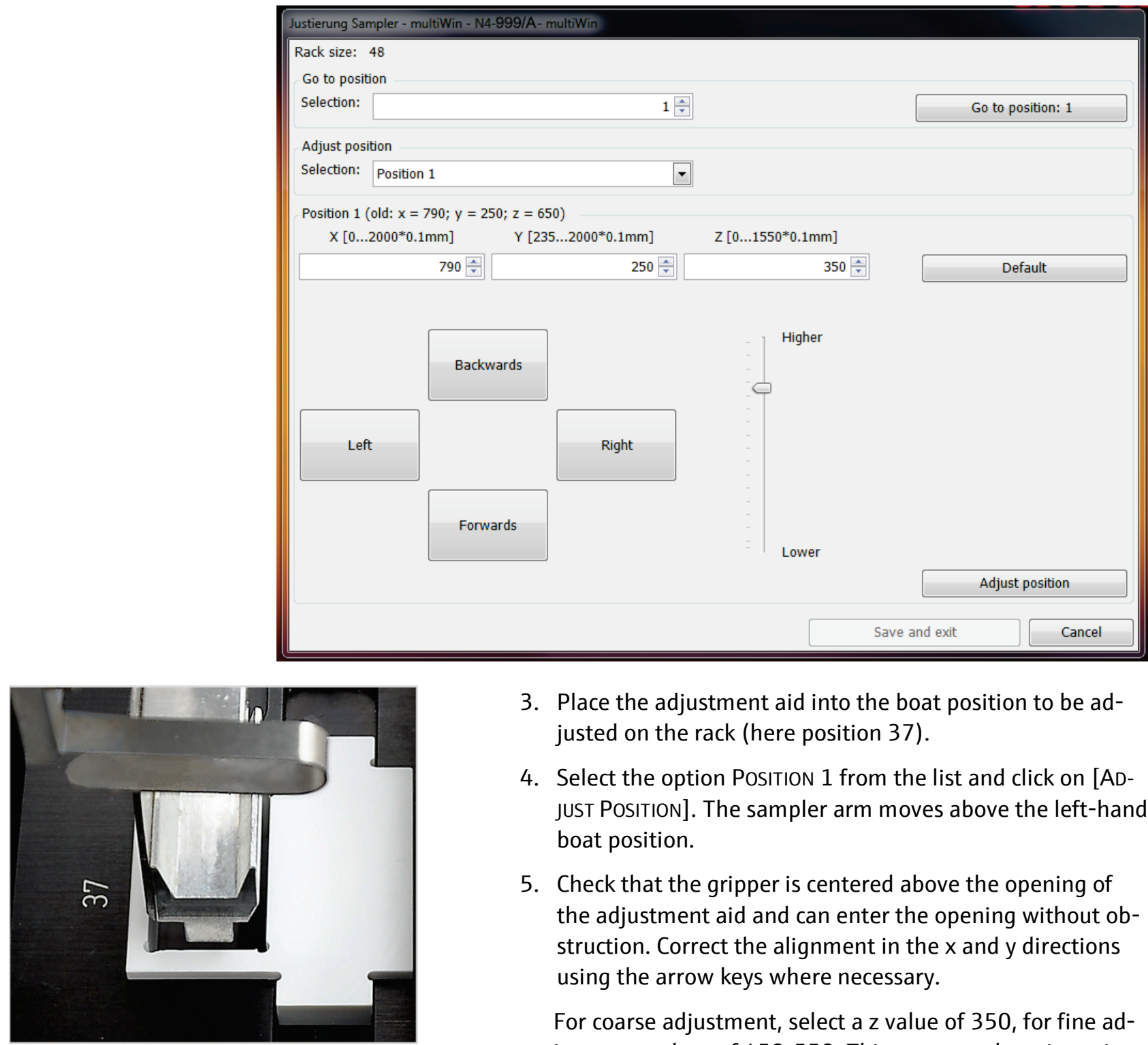

3. Place the adjustment aid into the boat position to be adjusted on the rack (here position 37).

4. Select the option Position 1 from the list and click on $[A D-$ JUST POSITION]. The sampler arm moves above the left-hand boat position.

5. Check that the gripper is centered above the opening of the adjustment aid and can enter the opening without obstruction. Correct the alignment in the $\mathrm{x}$ and $\mathrm{y}$ directions using the arrow keys where necessary.

For coarse adjustment, select a $z$ value of 350, for fine adjustment values of 450-550. This prevents the gripper impacting hard with the autosampler. Check the changes by clicking on [ADJUST POSITION].

6. Adjust the lowering depth of the gripper.

Click again on [ADJUST POSITION]. Remove the adjustment aid when the autosampler returns to its start position.

7. Using the slider HIGHER / LOWER adjust the lowering depth of the gripper and set the new position by clicking on [ADJUST POSITION]. 

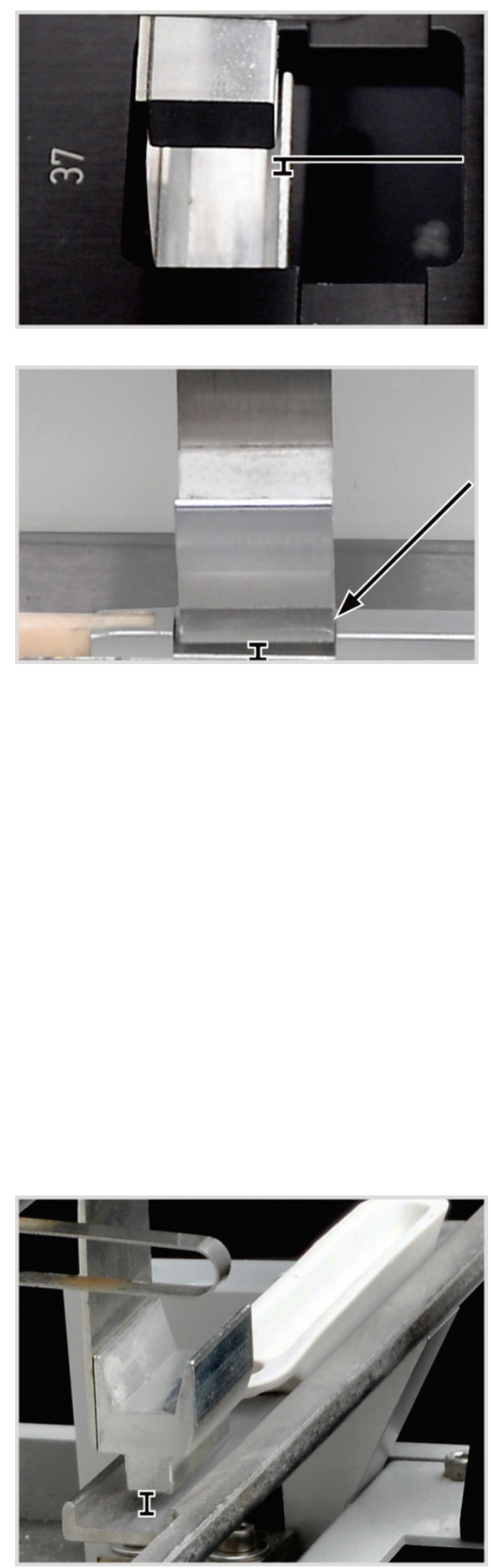

8. Repeat the process until the gripper is positioned just a few millimeters below the boat storage. This prevents the boat from moving when picked up by the gripper.

9. Click on [SAVE AND EXIT].

\section{Sliding position}

The sliding position is the cut-out in the sliding rod of the ceramic hook. The sampler arm enters this cut-out and moves the hook into the furnace.

1. Place the ceramic hook and sliding rod against the stop plate of the FPG 48.

2. In the window SAMPLER ALIGNMENT select SLIDING POSITION from the list and click on [ADJUST POSITION].

The sampler arm moves above the sliding position.

3. Using the slider HIGHER / LOWER adjust the lowering depth of the gripper. Using the buttons [LEFT]/[RIGHT] and [FORWARDS]/[BACKWARDS] adjust the position in the cut-out.

The gripper must be adjusted flush right and centered in the cut-out. The gripper must hover approx. $1 \mathrm{~mm}$ above the cut-out. The sampler arm must not exert any pressure on the sliding rod.

4. Set the new position by clicking on [ADJUST POSITION].

5. Repeat the process until the adjustment is correct. Finally click on [SAVE AND EXIT].

\section{Ejection rail}

Only if the boat storage is fitted (e.g. when using the automatic TIC solids module)

1. In the window SAMPLER Alignment select EJECTION RAIL from the list and click on [ADJUST POSITION].

2. Using the slider HIGHER / LOWER adjust the lowering depth of the gripper.

The gripper must hover approx. $1 \mathrm{~mm}$ above the rail and must not rest on it.

3. Place a boat next to the gripper and check that the boat cannot slide under the gripper.

4. Set the new position by clicking on [AdJUST POSITION].

5. Once the position has been adjusted click on [SAVE AND EXIT]. 


\subsubsection{Installing the boat sensor}

The boat sensor monitors the boat transfer from the sampler FPG 48 to the furnace. It detects the following fault conditions:

- Ceramic boat broken

- No ceramic boat on the hook

If one of the fault conditions occurs, the measurement is canceled immediately. An error message is issued in the multiWin software.

If the boat sensor is not already installed on the autosampler, you can mount it on the autosampler as follows:

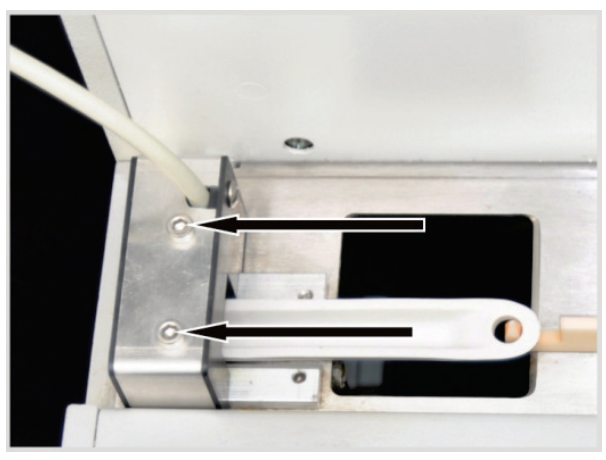

1. Slide the boat sensor from the left onto the short guide rail of the FPG 48.

2. Using the two hexagon socket screws tighten the boat sensor.

3. Connect the boat sensor to the "aux" connection at the rear of the FPG 48.

To resume a measurement after cancellation:

1. Acknowledge the error message in the software.

2. If necessary, remove the broken parts of the boat from the furnace and the hook.

3. Slide the ceramic hook manually to the stop plate.

4. Reinitialize the device.

\subsubsection{Retrofitting the sampler FPG 48 with a boat storage}

For measurements using the automatic TIC solids module the sampler must be converted. The following components must be retrofitted:

- Boat storage (block with ejection rail for used boats)

- Ceramic hook with long sliding rod

- Cover for ceramic hook and sliding rod

With the boat storage, the sampler can discard used boats wetted with acid in a waste container. The use of the boat storage is recommended to prevent unnecessary damage to the boat carousel from acid splashes when returning used boats.

The long sliding rod for the ceramic hook is required to allow the boats to be moved across the TIC reactor to the furnace of the basic device during TOC determination. The cover protrudes beyond the sampler on the right-hand side. It prevents the sliding rod or the ceramic hook from being damaged during the return.

The three components can also be ordered separately. 


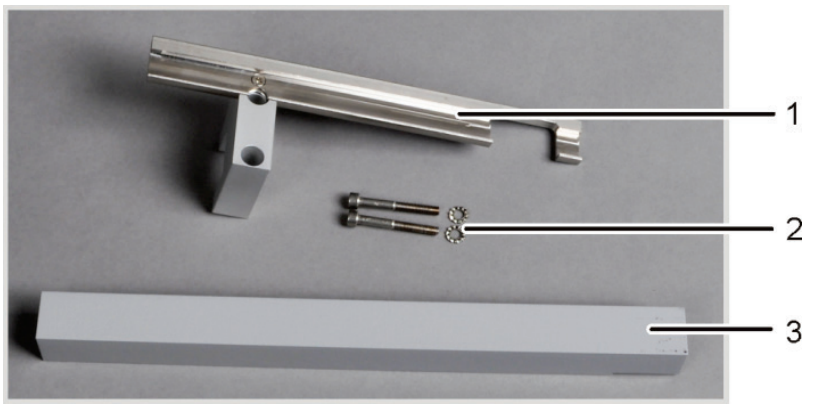

1 Boat storage

2 Hexagon socket screws with washers

3 Cover for sliding rod

Figure 40 Retrofit kit for FPG 48 to use the boat storage
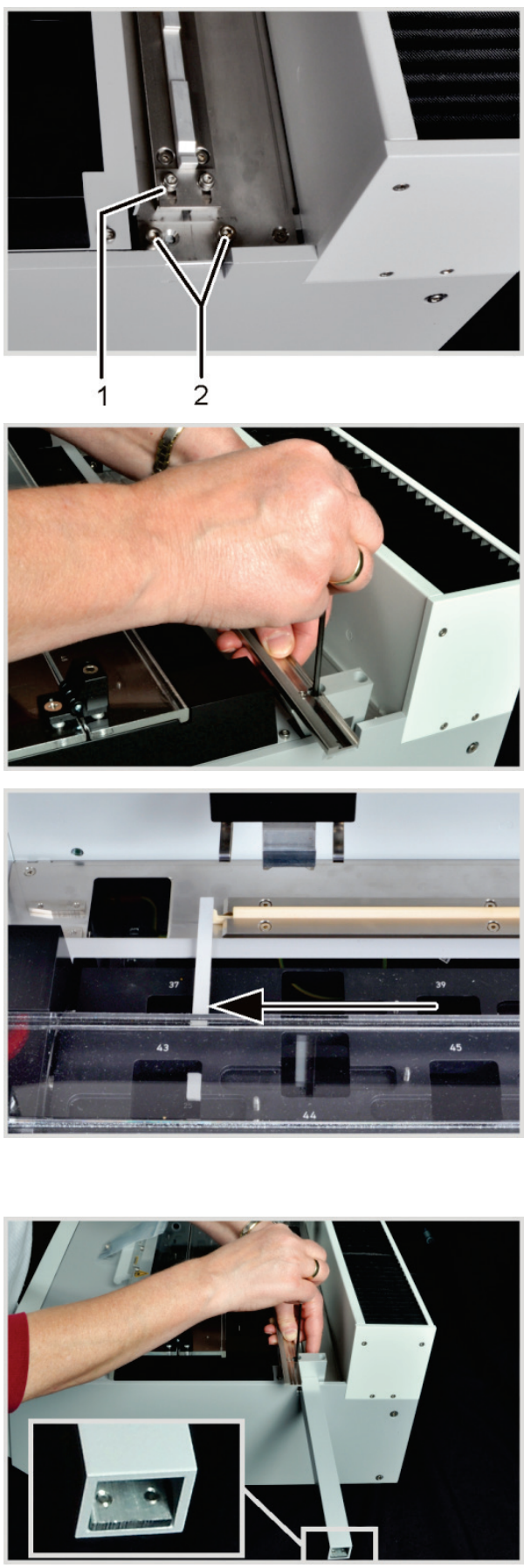

1. Unscrew the stop plate of the guide rail (1).

2. Remove the two hexagon socket screws (2).

3. Using the screws supplied screw the boat storage loosely to the FPG 48.

4. Slide the hook cover under the block.

5. Place the ceramic hook into the guide rail of the autosampler.

6. Place the long sliding rod onto the hook until the pin engages in the slot.

7. Adjust the ceramic hook in the start position. The hook tip must be flush with the right-hand edge of the left-hand boat position (here position 37).

Place a straight paper or plastic strip (e.g. a ruler) against the edge and align the ceramic hook with it.

8. Move the cover until the rear end of the sliding rod touches the stop plate at the end of the cover. (See image section for stop plate)

9. Tighten the hexagon socket screws at the block finger-tight and thereby clamp the cover in its adjusted position.

When tightening the screws align the boat storage parallel to the guide rail.

10. Start the multiWin software and log in as administrator.

11. Select the menu command DEVICE DEVICE - EDIT. 
A window with the same name opens.

12. In the area ACCESSORY MODULES place a tick for EJECTION RAIL.

13. Adjust the position of the gripper relative to the ejection rail ( $\rightarrow$ see section "Installing and adjusting the autosampler FPG 48" p. 62).

\subsubsection{Measurement cancellation when using the sampler FPG 48}

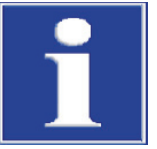

\section{NOTICE}

After manual measurement interruption or measurement interruption due to a device fault move the ceramic hook manually to the limit stop before resuming the measurement process.

\subsubsection{Use manual sample feed}

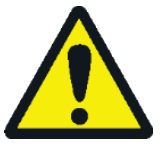

\section{CAUTION}

There is a risk of burns at the hot the combustion furnace! Allow the basic device to cool down sufficiently before positioning the manual sample feed!

During sample feed operation, there is a risk of burns at the hot boat and ceramic hook! After pulling out of the furnace, the boat and hook remain hot for a long time.

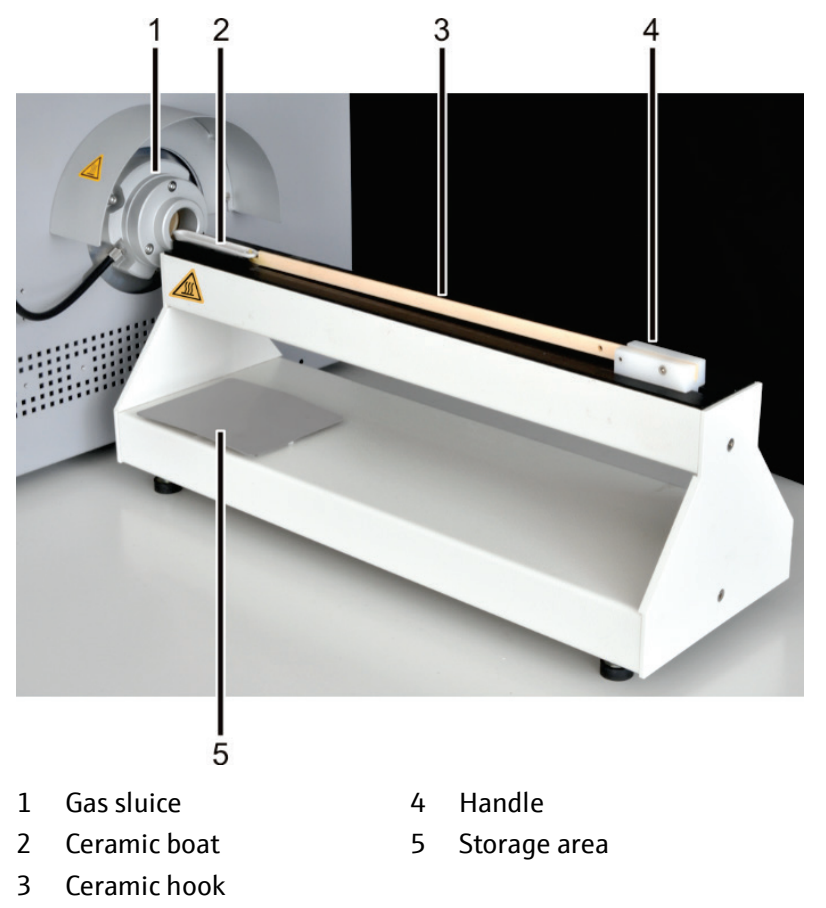

1. Position the manual sample feed in front of the gas sluice. Align the sample feed until the ceramic boat is moved exactly in the center into the gas sluice.

The distance between the sample feed and the gas sluice should be approx. $2 \mathrm{~mm}$.

2. Place a boat with the eye on the hook of the sample feed and carefully move the boat manually into the furnace.

Caution! Only touch the hook from the handle. There is a risk of burns on the furnace.

Correct the position of the sample feed if the boat gets jammed.

3. Manually remove the hot boats from the hook with pliers and place them onto the storage area to cool down. 


\subsection{Connecting and using the external scales}

When using the external scales the sample mass can be transferred directly to the sequence table.

1. Connect the scales to the "scale" connection of the $\mathrm{C} / \mathrm{S}$ module or $\mathrm{Cl}$ module.

2. Connect the scales to the power supply and switch on.

3. Set the baud rate to 9600 .

4. For further configurations see the documentation of the scales.

To transfer the sample weight proceed as follows:

5. Start the measurement up to the input of the analysis sequence.

6. In the sequence table click on the field WEIGHT of the sample.

7. Weigh the sample on the boat.

8. Transfer the value from the scales with [OK].

$\checkmark \quad$ The weight appears in the input field.

9. Repeat steps (2) - (4) for each sequence line. 


\section{Operation}

\subsection{Activation / warm-up phase / setup}

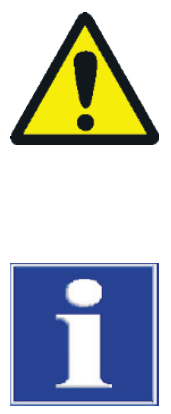

\section{CAUTION}

Crushing hazard at the autosampler FPG 48! The autosampler arm, the gripper and the boat carousel move during activation and initialization. Keep an adequate distance to avoid having your hands crushed.

\section{NOTICE}

In case of large temperature differences between storage and the installation wait until the multi EA 4000 has adapted to the ambient temperature before connecting it in order to prevent damage to the device from condensation water.

Before switching on check the following:

- The gases oxygen and argon (for $\mathrm{Cl}$ determination or the determination of elementary carbon) are connected with an inlet pressure of $200-400 \mathrm{kPa}(29-58 \mathrm{psi})$.

- A combustion tube has been inserted in the furnace.

- The gas hoses are connected to the gas sluice or the TIC reactor.

- The analysis modules have been connected.

- The manual sample feed or the autosampler have been positioned and adjusted.

- The PC is connected and the multiWin software installed.

Switching on sequence

1. Open the gas flows at the pressure reducer (inlet pressure $200-400 \mathrm{kPa}$ or 29 $58 \mathrm{psi})$.

2. Switch on the PC.

3. Switch on the sampler FPG 48 (optional).

$\checkmark \quad$ The sampler FPG 48 initializes.

4. Switch on the basic device multi EA 4000 from the mains switch at the rear of the device and the On/Off switch at the front (behind the doors).

5. Switch on the analysis modules.

$\checkmark$ The devices are booted. The status lights at the front panels of the basic device and the modules illuminate.

6. Start the multiWin program.

7. Log in as user.

Enter ADMIN as USER and as PASSWORD. This user has been installed during initial program installation and has administrator rights.

8. Click the [INITIALIZE ANALYZER] button.

$\checkmark \quad$ The initialization and the automatic detection of all connected and switched on components is performed after successful login. 
Warm-up and run-in phases
After successful login, automatic initialization and query of the components starts. The current values are displayed in the status window:

- Measuring gas flow: Appears after activation of the suction pump (100 $\pm 10 \mathrm{l} / \mathrm{h})$.

- Suction pump in the basic device: The pump switches on $50 \mathrm{~K}$ before reaching the target temperature.

- Furnace temperature: Dependent on the target temperature set the heating-up duration is approx. $30-60 \mathrm{~min}$.

- NDIR detector (C, S or C/S determination only): The C/S module requires a run-in time of approx. 15 min. after activation.

- Coulometer ( $\mathrm{Cl}$ determination only): approx. 10 min run-in time

In the status window, the displays for the components that are not yet ready for operation are red during this time.

\section{$6.2 \mathrm{C} / \mathrm{S}$ measurement}

\subsubsection{Preparing the multi EA 4000 and $C / S$ module}

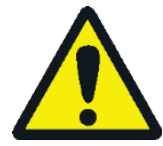

\section{WARNING}

Risk of electric short circuit! In the combustion furnace HTS1500 very high electrical currents occur in spite of a low voltage (max. $14 \mathrm{~V}$ ). The combustion tube is part of the cover of live components.

Only switch on the analyzer with the combustion tube inserted! Always switch off the analyzer from the mains switch at the rear of the device for conversions and maintenance to the combustion tube or combustion furnace.

\section{CAUTION}

There is a risk of burns at the hot the combustion furnace! Allow the basic device to cool down sufficiently before conversion!

The gas sluice for C/S measurements consists of a base element and a pressure ring. In the gas sluice a circular gap remains between the base element and the pressure ring to allow oxygen to enter the combustion tube. The base element is also used for measurements using the automatic TIC solids module.

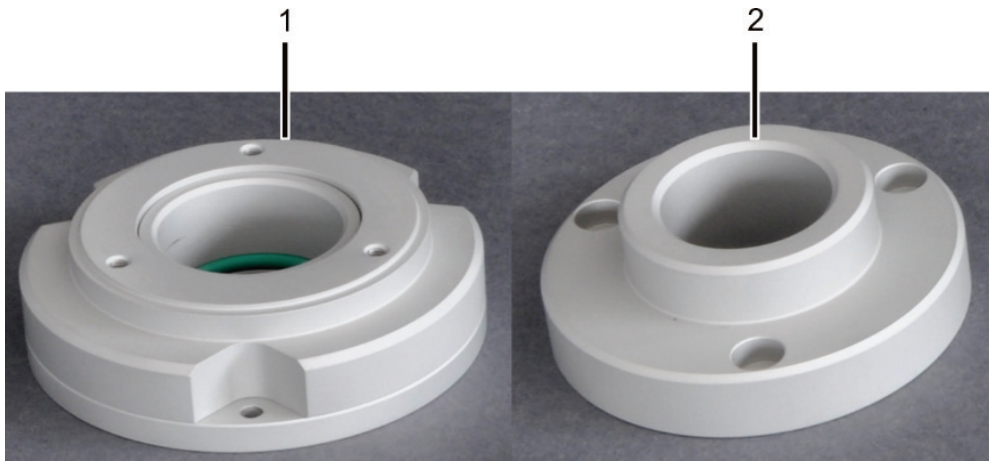

Figure 41 Gas sluice for $\mathrm{C} / \mathrm{S}$ measurements
1 Base element
2 Pressure ring 
For C/S measurements a ceramic combustion tube is used. It is chamfered at both ends and symmetrical. The combustion tube is pushed into the gas sluice and the dust trap at the chamfered ends.

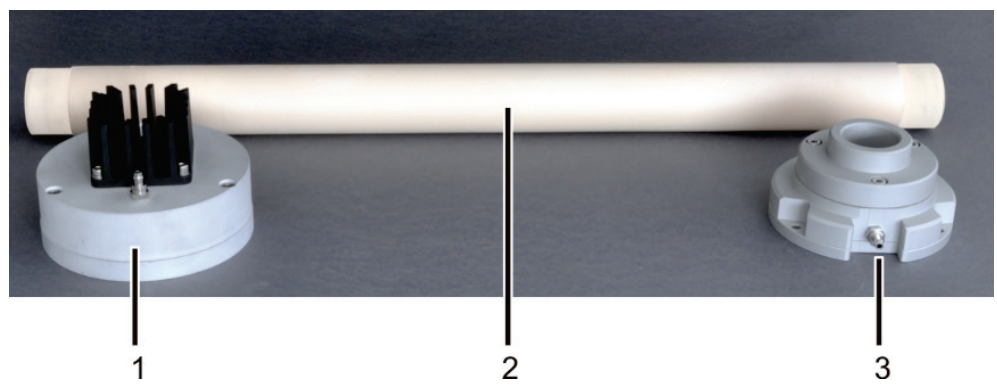

Figure 42 Ceramic tube with dust trap and gas sluice

1 Dust trap with cooling ribs

3 Gas sluice with gas connection

2 Chamfered ceramic tube

Check the electrical connections and hose connections according to section "Positioning the multi EA $4000 \mathrm{C} / \mathrm{S} "$ p. $49 \mathrm{ff}$.
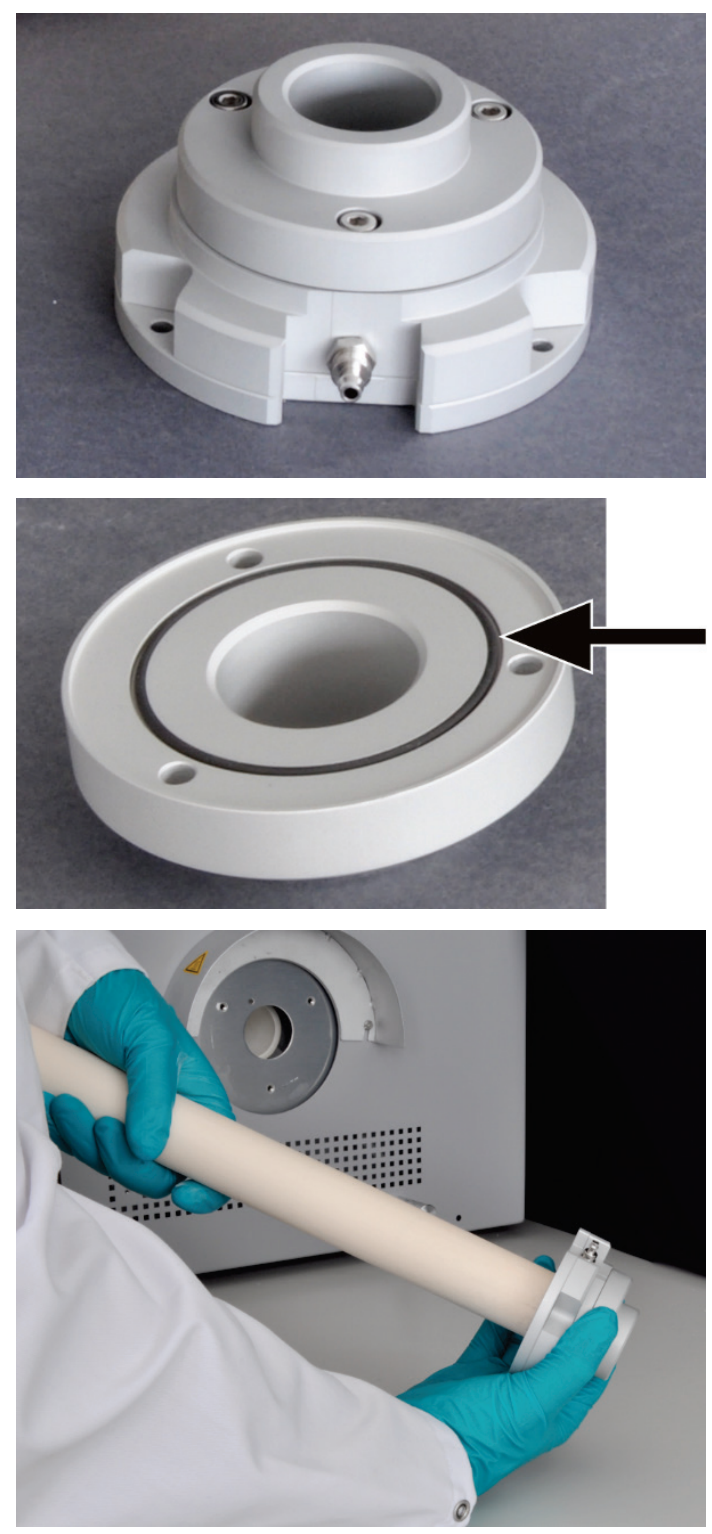

1. Assemble the gas sluice. Ensure correct fit of the sealing ring (see arrow).

Screw the base element and pressure ring together using 3 hexagon socket screws. Tighten the screws evenly in turn.

2. For carbon determination: Fill one end of the ceramic tube approx. $2.5 \mathrm{~cm}$ thick with quartz wool. Push the quartz wool approx. $2-4 \mathrm{~cm}$ deep into the tube.

NOTICE! Do not push the quartz wool too far into the tube, because the wool clumps together at high temperatures.

The filled end of the ceramic tube points later towards the dust trap.

3. Push the ceramic tube into the gas sluice up to the stop. 

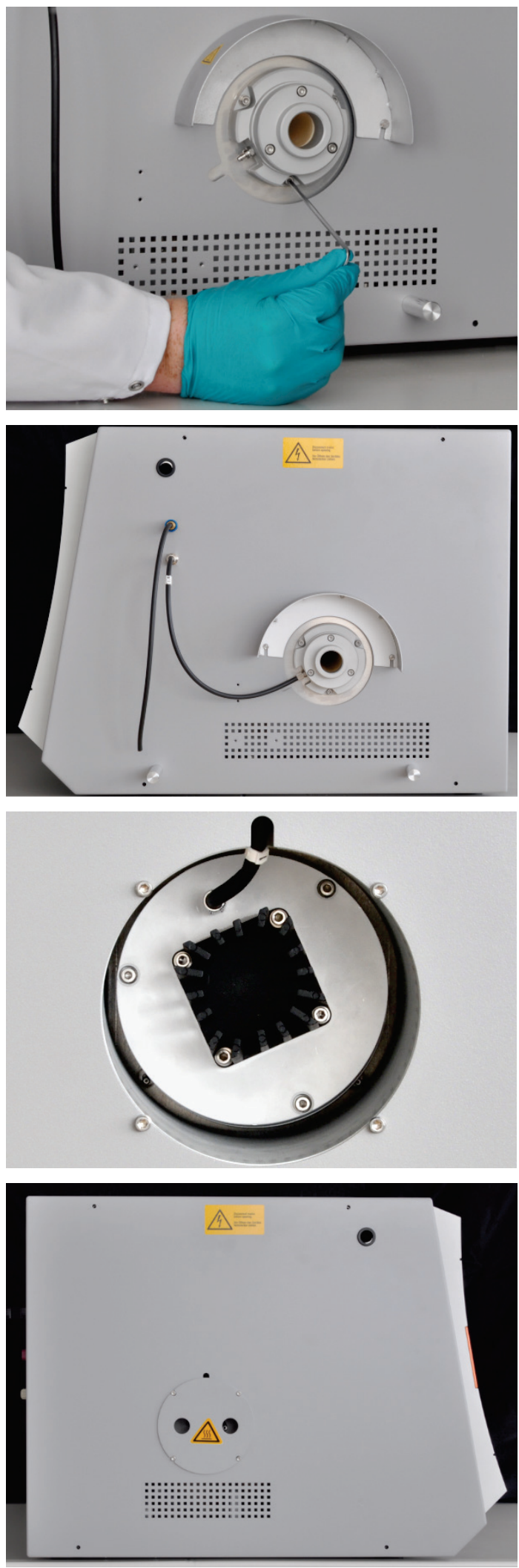

4. Insert the ceramic tube with gas sluice into the multi EA 4000 on the right-hand side. If the tube gets jammed, push it further without pressure by slightly rotating it.

5. Screw the gas sluice with 3 hexagon socket screws to the basic device. The gas connection must point to the front of the basic device.

6. Attach the oxygen hose (hose no. 17) to the gas sluice.

To do so, push the hose onto the gas connection and secure it with the union nut.

7. Pull off the dust trap contact guard from the opening on the left side of the basic device (see Figure below).

8. Place the dust trap onto the ceramic tube. Align the dust trap with the gas connection pointing up.

Slide the dust trap towards the tube axis onto the tube with a rotating motion and push slightly until the dust trap slides onto the tube up to the stop.

9. To do so, push the measuring gas hose (hose no. 1) onto the gas connection and secure it with the union nut.

10. Replace the dust trap contact guard. 
Inspecting the halide trap and drying tube

If the gas sluice has already been installed, the ceramic tube can also be inserted into the basic device from the left-hand side via the opening of the dust trap.

- For ease of handling first place the dust trap onto the ceramic tube.

- Insert the combustion tube with dust trap into the furnace from the left. Insert the tube up to the seal of the gas sluice.

- Make sure that the drying tube is filled with magnesium perchlorate and quartz wool is present in the lower part of the drying tube.

- For C determination install the halide trap filled with copper and brass wool in the gas path.

- For S determination remove the halide trap and connect an empty $U$ tube instead.

The halide trap binds some of the sulfur. For C/S determination the use of the halide trap must therefore be considered. With low sulfur concentrations it is recommended not to use a halide trap. With higher concentrations the halide trap should be installed in the gas path.
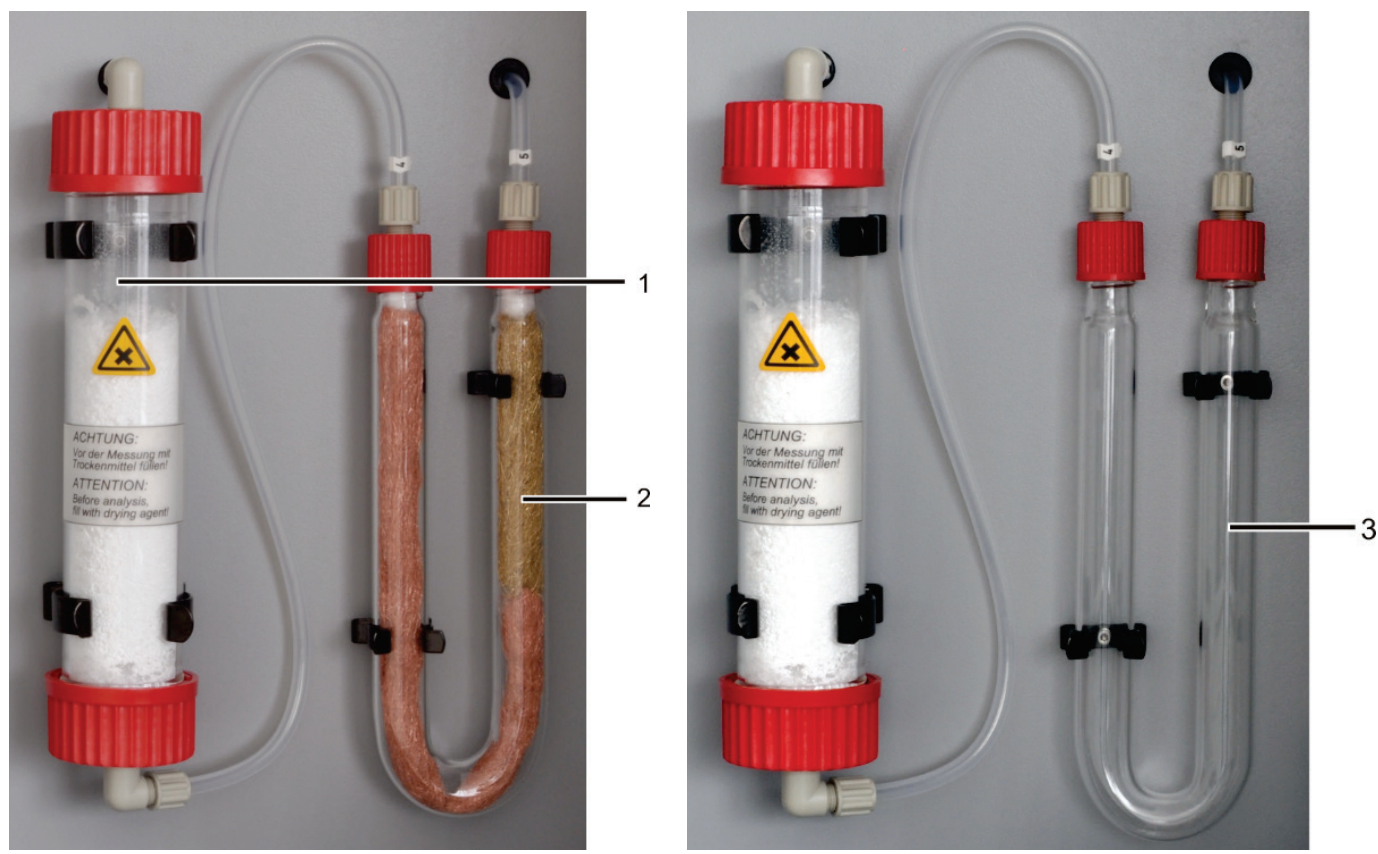

Figure 43 Inspecting the halide trap and drying tube

1 Drying tube with magnesium perchlorate

3 Empty U tube for S determination

2 Halide trap with copper and brass wool

for $C$ determination

\subsubsection{Performing the $\mathrm{C} / \mathrm{S}$ measurement}

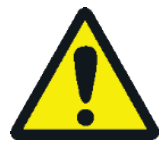

\section{CAUTION}

During the operation of the sampler and the manual sample feed there is a risk of burns at the hot boat and ceramic hook! After pulling out of the furnace the boat and hook remain hot for a long time. 


\section{CAUTION}

Crushing hazard at the autosampler! The autosampler arm, the gripper and the boat carousel move during activation and initialization and measurement operation. Keep an adequate distance to avoid having your hands crushed.

When filling the autosampler: Only open the cover when the boat carousel is no longer moving.

1. Switch on the basic device multi EA 4000, the C/S module and, where applicable, the FPG 48. Make sure to switch on the basic device both from the mains switch at the rear and the On/Off switch at the front.

$\checkmark$ The status lights at the front of the devices illuminate.

If an automatic TIC solids module is integrated, switch this on also. The extended transport path of the boat due to the intermediate TIC reactor is then taken into account.

Do not switch any $\mathrm{Cl}$ module present.

2. Start the multiWin program.

3. Change between the various analyzer modules. To do so, first activate the sensors:

- Select the menu command DEVICE DEVICE - EDIT.

- Enable the ELEMENTS to be analyzed.

- If both carbon/sulfur and chlorine are enabled, click on CERAMIC TUBE (CS) in the list COMBUSTION TUBE.

- As StATES enable the option SOLID.

4. Initialize the system by clicking on [INITIALIZE ANALYZER].

5. Load a method (menu item METHOD METHOD - ACTIVATE) or create a new method (menu item METHOD METHOD - NEW).

The following parameters can be selected for C/S measurements:

- TC (determine only total carbon content)

- TS (determine only total sulfur content)

- TC+TS (determine total carbon content and total sulfur content)

6. After the run-in time set the following gas flows at the flow regulators at the front of the basic device (1-3 in Figure 2 p. 19):

\begin{tabular}{lll}
\hline Pump & $\mathrm{O}_{2}$ & $\mathrm{Ar} / \mathrm{O}_{2}$ \\
\hline Set the intake flow until in & $2.3-2 . \mathrm{l} / \mathrm{min}$ & - \\
the STATUS ANALYZER window & \\
the value \\
NOMINAL $=100 \pm 10$ is dis- \\
played, corresponding to ap- \\
prox. $1.7 \mathrm{I} / \mathrm{min}$
\end{tabular}

The analysis system now has time to settle down.

If the intake flow differs greatly or changes later, readjust the intake flow at the "pump" valve of the multi EA 4000.

7. Weigh the samples onto the ceramic boats. 
8. Click on [START MEASUREMENT].

9. Create or select an analysis group for storing the measuring data.

10. Create an analysis sequence.

- Add the desired number of samples to the sample table with

- Enter the following data:

\begin{tabular}{ll}
\hline Column & Description \\
\hline SAMPLING POSITION & $\begin{array}{l}\text { Only for measurements with the autosampler. Position of } \\
\text { the sample on the sample rack } \\
\text { The sample rack must only be populated with ascending po- } \\
\text { sition numbers. However, it does not need to be without } \\
\text { gaps. }\end{array}$ \\
\hline SAmple ID \\
With \\
\hline ANALYSIS TYPE & Selection of the analysis type (SAMPLE, DAILY FACTOR DETERMI- \\
& NATION, CALIBRATION MEASUREMENT, AQA MEASUREMENT or DET. \\
& BOAT BLANK) \\
\hline NOMINAL VALUE & $\begin{array}{l}\text { Target concentration for calibration standards or AQS } \\
\text { standard }\end{array}$ \\
\hline OPERANDS & Input of the sample weight \\
\hline
\end{tabular}

- Populate the autosampler. Use the and buttons to move the sample rack to the desired position.

- Click on in the sequence row to release it for analysis. All sequence rows can be released by clicking on 10 .

$\checkmark$ Sequence rows released for analysis have a green fill.

11. Start the measurement by clicking on [START MEASUREMENT].

For measurements with manual sample feed an input window is shown before each measurement start to enter the sample weight.

$\checkmark \quad$ The analyzer starts processing the analysis sequence. The MEASUREMENT ANALYSIS window opens.

During extended measurement interruptions the oxygen supply can be deactivated in the multiWin program to save oxygen. However, the oxygen supply must be re-activated in good time (approx. $10 \mathrm{~min}$.) before starting the measurement. 


\subsection{Determination of carbon after pyrolysis}

\subsubsection{Preparing the multi EA 4000 and $\mathrm{C} / \mathrm{S}$ module}

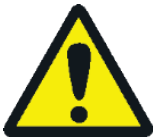

\section{CAUTION}

With pyrolysis volatile carbon compounds escape from the multi EA 4000. Attach an extraction pipe close to the furnace inlet and ensure that the pyrolysis gas is extracted.

1. Check the electrical connections and hose connections in accordance with section "Positioning the multi EA 4000 C/S" p. 49. Check in particular the argon connection at the multi EA 4000 .

2. Fit an extraction pipe on the right hand side of the multi EA 4000 to remove the pyrolysis gases.

3. Prepare the analyzer as described in section "Preparing the multi EA 4000 and C/S module" p. 71:

- Mount the ceramic tube with gas sluice and dust trap in the combustion furnace.

- Make sure that the drying tube is filled and the copper and brass wool in the halide trap is not discolored.

4. Position the sampler FPG 48 ( $\rightarrow$ see section "Connecting and using the autosampler" p. 62).

\subsubsection{Performing the determination of carbon after pyrolysis}

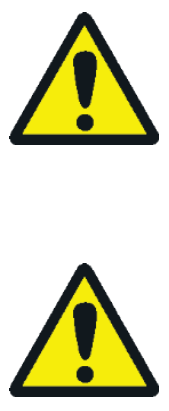

\section{CAUTION}

During the operation of the sampler and the manual sample feed there is a risk of burns at the hot boat and ceramic hook! After pulling out of the furnace the boat and hook remain hot for a long time.

\section{CAUTION}

Crushing hazard at the autosampler! The autosampler arm, the gripper and the boat carousel move during activation and initialization and measurement operation. Keep an adequate distance to avoid having your hands crushed.

When filling the autosampler: Only open the cover when the boat carousel is no longer moving.

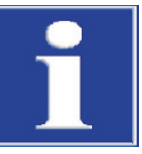

\section{NOTICE}

Danger of damage to furnace! To not constantly work with furnace temperatures below $1000^{\circ} \mathrm{C}$. Where possible limit the operating period of pyrolysis measurements (with $\mathrm{T}=850^{\circ} \mathrm{C}$ ).

1. Switch on the basic device multi EA 4000, the C/S module and, where applicable, the FPG 48. Make sure to switch on the basic device both from the mains switch at the rear and the On/Off switch at the front. 
$\checkmark \quad$ The status lights at the front of the devices illuminate.

Do not switch any $\mathrm{Cl}$ module present. If present, switch on the automatic TIC solids module from the mains switch at the rear.

2. Start the multiWin program.

3. Change between the various analyzer modules. To do so, first activate the sensors:

- Select the menu command DEVICE DEVICE - EDIT.

4. Enable the ELEMENTS to be analyzed.

- If both carbon/sulfur and chlorine are enabled, click on CERAMIC TUBE CS in the list COMBUSTION TUBE.

- As StATES enable the option SOLID.

5. Initialize the system by clicking on [INITIALIZE ANALYZER].

6. Load a method (menu item METHOD METHOD - ACTIVATE) or create a new method (menu item METHOD METHOD - NEW).

- Select the parameter "EC/TC" for the determination of carbon after pyrolysis.

- Recommended parameters for the method configuration (tab PROCESS):

\begin{tabular}{ll}
\hline FURNACE TEMPERATURE & $850^{\circ} \mathrm{C}$ \\
\hline EC PURGE TIME & $300 \mathrm{~s}$ \\
\hline
\end{tabular}

7. After the run-in time set the following gas flows:

\begin{tabular}{ll}
\hline pump & $\mathrm{O}_{2}$ \\
\hline Set the intake flow until in the STATUS ANALYZER window the value & $2.3-2.1 / \mathrm{min}$ \\
NomINAL = $100 \pm 10$ is displayed, corresponding to approx. 1.7 & \\
I/min & \\
\hline
\end{tabular}

The analysis system now has time to settle down.

If the intake flow differs greatly or changes later, readjust the intake flow at the "pump" valve of the multi EA 4000.

8. Weigh the samples onto two ceramic boats each.

9. Start the measurement by clicking on [START MEASUREMENT].

10. Create or select an analysis group for storing the measuring data.

11. Create an analysis sequence.

- Add the desired number of samples to the sample table with must be provided for each measurement and processed in sequence.

- Enter the following data:

\begin{tabular}{ll}
\hline Column & Description \\
\hline SAMPLING POSITION & $\begin{array}{l}\text { Position of the sample on the sample rack or in the analysis se- } \\
\text { quence for measurements with manual sample feed. The sample } \\
\text { rack must only be populated with ascending position numbers. } \\
\text { However, it does not need to be without gaps. }\end{array}$ \\
\hline NAME & Sample ID \\
\hline
\end{tabular}




\begin{tabular}{ll}
\hline With & an automatic sample ID can be created. \\
\hline ANALYSIS TYPE & $\begin{array}{l}\text { Selection of the analysis type (SAMPLE, DAILY FACTOR DETERMINATION, } \\
\text { CALIBRATION MEASUREMENT, AQA MEASUREMENT or DET. BOAT BLANK) }\end{array}$ \\
\hline NOMINAL VALUE & Target concentration for calibration standards or AOS standard \\
\hline OPERANDS & Input of the sample weight \\
\hline
\end{tabular}

- Populate the autosampler. Use the and buttons to move the sample rack to the desired position.

- Click on in the sequence row to release it for analysis. All sequence rows can be released by clicking on the button.

$\checkmark$ Sequence rows released for analysis have a green fill.

\section{Click on [START MEASUREMENT].}

For measurements with manual sample feed an additional input window is shown before each measurement start to enter the sample weight.

$\checkmark \quad$ The analyzer starts processing the analysis sequence. The MEASUREMENT ANALYSIS window opens.

- In the sample in boat 1 the elementary carbon (EC) is determined. Prior to the measurement of boat 1 the automatic deactivation of the intake pump and the change-over from oxygen to argon takes place. Now set the argon flow at the $\mathrm{Ar} / \mathrm{O}_{2}$ rotameter to $2.3-2.5 \mathrm{l} / \mathrm{min}$. This flow configuration is retained for the subsequent pyrolysis measurement.

- The sample in boat 1 is first pyrolized in the argon flow after expiry of the waiting period (flushing the combustion tube with argon). In the process the volatile parts of the carbon compounds contained escape at the selected temperature. Ideally and / or after appropriate pretreatment the elementary carbon $(E C)$ remains on the boat.

- After pyrolysis the change-over to oxygen takes place and the intake pump is activated again. The share of the remaining carbon (EC) in the already pyrolized sample is determined through combustion in the oxygen flow.

- The sample in boat 2 is moved into the oxygen flow for the determination of the total carbon content (TC).

- From the difference of the two measurements obtained (TC and EC) the volume of degradable or active carbon can be derived.

During extended measurement interruptions, the gas supply can be deactivated in the multiWin program to save oxygen. However, the oxygen supply must be re-activated in good time (approx. 10 min.) before starting the measurement. 


\subsection{Cl determination}

\subsubsection{Preparing the multi EA 4000 for $\mathrm{Cl}$ measurements}
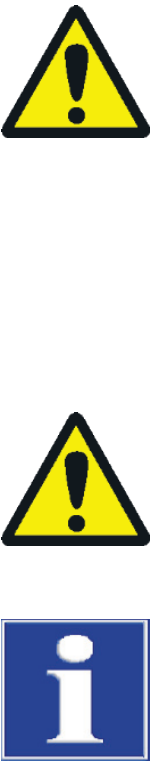

\section{WARNING}

Risk of electric short circuit! In the combustion furnace HTS1500 very high electrical currents occur in spite of a low voltage (max. $14 \mathrm{~V}$ ). The combustion tube is part of the cover of live components.

Only switch on the analyzer with the combustion tube inserted! Always switch off the analyzer from the mains switch at the rear of the device for conversions and maintenance to the combustion tube or combustion furnace.

\section{CAUTION}

There is a risk of burns at the hot the combustion furnace! Allow the basic device to cool down sufficiently before conversion!

\section{NOTICE}

Alkaline salts (hand perspiration) cause crystallizations in the quartz glass when heating the combustion furnace which reduce the service life of the tube.

Where possible do not touch the combustion tube with your hands. Wear protective gloves to install the lock on the combustion tube. If necessary, clean the combustion tube externally with Ethanol before installing it in the combustion furnace.

For $\mathrm{Cl}$ measurements a quartz tube is used to which the gas sluice is attached. No dust trap is attached to the quartz tube.

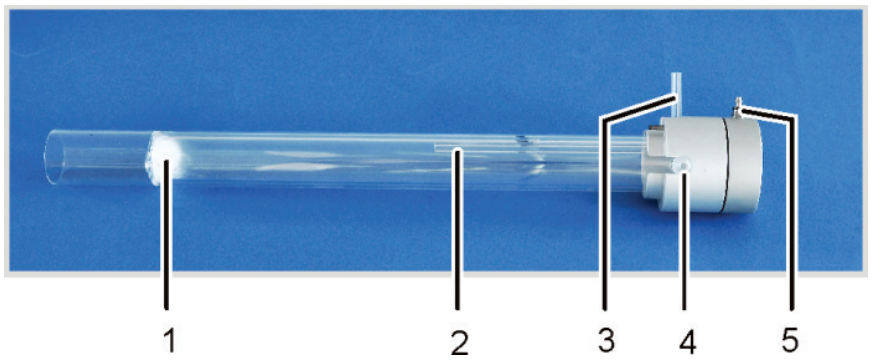

Figure 44 Quartz combustion tube with gas sluice
1 Quartz wool plug
Bypass for oxygen supply
Oxygen connection adapter

4 Measuring gas outlet with boat connection

The quartz tube can be attached to the multi EA 4000 via a coupling element. 


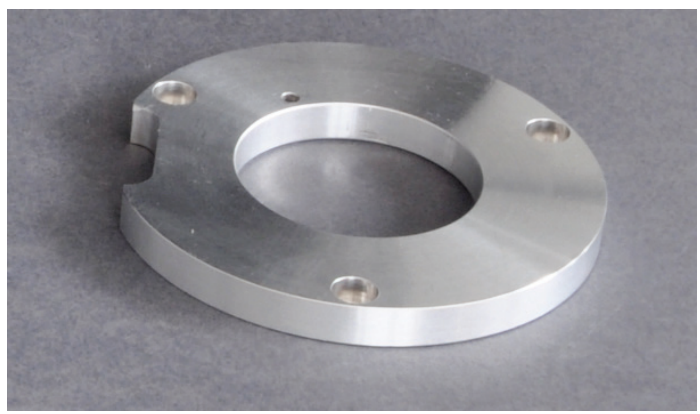

Figure 45 Coupling element for $\mathrm{Cl}$ measurements

Check the electrical connections and hose connections according to section "Positioning the multi EA $4000 \mathrm{Cl}$ " or "Positioning the multi EA $4000 \mathrm{C} / \mathrm{S} \mathrm{Cl"} \mathrm{p.} 51 \mathrm{ff}$.
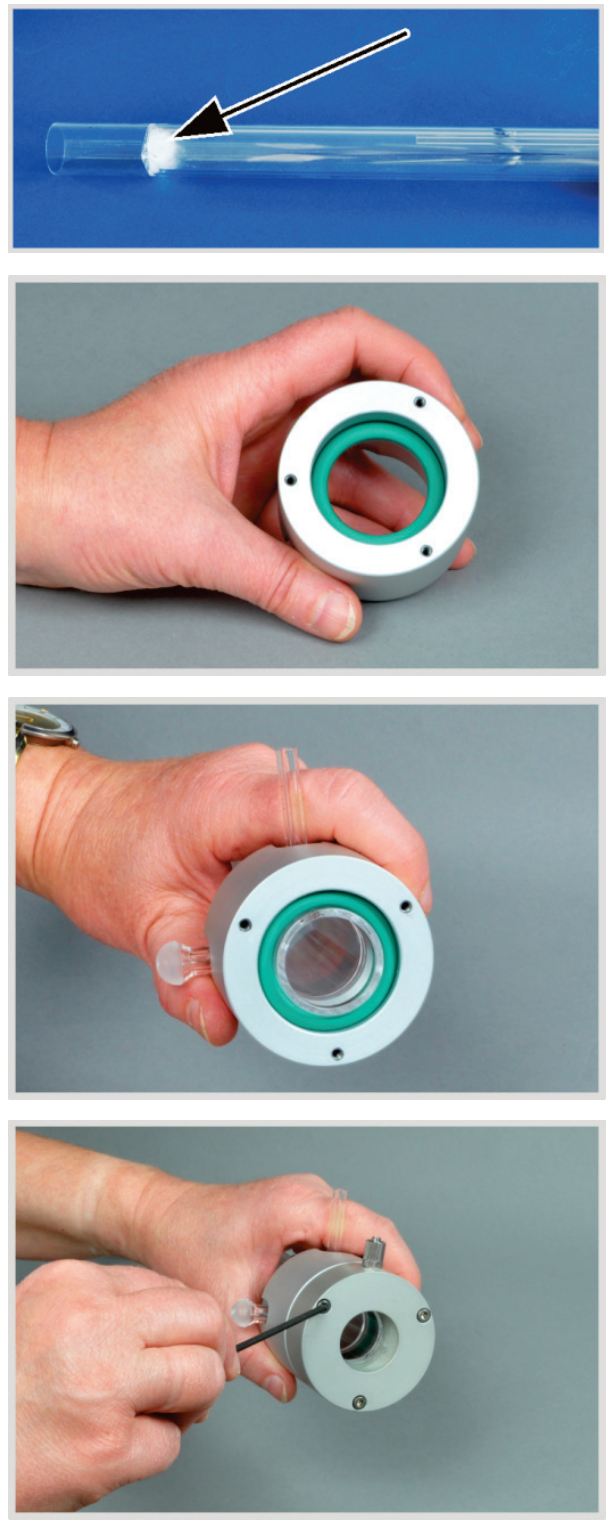

1. Fill the quartz tube with approx. $2.5 \mathrm{~cm}$ quartz wool and push the cotton plug into the end of the tube.

2. Place the sealing ring into the pressure ring of the gas sluice.

3. Push the quartz tube into the pressure ring until the gas outlets reach into the slots of the ring.

4. Attach the matching piece of the gas sluice with the three corresponding hexagon socket screws. Tighten the screws evenly in turn.

When tightening the screws make sure that the quartz tube is centered in the gas sluice. 

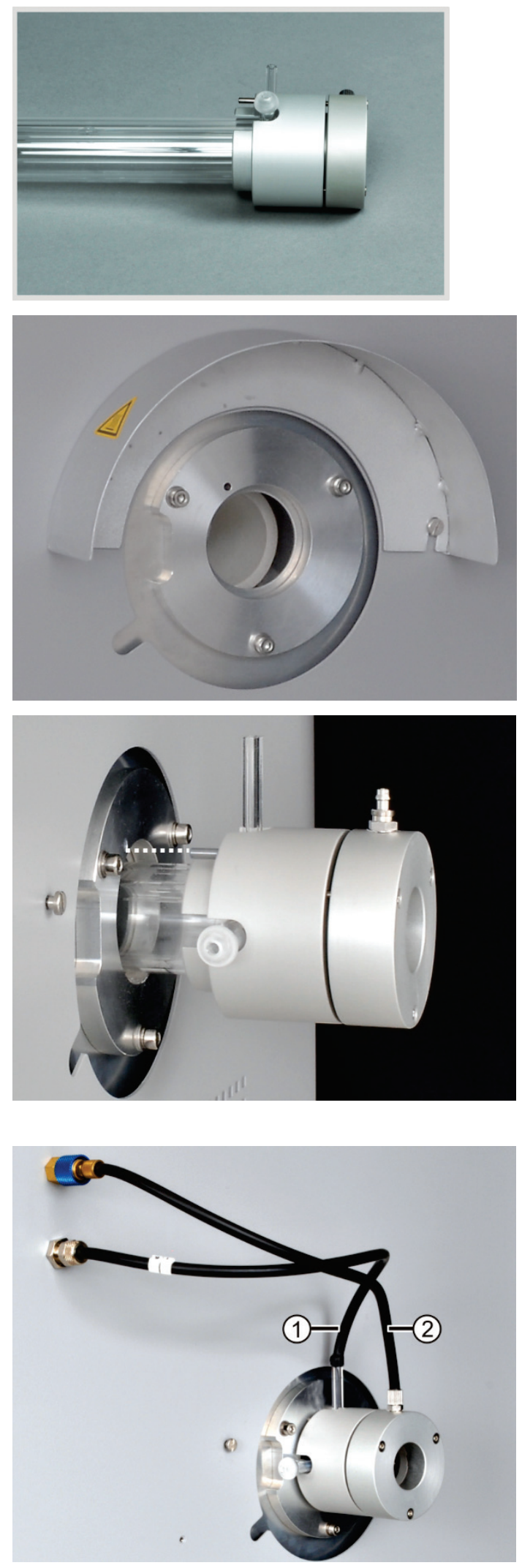

1 Oxygen connection

2 Argon connection $\checkmark \quad$ The gas sluice is correctly assembled if the gap between the pressure ring and the matching piece is evenly approx. $1 \mathrm{~mm}$ wide.
5. Fit the coupling element with three hexagon socket screws to the right side of the basic device. Make sure that the guide hole is above the slot in the basic device and the recess points towards the front.

6. Remove the heat guard. To do so, release 2 slotted screws with a screwdriver.

7. Slide the quartz tube with gas sluice up to the stop into the combustion furnace. In the process insert the guide pins into the guide hole (see dotted line).
When not using the flame sensor:

8. Push the hose for the oxygen supply (hose no. 17) onto the glass tube of the combustion tube (1).

9. Connect the hose for the argon supply to the gas sluice (2). NOTICE! The hoses must not be kinked or twisted.

$\checkmark$ The quartz tube is inserted in the multi EA 4000. 
Connecting the flame

sensor (optional)
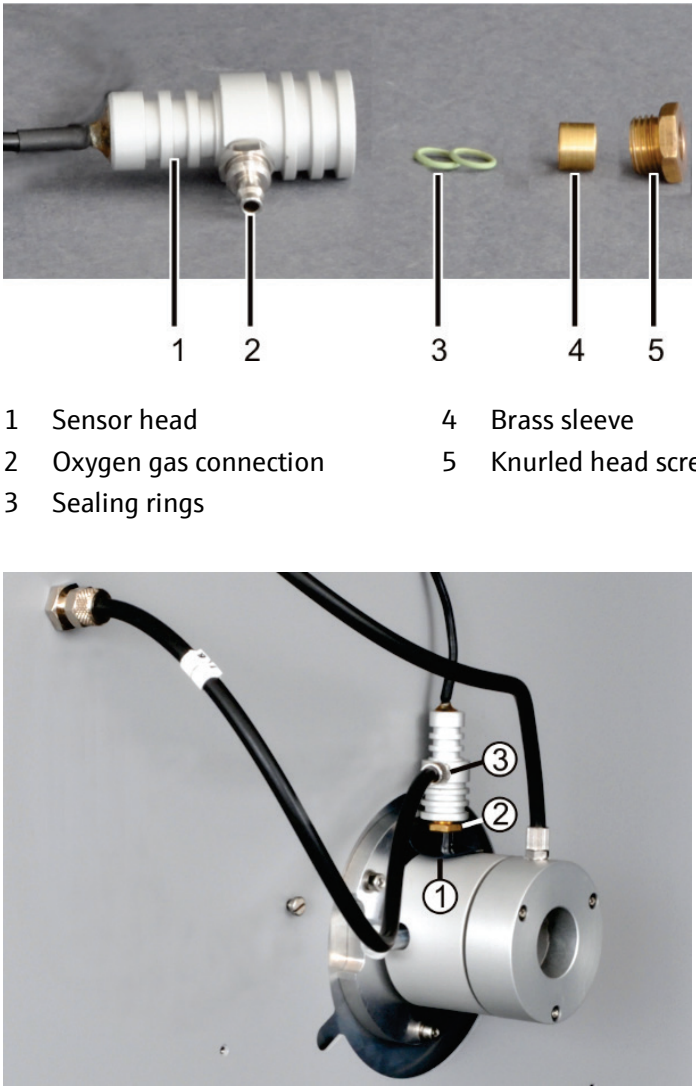

1. Assemble the flame sensor:

Consecutively insert the 2 sealing rings ( 3 ) and the brass sleeve (4) into the sensor head (1).

Screw the aluminum knurled head screw (5) only lightly to the sensor head.

Note: A third seal is included with the flame sensor as a replacement.

2. Push the black aperture disk (1) onto the gas connection of the quartz tube.

3. Attach the hose for the oxygen supply (hose no. 17) to the gas connection (3).

4. Push the flame sensor onto the gas connection and attach with the brass screw (2). Tighten screw finger-tight.

5. Connect the cable of the flame sensor to the "valve" connection at the rear of the C/S module (or $\mathrm{Cl}$ module).
Connect the sulfuric acid container.

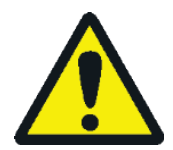

\section{WARNING}

The concentrated sulfuric acid used as desiccant in the sulfuric acid container can cause serious burns!

Wear appropriate protective clothing to replace the sulfuric acid! Observe all specifications in the safety data sheet! Take great care when filling in sulfuric acid!

Dependent on the measuring method a sulfuric acid container with or without split outlet is used. 

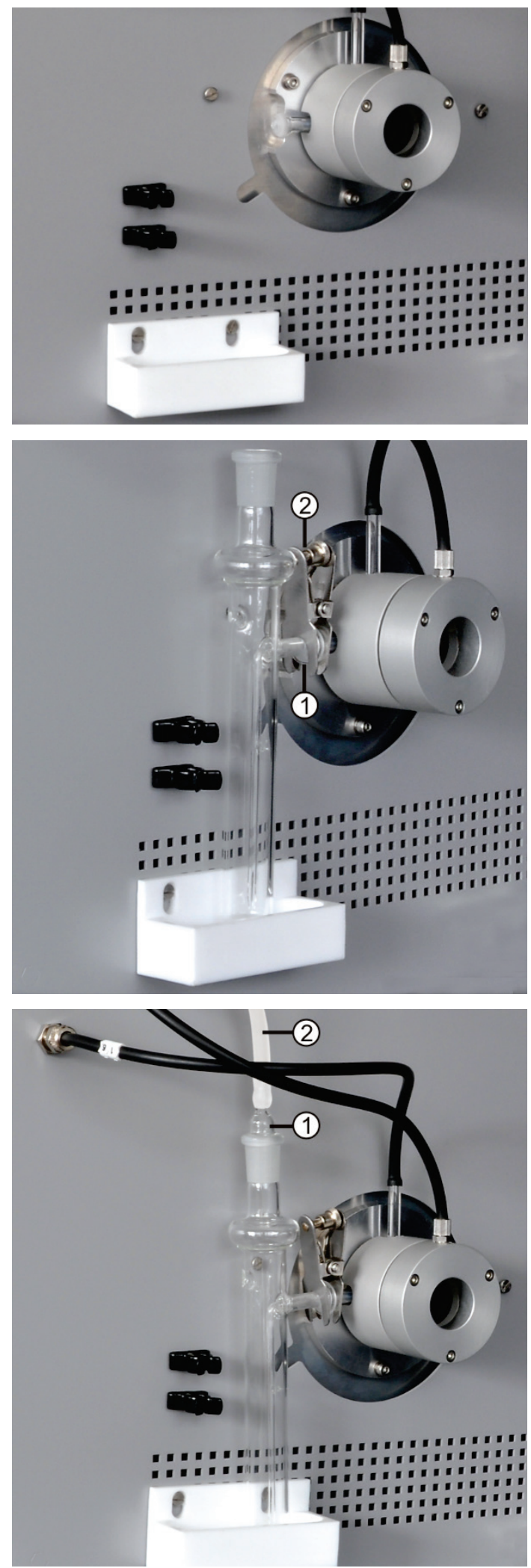

1. Screw the PTFE tray and the 2 clamps for the safety container to the basic device, if applicable.

2. Fill the sulfuric acid container with $12-15 \mathrm{ml}$ sulfuric acid.

3. Hold the filled sulfuric acid container above the PTFE tray.

4. Attach the gas outlet of the combustion tube to the inlet of the sulfuric acid container using the spherical joint connection (1).

5. Secure the spherical joint connection with the forked clamp (2). Tighten the knurled head screws finger-tight to do so.

6. Push the measuring gas hose (2, transparent) onto the hose connection of the gas olive.

7. Seal the sulfuric acid container with the gas olive (1). 


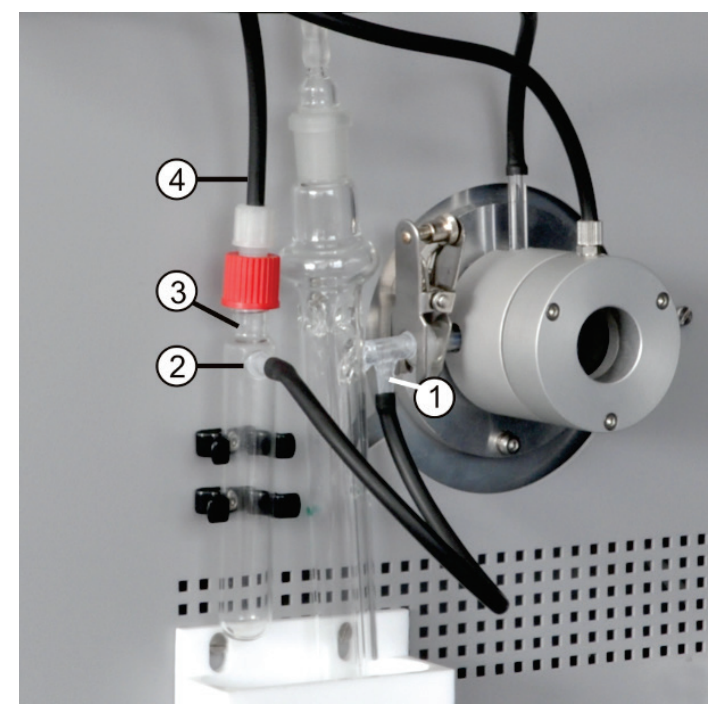

1 Split outlet

3 Safety container

2 Connection adapter
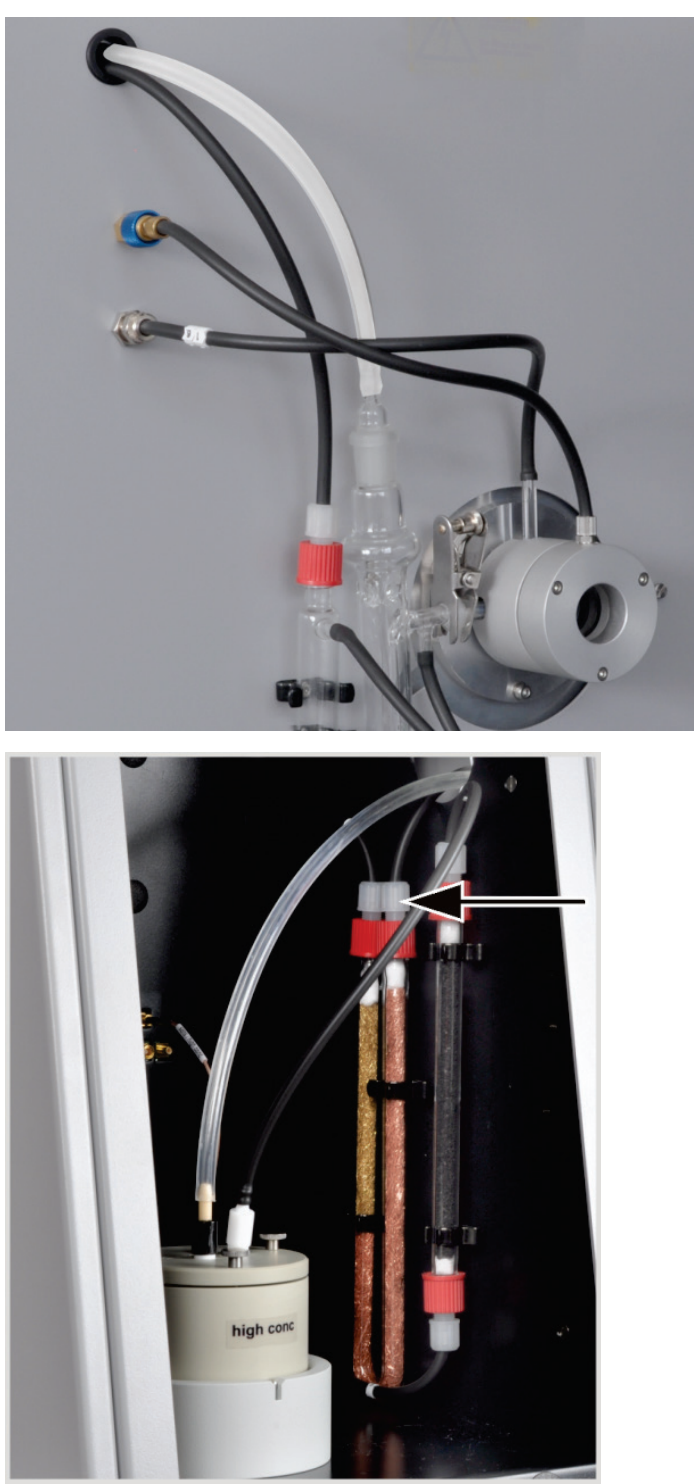

Only sulfuric acid containers with split outlet:

8. Connect the split outlet of the sulfuric acid container (1) via a short piece of hose to the lateral connection of the safety container (2).

9. Press the safety container into the 2 clamps.

10. Connect the black bypass hose (4) to the top of the safety container (3).

For sulfuric acid containers without split outlet the bypass hose remains unattached.

11. Slide the measuring gas hose (transparent) and the bypass hose (black) through the channel in the multi EA 4000. If necessary, pull the hoses out from the other end of the channel with tweezers.

Route the hoses through the opening on the lefthand side of the $\mathrm{Cl}$ module.

Only sulfuric acid containers with split outlet:

12. In the $\mathrm{Cl}$ module, connect the bypass hose to the gas inlet branch of the halide trap filled with copper wool.

The measuring gas hoses is later connected to the combined electrode $(\rightarrow$ see section "Preparing the measuring cell" p. 87). 


\subsubsection{Preparing the electrolyte solution}

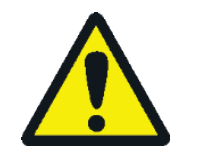

\section{WARNING}

The $99 \%$ acetic acid and nitric acid and thymol used to prepare the electrolyte solution can cause severe chemical burns!

Wear the appropriate protective clothing when preparing the electrolyte solution! Observe all specifications in the safety data sheets!

Reagents required:

- $200 \mathrm{ml}$ acetic acid c $=99 \%$

- $1.0 \mathrm{~g}$ thymol

- $4 \mathrm{ml}$ nitric acid conc.

- $0.3 \mathrm{~g}$ thymol blue

- 4 g gelatin

- $500 \mathrm{ml}$ methanol

Prepare the electrolyte solution as follows:

1. Solution A:

Fill $500 \mathrm{ml}$ ultrapure water into a $1000 \mathrm{ml}$ volumetric flask, add $4 \mathrm{ml} \mathrm{\textrm {HNO } _ { 3 }}$ (conc.), carefully add $200 \mathrm{ml}$ acidic acid and fill with ultrapure water up to the marking.

2. Solution B1:

Mix $4 \mathrm{~g}$ gelatin in a beaker with $400 \mathrm{ml}$ ultrapure water, allow to swell for 3 hours and then dissolve whilst heating to $35-45^{\circ} \mathrm{C}$.

3. Solution B2:

Dissolve $1.0 \mathrm{~g}$ thymol and $0.3 \mathrm{~g}$ thymol blue in a beaker in $500 \mathrm{ml}$ methanol.

4. Solution B:

After cooling solution $\mathrm{B} 1$ to $(18-22)^{\circ} \mathrm{C}$ add it slowly to solution $\mathrm{B} 2$ whilst stirring, filter, transfer into a $1000 \mathrm{ml}$ volumetric flask and fill with ultrapure water up to the marking.

5. Solution $\mathrm{C}$ - finished electrolyte:

Pipette $8 \mathrm{ml}$ of solution $\mathrm{B}$ in a $100 \mathrm{ml}$ measuring cylinder and fill with solution $\mathrm{A}$ to $100 \mathrm{ml}$, or pipette $40 \mathrm{ml}$ of solution $B$ in a $500 \mathrm{ml}$ measuring cylinder and fill with solution $A$ to $500 \mathrm{ml}$.

Storage and durability of the electrolyte solutions
- When stored at $4 \pm 3{ }^{\circ} \mathrm{C}$ in well-sealed bottles, solutions $\mathrm{A}$ and $\mathrm{B}$ can be kept for approx. 6 months.

- The finished electrolyte solution (solution C) can be kept for approx. 30 days if kept in a well-sealed glass container at $20-25^{\circ} \mathrm{C}$. 


\subsubsection{Preparing the measuring cell}

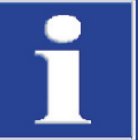

\section{NOTICE}

If the electrolyte dries on the combined electrode, it can damage the electrode. During brief interruptions in operation, e.g. overnight, store the electrode in electrolyte solution.

Leave the electrode for 1-2 $\mathrm{h}$ in electrolyte solution prior to first use. Reproducible values are only possible after that. The filled measuring cell and electrode must be connected to the device before the $\mathrm{Cl}$ module is switched on.

1. Fill the electrolyte into the measuring cell base element (for the preparation of the electrolyte see section "Preparing the electrolyte solution" p. 86):

- "sensitive" cell: approx. $20 \mathrm{ml}$

- "high concentration" cell: approx. $120 \mathrm{ml}$

2. Place a magnetic stirring rod on the floor of the measuring cell.

3. Attach the measuring cell cover with 3 knurled head screws.

4. Place the measuring cell into the holder of the $\mathrm{Cl}$ module. Make sure that the pin of the measuring cell points to the front and is engaged in the guide slot of the holder.

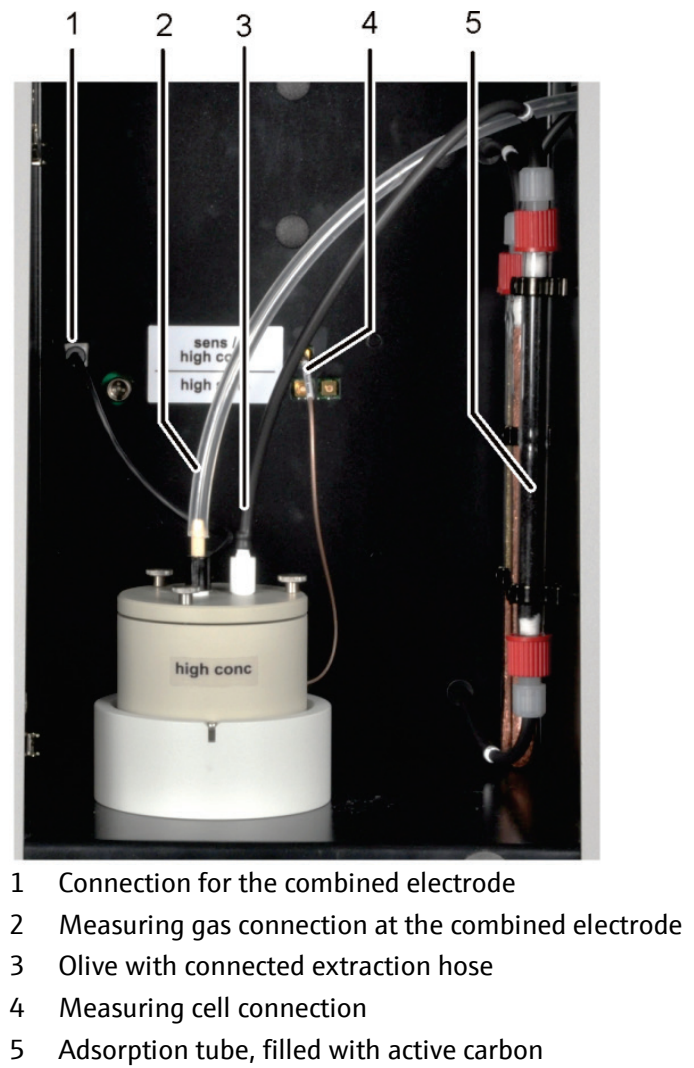

5. Insert the combined electrode and hose olive with the extraction hose into the openings of the measuring cell cover provided.

6. Connect the combined electrode and the measuring cell to the connections at the rear of the $\mathrm{Cl}$ module.

7. Push the measuring gas hose (transparent) approx. $1 \mathrm{~cm}$ far onto the end of the combined electrode.

NOTICE! If the hose is pushed too far onto the electrode, it will get stuck. When pulling off the hose, the electrode might then break.

8. Switch on the multi EA 4000 and its device components ( $\rightarrow$ see section "Performing the $\mathrm{Cl}$ measurement" p. 88).

9. Perform an end point routine ( $\rightarrow$ see section "End point routine" p. 88).

$\checkmark$ Once the end point routine has finished, the system is ready for measurements.

10. If necessary, test the cell using a direct method 


\subsubsection{End point routine}

An end point routine is necessary after every electrolyte change. The operating point of the coulometric measuring cell is in the range of 1500-5000 counts.

1. Start the end point routine via the menu item SYSTEM END POINT ROUTINE.

2. Pull the olive with the extraction hoses out of the cover of the measuring cell. Upon the prompt meter the $\mathrm{HCl}$ solution directly into the measuring cell:

- "sensitive" cell: $200 \mu \mathrm{l}$ of a 0.01 molar $\mathrm{HCl}$ solution

- "high concentration" cell : $200 \mu \mathrm{l}$ of a 0.1 molar $\mathrm{HCl}$ solution

3. Immediately after metering start the end point routine by clicking on [OK].

In the window STATUS ANALYZER the status END POINT ROUTINE is displayed during the process. After the end point routine the status STAND-BY TITRATION and the current indicator value are displayed in the window STATUS ANALYZER.

$\checkmark$ The system is ready for measurements.

The operating point determined for the combined electrode is displayed under the menu item SYSTEM C COMPONENT TEST in the CL-AMP tab.

\section{NOTICE}

To protect the combined electrode against wear, note the following:

- Always add fresh electrolyte to the measuring cell before the end point routine.

- Do not run the end point routine several times in succession.

\subsubsection{Performing the $\mathrm{Cl}$ measurement}

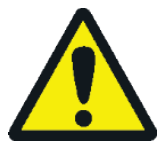

\section{CAUTION}

During the operation of the sampler and the manual sample feed there is a risk of burns at the hot boat and ceramic hook! After pulling out of the furnace the boat and hook remain hot for a long time.

\section{CAUTION}

Crushing hazard at the autosampler! The autosampler arm, the gripper and the boat carousel move during activation and initialization and measurement operation. Keep an adequate distance to avoid having your hands crushed.

When filling the autosampler: Only open the cover when the boat carousel is no longer moving.

1. Switch on the basic device multi EA 4000, the $\mathrm{Cl}$ module, $\mathrm{C} / \mathrm{S}$ module (only for multi EA $4000 \mathrm{C} / \mathrm{S} \mathrm{Cl}$ ) and, where applicable, the FPG 48. Make sure to switch on the basic device both from the mains switch at the rear and the On/Off switch at the front.

$\checkmark \quad$ The status lights at the front of the devices illuminate.

2. Start the multiWin program. 
3. Change between the various analyzer modules. To do so, first activate the sensors:

- Select the menu command DEVICE DEVICE - EDIT.

- Enable chlorine as ELEMENT to be analyzed.

- If both carbon/sulfur and chlorine are enabled, click on QUARTZ TUBE (C) in the list COMBUSTION TUBE.

- As StATES enable the option solid.

4. Initialize the system by clicking on [INITIALIZE ANALYZER].

5. Load a method (menu item METHOD METHOD - ACTIVATE) or create a new method (menu item METHOD METHOD - NEW).

The following parameters can be selected for $\mathrm{Cl}$ measurements:

- $\quad \mathrm{Cl}$ AMP (determining the chlorine content in solids)

- Cl_direct_AMP (testing the measuring cell by pipetting a liquid standard directly into the measuring cell)

6. Configuring the gas flows:

\section{$\mathrm{Cl}$ measurements without gas splitting}

- In the method SPLIT $100 \%$ must be selected on the PROCESS tab for the operation without split.

- The following gas flows must be configured for this purpose:

Gas flows for measurements without gas splitting

\begin{tabular}{lll}
\hline pump & $\mathrm{O}_{2}$ & $\mathrm{Ar}$ \\
\hline approx. $600 \mathrm{ml} / \mathrm{min}$ & $300-400 \mathrm{ml} / \mathrm{min}$ & $300-400 \mathrm{ml} / \mathrm{min}$ \\
\hline
\end{tabular}

- The following should be noted when configuring the gas flows:

The intake flow is set at the "pump" flow regulator. It must be approx. $200 \mathrm{ml} / \mathrm{min}$ greater than the oxygen flow. To guarantee the operation of the gas sluice, the sum total of argon and oxygen flow must be min. 200 $\mathrm{ml} / \mathrm{min}$ greater than the oxygen flow.

When prompted the user must manually reduce the intake flow at the "pump" flow regulator of the basic device.

\section{NOTICE}

It is essential to reduce the oxygen flow when prompted for operation without split! Otherwise sulfuric acid or electrolyte solution can be inducted into the hose system and downstream components where it can cause damage.

$\mathrm{Cl}$ measurements with gas splitting
1. In the method parameters configure one of the following split ratios (in \%) in the PROCESS tab:

\begin{tabular}{ll}
\hline Measuring gas & Split ratio \\
\hline 10 & $1: 10$ \\
\hline 20 & $1: 5$ \\
\hline
\end{tabular}

2. The following gas flows must be configured when working with a measuring gas split: 


\begin{tabular}{lll}
\hline \multicolumn{2}{l}{ Gas flows for measurements with measuring gas split } \\
\hline pump & $\mathrm{O}_{2}$ & $\mathrm{Ar}$ \\
\hline $\max$ (approx. $2.5 \mathrm{l} / \mathrm{min})$ & $1 \mathrm{l} / \mathrm{min}$ & $2.4 \mathrm{l} / \mathrm{min}$
\end{tabular}

First transfer the split factor from an existing method and then recalculate it.

3. Weigh the samples onto the quartz boats.

Samples, such as used oil, should be placed on annealed quartz sand during weighing into the quartz glass boat and covered with a sufficient quantity of quartz sand. Used oil sample weights must not exceed $50 \mathrm{mg}$.

4. Start the measurement by clicking on [START MEASUREMENT].

5. Select or create a new analysis group for storing the measuring data.

6. Creation an analysis sequence.

- Add the desired number of samples to the sample table with

- Enter the following data:

\begin{tabular}{ll}
\hline Column & Description \\
\hline SAMPLING POSITION & $\begin{array}{l}\text { Position of the sample on the sample rack } \\
\text { The sample rack must only be populated with ascending position } \\
\text { numbers. However, it does not need to be without gaps. }\end{array}$ \\
\hline NAME & Sample ID \\
& With \\
\hline ANALYSIS TYPE & Selection of the analysis type (SAMPLE, DAILY FACTOR DETERMINATION, \\
& CALIBRATION MEASUREMENT, AQA MEASUREMENT or DET. BOAT BLANK) \\
\hline NOMINAL VALUE & Target concentration for AOS Standards \\
\hline OPERANDS & Input of the sample weight \\
\hline
\end{tabular}

- Populate the autosampler. Use the and buttons to move the sample rack to the desired position.

- Click on in the sequence row to release it for analysis. All sequence rows can be released by clicking on the 18 button.

$\checkmark$ Sequence rows released for analysis have a green fill.

7. Click on [START MEASUREMENT].

The sample is pyrolized in the argon flow at temperatures between 300 and $600{ }^{\circ} \mathrm{C}$ (front furnace zone). The resulting pyrolysis products are completely oxidized in the oxygen flow at $1000{ }^{\circ} \mathrm{C}$.

- Select a suitable program for the feed of the sampler with an extended dwell time in the heating area at the furnace inlet.

- For highly reactive samples use the optional flame sensor. 


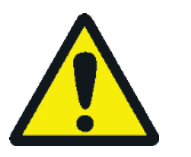

\section{CAUTION}

When feeding the furnace whilst simultaneously monitoring combustion protective goggles must be used.

- Start the measurement. Then move the boat into the furnace.

- Move the boat into the combustion tube up to just behind the gas sluice so that the center of the boat is at the height of the front plate. Allow the boat to briefly heat through.

- Then carefully move the boat into the hot zone of the combustion furnace. Constantly monitor the end of the oxygen supply tube whilst doing so. As soon as it lights up due to the combustion of the pyrolysis gases, hold the boat in the current position. Once the radiance has reduced, slowly move the boat on. When the boat lights up again, stop it again etc. until the boat is completely within the furnace (the position is marked by the stop of the sample feed). In this position, the volatile pyrolysis products are incinerated at $1000-1100{ }^{\circ} \mathrm{C}$.

- After moving the boat into the hot zone confirm the on-screen prompt with [OK].

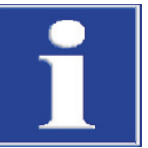

\section{NOTICE}

The boat must be moved extremely slowly to allow the pyrolysis gases to develop slowly and incinerate completely. If the sample is fed too quickly, this might lead to incomplete combustion and soot build-up in the analysis system, leading to incorrect measuring results.

$\checkmark \quad$ The analyzer starts processing the analysis sequence. The MEASUREMENT ANALYSIS window opens. The measuring routine starts with titration delay.

\subsubsection{Checking the split ratio}

The split ratio set must be checked before a measurement series with a standard and any deviation corrected.

The following standard concentrations are recommended:

\begin{tabular}{ll}
\hline Measuring cell & standard concentration \\
\hline "high concentration" & 1 molar $\mathrm{HCl}$ \\
\hline "sensitive" & 0.1 molar HCl
\end{tabular}

1. Transfer $50 \mu \mathrm{l}$ of the standard on a ceramic mat in a boat into the hot furnace.

2. Perform the determination with the method:

- Repeat the measurement of the standard three times and determine the average value.

- Calculate the split factor F:

$$
\begin{array}{ll}
F= & a_{\text {soll }} / \overline{a_{i s t}} \\
a_{\text {soll }} & \text { expected absolute } \mathrm{Cl} \text { content in } \mu \mathrm{g} \\
\overline{a_{\text {ist }}} & \text { average absolute } \mathrm{Cl} \text { content from the } 3 \text { standard measurements }
\end{array}
$$


- Enter the calculated factor in the method on the tab CALIBRATION in the input field DAY FACTOR. Accept the value with [ACCEPT] for the subsequent measurements.

For the calculation of a new split factor the day factor must be set to a value of $1 \mathrm{n}$ the method on the tab CALIBRATION.

\subsubsection{Burning off quartz boats}

Quartz boats must be burned off

- before first use,

- after cleaning heavy contamination.

To do so perform the measurement routine with empty quartz boats.

\subsection{TIC/TOC determination with the automatic TIC solids module}

\subsubsection{Preparing the automatic TIC solids module for the analysis}

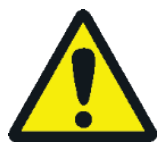

\section{WARNING}

Risk of electric short circuit! In the combustion furnace HTS1500 very high electrical currents occur in spite of a low voltage (max. $14 \mathrm{~V}$ ). The combustion tube is part of the cover of live components.

Only switch on the analyzer with the combustion tube inserted! Always switch off the analyzer from the mains switch at the rear of the device for conversions and maintenance to the combustion tube or combustion furnace.

\section{CAUTION}

There is a risk of burns at the hot the combustion furnace! Allow the basic device to cool down sufficiently before conversion!

The TIC reactor of the automatic TIC solids module consists of a quartz tube with inlets for acid and oxygen and a measuring gas outlet. The quartz tube is attached to the ceramic combustion tube with a coupling. The following components are required to connect the two tubes:

- Base element of the gas sluice for C/S measurements (with sealing rings)

- Pressure ring

- 2 sealing rings

- Knurled ring 


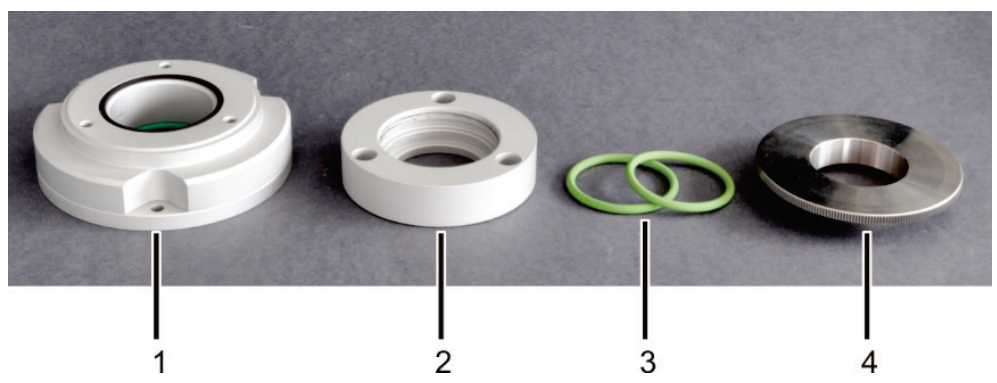

Figure 46 Components for connecting the TIC reactor and ceramic tube
1 Base element of the gas sluice 3 Sealing rings (in the Figure with black sealing ring for the pressure $\quad 4 \quad$ Knurled ring ring)
2 Pressure ring

The gas connection at the base element ( 1 in Figure 46) remains unattached during measurements with the automatic TIC solids module. The base element and pressure ring (2) are screwed together gas-tight to prevent ambient air entering the system or measuring gas escaping at this point.
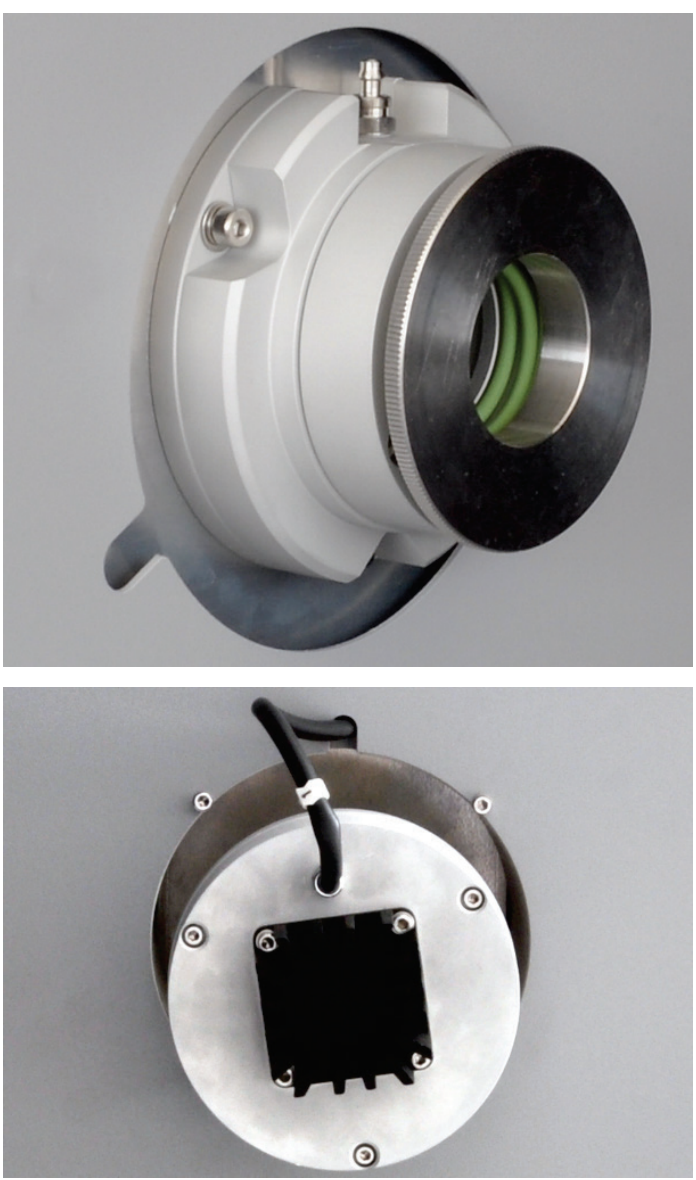

1. Assemble the components of the coupling for connecting the ceramic tube and TIC reactor.

Only tighten the knurled ring ( 4 in Figure 46) slightly.

2. Fit the coupling with 3 hexagon socket screws on the right-hand side of the multi EA 4000.

3. Slide the duct trap onto the ceramic combustion tube. Insert the ceramic tube with dust trap into the multi EA 4000 through the opening on the left-hand side.

Align the dust trap with the gas connection pointing up.

4. Attach the measuring gas hose (hose no. 1) to the dust trap. 

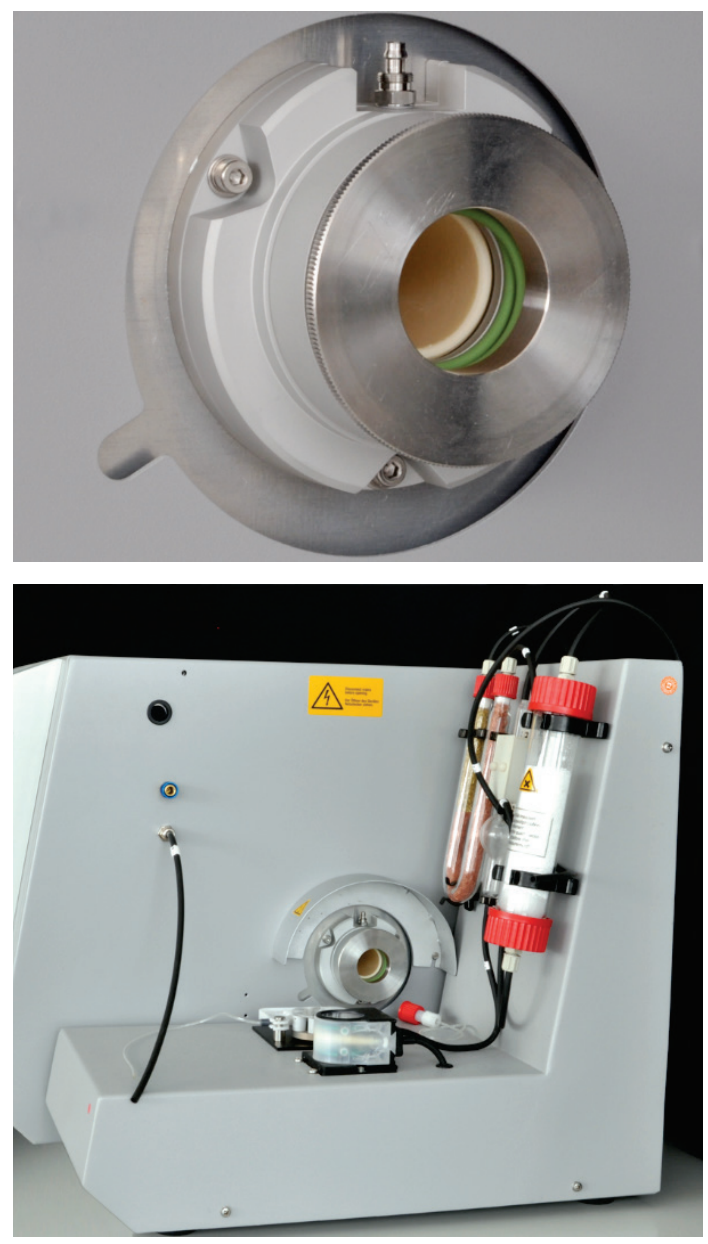

Connect the TIC reactor and sampler

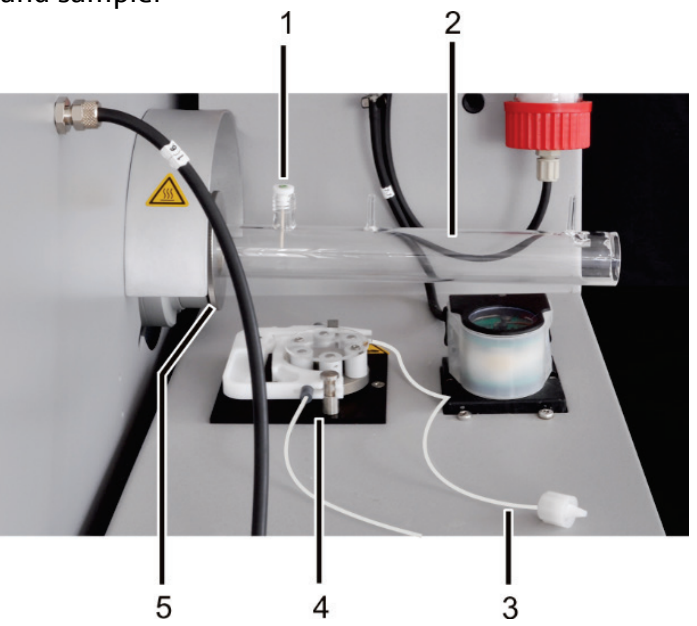

1 Ceramic cannula with sealing ring

2 Quartz glass TIC reactor

3 Pump hose with connection to TIC reactor

4 hose pump

5 Knurled ring
If the tube gets jammed, push it further without pressure by slightly rotating it. Insert the tube firmly into the seal of the gas sluice.

5. Place the dust trap contact guard on the left-hand side of the basic device.

6. Fit the heat guard above the gas sluice.

7. Unscrew the 2 spacers from the multi EA 4000.

8. Position the automatic TIC solids module to the right of the basic device. Move the TIC solids module as close to the wall of the basic device that the 2 white spacers at the TIC solids module touch the device wall.

9. Check the electrical connections and hose connections ( $\rightarrow$ see section "Positioning the automatic TIC solids module" p. 56ff.)

1. Slide the TIC reactor (2) into the coupling until it touches the ceramic tube. The connections of the TIC reactor must point up.

2. Attach the TIC reactor to the coupling. To do so, carefully tighten the knurled ring (5).

NOTICE! The reactor must be centered in the coupling.

If the TIC reactor cannot be inserted in this manner, unscrew the knurled ring. Push the knurled ring and the 2 green sealing rings onto the TIC reactor. Then insert the TIC reactor into the coupling and tighten.

3. Place the ceramic cannula with sealing ring (1) onto the port with the screw thread.

4. Clamp the pump hose in the cartridge of the hose pump (4).

The hose end with the connection to the reactor (3) must point towards the reactor. 

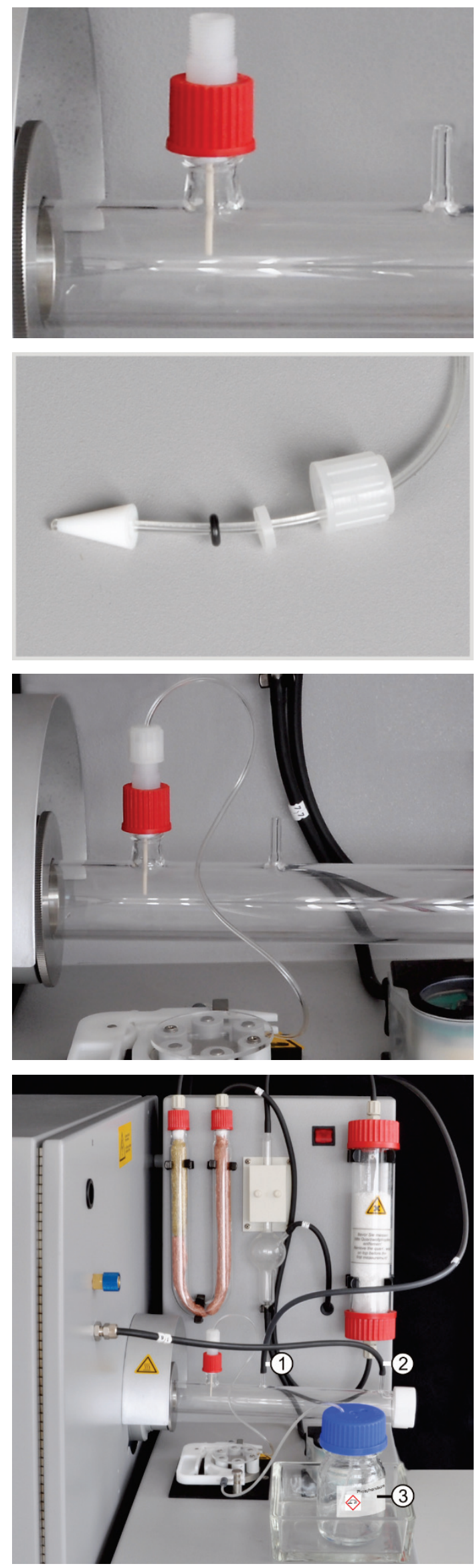

5. Secure the ceramic cannula with the red screw cap.

6. Check that the sealing cone, seals and screw cap have been fitted to the pump hose.

7. Screw the pump hose finger-tight onto the red screw cap. NOTICE! The TIC reactor can get hot. Install the pump hose so that it does not touch the hot reactor.

8. Connect the measuring gas outlet (1) with hose no. 72 to the top end of the cooling coil on the rear of the TIC solids module.

9. Slide the hose for the oxygen supply (no. 17) onto the reactor connection for the carrier gas (2).

NOTICE! Always support the reactor with one hand when attaching the hoses. With too much pressure on the gas cylinder, the TIC reactor might fracture.

10. Place the acid bottle (3) into a drip tray before the acid pump.

11. Feed the end of the pump hose through one of the openings in the screw cap into the acid bottle. 


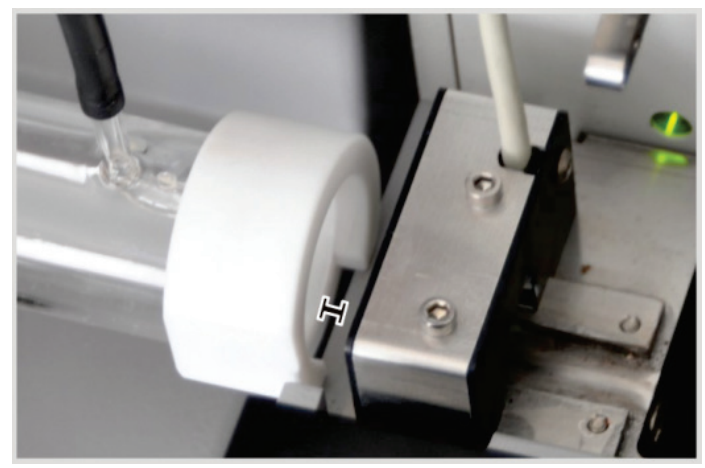

12. Slice the white PTFE ring onto the end of the TIC reactor.

13. Position the sampler FPG 48 and retrofit the boat storage $(\rightarrow$ see section "Installing and adjusting the autosampler FPG 48" p. 62).

Move the sampler towards the TIC solids module. The TIC reactor with the PTFE ring will rest on the edge of the sampler.

A gap of 2-4 mm must remain between the TIC reactor and the sampler to prevent tension from the thermal expansion of the ceramic tube.

14. Align the sampler until the ceramic boat can just be moved into the reactor and further into the furnace for TOC measurements.

15. Provide a container for the used ceramic boats to the right of the FPG 48 under the ejection rail.

\subsubsection{Reagents required}

The following reagents are required for TIC determination:

- $40 \%$ orthophosphoric acid (for the recommended differential method)

- $10 \%$ hydrochloric acid for TOC determination (for the direct method)

\subsubsection{TIC determination with the automatic TIC solids module}

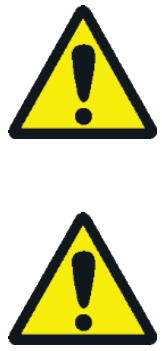

\section{CAUTION}

During autosampler operation there is a risk of burns at the hot boat and ceramic hook! After pulling out of the furnace the boat and hook remain hot for a long time.

\section{CAUTION}

Crushing hazard at the autosampler! The autosampler arm, the gripper and the boat carousel move during activation and initialization and measurement operation. Keep an adequate distance to avoid having your hands crushed.

When filling the autosampler: Only open the cover when the boat carousel is no longer moving.

1. Fill the acid bottle of the TIC solids module with orthophosphoric acid.

2. Switch on the basic device multi EA 4000, the C/S module, the automatic TIC solids module and the sampler FPG 48. Make sure to switch on the basic device both from the mains switch at the rear and the On/Off switch at the front.

$\checkmark \quad$ The status lights at the front of the devices illuminate.

Do not switch any $\mathrm{Cl}$ module present.

3. Start the multiWin program.

4. Change between the various analyzer modules. To do so, first activate the sensors: 
- Select the menu command DEVICE DEVICE - EDIT.

- Enable "C" in the list ELEMENTS.

- In the list COMbustion tube click on CeRAmic tUBE (CS).

- As StATES enable the option SOLID.

- Enable the option EJECTION RAIL.

5. Initialize the system by clicking on [INITIALIZE ANALYZER].

6. Load a method (menu item METHOD METHOD - ACTIVATE) or create a new method (menu item METHOD METHOD - NEW).

Select the parameter TIC (TIC content determination only).

7. After the run-in time set the following gas flows:

\begin{tabular}{lll}
\hline pump & $\mathrm{O}_{2}$ & $\mathrm{Ar} / \mathrm{O}_{2}$ \\
\hline $\begin{array}{l}\text { approx.1.7 I/min } \\
\text { corresponds to NOMINAL }=\end{array}$ & $2.5 \mathrm{I} / \mathrm{min}$ & $1.5 \mathrm{I} / \mathrm{min}$ \\
$100 \pm 10$ in the STATUS ANA- & & \\
LYZER window & & \\
\hline
\end{tabular}

Argon is not required for operation, oxygen is automatically available at the "Ar/ $\mathrm{O}_{2}$ " rotameter.

The analysis system now has time to settle down.

If the intake flow differs greatly or changes later, readjust the intake flow at the "pump" valve of the multi EA 4000.

8. Weigh the sample on a ceramic boat. The sample weight for TIC determination must be max. $50 \mathrm{mg}$. Cover the sample with some annealed quartz sand. The quartz sand improves the wetting of the sample with acid.

9. Start the measurement by clicking on [START MEASUREMENT].

10. Select or create a new analysis group for storing the measuring data.

11. Create an analysis sequence.

- Add the desired number of samples to the sample table with

- Enter the following data:

\begin{tabular}{ll}
\hline Column & Description \\
\hline SAMPLING POSITION & $\begin{array}{l}\text { Position of the sample on the sample rack } \\
\text { The sample rack must only be populated with ascending po- } \\
\text { sition numbers. However, it does not need to be without } \\
\text { gaps. }\end{array}$ \\
\hline NAME & $\begin{array}{l}\text { Sample ID } \\
\text { With } 78 \text { an automatic sample ID can be created. }\end{array}$ \\
\hline ANALYSIS TYPE & $\begin{array}{l}\text { Selection of the analysis type (SAMPLE, DAILY FACTOR DETERMI- } \\
\text { NATION, CALIBRATION MEASUREMENT, AOA MEASUREMENT or DET. } \\
\text { BOAT BLANK) }\end{array}$ \\
\hline TaMINAL VALUE & $\begin{array}{l}\text { Target concentration for calibration standards or AOS } \\
\text { standard }\end{array}$ \\
\hline OPERANDS & Input of the sample weight \\
\hline
\end{tabular}


- Populate the autosampler. Use the and buttons to move the sample rack to the desired position.

- Click on in the sequence row to release it for analysis. All sequence rows can be released by clicking on the button.

$\checkmark$ Sequence rows released for analysis have a green fill.

12. Click on [START MEASUREMENT].

$\checkmark \quad$ The analyzer starts processing the analysis sequence. The MEASUREMENT ANALYSIS window opens.

- The boat pick-up picks up a boat from the sample rack and places it onto the ceramic hook.

- The ceramic hook moves the boat into the TIC reactor. As soon as the boat has reached the position under the ceramic cannula, the acid addition starts automatically. During the slow boat feed acid is added to the entire sample.

- The measuring gas from the purged TIC is passed via the measuring gas drying and cleaning of the automatic TIC solids module to the detector in the C/S module. The oxygen supply at the inlet of the TIC reactor prevents measuring gas from escaping through the open inlet.

\subsubsection{TOC determination based on differentiation method}

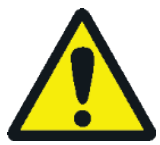

\section{CAUTION}

During autosampler operation there is a risk of burns at the hot boat and ceramic hook! After pulling out of the furnace the boat and hook remain hot for a long time.

\section{CAUTION}

Crushing hazard at the autosampler! The autosampler arm, the gripper and the boat carousel move during activation and initialization and measurement operation. Keep an adequate distance to avoid having your hands crushed.

When filling the autosampler: Only open the cover when the boat carousel is no longer moving.

This is the method recommended here.

1. Fill the acid bottle of the TIC solids module with $40 \%$ orthophosphoric acid.

2. Switch on the basic device multi EA 4000, the C/S module, the automatic TIC solids module and the FPG 48. Make sure to switch on the basic device both from the mains switch at the rear and the On/Off switch at the front.

$\checkmark$ The status lights at the front of the devices illuminate.

Do not switch any $\mathrm{Cl}$ module present.

3. Start the multiWin program.

4. Change between the various analyzer modules. To do so, first activate the sensors: 
- Select the menu command DEVICE DEVICE - EDIT.

- Enable "C" in the list ELEMENTS.

- In the list COMbustion tube click on CeRAmic tUBE (CS).

- As StATES enable the option SOLID.

- Enable the option EJECTION RAIL.

5. Initialize the system by clicking on [INITIALIZE ANALYZER].

6. Load a method (menu item METHOD METHOD - ACTIVATE) or create a new method (menu item METHOD METHOD - NEW).

Select the TOC parameters.

7. After the run-in time set the following gas flows:

\begin{tabular}{lll}
\hline pump & $\mathrm{O}_{2}$ & $\mathrm{Ar} / \mathrm{O}_{2}$ \\
\hline $\begin{array}{l}\text { approx.1.7 I/min } \\
\text { corresponds to NOMINAL }=\end{array}$ & $2.5 \mathrm{I} / \mathrm{min}$ & $1.5 \mathrm{I} / \mathrm{min}$ \\
$100 \pm 10$ in the STATUS ANA- & & \\
LYZER window & & \\
\hline
\end{tabular}

The analysis system now has time to settle down.

If the intake flow differs greatly or changes later, readjust the intake flow at the "pump" valve of the multi EA 4000.

8. Weigh the sample on 2 ceramic boats.

The sample weight on boat 1 for TIC determination must be max. $50 \mathrm{mg}$. Cover the sample with some annealed quartz sand. The quartz sand improves the wetting of the sample with acid.

9. Start the measurement by clicking on [START MEASUREMENT].

10. Create or select an analysis group for storing the measuring data.

11. Create an analysis sequence.

- Add the desired number of samples to the sample table with

- Enter the following data:

\begin{tabular}{ll}
\hline Column & Description \\
\hline SAMPLING POSITION & $\begin{array}{l}\text { Position of the sample on the sample rack } \\
\text { The sample rack must only be populated with ascending position } \\
\text { numbers. However, it does not need to be without gaps. }\end{array}$ \\
\hline NAME & Sample ID \\
& With \\
\hline ANALYSIS TYPE & Selection of the analysis type (SAMPLE, DAILY FACTOR DETERMINATION, \\
& CALIBRATION MEASUREMENT, AQA MEASUREMENT or DET. BOAT BLANK) \\
\hline NOMINAL VALUE & Target concentration for calibration standards or AOS standard \\
\hline OPERANDS & Input of the sample weight
\end{tabular}

- Populate the autosampler. Use the and buttons to move the sample rack to the desired position. 
- Click on in the sequence row to release it for analysis. All sequence rows can be released by clicking on the button.

$\checkmark$ Sequence rows released for analysis have a green fill.

12. Click on [START MEASUREMENT].

$\checkmark \quad$ The analyzer starts processing the analysis sequence. The MEASUREMENT ANALYSIS window opens.

- The boat pick-up picks up boat 1 from the sample rack and places it onto the ceramic hook.

- The ceramic hook moves the boat into the TIC reactor. As soon as the boat has reached the position under the ceramic cannula, the acid addition starts automatically. During the slow boat feed acid is added to the entire sample.

- The measuring gas from the purged TIC is passed via the measuring gas drying and cleaning of the automatic TIC solids module to the detector in the C/S module.

- Boat 1 is then pulled out of the TIC reactor and placed onto the ejection rail.

- The sampler picks up boat 2 with the same sample from the sample rack and moves it directly into the hot zone of the furnace. Here it is incinerated in the oxygen flow. The total carbon content (TC) is determined in this manner.

- The difference of the two measured values (TC-TIC) is then generated and output as TOC result in the program.

During extended measurement interruptions the gas supply can be turned down in the multiWin program to save gas accordingly. However, the gas supply must be ensured again in good time (approx. $10 \mathrm{~min}$.) before starting the measurement. 


\subsubsection{TOC measurement using direct determination}

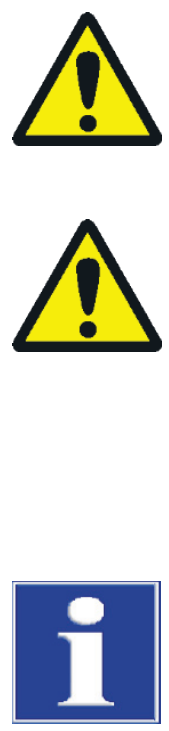

\section{CAUTION}

During autosampler operation there is a risk of burns at the hot boat and ceramic hook! After pulling out of the furnace the boat and hook remain hot for a long time.

\section{CAUTION}

Crushing hazard at the autosampler! The autosampler arm, the gripper and the boat carousel move during activation and initialization and measurement operation. Keep an adequate distance to avoid having your hands crushed.

When filling the autosampler: Only open the cover when the boat carousel is no longer moving.

\section{NOTICE}

For the TOC measurement with the automatic TIC solids module the differential method is preferred. In the direct method the combustion tube, the halide trap and the detectors are loaded with acid, leading to wear.

Only use $\mathrm{HCl}$ acid to purge the TIC from the sample. Phosphoric acid is unsuitable for the direct determination of the TOC.

Perform a measurement as follows:

1. Fill the acid bottle with $10 \%$ hydrochloric acid.

2. Switch on the basic device multi EA 4000, the C/S module, the automatic TIC solids module and the FPG 48. Make sure to switch on the basic device both from the mains switch at the rear and the On/Off switch at the front.

$\checkmark$ The status lights at the front of the devices illuminate.

Do not switch any $\mathrm{Cl}$ module present.

3. Start the multiWin program.

4. Change between the various analyzer modules. To do so, first activate the sensors:

- Select the menu command DEVICE DEVICE - EDIT.

- Enable "C" in the list ELEMENTS.

- In the list Combustion tube click on Ceramic tUBe (CS).

- As StATES enable the option SOLID.

- Enable the option EJECTION RAIL.

5. Initialize the system by clicking on [INITIALIZE ANALYZER].

6. Load a method (menu item METHOD METHOD - ACTIVATE) or create a new method (menu item METHOD METHOD - NEW).

Select the IC/OC parameters.

7. After the run-in time set the following gas flows: 


\begin{tabular}{lll}
\hline pump & $\mathrm{O}_{2}$ & $\mathrm{Ar} / \mathrm{O}_{2}$ \\
\hline approx.1.7 I/min & $2.5 \mathrm{I} / \mathrm{min}$ & $1.5 \mathrm{I} / \mathrm{min}$ \\
corresponds to NOMINAL $=$ & & \\
$100 \pm 10$ in the STATUS ANA- & & \\
LYZER window & & \\
\hline
\end{tabular}

The analysis system now has time to settle down.

If the intake flow differs greatly or changes later, readjust the intake flow at the "pump" valve of the multi EA 4000.

8. Weigh the sample on a ceramic boat.

9. Start the measurement by clicking on [START MEASUREMENT].

10. Select or create a new analysis group for storing the measuring data.

11. Create an analysis sequence.

- Add the desired number of samples to the sample table with

- Enter the following data:

\begin{tabular}{ll}
\hline Column & Description \\
\hline SAMPLING POSITION & $\begin{array}{l}\text { Position of the sample on the sample rack } \\
\text { The sample rack must only be populated with ascending po- } \\
\text { sition numbers. However, it does not need to be without } \\
\text { gaps. }\end{array}$ \\
\hline Sample ID \\
With \\
Selection of the analysis type (SAMPLE, DAILY FACTOR DETERMI- \\
NATION, CALIBRATION MEASUREMENT, AQA MEASUREMENT or DET. \\
BOAT BLANK) \\
\hline Target concentration for calibration standards or AOS \\
standard \\
\hline OPERANALS
\end{tabular}

- Populate the autosampler. Use the and buttons to move the sample rack to the desired position.

- Click on in the sequence row to release it for analysis. All sequence rows can be released by clicking on the button.

$\checkmark$ Sequence rows released for analysis have a green fill.

12. Click on [START MEASUREMENT].

$\checkmark \quad$ The analyzer starts processing the analysis sequence. The MEASUREMENT ANALYSIS window opens.

- The boat pick-up picks up a boat from the sample rack and places it onto the ceramic hook.

- The ceramic hook moves the boat into the TIC reactor. As soon as the boat has reached the position under the ceramic cannula, the acid addition starts automatically. During the slow boat feed acid is added to the entire sample. 
- The measuring gas from the purged TIC is passed via the measuring gas drying and cleaning of the automatic TIC solids module to the detector in the C/S module.

- The same boat is then moved further into the furnace to determine the TOC (after removing the TIC) through combustion in the oxygen flow.

\subsection{TIC determination with the manual TIC solids module}

\subsubsection{Preparing the manual TIC solids module and analyzer}

The manual TIC solids module only works in conjunction with the C/S module. Here, the measuring gas is not sucked through the detector with the pump of the basic device, but is purged with acid in the closed system and transported with the carrier gas (oxygen) to the detector.

1. Detach the "pump" and "analyte" connection between the multi EA 4000 and the C/S module. (All other connections can remain as they are).

2. Check the hoses, see hose diagram (Figure 38 p. 60 and Figure 39 p. 61).

3. Connect the manual TIC solids module to the C/S module:

\begin{tabular}{lll}
\hline C/S module connections & & Target \\
\hline "PC" & $\Rightarrow$ & USB port for connection to the computer \\
\hline "scale" & $\Rightarrow$ & External scales (optional) \\
\hline Socket for mains plug & $\Rightarrow$ & Mains connection \\
\hline "analyte" connection & $\Rightarrow$ & TIC module "analyte" \\
\hline $\begin{array}{l}\text { Additional TIC module con- } \\
\text { nections }\end{array}$ & & \\
\hline "O ${ }_{2}$ " & $\Rightarrow$ & $\begin{array}{l}\text { Oxygen gas connection with quick-release coupling } \\
\text { Set oxygen inlet pressure to } 200-400 \mathrm{kPa} \\
\text { (29 - 58 psi). }\end{array}$ \\
\hline Socket for mains plug & $\Rightarrow$ & Mains connection \\
\hline
\end{tabular}

\section{NOTICE}

Always interrupt the "pump" connection between the $\mathrm{C} / \mathrm{S}$ module and the multi EA 4000. Otherwise, phosphoric acid might be inducted into the system and damage the detectors.

For C/S measurements the "pump" connections must be restored again.

\subsubsection{Performing a TIC measurement}

Only use dry $50 \mathrm{ml}$ Erlenmeyer flasks with a standard ground joint of NS 29/32 for analysis purposes.

The sample should be pulverized as finely as possible and homogeneous. 
In addition to the safety instructions for the analyzer multi EA 4000 provided in section "Safety instructions" p. 10, the following instructions also apply specifically when operating the manual solids module:

\section{CAUTION}

The reactor vessel and the hoses for supplying acid contain phosphoric acid! Phosphoric acid is irritating to eyes, skin and mucous membranes!

Perform slow metering operations with the dispenser to avoid overpressure!

Wear protective gloves and protective goggles when handling concentrated acid! Rinse affected skin with water immediately.

\section{CAUTION}

Observe the following during the operation of the magnetic stirrer:

- Do not operate the heating plate without supervision!

- Avoid overheating the acid bath! Limit the maximum temperature to $80^{\circ} \mathrm{C}$.

- Place the glass flask in the center of the heating plate to ensure that the magnet does not hit against the wall of the flask.

- Do not set the stirring speed of the magnet too high.

1. Fill the acid bottle with $40-50 \%$ phosphoric acid. Place the acid bottle into the plastic insert in the upper housing.

2. Screw the dispenser onto the bottle. Connect the hose for supplying acid to the valve and to the TIC head.

3. Switch on the basic device multi EA 4000, the C/S module and the manual TIC solids module. Make sure to switch on the basic device both from the mains switch at the rear and the On/Off switch at the front.

$\checkmark \quad$ The status lights at the front of the devices illuminate.

4. Switch on the heating plate.

Adjust the temperature using the left rotary switch on the heating plate. A temperature setting of approx. $80^{\circ} \mathrm{C}$ is recommended. If the temperature selected is too high, too much water will evaporate; if the temperature is too low, the reaction will take longer.

5. Start the multiWin program.

6. Change between the various analyzer modules. To do so, first activate the sensors:

- Select the menu command DEVICE DEVICE - EDIT.

- Enable the ELEMENTS to be analyzed.

- In the list Combustion tube enable the option Ceramic tube (CS).

- As STATES enable the option SOLID.

- Enable the option TIC MANUAL.

7. Initialize the system by clicking on [INITIALIZE ANALYZER].

8. Load a method (menu item METHOD METHOD - ACTIVATE) or create a new method (menu item METHOD METHOD - NEW) with the parameter TIC (determining TIC content only). 
In the method on the PROCESS tab set the furnace temperature to a value of $0{ }^{\circ} \mathrm{C}$. This means the combustion furnace is not monitored and the analyzer released for the measurement.

9. Adjust the oxygen flow at the valve to $16 \mathrm{l} / \mathrm{h}$.

10. Weigh the finely pulverized sample into the Erlenmeyer flask.

When transferring the sample, ensure that it does not adhere to the wall of the flask. Only the bottom of the Erlenmeyer flask is covered with acid. Any sample material adhering to the walls will not be included in the analysis.

11. Carefully place the magnetic stirring rod into the Erlenmeyer flask and position the flask in the center of the heating plate.

12. Place the TIC head onto the flask. Rotate press the flask and the TIC head and slightly press them together. The ground joint connection must be gas-tight to ensure no measuring gas is lost.

13. Start the measurement by clicking on [START MEASUREMENT].

14. Select or create a new analysis group for storing the measuring data.

15. Create an analysis sequence.

- Add the desired number of samples to the sample table with

- Enter the following data:

\begin{tabular}{ll}
\hline Column & Description \\
\hline NAME & Sample ID \\
& With an automatic sample ID can be created. \\
\hline ANALYSIS TYPE & $\begin{array}{l}\text { Selection of the analysis type (SAMPLE, DAILY FACTOR DETERMI- } \\
\text { NATION, CALIBRATION MEASUREMENT, AQA MEASUREMENT or DET. } \\
\text { BOAT BLANK) }\end{array}$ \\
\hline NOMINAL VALUE & $\begin{array}{l}\text { Target concentration for calibration standards or AOS stand- } \\
\text { ard }\end{array}$ \\
\hline OPERANDS & Input of the sample weight \\
\hline
\end{tabular}

- Click on in the sequence row to release it for analysis. All sequence rows can be released by clicking on the button.

$\checkmark$ Sequence rows released for analysis have a green fill.

16. Click on [START MEASUREMENT].

17. Enter the sample weight in [mg].

18. Wait for the ready message of the analyzer. Before the measurement is started, the analyzer must be conditioned with oxygen. For this, the air must be driven out of the flask and the hose system and only oxygen must still reach the detector. Depending on the flask size, this can take up to 2 minutes.

- $\quad$ After the "PlEASE PRESS [OK] TO StART INTEGRATION AND THEN ADD ACID!" message appears, click on [OK].

- Initially meter $2 \mathrm{ml}$ phosphoric acid. 
- Slowly adjust the stirrer to stage 5. The sample must not be spun against the wall of the flask. Jolting or rapid movement of the stirrer must therefore always be avoided.

- Add $2 \mathrm{ml}$ acid evenly 1-3 times (dependent on the concentration and sample volume).

- Then close the valve in the metering pump stop cock.

Since the release of $\mathrm{CO}_{2}$ is also dependent on the metering speed and the stirring speed of the stirrer magnet, always ensure the same cycle and the same speeds are used in each measurement.

$\checkmark \quad$ The analyzer starts processing the analysis sequence. The MEASUREMENT ANALYSIS window opens.

19. After completing the measurement stop the magnetic stirrer and open the flask: Detach the TIC head with a twisting motion. Move the arm of the stand-up, swivel it back and lock it in this position.

20. Clean and dry the flask.

21. Connect a dry Erlenmeyer flask to the TIC head during breaks in measurements. This maintains the oxygen flush (conditioning) and the dry gas flow frees the hose system of moisture residue.

22. Keep the heating plate at a constant temperature. Only switch off the thermostat during longer measuring breaks. 


\section{$7 \quad$ Maintenance and care}

Maintenance and care of the analyzer are described in this section separately for the individual modules. Observe the notes for all modules combined in your system.

\subsection{Basic device multi EA 4000}

Maintenance intervals

\begin{tabular}{ll}
\hline Maintenance task & Maintenance interval \\
\hline Clean and maintain the device & Weekly \\
\hline Check fastening screws for tight fit & Monthly \\
\hline Check all screw connections for tight fit & Weekly \\
\hline
\end{tabular}

\subsubsection{Clean and maintain the device}

- Wipe off chemical splashes (acid, electrolyte solution) with cellulose immediately.

- Clean the device with a damp cloth.

- Do not wet the safety notices at the device with solvent. Replace damaged safety notices.

\subsubsection{Check tube connection}

Screw connections of various size and materials are used to connect the hoses to the individual components (halide trap, drying tube, adsorption tube etc.).

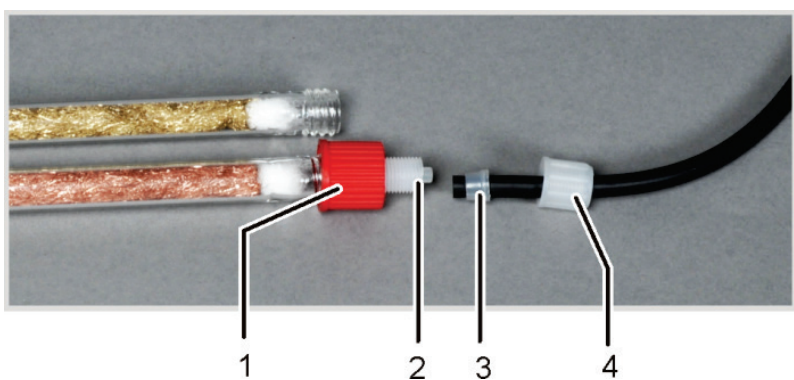

1 Union nut

2 Basic screw element

3 Conical sealing ring

4 Union nut

Figure 47 Screw connection at the halide trap

- The narrow side of the conical sealing rings points to the hose end.

- Always tighten the screw connections by hand without using tools.

- Always place the union nuts straight onto the threat without twisting.

- Make sure that the flexible hoses are not twisted or kinked. 


\subsection{Operation with $\mathrm{C} / \mathrm{S}$ module}

Maintenance intervals

\begin{tabular}{ll}
\hline Maintenance task & Maintenance interval \\
\hline $\begin{array}{l}\text { Inspect ceramic tube for cracks and visible } \\
\text { damage, replace if necessary }\end{array}$ & Every three months \\
\hline Inspect and clean dust trap & $\begin{array}{l}\text { Monthly (dependent on combustion and } \\
\text { sample matrix) }\end{array}$ \\
\hline $\begin{array}{l}\text { Inspect the dust filter, replace in case of visible } \\
\text { contamination }\end{array}$ & $\begin{array}{l}\text { Monthly (dependent on combustion and } \\
\text { sample matrix) }\end{array}$ \\
\hline Changing the desiccant in the drying tube & $\begin{array}{l}\text { As required (blackening or clumping due to } \\
\text { moisture absorption) }\end{array}$ \\
\hline Replace the halide trap & $\begin{array}{l}\text { when half of the copper wool or the brass } \\
\text { wool is discolored }\end{array}$ \\
\hline
\end{tabular}

\subsubsection{Inspect and replace ceramic tube}
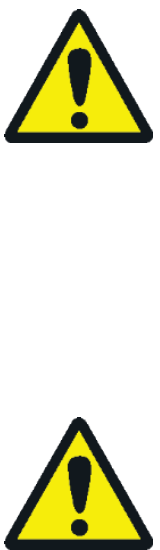

Removing the ceramic tube

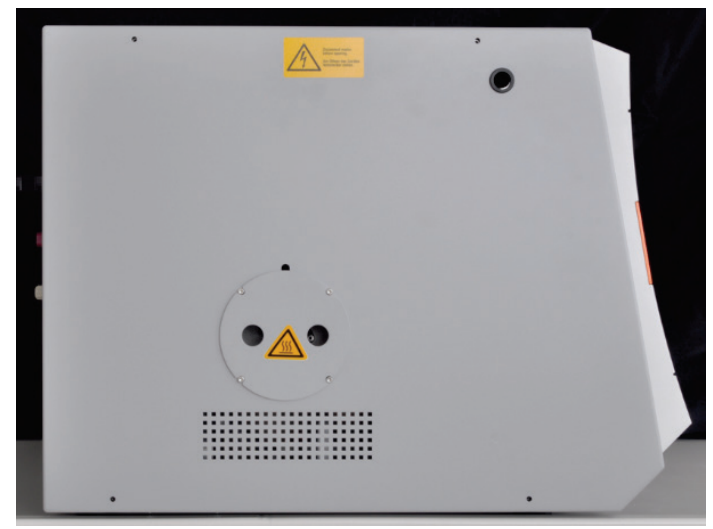

\section{WARNING}

Risk of electric short circuit! In the combustion furnace HTS1500 very high electrical currents occur in spite of a low voltage (max. $14 \mathrm{~V}$ ). The combustion tube is part of the cover of live components.

Only switch on the analyzer with the combustion tube inserted! Always switch off the analyzer from the mains switch at the rear of the device for conversions and maintenance to the combustion tube or combustion furnace.

\section{CAUTION}

There is a risk of burns on the combustion furnace! Only remove the combustion tube when the device is cold or allow the device to cool down sufficiently (best overnight)!
1. Switch off the basic device from the mains switch, pull the mains switch out of the outlet and disconnect the gas supply.

2. Create at least $50 \mathrm{~cm}$ space on the left side of the basic device. To do so, move the detector module aside or turn it to the back to expose the opening of the dust trap.

3. Pull the contact guard off the opening. The dust trap is now visible. 

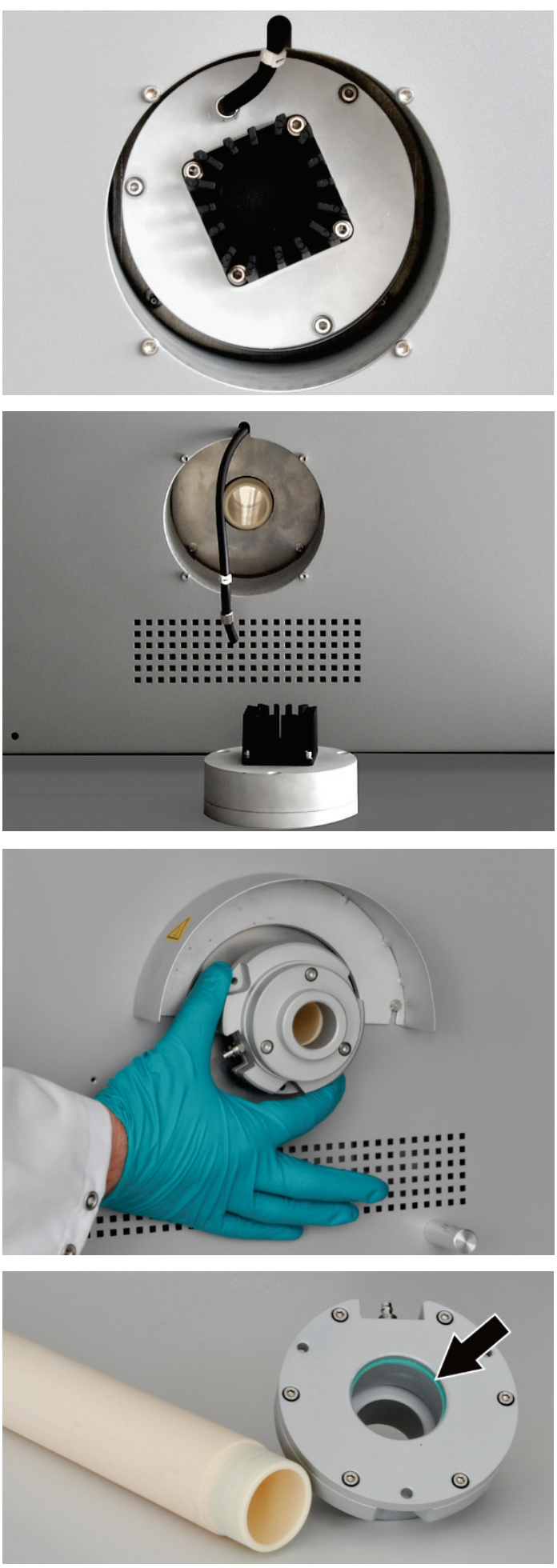

4. Detach the measuring gas hose (hose no. 1) from the dust trap.

5. Slightly pull the dust trap to detach it.

NOTICE! The dust trap might come loose abruptly. Support yourself with your hands when pulling.

The ceramic tube might come loose with the dust trap. In this case, carefully pull the tube out of the furnace with a twist.

6. Hold the ceramic tube from the chamfered end and turn it carefully to detach it. Carefully pull the tube out with a twisting motion.

7. If the ceramic tube does not come loose, unscrew the gas sluice on the right-hand side of the basic device. To this end move accessories (e.g. FPG 48) aside. Detach the three hexagon socket screws at the sluice.

8. Pull out the ceramic tube with gas sluice from the basic device through the opening on the right-hand side.

9. Pull the gas sluice off the ceramic tube with a twisting motion.

10. Inspect the wide green sealing ring in the gas sluice (see arrow) for cracks or brittle spots.

11. Replace the sealing ring if necessary. To do so, remove the sealing ring with tweezers and replace it with a new ring.

12. Remove the quartz wool from the ceramic tube.
Removing a broken ceramic tube
If the ceramic tube is removed from the furnace without due care, it might break into two halves. The ceramic tube can also break during heating in the furnace if tension occurs in the tube e.g. due to traces of moisture.

If the ceramic tube is broken, only a fraction of the tube is removed with the dust trap. The other broken part must be removed through the opening for the gas sluice:

1. Create some space on the right side of the basic device. To do so move accessories (sampler FPG 48, automatic TIC solids module) aside. 
Cleaning the ceramic tube

2. Detach the 3 fastening screws for the gas sluice and remove the gas sluice.

3. Remove the fractured parts of the ceramic tube from the furnace.

NOTICE! The heating elements of the furnace must not be damaged when removing fractured pieces!

1. Blow out dust from the ceramic tube with compressed air. Remove deposits with a brush.

2. Rinse the ceramic tube with ultrapure water and allow it to dry thoroughly.

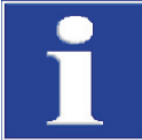

Installing the ceramic tube

\section{NOTICE}

With residual moisture there is the risk that the ceramic tube bursts when heated in the furnace! Dry the ceramic tube thoroughly after cleaning before re-use.

1. Carefully slide the ceramic tube with the gas sluice fitted through the opening in the right-hand side panel of the basic device. When a resistance can be felt, push the tube with a twisting motion further up to the stop. The chamfered tube end must be visible through the opening in the left-hand side panel.

2. Screw the gas sluice with 3 hexagon socket screws to the basic device. The gas connection must point to the front of the basic device. Attach the oxygen hose (hose no. 17) to the gas sluice.

3. Place the dust trap onto the ceramic tube. Align the dust trap with the gas connection pointing up. Press the dust trap slightly against the tube towards the tube axis until the dust trap slips onto the tube and cannot be moved further.

4. Connect the measuring gas hose (hose no. 1) to the gas connection at the dust trap.

5. Push the dust trap contact guard into the opening in the left-hand side panel of the basic device.

6. Position the detector module and accessories back next to the basic device.

\subsubsection{Cleaning the dust trap}
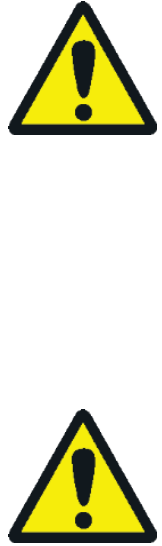

\section{WARNING}

Risk of electric short circuit! In the combustion furnace HTS1500 very high electrical currents occur in spite of a low voltage (max. $14 \mathrm{~V}$ ). The combustion tube is part of the cover of live components.

Only switch on the analyzer with the combustion tube inserted! Always switch off the analyzer from the mains switch at the rear of the device for conversions and maintenance to the combustion tube or combustion furnace.

\section{CAUTION}

There is a risk of burns on the combustion furnace! Only remove the dust trap when the device is cold or allow the device to cool down sufficiently (best overnight)!

The dust trap must be cleaned:

- when larger amounts of dust are deposited in the dust filter 
- when the pump flow drops as an indication of clogging

Check monthly whether the dust filter on the front of the device is clogged. If so, replace the dust filter and clean the dust trap.

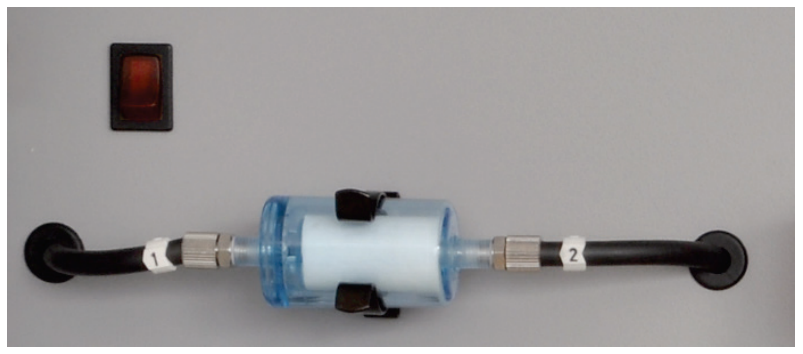

Figure 48 Dust filter
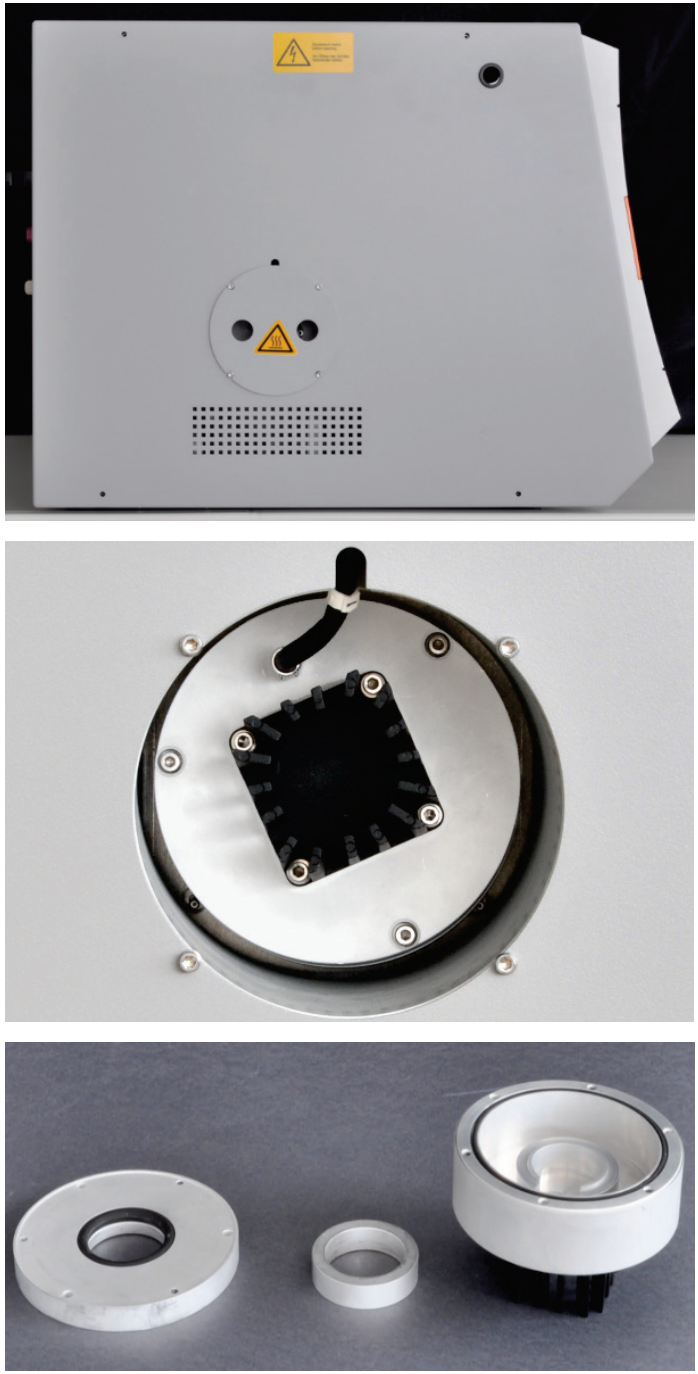

1. Create at least $50 \mathrm{~cm}$ space on the left side of the basic device. To do so, move the detector module aside or turn it to the back to expose the opening of the dust trap.

2. Pull the contact guard off the opening. The dust trap is now visible.

3. Detach the measuring gas hose (hose no. 1) from the dust trap.

4. Slightly pull the dust trap to detach it.

NOTICE! The dust trap might come loose abruptly. Support yourself with your hands when pulling.

5. Open the dust trap. To do so, undo the 3 hexagon socket screws on the side of the cooling ribs.

6. Remove dust with a brush from the interior of the dust trap.

7. Inspect the 2 sealing rings and replace if necessary.

8. Rinse the dust trap with ultrapure water. Also clean the gas connection first with ultrapure water, then with Ethanol. Allow the dust trap to dry thoroughly.

9. Re-assemble the dust trap. 


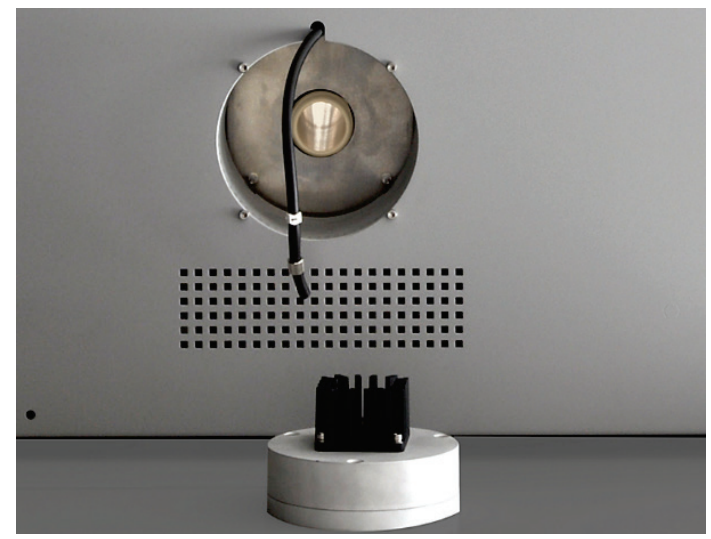

10. Place the dust trap onto the ceramic tube and align it with the gas connection pointing up. Press the dust trap slightly against the tube towards the tube axis until the dust trap slips onto the tube and cannot be moved further.

11. Connect the measuring gas hose (hose no. 1 ) to the gas connection at the dust trap.

12. Push the contact guard into the opening in the left-hand side panel of the basic device.

13. Position the detector module and accessories back next to the basic device.

\subsubsection{Changing the desiccant in the drying tube}

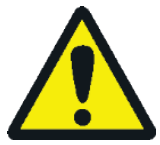

\section{CAUTION}

Danger of irritation of eyes, skin and respiratory system! Wear suitable physical protection when handling magnesium perchlorate and avoid the creation of dust during refilling. Keep magnesium perchlorate away from flames. The oxidant can make a fire worse.

Drying tubes are used in the following measurement arrangements:

- C/S measurement at the multi EA 4000 basic device

- TIC measurement: in the corresponding TIC solids modules

The desiccant must be changed if water absorption is visible. If the desiccant is discolored by rust or other particles, it must also be changed immediately.

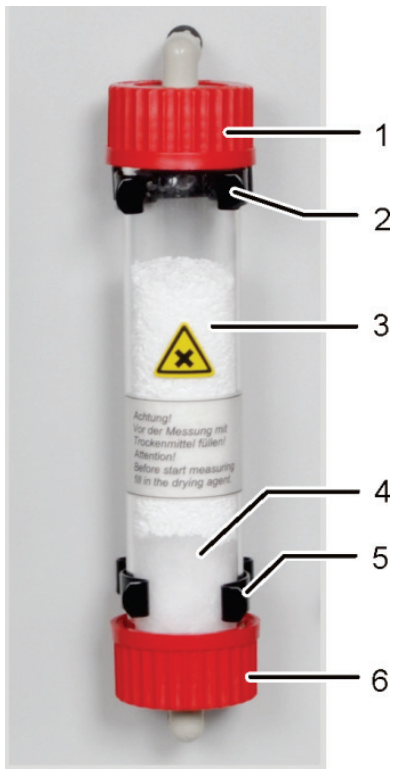

1,6 Screw closures

2, 5 Retention clips

3 Desiccant

(magnesium perchlorate)

4 Quartz wool
1. Detach the screw closures at the glass tube.

NOTICE! The seals must not be lost and must be reinstalled in the same manner.

2. Remove the desiccant and the quartz wool. Dispose of the desiccant correctly.

3. Rinse the glass tube and let it dry.

4. Seal one end of the glass tube approx. $2 \mathrm{~cm}$ thick with quartz wool.

5. Fill the glass tube with $50--60 \mathrm{~g}$ of fresh desiccant (magnesium perchlorate).

6. Firmly screw the glass tube in and push it back into the holder. Do not kink the hoses. 


\subsubsection{Replace the halide trap}

Halide traps are used in the following measurement arrangements:

- TC measurement at the multi EA 4000 basic device

- $\mathrm{Cl}$ measurement in the $\mathrm{Cl}$ module

- TIC measurement: in the corresponding TIC solids modules

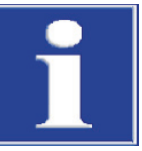

\section{NOTICE}

Risk of damage to optical and electronic components (detectors, flow sensors) from aggressive combustion products if the copper wool in the halide trap is used up!

Replace the complete filling of the halide trap as soon as half of the copper wool or the brass wool is discolored.

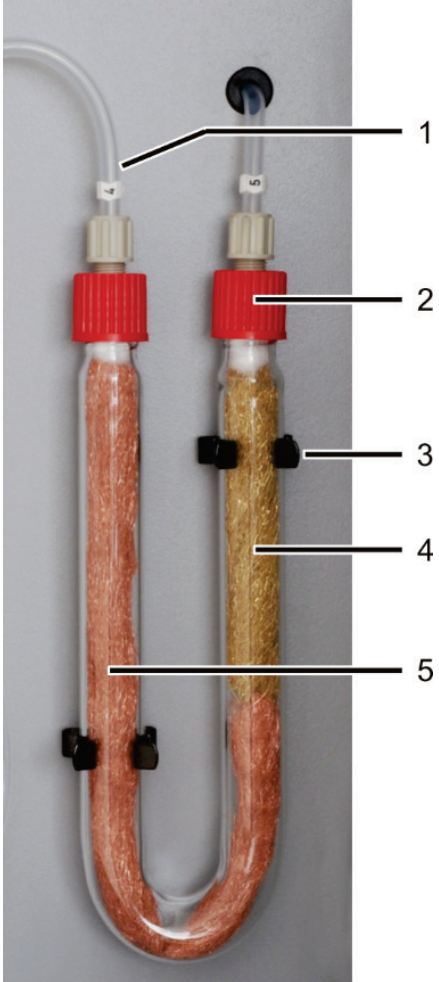

Gas inlet (hose no. 4)

Gas outlet (hose no. 5

Clamp

Brass wool

Copper wool
1. Unscrew the red union nuts from the U-tube and pull the U-tube out of the clamps (3).

2. Pull out the depleted copper wool or brass wool from the U-tube with a tweezers or a small hook.

3. Inspect the U-tube for cracks.

Only reuse a fully intact $U$ tube!

4. Rinse the U-tube with ultrapure water and allow it to dry well.

5. Fill the U-tube with new copper wool and brass wool using tweezers or a small hook.

Replace the complete contents of the U-tube. When filling the halide trap, make sure that the copper wool and brass wool is not compacted too much and no larger cavities are created.

6. Cover the copper wool and the brass wool with cotton wool.

7. Screw the gas inlet (hose no. 4) to the branch with copper wool and the gas outlet (hose no. 5) to the branch with brass wool.

8. Press the filled U-tube carefully into the clamps. 


\subsection{Operation with $\mathrm{Cl}$ module}

Maintenance intervals

\begin{tabular}{|c|c|}
\hline Maintenance task & Maintenance interval \\
\hline $\begin{array}{l}\text { Remove splashes of chemicals from the } \\
\text { housing }\end{array}$ & Immediately \\
\hline $\begin{array}{l}\text { Inspect the combustion tube and replace } \\
\text { if necessary }\end{array}$ & After approx. 100 operating hours \\
\hline \multirow[t]{2}{*}{ Clean measuring cell } & At least weekly \\
\hline & $\begin{array}{l}\text { Recommendation: wipe clean after electrolyte } \\
\text { replacement }\end{array}$ \\
\hline Replace electrolyte solution & As required, min. once per measuring day \\
\hline Sulfuric acid replacement & $\begin{array}{l}\text { If the sulfuric acid drops below } 70 \% \text {, i.e. the } \\
\text { acid volume increases by } 1 / 3 \mathrm{rd} \text {. }\end{array}$ \\
\hline Replace the halide trap & $\begin{array}{l}\text { when half of the copper wool or the brass wool } \\
\text { is discolored }\end{array}$ \\
\hline Replacing the adsorption agent & Weekly (every 40 operating hours) \\
\hline
\end{tabular}

The copper and brass wool in the halide trap is replaced analogous to the replacement of the halide trap in the basic device multi EA 4000 ( $\rightarrow$ see section "Replace the halide trap" p. 113).

\subsubsection{Replacing the sulfuric acid/cleaning the sulfuric acid container}

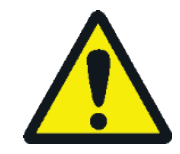

\section{WARNING}

The concentrated sulfuric acid used as desiccant in the sulfuric acid container can cause serious burns!

Wear appropriate protective clothing when working at the sulfuric acid container.

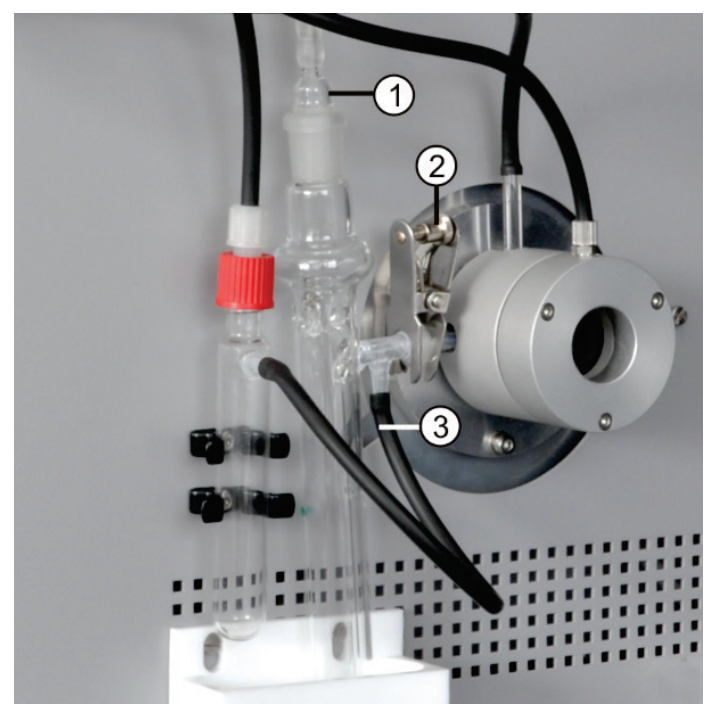

1. Pull the gas olive (1) out of the sulfuric acid container.

2. When using a container with split outlet: Pull the black hose (3) off the bypass of the sulfuric acid container.

3. Hold the sulfuric acid container, remove the forced clamp (2) and detach the spherical joint connection.

4. Carefully take the sulfuric acid container out of the drip tray.

5. Dispose of the sulfuric acid. Observe the regulations for handling concentrated sulfuric acid. 
6. Rinse the sulfuric acid container with a small amount of fresh sulfuric acid. If heavily contaminated, rinse the sulfuric acid container several times with ultrapure water and allow it to dry fully.

7. Fill the sulfuric acid container with $12-15 \mathrm{ml}$ concentrated sulfuric acid and reconnect it in accordance with section "Connect the sulfuric acid container." p. 83.

\subsubsection{Servicing/replacing the quartz glass combustion tube}

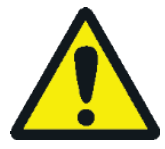

\section{WARNING}

Risk of electric short circuit! In the combustion furnace HTS1500 very high electrical currents occur in spite of a low voltage (max. $14 \mathrm{~V}$ ). The combustion tube is part of the cover of live components.

Only switch on the analyzer with the combustion tube inserted! Always switch off the analyzer from the mains switch at the rear of the device for conversions and maintenance to the combustion tube or combustion furnace.

\section{WARNING}

The concentrated sulfuric acid used as desiccant in the sulfuric acid container can cause serious burns!

Wear appropriate protective clothing when working at the sulfuric acid container.

\section{CAUTION}

There is a risk of burns on the combustion furnace! Allow the device to cool down sufficiently before removing the combustion tube!

\section{NOTICE}

Alkaline salts (hand perspiration) cause crystallizations in the quartz glass when heating the combustion furnace, which reduce the service life of the combustion tube.

Where possible do not touch the cleaned combustion tube with your hands. Wear protective gloves to install the lock on the combustion tube.

If necessary, clean the combustion tube externally with Ethanol before installing it in the combustion furnace. 


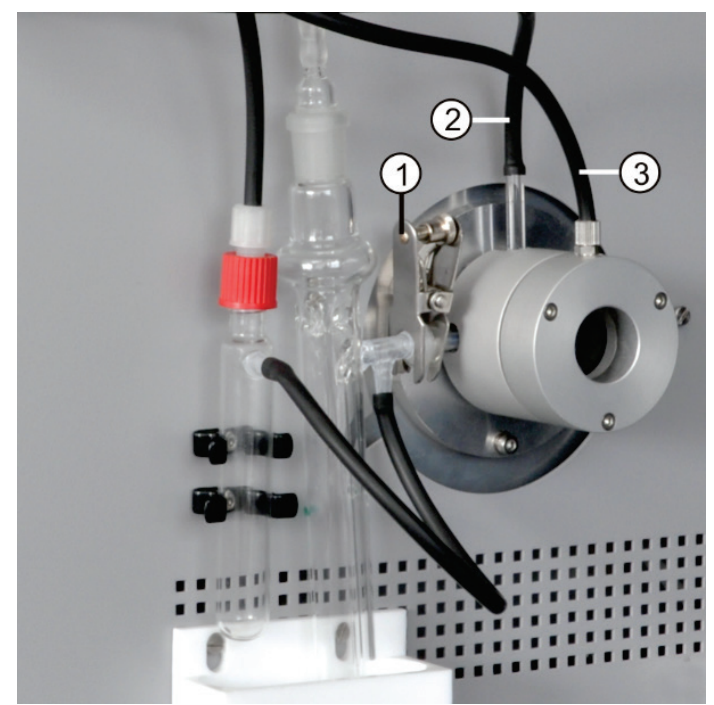

Forked clamp

2 Connection for oxygen supply

3 Connection for argon
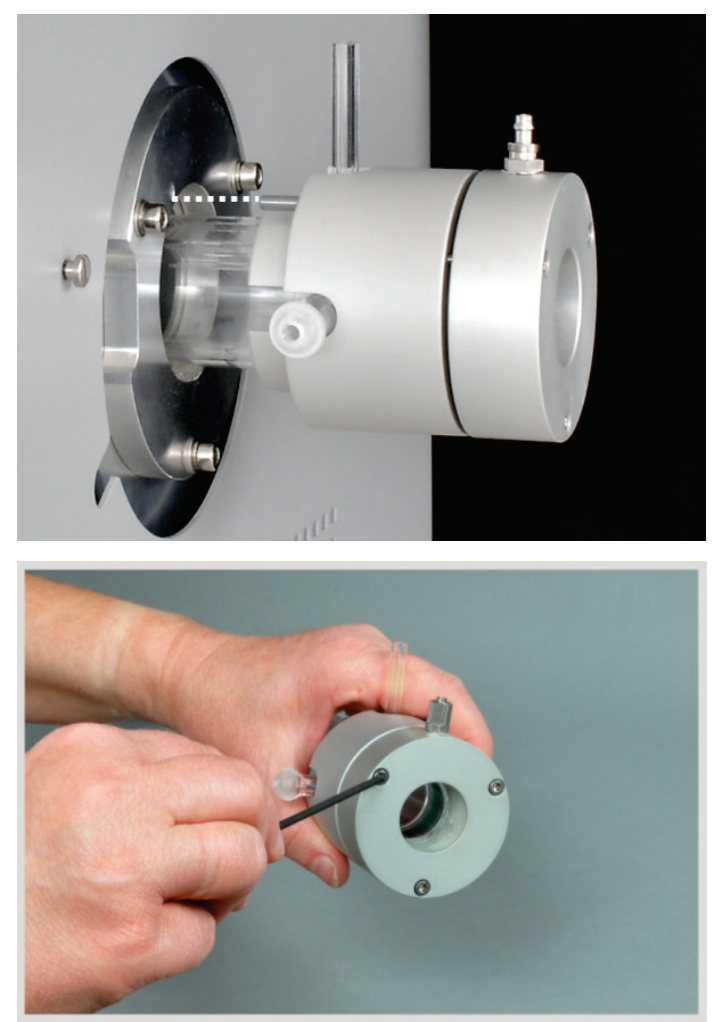

1. Switch off the basic device from the mains switch, pull the mains switch out of the outlet and disconnect the gas supply.

2. Pull the gas olive out of the sulfuric acid container.

When using the safety container:

Pull the black hose off the bypass of the sulfuric acid container.

3. Hold the sulfuric acid container, remove the forked clamp (1) and detach the spherical joint connection between the gas outlet of the quartz tube and the sulfuric acid container.

4. Carefully remove and empty the acid container.

5. Pull the gas hose off the gas inlet connection of the quartz tube (2).

When using the flame sensor: Unscrew the flame sensor $\rightarrow$ (see section "Connecting the flame sensor (optional)" p. 83).

6. Detach the union nut at the argon connection of the gas sluice (3) and pull off the hose.

7. Hold the gas sluice and carefully pull the quartz tube out of the combustion tube.

10. Check the quartz tube for excessive crystallization, cracks and blow-outs. NOTICE! Only reuse intact tubes.

11. Check the sealing rings in the gas sluice for cracks and brittle spots. Replace the sealing rings if necessary.

12. Rinse the tube with ultrapure water and allow it to dry. 
13. Place approx. $2.5 \mathrm{~cm}$ quartz wool in the inlet of the quartz tube and push the quartz wool towards the end of the tube with a hook.

14. Refit the gas sluice and insert the combustion tube into the furnace. Restore all gas connections ( $\rightarrow$ see section "Preparing the multi EA $4000 \mathrm{for} \mathrm{Cl}$ measurements" p. 80).

\subsubsection{Servicing the combined electrode}
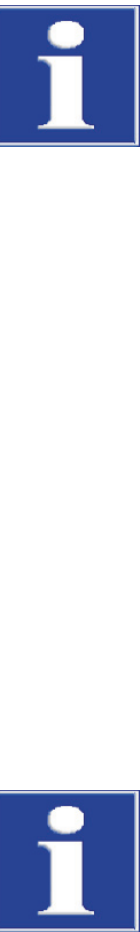

\section{NOTICE}

The combined electrode can be destroyed by detergents or abrasives.

For cleaning the combined electrode may only be rinsed with Ethanol or distilled water. The use of abrasive detergents or abrasives is prohibited.

Drying of electrolyte on the combined electrode can cause an irreversible reduction of its sensitivity or damage the electrode. Therefore, make sure that the electrolyte never dries on the combined electrode.

- For brief interruptions of operation (one day to the next): Store the electrode in the electrolyte solution.

- For decommissioning over several days:

Rinse the combined electrode with distilled water and Ethanol. Immerse the electrode in Ethanol over-night, stirred with a magnetic stirrer. Then wipe the combined electrode with cellulose and store it dry.

\section{NOTICE}

The combined electrode consists of ceramic materials and is particularly sensitive near the fused electrodes.

Handle the combined electrode with great care! As a wearing part it is not covered by the warranty!

Pulling the combined electrode out of the cover of the measuring cell and connecting it to the measuring gas can result in great mechanical stress if handled incorrectly and lead to its electrical connection becoming fractured. 


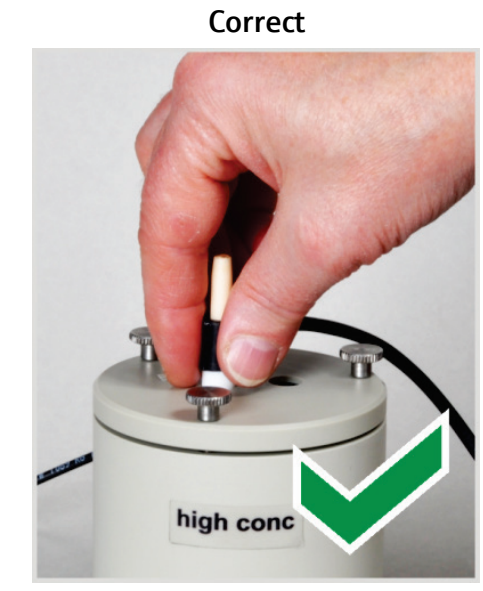

Hold the electrode from the top and pull the electrode straight upwards out of the cover.

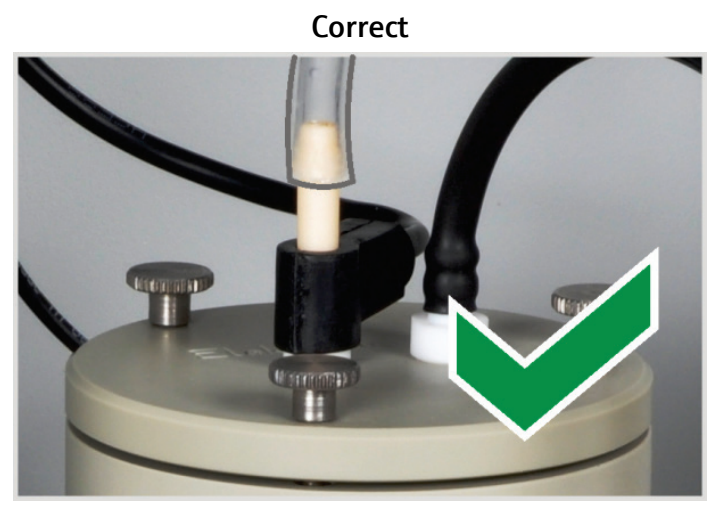

Only push the measuring gas hose approx. $1 \mathrm{~cm}$ onto the electrode. This ensures gas tightness.

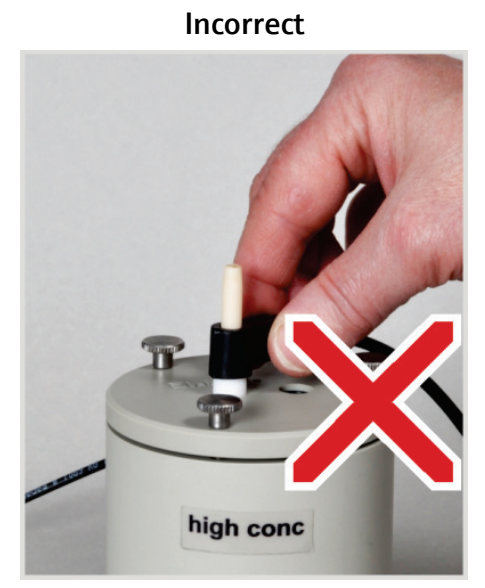

Do not pull and jolt the lateral connection sleeve for the electrical connections. The connections in the sleeve will break (not visible from outside)!

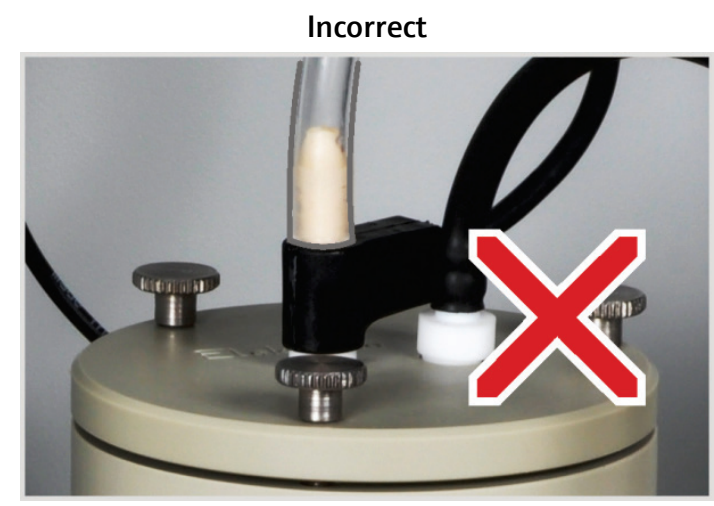

If you push the hose too far onto the electrode, it will get stuck on the electrode. When pulling off the hose, the electrode might break!

\subsubsection{Servicing the measuring cells}

Since the introduction of hot reaction gases during the measurements causes electrolyte components to evaporate, it is recommended to change the electrolyte solution daily:

1. Remove the used electrolyte.

2. First rinse the measuring cell and magnetic stirring rod with distilled water, then with Ethanol.

3. Carefully wipe the measuring cell and magnetic stirring rod with cellulose to remove any silver chloride deposits.

4. Refill the measuring cell with electrolyte ( $\rightarrow$ see section "Preparing the measuring cell" p. 87). 
Observe the following notes:

- If the system is decommissioned for several days, clean the measuring cell and store it dry.

- Regularly check the casing of the magnetic stirring rod for cracks. Metal ions entering the electrolyte solution can distort the analysis.

- Avoid fluids from entering the stirring/cooling block and the plug-in contacts (risk of short circuit).

\subsubsection{Replacing the adsorption agent}

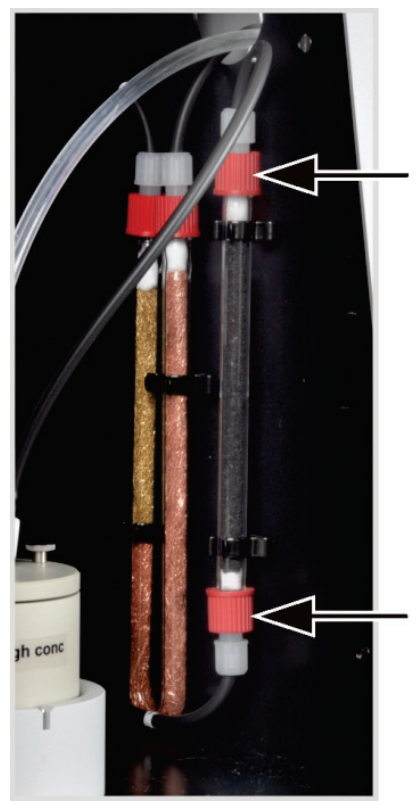

1. Switch off the basic device and the $\mathrm{Cl}$ module from the mains switch. Turn off the gas supply.

2. Pull the adsorption tube out of its mount.

3. Unscrew the screw caps from the glass tube.

4. Remove the cotton plug and spill the adsorption agent.

5. Seal one side of the glass tube with cotton wool and fill with adsorption agent.

6. Seal the glass tube with cotton wool.

7. Screw the filled adsorption tube back on finger-tight.

8. Press the adsorption tube back in to its mount.

NOTICE! Do not twist or kink the hoses!

\subsection{Operation with the automatic TIC solids module}

Maintenance intervals

\begin{tabular}{|c|c|}
\hline Maintenance task & Maintenance interval \\
\hline $\begin{array}{l}\text { Remove splashes of chemicals from } \\
\text { the housing }\end{array}$ & Immediately \\
\hline \multirow[t]{2}{*}{ Cleaning the $\mathrm{TIC}$ reactor } & Daily, \\
\hline & In case of visible contamination \\
\hline Changing the desiccant in the drying tube & $\begin{array}{l}\text { As required (blackening or clumping due to } \\
\text { moisture absorption) }\end{array}$ \\
\hline Replace the halide trap & $\begin{array}{l}\text { As required, } \\
\text { when half of the copper wool or the brass } \\
\text { wool is discolored }\end{array}$ \\
\hline $\begin{array}{l}\text { Inspect the dust filter, replace in case of visible } \\
\text { contamination }\end{array}$ & Monthly \\
\hline Inspect the condensation coil for damage & After 3 months \\
\hline
\end{tabular}




\begin{tabular}{ll}
\hline Maintenance task & Maintenance interval \\
\hline Clean the condensation coil & $\begin{array}{l}\text { As required, but no later than after } 12 \\
\text { Months }\end{array}$ \\
\hline Inspect the condensate container for damage & After 3 months \\
\hline Clean the condensate container & $\begin{array}{l}\text { As required, but no later than after } 12 \\
\text { months }\end{array}$ \\
\hline Replace the metering pump, pump hose & After 3 months \\
\hline Replace the condensate pump, pump hose & $\begin{array}{l}\text { Inspect every } 3 \text { months, } \\
\text { replace as required, but no later than after } \\
12 \text { months }\end{array}$ \\
\hline
\end{tabular}

The desiccant in the drying tube is replaced in the same manner as in the basic device multi EA 4000 ( $\rightarrow$ see section "Changing the desiccant in the drying tube" p. 112).

The copper and brass wool in the halide trap is also replaced as in the basic device multi EA 4000 ( $\rightarrow$ see section "Replace the halide trap" p. 113).

\subsubsection{Cleaning the TIC reactor of the automatic TIC solids module}

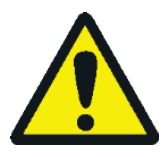

\section{WARNING}

Risk of electric short circuit! In the combustion furnace HTS1500 very high electrical currents occur in spite of a low voltage (max. $14 \mathrm{~V}$ ). The combustion tube is part of the cover of live components.

Only switch on the analyzer with the combustion tube inserted! Always switch off the analyzer from the mains switch at the rear of the device for conversions and maintenance to the combustion tube or combustion furnace.

\section{WARNING}

The phosphoric or hydrochloric acid used for purging the TIC can cause severe burns!

Wear protective gloves and protective goggles when handling concentrated acid! Rinse affected skin immediately.

\section{CAUTION}

There is a risk of burns on the combustion furnace! Allow the device to cool down sufficiently before removing the combustion tube!

1. Switch off the basic device and the TIC solids module from the mains switch. Turn off the gas supply.

2. Allow the device to cool down sufficiently (min. $2 \mathrm{~h}$ ).

3. Move the FPG 48 approx. $30 \mathrm{~cm}$ to the right to make room for the removal of the TIC reactor.

NOTICE! When pulling off the hoses support the TIC reactor with one hand. The reactor can fracture from unilateral pressure. It is also possible to first pull the reactor out of the coupling and then remove the connections. 


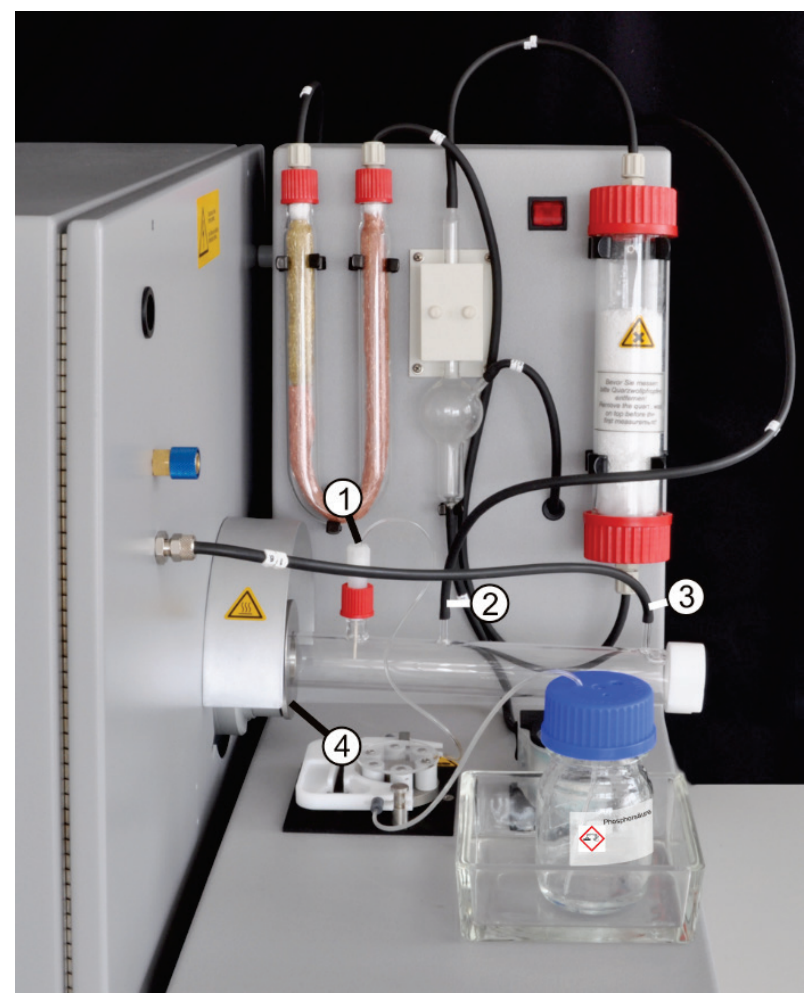

4. Put the acid container and drip tray aside. Carefully wipe the pump hose clean.

NOTICE! The acid from the hose must not drip onto the device.

5. Unscrew the connection for the acid supply (1) from the TIC reactor. Take the ceramic cannula out of the connection.

6. Rinse the ceramic cannula and the sealing ring with ultrapure water and wipe with cellulose.

NOTICE! The ceramic cannula is fragile!

7. Pull the measuring gas hose (2) and the hose for the oxygen supply (3) off the reactor.

8. Release the knurled head screw (4) at the coupling with the basic device.

9. Pull the TIC reactor out of the coupling.

10. Inspect the TIC reactor for cracks and blow-outs.

NOTICE! Only re-use intact reactors.

11. If applicable, clean the reactor with a suitable solvent and brush or cellulose.

12. Rinse the reactor with ultrapure water and allow it to dry.

13. Re-insert the reactor into the coupling and attach it by tightening the knurled ring.

14. Attach the acid and gas connections to the reactor and re-position the FPG $48(\rightarrow$ see section "Connect the TIC reactor and sampler" p. 94 and "Connecting and using the autosampler" p. 62).

\subsubsection{Cleaning the condensation coil}

1. Switch off the basic device and the automatic TIC solids module from the mains switch and pull the mains plug of the TIC solids module out of the outlet. Turn off the gas supply.

2. Move the FPG 48 aside, remove the acid container and drip tray and remove the TIC reactor.

3. Rotate the TIC solids module until the rear is accessible. 


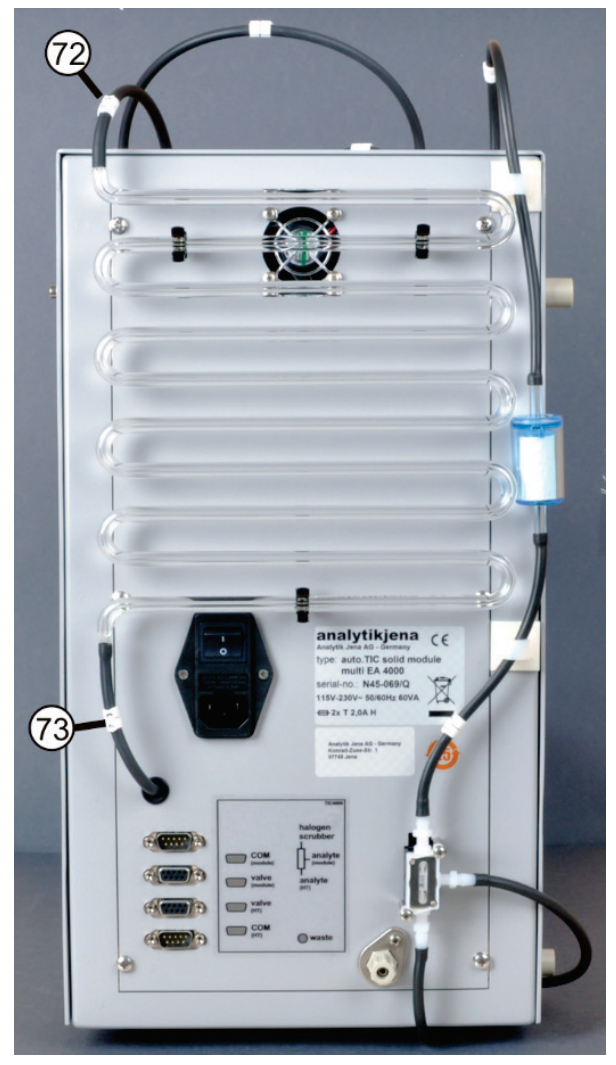

4. Pull the hoses off the condensation coil.

5. Carefully pull the condensation coil out of its mount.

6. Inspect the condensation coil for deposits and cracks.

7. If necessary, rinse the condensation coil with ultrapure water and allow to dry well.

8. Carefully press the condensation coil back into its mount at the rear of the TIC solids module.

9. Connect hose no. 72 (from the reactor) to the top connection of the condensation coil.

10. Connect hose no. 73 (to the condensate container) to the bottom connection of the condensation coil.

11. Rotate the TIC solids module back into its original position.

12. Re-assemble the TIC reactor and FPG $48(\rightarrow$ see section "Connect the TIC reactor and sampler" p. 94 and "Connecting and using the autosampler" p. 62).

\subsubsection{Removing and replacing the pump hose}

Acid pump

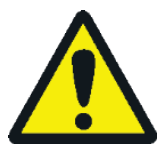

\section{CAUTION}

The pump hose contains phosphoric or hydrochloric acid (dependent on application). The acids are irritating to eyes, skin and mucous membranes!

Wear protective gloves and protective goggles when handling concentrated acid! Rinse affected skin immediately.

Replace the pump hose at the cartridge pump as follows:

1. Pull the hose out of the acid bottle. Put the acid bottle and drip tray aside. Make sure that the acid does not drip onto the device.

2. Unscrew the pump hose from the reactor.

3. Open the hose cartridge ( 3 in Figure 49) and remove the pump hose. 


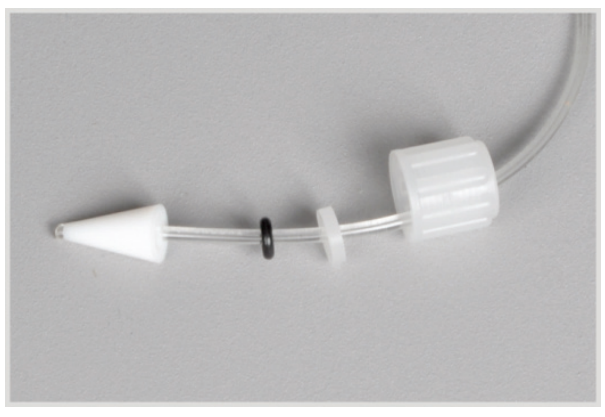

4. Pull the sealing elements and the white union nut off the worn pump hose.

5. Slide the sealing elements onto the new pump hose in the sequence shown.

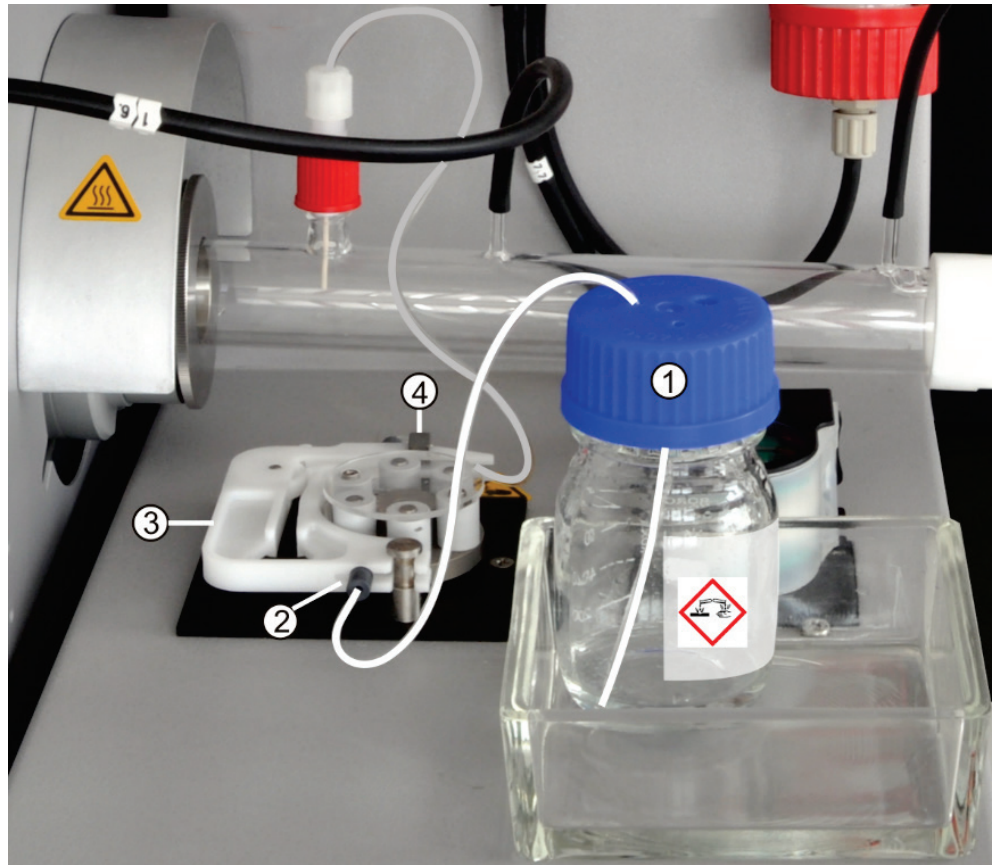

Figure 49 Clamping the pump hoses

1 Phosphoric acid bottle

2 Stopper at the pump hose

3 Hose cartridge

4 Hose connection at the TIC reactor

6. Clamp the pump hose between the two plastic stoppers (2 in Figure 49) in the hose cartridge.

7. Insert the hose cartridge into the pump and allow it to engage.

8. Screw the pump hose to the TIC reactor.

NOTICE! The TIC reactor can get hot. Install the pump hose so that it does not touch the hot reactor.

9. Place the acid container in the drip tray onto the TIC module. Push the other end of the pump hose into an opening of the acid container. 


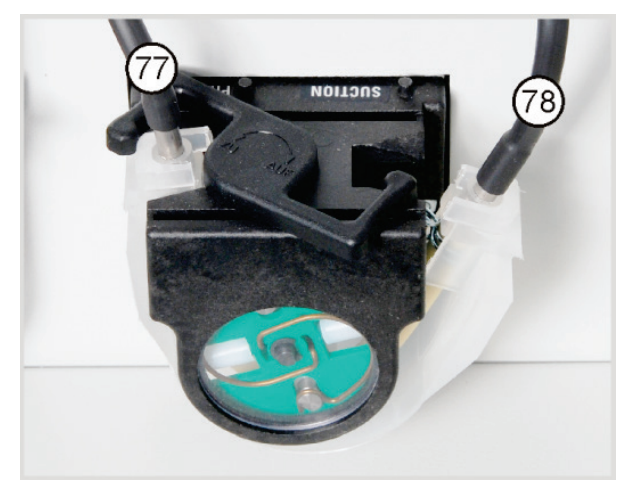

1. Push the bracket on the condensate pump to the left.

2. Pull the hoses no. 77 and no. 78 off the connections.

3. Remove the conveyor belt with the pump hose from the pump body.

4. Check the pump hose and the connections on excessive wear and cracks.

NOTICE! If moisture escapes from the pump hose or the connections, the pump hose must be replaced.

5. Wipe the pump body and roller carrier with ultrapure water.

6. Check the pump body and roller carrier for wear.

NOTICE! Notify customer service if pump body and roller carrier are strongly affected.

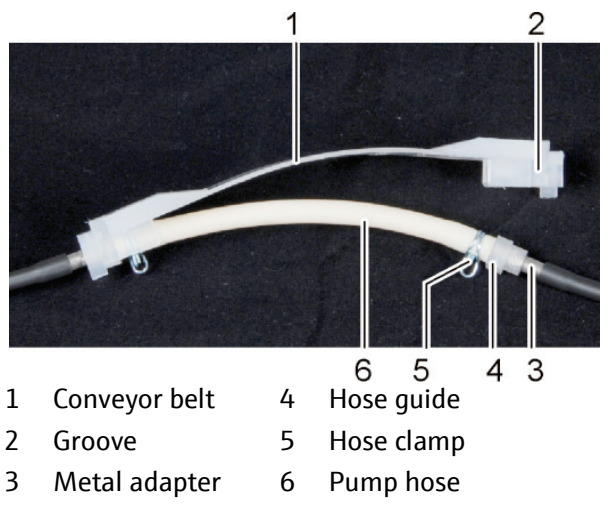

7. Push the intact or new pump hose back into the conveyor belt.

During installation, the hose clamps must be rotated downwards.

Push the hose guide into the groove on the conveyor belt.

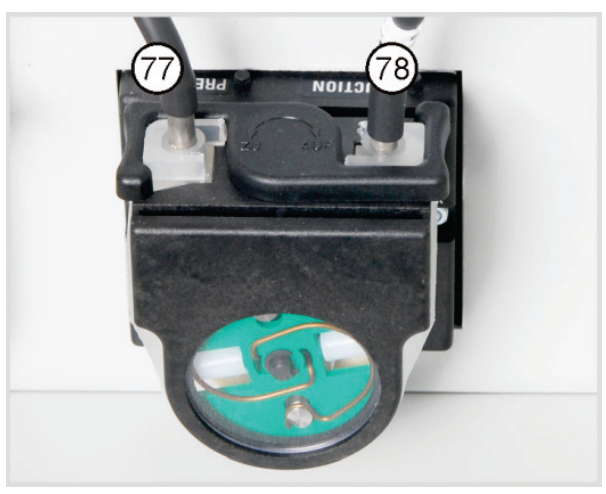

8. Position the conveyor belt around the pump body.

9. Press the conveyor belt upwards with one hand and rotate the bracket with the other hand to the right until it engages.

10. Push hoses 77 and 78 back onto their adapters. 


\subsubsection{Cleaning the condensate container}

Clean the condensate container as required:

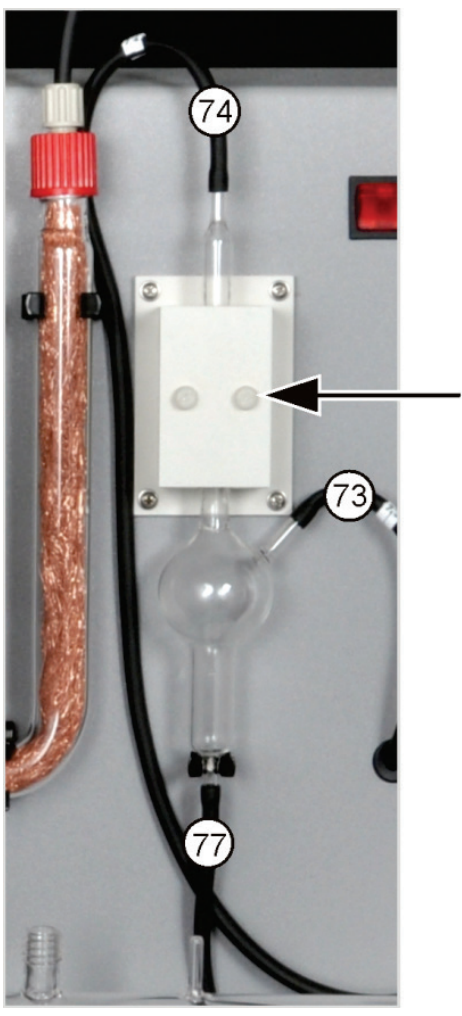

1. Detach the 2 knurled head screws (arrow) at the cover of the cooling block and remove the cover.

2. Pull the hoses off the connections of the condensate container.

3. Inspect the condensate container for deposits and cracks.

4. If necessary, rinse the condensate container with ultrapure water.

5. Attach the hoses (see figure).

- Hose no. 73 (from the bottom end of the condensation coil at the rear) to the side inlet of the condensate container

- Hose no. 77 (to the condensate pump) at the bottom outlet

- Hose no. 74 (to the drying container) at the top outlet

Push the hoses approx. $1 \mathrm{~cm}$ onto the glass connections of the condensate container.

\subsection{Manual TIC solids module}

Maintenance intervals

\begin{tabular}{ll}
\hline $\begin{array}{l}\text { Maintenance task } \\
\text { Remove splashes of chemicals from the hous- }\end{array}$ & Maintenance interval \\
\hline Clean the TIC reactor (Erlenmeyer flask) & After each sample \\
\hline Changing the desiccant in the drying tube & $\begin{array}{l}\text { As required (blackening or clumping due to } \\
\text { moisture absorption) }\end{array}$ \\
\hline Replace the halide trap & $\begin{array}{l}\text { when half of the copper wool or the brass } \\
\text { wool is discolored }\end{array}$ \\
\hline Replace the water traps & $\begin{array}{l}\text { As required, but no later than after } 3 \\
\text { months }\end{array}$ \\
\hline
\end{tabular}

The desiccant in the drying tube is replaced in the same manner as in the basic device multi EA 4000 ( $\rightarrow$ see section "Changing the desiccant in the drying tube" p. 112).

The copper and brass wool in the halide trap is also replaced analogous to the replacement of the halide trap in the basic device multi EA 4000 ( $\rightarrow$ see section "Replace the halide trap" p. 113). 


\subsubsection{Cleaning the TIC reactor at the manual TIC solids module}

After each measurement, rinse the TIC reactor (Erlenmeyer flask) with ultrapure water. Next dry it thoroughly (see also "Performing a TIC measurement" p. 103).

\subsection{Replacing the water traps}

\section{NOTICE}

The water traps (TC prefilter and disposable retention filter) can be replaced in the switched-on state but not during a measurement. Always replace both water traps! The water traps only serve their function if they are inserted in the order and installation direction specified!

Replace the water traps dependent on the sample matrix, but no later than after 6 months, as follows:

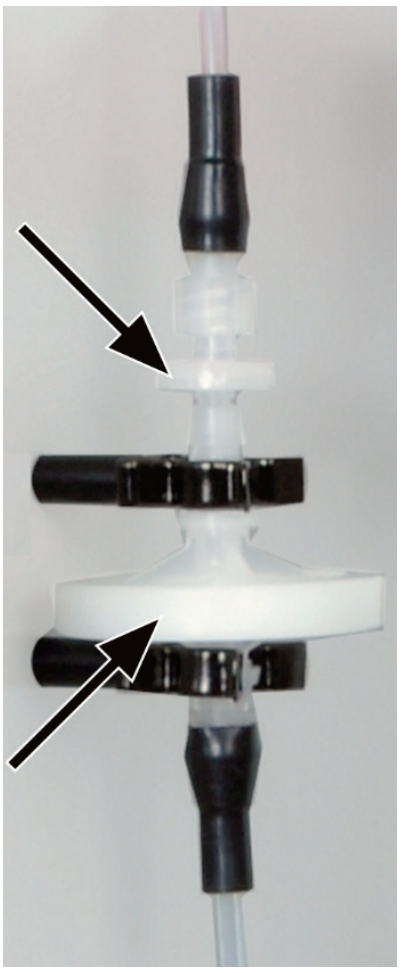

1. Pull the water traps out of the 2 retaining clips.

2. Detach the hose connections from the water traps. To do so unscrew the Luer adapter from the small water trap.

3. Assemble the new water traps.

The label "INLET" on the large water trap (aerosol trap) must point down and the label of the small water trap (disposable retention filter) must point up (arrows in fig. on the left).

4. Screw the small water trap into the Luer adapter at hose no. 9 .

5. Connect the large water trap with the FAST connector to hose no. 8 .

6. Press the water traps into the 2 retaining clips on the rear of the device. 


\section{Fault removal}

\subsection{General information}

For fault analysis it is possible to record log files. The recording of log files should be enabled in coordination with the Analytik Jena AG customer service department.

- Enable the recording of the device-specific log files multiWin_Comm.log and multiWin_Flow.log under EXTRAS CONFIGURATION ERROR ANALYSIS.

The recording of the file multiWin_Error.log is always enabled.

- Enable the recording of the log file specific to multiWin multiWin_Exception.log under EXTRAS C CONFIGURATION ERROR ANALYSIS.

- Via the menu command HELP ERROR ANALYSIS create a zip file that can be provided to customer service.

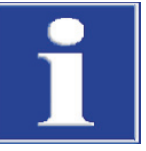

\section{NOTICE}

If the faults cannot be remedied, the Analytik Jena AG service department must always be informed. This also applies for the repeated occurrence of individual faults. For the fault diagnosis the zip file created must be sent by email to the Analytik Jena AG service department.

\subsection{Error messages in multiWin}

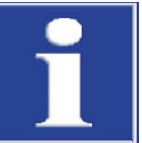

\section{NOTICE}

Unsuitable USB cables or impermissible extensions often cause problems in the communication between the control module and the PC. Only use the USB cable supplied by Analytik Jena AG. Extensions of the USB connection are not permitted!

\begin{tabular}{ll}
\hline \multicolumn{2}{l}{ Error message } \\
\hline No reply from firmware & Remedy \\
\hline Cause & - Switch on control module and basic device \\
\hline Control module and basic device not switched on & - Check connection between control module and PC \\
\hline Control module not connected to PC & - Check plugged in port on the PC. \\
\hline Incorrect port selected o the PC & - if applicable, select different port in multiWin via \\
& the menu [EXTRAS] \\
& - IINTERFACE]
\end{tabular}




\begin{tabular}{|c|c|c|}
\hline \multirow[t]{2}{*}{2} & \multicolumn{2}{|l|}{ Serial port not present! } \\
\hline & Cause & Remedy \\
\hline & Communication problems & $\begin{array}{l}\text { Disconnect USB connection between the control } \\
\text { module and PC and re-connect after approx. } 10 \mathrm{~s} \\
\text { - Initialize }\end{array}$ \\
\hline \multirow[t]{4}{*}{3} & Serial port not reachable! & \\
\hline & Cause & Remedy \\
\hline & Communication problems & $\begin{array}{l}\text { Disconnect USB connection between the control } \\
\text { module and PC and re-connect after approx. } 10 \mathrm{~s} \\
\text { - Initialize }\end{array}$ \\
\hline & $\begin{array}{l}\text { Another program is using the interface, e.g. } \\
\text { Service Terminal after an update }\end{array}$ & - Close the other program \\
\hline \multirow[t]{3}{*}{4} & Unknown connection type! & \\
\hline & Cause & Remedy \\
\hline & Communication problems & $\begin{array}{l}\text { Disconnect USB connection between the control } \\
\text { module and PC and re-connect after approx. } 10 \mathrm{~s} \\
\text { - Initialize }\end{array}$ \\
\hline \multirow[t]{4}{*}{5} & Error when opening the port! & \\
\hline & Cause & Remedy \\
\hline & Communication problems & $\begin{array}{l}\text { Disconnect USB connection between the control } \\
\text { module and PC and re-connect after approx. } 10 \mathrm{~s} \\
\text { - Initialize }\end{array}$ \\
\hline & $\begin{array}{l}\text { Another program is using the interface, e.g. } \\
\text { Service Terminal after an update }\end{array}$ & - Close the other program \\
\hline \multirow[t]{3}{*}{7} & Operating system error: Unauthorized access! & \\
\hline & Cause & Remedy \\
\hline & Undefined termination of multiWin & $\begin{array}{l}\text { - } \text { Exit multiWin } \\
\text { - } \text { Detach USB cable and re-connect after approx. } 10 \\
\text { - } \\
\text { - Restart operating system (PC) } \\
\text { - Restart firmware (basic module) } \\
\text { - Restart multiWin }\end{array}$ \\
\hline
\end{tabular}

\begin{tabular}{ll}
\hline 11 No reply to signal & \\
\cline { 2 - 3 } Cause & Remedy \\
\hline Firmware crashed & - Exit multiWin \\
& - Detach USB cable between PC and control module \\
& - and re-connect after approx. $10 \mathrm{~s}$ \\
& - Switch on analyzer \\
& - Start multiWin
\end{tabular}




\begin{tabular}{|c|c|c|}
\hline \multirow[t]{2}{*}{14} & \multicolumn{2}{|l|}{ Data transfer interrupted } \\
\hline & Cause & Remedy \\
\hline & no data transfer for $10 \mathrm{~s}$ & - Initialize \\
\hline \multirow[t]{3}{*}{17} & Incorrect interface protocol ID & \\
\hline & Cause & Remedy \\
\hline & $\begin{array}{l}\text { Fault after update } \\
\text { (program versions of firmware multiWin don't match) }\end{array}$ & - update required \\
\hline \multirow[t]{3}{*}{20} & Timeout: InitEnd & \\
\hline & Cause & Remedy \\
\hline & timeout during initialization & - Initialize \\
\hline \multirow[t]{3}{*}{21} & Timeout: StatusBusy & \\
\hline & Cause & Remedy \\
\hline & $\begin{array}{l}\text { Timeout during operation } \\
\text { (device not ready to measure) }\end{array}$ & $\begin{array}{l}\text { - Acknowledge message } \\
\text { - Initialize }\end{array}$ \\
\hline \multirow[t]{3}{*}{22} & Timeout: End & \\
\hline & Cause & Remedy \\
\hline & Timeout when exiting multiWin & $\begin{array}{l}\text { - Acknowledge message } \\
\text { - Initialize }\end{array}$ \\
\hline \multirow[t]{3}{*}{23} & Timeout: StopEnd & \\
\hline & Cause & Remedy \\
\hline & Timeout during measurement cancellation & $\begin{array}{l}\text { - Acknowledge message } \\
\text { - Initialize }\end{array}$ \\
\hline \multirow[t]{4}{*}{24} & Timeout: Measurement & \\
\hline & Cause & Remedy \\
\hline & Timeout during measurement & - Check analyzer \\
\hline & Maximum integration time has been exceeded & - Check method configuration \\
\hline \multirow[t]{3}{*}{25} & Timeout: Analyzer command processing & \\
\hline & Cause & Remedy \\
\hline & Timeout during command processing & $\begin{array}{l}\text { - Acknowledge message } \\
\text { - Initialize }\end{array}$ \\
\hline \multirow[t]{3}{*}{30} & Chloride needs adding & \\
\hline & Cause & Remedy \\
\hline & $\begin{array}{l}\text { - Measuring cell and/or electrolyte solution contam- } \\
\text { inated } \\
\text { - Combined electrode faulty or aged strongly }\end{array}$ & $\begin{array}{l}\text { - Clean measuring cell, fill fresh electrolyte } \\
\text { - Use new electrode for chloride determination. }\end{array}$ \\
\hline \multirow[t]{3}{*}{50} & Firmware reset & \\
\hline & Cause & Remedy \\
\hline & internal computer (firmware) restarted & $\begin{array}{l}\text { - Acknowledge message } \\
\text { - Initialize }\end{array}$ \\
\hline \multirow[t]{3}{*}{52} & Firmware standby & \\
\hline & Cause & Remedy \\
\hline & Firmware has been moved to standby & - Acknowledge message. Initialize. \\
\hline
\end{tabular}




\begin{tabular}{|c|c|c|}
\hline 61 & Command from the PC not complete & \\
\hline 62 & Command from the PC without STX & \\
\hline 64 & Command from the PC CRC error & \\
\hline 65 & Command from the PC invalid command & \\
\hline 66 & Command from the PC invalid MEAS command & \\
\hline \multirow[t]{3}{*}{67} & Command MTXT from PC missing & \\
\hline & Cause & Remedy \\
\hline & communication error & $\begin{array}{l}\text { - Acknowledge message } \\
\text { - Initialize }\end{array}$ \\
\hline \multirow[t]{3}{*}{100} & C sensor: no connection & \\
\hline & Cause & Remedy \\
\hline & $\begin{array}{l}\text { Communication faulty after sensor } \\
\text { was detected during initialization }\end{array}$ & $\begin{array}{l}\text { - Acknowledge message } \\
\text { - Initialize }\end{array}$ \\
\hline \multirow[t]{3}{*}{101} & C detector: CRC error & \\
\hline & Cause & Remedy \\
\hline & $\begin{array}{l}\text { Communication faulty after sensor } \\
\text { was detected during initialization }\end{array}$ & $\begin{array}{l}\text { - Acknowledge message } \\
\text { - Initialize }\end{array}$ \\
\hline 104 & C sensor: Analog values out of range & \\
\hline \multirow[t]{3}{*}{107} & C sensor: Analog values out of range (coarse) & \\
\hline & Cause & Remedy \\
\hline & $\begin{array}{l}\text { The analog values of the detector } \\
\text { are outside the operating range }\end{array}$ & $\begin{array}{l}\text { - Check the quality of the carrier gas } \\
\text { - Initialize } \\
\text { - Check the analog values in the component test (via } \\
\text { menu item SYSTEM }>\text { COMPONENT TEST tab C-NDIR) }\end{array}$ \\
\hline \multirow[t]{3}{*}{106} & C sensor: incorrect response to command & \\
\hline & Cause & Remedy \\
\hline & communication faulty & $\begin{array}{l}\text { - Switch C module off and back on } \\
\text { - Initialize }\end{array}$ \\
\hline 120 & S sensor: no connection & \\
\hline \multirow[t]{3}{*}{130} & $\mathrm{Cl}$ sensor: no connection & \\
\hline & Cause & Remedy \\
\hline & $\begin{array}{l}\text { Communication faulty after sensor } \\
\text { was detected during initialization }\end{array}$ & $\begin{array}{l}\text { - Acknowledge message } \\
\text { - Initialize }\end{array}$ \\
\hline \multirow[t]{3}{*}{120} & S sensor: no connection & \\
\hline & Cause & Remedy \\
\hline & $\begin{array}{l}\text { Communication faulty after detector } \\
\text { was detected during initialization }\end{array}$ & $\begin{array}{l}\text { - Acknowledge message } \\
\text { - Initialize }\end{array}$ \\
\hline \multirow[t]{3}{*}{124} & S sensor: incorrect status & \\
\hline & Cause & Remedy \\
\hline & Change of smoothing factor & - Repeat action \\
\hline
\end{tabular}




\begin{tabular}{|c|c|c|}
\hline \multirow[t]{3}{*}{128} & \multicolumn{2}{|l|}{ S sensor: inactive } \\
\hline & Cause & Remedy \\
\hline & Detector type transfer failed & - Repeat action \\
\hline \multirow[t]{3}{*}{130} & $\mathrm{Cl}$ sensor: no connection & \\
\hline & Cause & Remedy \\
\hline & $\begin{array}{l}\text { Communication faulty after detector was detected } \\
\text { during initialization }\end{array}$ & $\begin{array}{l}\text { - Acknowledge message } \\
\text { - Initialize }\end{array}$ \\
\hline \multirow[t]{3}{*}{131} & $\mathrm{Cl}$ sensor: incorrect command structure & \\
\hline & Cause & Remedy \\
\hline & communication to the chlorine module faulty & $\begin{array}{l}\text { - Acknowledge message } \\
\text { - switch chlorine module on/off } \\
\text { - Initialize }\end{array}$ \\
\hline \multirow[t]{3}{*}{133} & $\mathrm{Cl}$ sensor: incorrect cell & \\
\hline & Cause & Remedy \\
\hline & no initialization after cell change & - Initialize \\
\hline \multirow[t]{3}{*}{134} & $\mathrm{Cl}$ sensor: incorrect status & \\
\hline & Cause & Remedy \\
\hline & communication faulty & $\begin{array}{l}\text { - Acknowledge message } \\
\text { - Initialize } \\
\text { - Check titration cell status via } \\
\text { menu item SYSTEM }>\text { COMPONENT TEST tab CL-AMP }\end{array}$ \\
\hline \multirow[t]{3}{*}{135} & $\mathrm{Cl}$ sensor: incorrect version & \\
\hline & Cause & Remedy \\
\hline & transmission fault & $\begin{array}{l}\text { - Acknowledge message } \\
\text { - } \text { Initialize } \\
\text { - } \text { Check titration cell status via } \\
\text { menu item SYSTEM }>\text { COMPONENT TEST }>\text { CL-AMP }\end{array}$ \\
\hline \multirow[t]{3}{*}{137} & $\mathrm{Cl}$ sensor: check measuring cell & \\
\hline & Cause & Remedy \\
\hline & End point routine failed 3 times & $\begin{array}{l}\text { - Check electrolyte filling } \\
\text { - Check electrodes }\end{array}$ \\
\hline \multirow[t]{3}{*}{138} & $\mathrm{Cl}$ sensor: inactive & \\
\hline & Cause & Remedy \\
\hline & Detector type transfer failed & - Repeat action \\
\hline 139 & $\mathrm{Cl}$ sensor: STA error & \\
\hline \multirow[t]{3}{*}{140} & $\mathrm{Cl}$ sensor: STA error & \\
\hline & Cause & Remedy \\
\hline & Error during the update of the $\mathrm{Cl}$ detector & - Repeat update \\
\hline \multirow[t]{3}{*}{207} & Flow error & \\
\hline & Cause & Remedy \\
\hline & Flow status not OK & - Check for leaks, check gas supply \\
\hline
\end{tabular}




\begin{tabular}{|c|c|c|}
\hline \multirow{2}{*}{208} & \multicolumn{2}{|l|}{$\mathrm{O}_{2}$ pressure missing } \\
\hline & Cause & Remedy \\
\hline & $\mathrm{O}_{2}$ flow inadequate & - Check $\mathrm{O}_{2}$ connection \\
\hline & & - Check pressure \\
\hline \multirow[t]{4}{*}{209} & Ar pressure missing & \\
\hline & Cause & Remedy \\
\hline & Argon flow inadequate & - Check argon connection \\
\hline & & - Check pressure \\
\hline \multirow[t]{4}{*}{220} & Sampler: no connection & \\
\hline & Cause & Remedy \\
\hline & Communication faulty after sampler was detected dur- & - Acknowledge message \\
\hline & ing initialization & - Initialize \\
\hline \multirow[t]{4}{*}{226} & Sampler: runtime exceeded & \\
\hline & Cause & Remedy \\
\hline & Completion message of the sampler movement takes & - record log files \\
\hline & too long (sampler faulty) & - inform Service \\
\hline \multirow[t]{4}{*}{290} & Scales: no connection & \\
\hline & Cause & Remedy \\
\hline & No communication with scales & - Check connection \\
\hline & & - Check configuration of scales \\
\hline \multirow[t]{3}{*}{291} & Scales: incorrect weight unit & \\
\hline & Cause & Remedy \\
\hline & Currently only one unit $[\mathrm{g}]$ is permitted & - Set the unit gram $[\mathrm{g}]$ in the menu of the scales \\
\hline \multirow[t]{4}{*}{300} & Temperature controller: no connection & \\
\hline & Cause & Remedy \\
\hline & communication faulty & - Acknowledge message \\
\hline & & - Initialize \\
\hline \multirow[t]{3}{*}{301} & Thermocouple break & \\
\hline & Cause & Remedy \\
\hline & HTS1500 thermocouple faulty & - Contact Service \\
\hline 303 & Temperature controller: EPROM error & \\
\hline \multirow[t]{4}{*}{304} & Temperature controller: Communication error & \\
\hline & Cause & Remedy \\
\hline & Communication error with basic device & - Switch basic device off/on \\
\hline & & - Initialize \\
\hline \multirow[t]{3}{*}{306} & External furnace not present & \\
\hline & Cause & Remedy \\
\hline & Basic device not recognized as hardware & $\begin{array}{l}\text { - Check connection between basic device and control } \\
\text { module }\end{array}$ \\
\hline
\end{tabular}




\subsection{Displays in the Device Status window}

In the DEVICE STATUS window, information on the device status or individual modules is displayed.

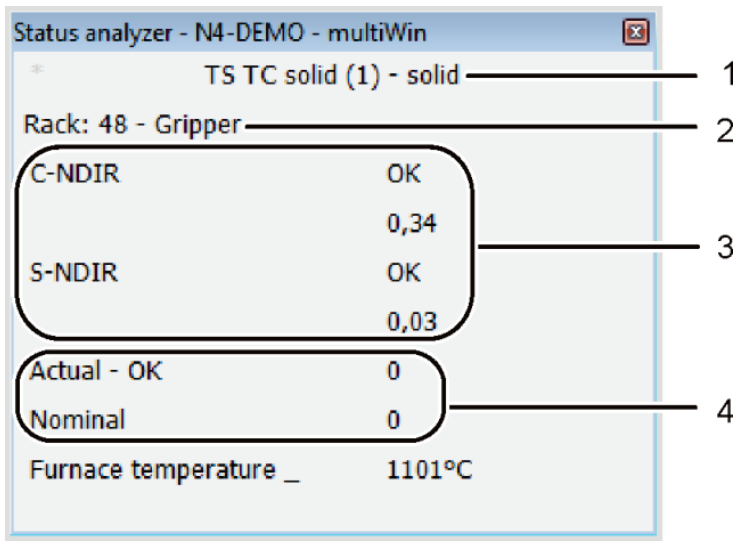

Figure 50 Window STATUS ANALYZER
1 Method
4 Flow indication (not for $\mathrm{Cl}$ measurements)
2 Analysis module / sampler
5 Temperature indication

3 Detection/sensor module

The displays in the STATUS ANALYZER window are indicated in color. The colors have the following meanings:

\begin{tabular}{ll}
\hline Color & Description \\
\hline Black & Status of the corresponding component is ok, device is ready for measurement \\
\hline Gray & Detector is inactive \\
\hline Green & Detector is ok, device is ready for measurement (OK) \\
& or \\
& Detector is busy, a measurement can only be started once the routine is com- \\
& plete (detector-specific) \\
Red & Component is not ready for measurement \\
& Fun-in time not yet complete wait for run-in time to complete \\
& multiWin via the menu item SySTEM $>$ ComponENT TEST
\end{tabular}

In the top row of the window STATUS ANALYZER the name of the active method and the sample state (solid) are displayed.

During initialization, it is detected whether the sampler FPG 48 is connected and switched on. If so, the display RACK 48 appears. A connected automatic TIC solids module is also detected and indicated with TIC (AUTOMATIC).

All the detector modules identified during initialization are displayed in the detector module area. The following displays are possible:

\begin{tabular}{ll}
\hline Display & Description \\
\hline C-NDIR & NDIR detector for carbon \\
\hline S-NDIR & NDIR detector for sulfur \\
\hline Cl-AMP smallCell & Chlorine module with "sensitive" cell \\
\hline Cl-AMP largeCell & Chlorine module with "high concentration" cell \\
\hline
\end{tabular}


The respective status of the detector modules is indicated by color (see above). The following status displays are possible:

\begin{tabular}{|c|c|}
\hline \multicolumn{2}{|c|}{ Device ready for measurement } \\
\hline Display & Description \\
\hline OK (green, black) & Detector is ready for measurement \\
\hline \multicolumn{2}{|c|}{ Device not ready for measurement - general } \\
\hline Display & Description \\
\hline $\begin{array}{l}\text { no detector displayed } \\
\text { (display empty) }\end{array}$ & $\begin{array}{l}\text { no detector identified: } \\
\text { - activate detector } \\
\text { - Initialize }\end{array}$ \\
\hline communication error (rot) & $\begin{array}{l}\text { communication interrupted: } \\
\text { - deactivate/activate the device } \\
\text { - Initialize }\end{array}$ \\
\hline no connection (red) & $\begin{array}{l}\text { connection interrupted: } \\
\text { - check connection cable } \\
\text { - deactivate/activate the device } \\
\text { - Initialize }\end{array}$ \\
\hline \multicolumn{2}{|c|}{ Device not ready for measurement - C-NDIR / S-NDIR } \\
\hline Display (rot) & Description \\
\hline warning, analog values & $\begin{array}{l}\text { analog values outside range: } \\
\text { - Read the values via menu item SYSTEM COMPONENT TEST } \\
\text { on the tab C-NDIR; S-NDIR, } \\
\text { - See also fault description of the C/S module p. } 135\end{array}$ \\
\hline warm-up time & $\begin{array}{l}\text { detector is not yet ready for operation: } \\
\text { wait until the warm-up time is complete after activation } \\
\text { (approx. } 30 \mathrm{~min} \text { ) }\end{array}$ \\
\hline \multicolumn{2}{|c|}{ Device not ready for measurement - Cl-AMP } \\
\hline Display (rot) & Description \\
\hline inactive & $\begin{array}{l}\text { no cell identified: } \\
\text { use cell }\end{array}$ \\
\hline \multicolumn{2}{|c|}{ Device not ready for measurement - Cl-AMP } \\
\hline Display (green) & Description \\
\hline interval titration & $\begin{array}{l}\text { interval titration running: } \\
\text { - possible to start measurement }\end{array}$ \\
\hline End point routine & $\begin{array}{l}\text { end point routine running: } \\
\text { - wait until the end point routine has finished }\end{array}$ \\
\hline
\end{tabular}

In the area of the flow indication the current intake flow (ACTUAL) and the target flow to be reached (NOMINAL) are displayed. The target flow is $100 \mathrm{l} / \mathrm{h}$. The intake flow may differ $\pm 10 \mathrm{l} / \mathrm{h}$ from the target flow. Adjust the intake flow at the rotameter "pump" at the front panel of the basic device. The temperature display shows the current furnace temperature. If the temperature display is red, the current furnace temperature does not match the temperature set in the method. In this case, wait until the target temperature has been reached or check the temperature configuration in the method. 


\subsection{Equipment fault}

Other problems not detected by the system monitoring can also occur. Starting a measurement is possible. Such errors are usually detected on the basis of implausible measuring results (analytical problems). Often, they are clearly recognizable in the equipment technology. If the suggested solutions are not successful, inform Service.

\subsubsection{Basic device}

\begin{tabular}{|c|c|}
\hline Error & \\
\hline \multicolumn{2}{|l|}{ furnace does not heat } \\
\hline Cause & Solution \\
\hline $\begin{array}{l}\text { - Malfunction in electronics } \\
\text { - Heating element broken. } \\
\text { - Fuse in the basic device has tripped. }\end{array}$ & $\begin{array}{l}\text { - Check electrical plug connection (mains cable, interface } \\
\text { cable). } \\
\text { - Inform Service. }\end{array}$ \\
\hline \multicolumn{2}{|c|}{ Fans on the rear of the device are not running } \\
\hline Cause & Solution \\
\hline $\begin{array}{l}\text { - } \quad \text { Fuse faulty. } \\
\text { - Electronics faulty. }\end{array}$ & $\begin{array}{l}\text { - Switch off the analyzer from the mains switch. } \\
\text { - Inform Service. }\end{array}$ \\
\hline \multicolumn{2}{|l|}{ No intake flow at the "pump" flow regulator } \\
\hline Cause & Solution \\
\hline - Pump not switched on. & $\begin{array}{l}\text { - Check temperature difference. } \\
\text { - Wait for the temperature difference between target and } \\
\text { actual temperature to approximate } 50^{\circ} \mathrm{C} \text {. } \\
\text { If the pump does not activate at a temperature differ- } \\
\text { ence between target and actual temperature of less } \\
\text { than } 50^{\circ} \mathrm{C} \text {, inform Service. }\end{array}$ \\
\hline - Hoses detached. & - Check the hose system for kinked or squeezed hoses. \\
\hline
\end{tabular}

\subsubsection{C/S module}

multiWin: Flow error

ACTUAL measuring gas flow $<90 \mathrm{l} / \mathrm{h}$ o $>110 \mathrm{l} / \mathrm{h}$

Cause Solution

- No intake flow or too low

- Desiccant too moist and clumped. multiWin: Flow error

Measuring gas flow ACTUAL $=0$

\begin{tabular}{ll}
\hline Cause & Solution \\
\hline - No intake flow. & - Check temperature difference.
\end{tabular}

- With the intake pump switched on correct intake flow at the "pump" flow regulator at the basic module.

- Check the hose system for kinked or squeezed hoses.

- Replace desiccant. 
- Pump not switched on.
- Wait for the temperature difference between target and actual temperature to approximate $50 \mathrm{~K}$.

If the pump does not activate at a temperature difference between target and actual temperature of less than 50 K, inform Service.

\section{Analog values of the NDIR optics fluctuate}

\begin{tabular}{ll}
\hline Cause & Solution \\
\hline - Leaks & - Wait for the warm-up phase of $15 \mathrm{~min}$. \\
- Configuration or fault of the NDIR detector & - If the analog values are not constant after $1 \mathrm{~h}$ (with ox- \\
- Detector stabilization during the warm-up phase of the & $\begin{array}{l}\text { ygen present), a leak might be present. Inform Service. } \\
\text { analyzer not yet complete }\end{array}$ \\
& $\begin{array}{l}\text { - } \\
\text { Replace the halide trap if discolored to protect the de- } \\
\text { tector. }\end{array}$
\end{tabular}

multiWin: Optics fault, analog values outside range

The values of the NDIR detector are shown in yellow in the status window.

\begin{tabular}{ll}
\hline Cause & Solution \\
\hline - The ADU values of the NDIR detector differ from & - Check the oxygen supply of the gas supply. \\
the target value and are outside tolerances. & - Check the oxygen supply at the flow regulator, open \\
Note: Measurements can still continue. & valve. \\
& - Check the oxygen flow through the detector \\
& (hoses) \\
\end{tabular}

multiWin: no connection to optics (NDIR)

multiWin: Optics status error

\begin{tabular}{ll}
\hline Cause & Solution \\
\hline - communication error & - Reinitialize the device. \\
- NDIR detector faulty & - Inform Service. \\
\hline
\end{tabular}

Control light does not illuminate

\begin{tabular}{ll}
\hline Cause & Solution \\
\hline - Internal program has not been started. & - $\begin{array}{l}\text { Restart the internal computer with the mains switch of } \\
\text { the module. }\end{array}$ \\
\hline
\end{tabular}

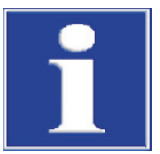

\section{NOTICE}

The ADU values of the NDIR detector drop slowly due to normal aging. If the values drop within a few analyses, this indicates damage to the detector by components of the analysis gas!

\subsubsection{Cl module}

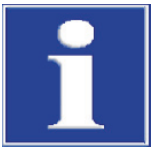

\section{NOTICE}

To prevent faults always note:

- Connect the measuring cell with stirring rod (filled with electrolyte) and electrode before switching on the analyzer.

- Only start the multiWin software approx. 3 min. after switching on the analyzer. 
multiWin: no connection to $\mathrm{Cl}$ sensor

\begin{tabular}{|c|c|}
\hline Cause & Solution \\
\hline $\begin{array}{l}\text { - No communication between the internal computer and } \\
\text { coulometer. } \\
\text { - } \mathrm{Cl} \text { module not switched on. }\end{array}$ & $\begin{array}{l}\text { Observe activation sequence: } \\
\text { 1. Switch on basic device. } \\
\text { 2. Switch on } \mathrm{Cl} \text { module. } \\
\text { 3. Wait approx. } 3 \text { min. for coulometer to communicate with } \\
\text { the internal computer. } \\
\text { 4. Start the multiWin software. }\end{array}$ \\
\hline - Connection cable not connected or faulty. & - Check cable connection \\
\hline \multicolumn{2}{|l|}{ multiWin: wrong command structure $\mathrm{Cl}$ sensor } \\
\hline Cause & Solution \\
\hline $\begin{array}{l}\text { - Data transmission fault } \\
\text { coulometer - internal computer }\end{array}$ & $\begin{array}{l}\text { - Re-initialize the analyzer. } \\
\text { - Inform Service. }\end{array}$ \\
\hline \multicolumn{2}{|l|}{ multiWin: Indicator error } \\
\hline Cause & Solution \\
\hline $\begin{array}{l}\text { - Electrode connector not connected. } \\
\text { - Electrode faulty. }\end{array}$ & $\begin{array}{l}\text { - Connect electrode and reinitialize the device. } \\
\text { - Replace faulty electrode. } \\
\text { - Inform Service. }\end{array}$ \\
\hline
\end{tabular}

\subsection{Device communication fault}

Software does not respond.

\begin{tabular}{ll}
\hline Cause & Solution \\
\hline - Computer crash & - $\begin{array}{l}\text { Switch off analyzer completely, incl. basic device, } \\
\text { printer, sampler and external PC, restart the system af- } \\
\text { ter a few seconds. }\end{array}$ \\
\hline
\end{tabular}

multiWin: Communication error - analyzer

\begin{tabular}{|c|c|}
\hline Cause & Solution \\
\hline $\begin{array}{l}\text { - Module with internal computer not switched on } \\
\text { - } \text { multiWin started too early } \\
\text { - Module with internal computer not yet connected to PC } \\
\text { - Incorrect COM interface selected in multiWin }\end{array}$ & $\begin{array}{l}\text { - Switch on the module } \\
\text { - Check connection between module with internal com- } \\
\text { puter and PC } \\
\text { - Only start multiWin after the LED display LOCK-IN illu- } \\
\text { minates } \\
\text { - Check the plugged in interface at the external computer } \\
\text { and the one set in multiWin } \\
\text { (menu command EXTRAS INTERFACE) }\end{array}$ \\
\hline
\end{tabular}

during running operation of the device together with the fault multiWin: Restart computer in the analysis device

\begin{tabular}{ll}
\hline Cause & Solution \\
\hline - internal computer reset & - If the front LED illuminates, initialize the analyzer. \\
& - If it happens repeatedly, monitor the time of fault (sta- \\
& tus line) and inform Service. \\
\hline
\end{tabular}


multiWin: Communication error - incorrect command set between PC and device

\begin{tabular}{ll}
\hline Cause & Solution \\
\hline - Internal and external program versions do not match. & - Repeat update. \\
\hline multiWin: no connection to temperature controller & \\
\hline Cause & Solution \\
\hline - Basic device not switched on. & - Switch on basic device and re-initialize multiWin 1 min. \\
- Interface cable between module with internal & later \\
$\quad \begin{array}{l}\text { computer and basic device not connected or } \\
\text { faulty. }\end{array}$ & - Check the connection of the interface cable \\
- Temperature controller faulty. & Solution \\
\hline No connection to the autosampler & - check connection cable \\
\hline Cause & - Switch on sampler and initialize analyzer. \\
\hline - No communication between basic device and & \\
$\quad \begin{array}{l}\text { autosampler } \\
\text { - Sampler not switched on }\end{array}$ &
\end{tabular}

\subsection{Analytical problems}

\subsubsection{C/S determination}

Recovery generally too low
Cause
- Desiccant too moist
- Sooted filter and measuring gas hoses
- Leaks

Recovery generally too low

\section{Solution}

- Inspect and replace desiccant

- Inspect and replace filter

- Inspect the dust trap, if heavily contaminated (particle deposits) clean the dust trap

- In case of leaks inspect the sealing rings in the gas sluice and the dust trap, replace cracked / brittle sealing rings

\section{Low results for TS}

Cause Solution

- Halide trap still in the measuring gas flow

- Replace the halide trap with an empty glass tube

- Digestion temperature too low (especially with sulfatic bonding)

- Increase the furnace temperature in the method if the $\mathrm{S}$ measuring graph is highly irregular or has a long tailing and does not drop to the baseline.

- If necessary, add additives (e.g. iron phosphate, tungsten oxide, vanadium pentoxide, tin...).

- Contamination of the hoses carrying measuring gas up to the optics
- Remove hoses up to the NDIR optics, clean, dry and reinstall.

We recommend to have the hoses cleaned by the Service department. 


\begin{tabular}{ll}
\hline High results for TC & Solution \\
\hline Cause & $\begin{array}{l}\text { Ambient air can enter the system through cracks leading } \\
\text { to significant high results for TC. In this case, replace } \\
\text { combustion tube. }\end{array}$ \\
\hline Baseline drift & Solution \\
\hline Cause & - \begin{tabular}{l} 
During the warm-up phase of the device the detector \\
needs to stabilize. It is therefore possible for the base- \\
\hline Detector not stable
\end{tabular} \\
$\begin{array}{l}\text { line to still drift a little at the start of the measurement } \\
\text { (temperature dependency). The peak surface }\end{array}$ \\
modified by the drift is automatically corrected and the \\
measuring results are always independent of it. \\
- If the drift does not correct itself, inform Service.
\end{tabular}

\subsubsection{Cl determination}

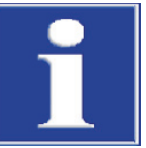

\section{NOTICE}

To prevent faults always note:

- Connect the measuring cell with stirring rod (filled with electrolyte) and electrode before switching on the basic device and $\mathrm{Cl}$ module.

- Only start the multiWin program approx. $3 \mathrm{~min}$. after switching on the analyzer.

Recovery too low (split factor $>1.4)$

\begin{tabular}{|c|c|}
\hline Cause & Solution \\
\hline - Sulfuric acid too diluted & - Check and replace the sulfuric acid. \\
\hline - Sooted components or measuring gas hoses. & $\begin{array}{l}\text { Check the combustion tube for contamination. } \\
\text { Clean the combustion tube by burning off deposits with } \\
\text { a Bunsen burner or in the muffle furnace at } 1000^{\circ} \mathrm{C} \text {. Re- } \\
\text { place heavily contaminated tubes. } \\
\text { Replace quartz wool in the combustion tube. }\end{array}$ \\
\hline
\end{tabular}

- Check the sulfuric acid container for soot. If particles have reached all the way to the sulfuric acid container, clean the container and connection at the furnace outlet and refill the container.

Recovery too high (split factor $>0.6$ )

\begin{tabular}{ll}
\hline Cause & Solution \\
\hline - Sample deposits in the combustion tube (e.g. salts) & $\begin{array}{l}\text { - } \\
\text { Replace or clean the combustion tube, e.g. by "soaking" } \\
\text { the combustion tube overnight in } 10 \% \mathrm{HNO}_{3}, \text { followed } \\
\text { by thorough rinsing with distilled water } \\
\text { and drying. }\end{array}$ \\
\hline
\end{tabular}

Operating point below 1500

Cause Solution

- Combined electrode faulty or aged strongly - Use new electrode for chloride determination. 


\subsubsection{TIC determination (automatic TIC solids module)}

\begin{tabular}{|c|c|}
\hline \multicolumn{2}{|l|}{ Lower results } \\
\hline Cause & Solution \\
\hline - Sample weight chosen too high & $\begin{array}{l}\text { The sample weight should not exceed } 50 \mathrm{mg} \text {, otherwise } \\
\text { the metered acid volume }(400 \mu \mathrm{l}) \text { is not enough to fully } \\
\text { digest the carbonate or the acid volume cannot fully wet } \\
\text { the sample. }\end{array}$ \\
\hline $\begin{array}{l}\text { - Sample not distributed evenly across the entire boat } \\
\text { length }\end{array}$ & $\begin{array}{l}\text { - The sample must be evenly distributed to allow the } \\
\text { sample to be completely wetted with acid. }\end{array}$ \\
\hline $\begin{array}{l}\text { - Acid strength too weak } \\
\text { (long tailing of the measuring graph, measuring graph } \\
\text { does not return to baseline) }\end{array}$ & $\begin{array}{l}\text { - If the sample contains very stable carbonates }\left(\mathrm{FeCO}_{3}\right) \text { in } \\
\text { high quantities, the digestion speed with } 40 \% \mathrm{H}_{3} \mathrm{PO}_{4} \text { is } \\
\text { too slow. In this case } \\
\text { use a stronger acid instead (e.g. } 25 \% \mathrm{HCl}) \text {. } \\
\text { NOTICE! Do not use } \mathrm{HCl} \text { permanently. }\end{array}$ \\
\hline
\end{tabular}

\section{Scattering measurements}

\begin{tabular}{ll}
\hline Cause & Solution \\
\hline $\begin{array}{l}\text { - Sample not distributed evenly across the entire boat } \\
\text { length }\end{array}$ & - $\begin{array}{l}\text { The sample must be evenly distributed to allow the } \\
\text { sample to be completely wetted with acid. }\end{array}$ \\
\hline - Sample matrix is hydrophobic & - If it is difficult to wet the sample with acid, it is helpful \\
& to cover the sample with annealed quartz sand to im- \\
prove the effect of the acid. & $\begin{array}{l}\text { Sometimes hydrochloric acid wets better than phos- } \\
\text { phoric acid. } \\
\text { NOTICE! Do not use } \mathrm{HCl} \text { permanently. }\end{array}$ \\
\end{tabular}

\subsubsection{TIC determination (manual TIC solids module)}

\section{Lower results}

\begin{tabular}{ll}
\hline Cause & Solution \\
\hline - Acid strength too weak & - If the sample contains very stable carbonates $\left(\mathrm{FeCO}_{3}\right)$ in \\
$\begin{array}{l}\text { (long tailing of the measuring graph, measuring graph } \\
\text { does not return to baseline within max. integration time } \\
\text { of } 600 \mathrm{~s} \text { ) }\end{array}$ & $\begin{array}{l}\text { too slow. In this case } \\
\text { use a stronger acid instead (e.g. } 25 \% \mathrm{HCl}) .\end{array}$ \\
& NOTICE! Do not use $\mathrm{HCl}$ permanently.
\end{tabular}




\subsubsection{Measurements in pyrolysis mode (EC)}

Low results of elementary carbon (after pyrolysis)

Cause Solution

- Waiting period for purging oxygen by argon in the combustion tube chosen too short

- The waiting period after changing from oxygen to argon supply should be min $60 \mathrm{~s}$.

High results of elementary carbon (after pyrolysis)

Cause Solution

- Pyrolysis period selected too short

- The pyrolysis period should be $\min 3 \mathrm{~min}$ to ensure that all organic compounds are fully digested and purged.

- Pyrolysis temperature chosen too high

- At temperatures above $1000{ }^{\circ} \mathrm{C}$ soot is increasingly formed from organic compounds (plastic) through "coking" and is also detected as elementary carbon in stage 2. The optimum furnace temperature for pyrolysis measurements is $850^{\circ} \mathrm{C}$.

NOTICE! Where possible limit the operating period of pyrolysis measurements (with $\mathrm{T}=850^{\circ} \mathrm{C}$ ), because it shortens the service life of the heating elements. 


\section{Transport and storage}

\section{$9.1 \quad$ Transport}

\subsubsection{Preparing the analyzer for transport}

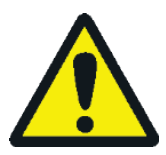

\section{WARNING}

Risk of damage to health due to improper decontamination!

Perform a professional and documented decontamination of the device before returning it to Analytik Jena. The decontamination report is available from Service when registering the return. Analytik Jena must refuse acceptance of contaminated devices. The sender may be liable for any damage caused by inadequate decontamination of the device.

\section{CAUTION}

Risk of burning at the hot furnace! Only remove the combustion furnace when the device is cold or allow the device to cool down sufficiently!

\section{CAUTION}

When removing the glass components there is a risk of injury from glass breakage! Remove all glass components carefully from the analyzer!

\section{NOTICE}

The heating elements and furnace cartridge can be damaged by vibration during transport. Therefore, these device components must be removed from the multi EA 4000 and packaged separately before a transport. Reinstallation and recommissioning of the basic device may only be performed by the Analytik Jena AG customer service or trained specialist personnel authorized and trained by Analytik Jena AG.

Unsuitable packaging material and residue of measuring solution and chemicals can damage individual components of the analyzer!

Only transport the analyzer in its original packaging! Ensure that the analyzer is fully drained and all transport locks have been fitted!

Prepare the multi EA 4000 and its modules for transport as follows:

Basic device multi EA 4000
1. Switch off the analyzer from the mains switch at the rear of the device and allow the device to cool down.

2. Switch off the gas supply and disconnect the mains plug from the mains outlet.

3. Disconnect all connections on the rear of the analyzer.

4. Open the doors of the analyzer. Drain the drying tube. Re-insert the drying tube.

5. Unscrew the connections at the halide trap and press the halide trap out of its clamps. Drain the halide trap.

6. Pull the combustion tube out of the furnace.

7. Package the accessories carefully and in particular protect glass components against breakage. 
C/S module

$\mathrm{Cl}$ module

Automatic TIC solids module
8. Remove the heating elements and the furnace cartridge from the multi EA 4000 and package these device components separately ( $\rightarrow$ see section "Removing the heating elements and furnace cartridge" p. 144).

1. Switch off the $\mathrm{C} / \mathrm{S}$ module from the mains switch.

2. Disconnect the mains plug from the mains socket.

3. Disconnect all connections on the rear of the module.

1. Switch off the $\mathrm{Cl}$ module from the mains switch.

2. Remove the measuring cell from the device and drain it $(\rightarrow$ see section "Servicing the measuring cells" $p 118$.

3. Rinse and dry the measuring cell and combined electrode.

4. Unscrew and drain the adsorption tube.

5. Remove and drain the halide trap.

6. Re-install the empty adsorption tube and halide trap in the $\mathrm{Cl}$ module.

7. Disconnect all connections on the rear of the module.

8. Remove the sulfuric acid container and the safety container from the basic device multi EA 4000. Drain and clean the sulfuric acid container $(\rightarrow$ see section "Replacing the sulfuric acid/cleaning the sulfuric acid container" p. 114).

9. Pull the measuring gas hose (transparent) and the bypass hose (black) out of the channel in the multi EA 4000.

10. Package the accessories carefully and in particular protect glass components against breakage.

1. Switch off the TIC solids module from the mains switch.

2. Disconnect all connections on the rear of the module.

3. Switch off the gas supply and disconnect the mains plug from the mains outlet.

4. Put the acid container and drip tray aside. Drain and clean the acid container.

5. Detach the hoses for gas and acid from the TIC reactor. Remove the TIC reactor. Package the ceramic cannula separately.

6. Drain the drying tube. Re-insert the drying tube.

7. Drain the condensate container.

8. Remove and clean the pump hose for acid from the cartridge pump.

9. Carefully pull the condensation coil out of its mount.

10. Package the accessories carefully and in particular protect glass components against breakage. 


\subsubsection{Removing the heating elements and furnace cartridge}

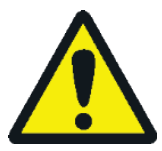

\section{WARNING}

Life-threatening electrical voltages and high currents may occur in the interior of the analyzer! For the removal of the heating elements and furnace cartridge witch off the analyzer from the mains switch at the rear of the device and disconnect the mains plug from the mains outlet.

The heating elements and furnace cartridge may only be reinstalled by the customer service department of Analytik Jena AG or by specialist personnel authorized and trained by Analytik Jen. AG! The recommissioning of the basic device must also be performed by these persons.

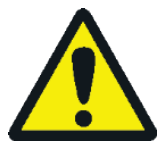

\section{CAUTION}

There is a risk of burns on the furnace! Only do the removal when the device is cold or allow the device to cool down sufficiently (best overnight)!

Caution when opening the right side panel. There is a risk of injury from sharp-edged components.

The high temperature ceramic heating elements and furnace cartridge can be damaged by vibration during transport. Therefore, the device components must be removed from the basic device and packaged separately before a transport. The heating elements and furnace cartridge need not be removed for moving within the laboratory.
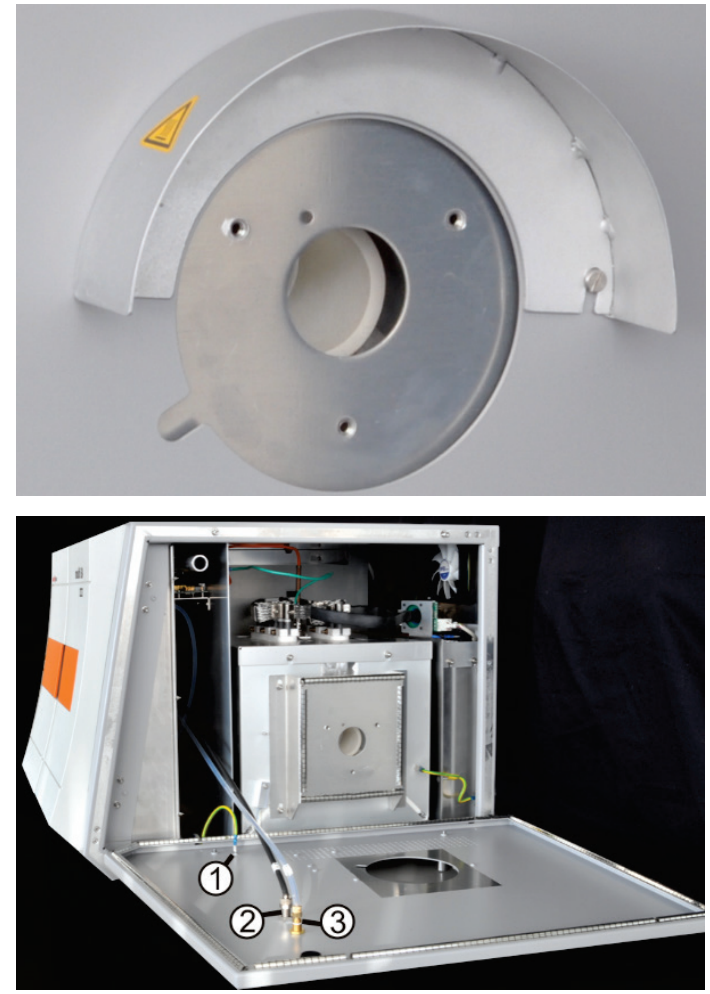

1. If not yet done, remove the dust trap through the opening in the left side panel of the basic device.

2. Unscrew the gas sluice. Remove the combustion tube from the furnace.

3. Open the right side panel of the basic device. To do so, undo the 4 hexagon socket screws. Do not unscrew the screws fully.

4. Detach the protective conductor (1) and the two gas hoses $(2,3$, hose no. 13 and 16$)$ from the inside of the side panel. Remove the side panel. 

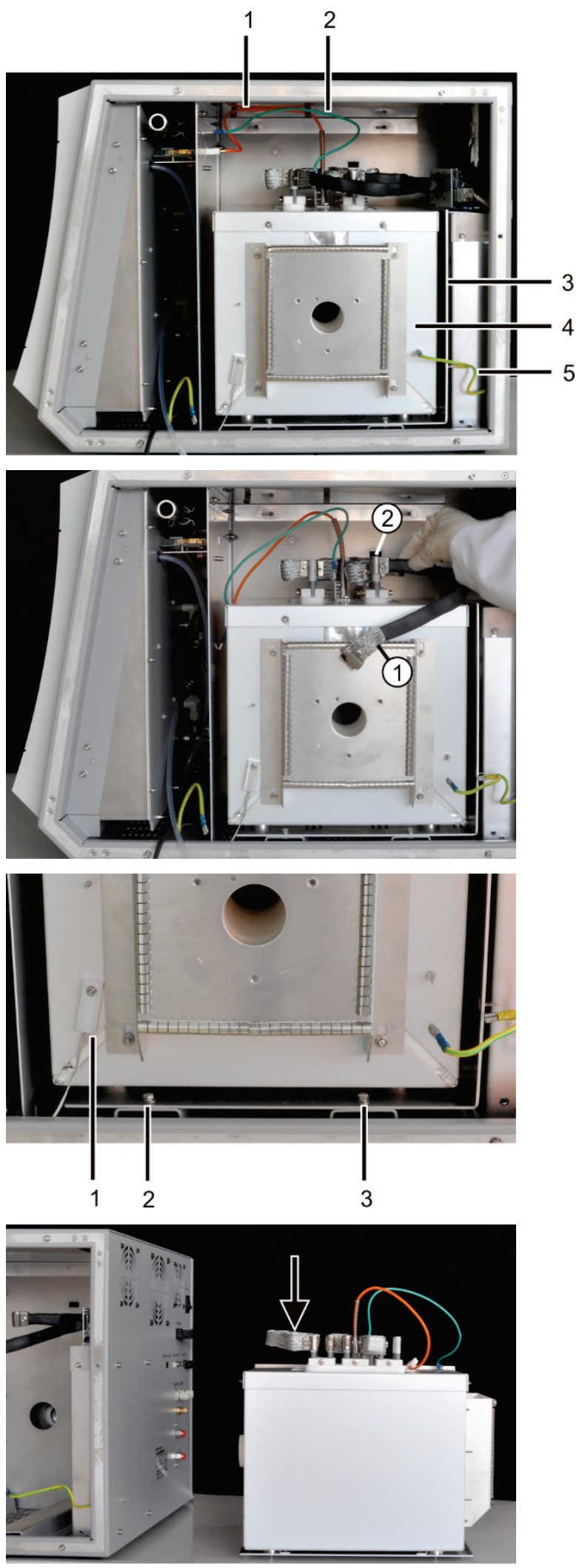

5. Detach the protective conductor (5) from the furnace cartridge (4) and the L-shaped mounting plate (3).

6. Detach the orange connection cable of the thermocouple (1) and the green ground conductor (2) from the inside wall of the basic device.

7. Detach the electric supply cables (1.2) from the heating elements. To do so undo the hexagon socket screws at the braided wires. Pull out the cable with braided wires from the top by twisting them to and fro slightly.

8. Detach the two screws $(2,3)$ attaching the furnace cartridge and mounting plate in the analyzer.

9. Unscrew the temperature sensor (1) from the furnace cartridge.

10. Pull the furnace cartridge and mounting plate fully out of the analyzer and put them safely aside.

11. Detach the long braided wire (see arrow) connecting the two heating elements electrically to each other.

12. To do so release the hexagon socket screws and pull out the braided wire from the top by twisting it to and fro slightly. 

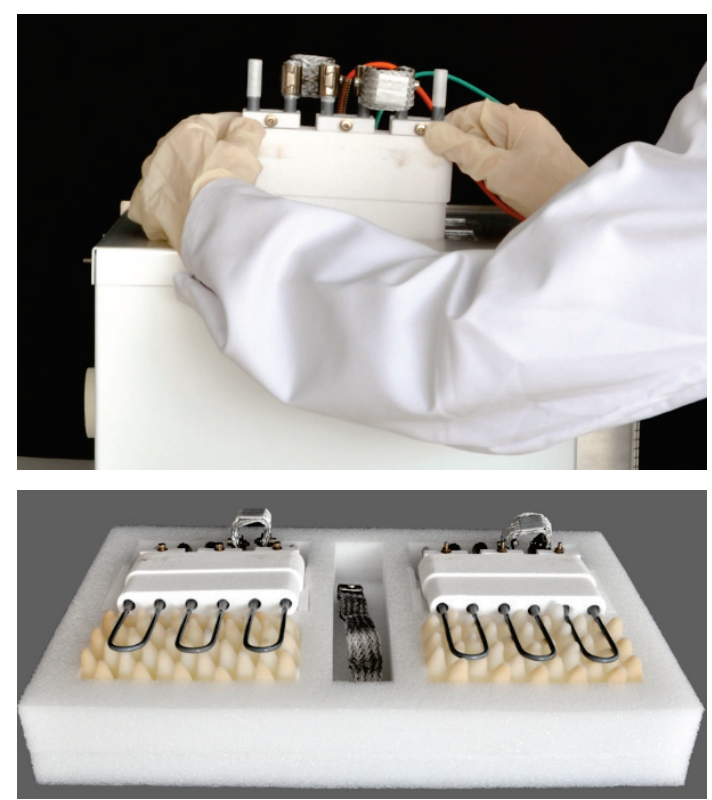

13. Successively lift out the heating elements carefully from the furnace cartridge.

14. Package the two heating elements and the braided wire and the furnace cartridge in separate transport containers.

\subsubsection{Transport notes}

Observe the safety instructions in section "Safety instructions, transport and " p. 12. Transport the analyzer very carefully to prevent damage from impact or vibration. For the transport the heating elements and furnace cartridge must be removed and packaged separately in the transport container. Otherwise, there is a risk of breakage!

The analyzer should be transported in such a way that major temperature fluctuations are avoided and the formation of condensate is thus prevented in the transport container.

\subsubsection{Moving the analyzer in the laboratory}

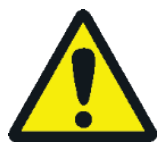

\section{CAUTION}

Unintentional dropping of the analyzer poses a risk of injury and the analyzer will be damaged!

Move the analyzer with great care! 2 persons are required to lift and carry the analyzer!

Observe the following when moving the analyzer within the laboratory:

- Insufficiently secured components pose a risk of injury! Before moving the analyzer remove all loose components, in particular the reagent bottle with phosphoric acid and the sulfuric acid container.

- Disconnect all supply connections and add-on devices from the analyzer. For a transport within the laboratory the heating elements and furnace cartridge need not be removed from the analyzer.

- To prevent health damage the following must be observed when moving the analyzer in the laboratory (lifting and carrying): 
- For reasons of safety 2 persons are required to transport the analyzer and must position themselves on both sides of the equipment.

- Because the analyzer does not feature any handles, firmly grip the device from the bottom and make sure prior to simultaneous lifting the device that the sensitive components at the front are protected by the closed doors.

- Observe the guide values and adhere to the legally mandated limits for lifting and carrying without auxiliary means!

- For the setup at the new location observe the notes in section "Site requirements" p. 47.

\subsection{Storage}

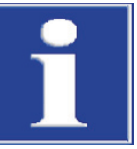

\section{NOTICE}

Environmental influences and condensate formation can destroy individual components of the analyzer!

The analyzer must only be stored in acclimatized rooms. The atmosphere must be low in dust and free from aggressive vapors.

If the analyzer and add-on devices are not positioned immediately after delivery or are not required for a prolonged period of time, they should best be stored in their original packaging. A suitable desiccant should be added to the equipment to prevent damage from moisture.

The following requirements are placed on the climatic conditions in the storage room:

- Temperature range: $+5^{\circ} \mathrm{C}$ to $+55^{\circ} \mathrm{C}$

- Max. humidity: $10 \%$ to $30 \%$

- Air pressure: $70 \mathrm{kPa}$ to $106 \mathrm{kPa}$ 


\section{Disposal}

Sulfuric acid

Magnesium perchlorate

Electrolyte solution

Adsorption agent

Halide trap

Analyzer
The used desiccant of $\mathrm{Cl}$ determination is initially carefully diluted with water and then neutralized with sodium hydroxide. The corresponding hazard information and safety advice must be observed! This neutralized waste must be brought to the appropriate waste disposal center for correct disposal according to the appropriate legal guidelines.

The used desiccant of $\mathrm{C}$ and $\mathrm{S}$ determination is turned into less hazardous reduction products by adding it to sodium thiosulfate solution - with added acid where applicable. This potentially neutralized waste must be brought to the appropriate waste disposal center for correct disposal according to the appropriate legal guidelines.

The electrolyte solution is carefully neutralized and collected as silver salt residue in containers. This should be correctly disposed of or recycled in accordance with the statutory requirements.

The active carbon used for the adsorption of acetic acid vapor should be disposed of in accordance with public regulations.

The halide trap contains copper. Contact the responsible institution (authority or waste disposal company). There you will receive the information regarding recycling or disposal.

At the end of its service life the multi EA 4000 and all its electronic components must be disposed of as electronic waste in accordance with the applicable regulations. 


\section{Specification}

\subsection{Technical data}

\begin{tabular}{|c|c|}
\hline \multicolumn{2}{|l|}{ General characteristics } \\
\hline Designation/type & Analyzer multi EA 4000 \\
\hline \multirow[t]{3}{*}{ Dimensions } & Basic device $(\mathrm{W} \times \mathrm{H} \times \mathrm{D}) 600 \times 470 \times 620 \mathrm{~mm}$ \\
\hline & each module: $300 \times 470 \times 550 \mathrm{~mm}$ \\
\hline & Autosampler: $520 \times 500 \times 700 \mathrm{~mm}$ \\
\hline \multirow[t]{3}{*}{ Mass } & approx. 35 kg \\
\hline & each module approx. $8 \mathrm{~kg}$ \\
\hline & Autosampler approx. $20 \mathrm{~kg}$ \\
\hline \multicolumn{2}{|l|}{ Procedural data } \\
\hline Digestion principle & oxidative combustion \\
\hline Digestion temperature & $\begin{array}{l}\text { dependent on application } 1000-1500{ }^{\circ} \mathrm{C} \\
\text { (lower temperatures also possible) }\end{array}$ \\
\hline Measuring methods & $\mathrm{TC}, \mathrm{TIC}, \mathrm{TOC}, \mathrm{TS}, \mathrm{EC}, \mathrm{TCl}$ \\
\hline $\mathrm{C}$ and $\mathrm{S}$ detection & NDIR (coupled with VITA method) \\
\hline $\mathrm{Cl}$ detection & Coulometry \\
\hline Sample volume & up to $3000 \mathrm{mg}$ \\
\hline \multirow[t]{2}{*}{ Sample Feed } & Weighing in porcelain or quartz glass boats \\
\hline & Automatic sampler or manual feed \\
\hline Gas supply & $\begin{array}{l}\text { Oxygen min. } 2.5 \text { and argon } 4.6 \\
\text { with inlet pressure } 200-400 \mathrm{kPa}(29-58 \mathrm{psi})\end{array}$ \\
\hline $\begin{array}{l}\text { Control/analysis (control and anal- } \\
\text { ysis software multiWin) }\end{array}$ & $\begin{array}{l}\text { Real-time graphics, status indication during analysis, } \\
\text { graphical display of the measured results, } \\
\text { result print-out }\end{array}$ \\
\hline \multicolumn{2}{|l|}{ Electrical variables } \\
\hline $\begin{array}{l}\text { Furnace module HTS1500 connec- } \\
\text { tion }\end{array}$ & $200-240 \mathrm{VAC}(+10 \%,-5 \%), 50-60 \mathrm{~Hz}$ \\
\hline $\begin{array}{l}\text { Module and } \\
\text { sampler connection }\end{array}$ & $100-240 \mathrm{VAC}( \pm 10 \%), 50-60 \mathrm{~Hz}$ \\
\hline \multirow[t]{2}{*}{ Man. TIC solids module } & $220-240 \mathrm{VAC}( \pm 10 \%), 50 / 60 \mathrm{~Hz}$ \\
\hline & (100 V AC / 115 V AC upon request) \\
\hline \multirow[t]{7}{*}{ Fuses } & HTS1500 furnace module \\
\hline & Device control: T $2 \mathrm{AH}$ \\
\hline & Heating: Circuit breaker type B16 \\
\hline & $\begin{array}{l}\text { The fuses are inside the device and may only be re- } \\
\text { placed by the customer service of Analytik Jena AG! }\end{array}$ \\
\hline & $2 \times \mathrm{T} 4.0 \mathrm{AH}$ \\
\hline & $\mathrm{Cl}$ module \\
\hline & Only use original fuses by Analytik Jena AG! \\
\hline
\end{tabular}


Minimum equipment for the control and analysis unit

Technical data

$\mathrm{Cl}$ module

\begin{tabular}{lll}
\hline Maximum power consumption & HTS1500 furnace module & 2400 VA \\
\cline { 2 - 3 } & C/S module & $60 \mathrm{VA}$ \\
\cline { 2 - 3 } & Cl module & $60 \mathrm{VA}$ \\
\cline { 2 - 3 } & Autosampler FPG 48 & 30 VA \\
\cline { 2 - 3 } & Autom. TIC solids module & 20 VA \\
\cline { 2 - 3 } & Man. TIC solids module & 415 VA \\
\cline { 2 - 3 } & Overall system & approx. 3000 VA \\
\hline PC interface & USB & \\
\hline Environmental conditions & & \\
\hline Temperature during storage & $5-55^{\circ} \mathrm{C}$ & \\
\hline Temperature during operation & $10-35^{\circ} \mathrm{C}$ & \\
\hline Humidity during operation & Max. $90 \%$ at $+30{ }^{\circ} \mathrm{C}$ & \\
\hline Humidity during storage & $(10-30) \%$ (use desiccant) & \\
\hline Air pressure & $70-106 \mathrm{kPa}$ & \\
\hline
\end{tabular}

\begin{tabular}{ll}
\hline Operating system: & Windows 7 Professional or later \\
\hline Processor: & Intel Core 13 or better \\
\hline Working memory: & $4 \mathrm{~GB}$ \\
\hline Free hard disk space: & $40 \mathrm{~GB}$ \\
\hline Drive: & CD-ROM drive (for installation) \\
\hline Monitor resolution: & $1024 \times 768$ \\
\hline Interfaces & USB 2.0 \\
\hline
\end{tabular}

\begin{tabular}{ll}
\hline $\begin{array}{l}\text { Measuring range } \\
\text { (* with measuring gas splitting) }\end{array}$ & $1-100 \mu \mathrm{g} / 10 \mu \mathrm{g}-20 \mathrm{mg}^{*}$ absolute total chlorine \\
\hline Furnace temperature & up to $1000^{\circ} \mathrm{C}$ \\
\hline Heating-up period & Up to $30 \mathrm{~min}$. \\
\hline Analysis time & $\begin{array}{l}\text { Up to } 10 \mathrm{~min} \text { - dependent on combustion period and } \\
\text { concentration }\end{array}$ \\
\hline $\begin{array}{l}\text { Sample weight } \\
\text { (dependent on consistency and } \\
\text { matrix) }\end{array}$ & up to $3000 \mathrm{mg}$ \\
\hline
\end{tabular}




\subsection{Standards and directives}

Protection class and

type of protection

Device safety

EMC compatibility

Environmental compatibility

EU directives

Guidelines for China
The analyzer has a protection class of I.

The housing has safety type IP 20.

The analyzer complies with the safety standards

- EN 61010-1

- EN 61010-2-081

- EN 61010-2-010

- EN 61010-2-051 (for operation with manual TIC solids module)

The analyzer has been checked for interference emission and noise immunity.

It meets the requirements for interference emission of

- EN 61326-1 (EN 55011 group 1, class B)

It meets the requirements for noise immunity of

- EN 61326-1 (requirements for use in a basic EMC environment)

The analyzer has been tested for environmental compatibility and meets the requirements of

- ISO 9022-3

- ISO 9022-2

The analyzer meets the requirements of Directive 2011/65/EU (RoHS II).

The analyzer has been designed and tested in accordance with standards meeting the requirements of EU directives 2014/35/EU and 2014/30/EU. The device leaves the factory in a sound condition as far as technical safety is concerned. To maintain this condition and to ensure safe operation, the operator must strictly observe the safety and operating instructions contained in this operating manual. For accessories which have also been supplied, and system components from other manufacturers, their operating instructions should be referred to.

The device contains controlled substances (according to the guideline "Management Methods for the Restriction of the Use of Hazardous Substances in Electrical and Electronic Products"). Analytik Jena AG guarantees that the substances will not leak within the next 25 years and, therefore, will not cause any environmental danger or health risk within this period of time if the device is used as intended. 